\title{
XV Congreso Chileno de Endocrinología y Diabetes 2004 y Jornadas Chileno-Argentinas
}

Resúmenes de Trabajos Libres

Editor Encargado: Dr. Jorge Sapunar Z. 
— Rev Méd Chile 2004; 132 (Supl): 1263-1330 


\section{EVALUACIÓN DE UN MODELO DE EDUCACIÓN EN DIABETES PARA PERSONAS CON DIABETES MELLITUS TIPO 2}

Allel NL, Rodríguez CG, Piñeiro L, Yánez MA. IINSEDUC

Introducción: Existe consenso mundial en relación a la importancia y utilidad de la Educación en Diabetes como parte integral y permanente del plan terapéutico para la prevención de complicaciones agudas y crónicas en estos pacientes. En los planes y programas de Atención del Diabético, se recomienda y propone esta «educación», pero no existe en Chile, a nivel de Seguros médicos, estatales o privados y de libre elección su incorporación como parte de la terapia, en forma estructurada, continua y evaluada. Objetivos: Evaluar una intervención educativa estructurada, mostrando los resultados de su aplicación en un grupo de pacientes diabéticos Tipo 2, en aspectos cognitivos, sicológicos, metabólicos y actitudes en relación al auto-cuidado de su enfermedad y que pueda ser usado y financiado como un modelo educativo «ipo», vía programa, por entidades aseguradoras de salud, haciendo énfasis en el aspecto costo/beneficio al propender a la disminución o retraso de complicaciones. Metodología: Cuasi-Experimental. Aplicación de un Modelo de educación a un grupo de 27 pacientes con esta patología provenientes de 2 consultorios de Providencia, con metodología grupal, interactiva y participativa, en programa de 6 sesiones básicas semanales de 3,5 horas cada una y un fase de refuerzo de sesiones quincenales de 1,5 horas por 6 meses. Análisis estadístico vía T de Studens, comparación de promedios antes y después.

Resultados: Test cognitivo de inicio, 63\% respuestas comectas, a las 6 semanas es $75 \%$ y a los 6 meses 74\%, lo que es significativo, con $\mathrm{P}<0,0001$, Test Psicológico de inicio 22,5 DS 8,7 y a los 6 meses 20,7 DS 4.3 con un $\mathrm{P} \varangle 0,36$. Episodios de Complicaciones agudas de inicio 1,48/persona/periodo, al final 1,29/pers/periodo. IMC al inicio 32,1 DS 4,8 al final 30,8 DS 4,9 no significativo, pero un $52 \%$ disminuyen mas del $5 \%$ de su peso inicial. HbA1c: de inicio es 7,4 DS 4,5 y final es 7,27 DS 2,7, disminución no significativa. La HbA1c de 5 de ellos al inicio fue de 4,8\% o menor (hipoglicemias). Actividad física (30 minutos 30 mas veces por semana), al inicio 52\%, al final $89 \%$. Autocontrol (al menos 1 por semana) al inicio 20\%, al final $41 \%$, mejorado en total, el $64 \%$.

Conclusiones: 1. El modelo educativo presentado, mejora significativamente los conocimientos de los pacientes en relación a la etiología, alimentación, prevención y tratamiento de la enfermedad. 2. Existe una tendencia a disminución de niveles de problemas sicológicos y a mejorar la aceptación de la enfermedad. 3. Se observa una disminución de episodios complicaciones agudas a pesar del mayor reconocimiento de ellas. 4 Se observa una mejoría de parámetros metabólicos tales como el peso, y una leve tendencia en HbA1, posiblemente por graves hipoglicemias de inicio en este grupo. 5. Se observa una gran adherencia al modelo educativo, con un
$81,5 \%$ de pacientes que terminan el ciclo básico y un $63 \%$ que completan el programa de refuerzos. 6. Se calcula un costo operativo por paciente (sin considerar costo de infraestructura y sistema audiovisual) de $\$ 4388 /$ paciente/mes, promediando costos por 15 pacientes por grupo y 8 grupos por año.

\section{FRECUENCIA DE LA DELECIÓN DEL EXÓN 3 DEL RECEPTOR DE HORMONA DE CRECIMIENTO (GHRD3) EN NIÑNOS CON DIABETES TIPO 1}

Angel B, García D, Carrasco E, Albala C, Santos Jl, Pérez F. Laboratorio de Epidemiología Genética. Instituto de Nutrición y Tecnología de los Alimentos (INTA) y Unidad de Diabetes. Hospital San Juan de Dios. Facultad de Medicina. Universidad de Chile (Proyecto Fondecyt 1030680).

Introducción: La diabetes tipo 1 es una enfermedad eminentemente autoinmune, multifactorial en la cual intervienen factores genéticos y ambientales. Las isoformas del receptor de hormona de crecimiento (GHR), GHRwt y GHRd3 se expresan en diversos órganos, tales como hígado, páncreas, estómago e intestino delgado. Los altos niveles de expresión del gen GHR en la mucosa intestinal han sugerido la posibilidad que este receptor cumpla algún papel en la función inmune y digestiva. Hasta la fecha el papel funcional del polimorfismo GHRd3 ha sido escasamente estudiado.

Objetivo: Analizar la frecuencia del polimorfismo GHRd3 en población chilena e investigar el posible efecto putativo de esta variante genética sobre el perfil de citoquinas y autoanticuerpos en la diabetes tipo 1.

Pacientes y Métodos: Se analizó un grupo control $(n=150$, edad: $12,2 \pm 4,5$ años) y un grupo de pacientes diabéticos recién diagnosticados ( $\mathrm{n}=111$, edad: $8,7 \pm 3,6$ años) para las variables peso y talla de nacimiento. Citoquinas: IL-1ß, IL-2, IL4, TGFß1 e INFy mediante ELISA. Auto-anticuerpos: IAA, IA-2 y GAD65 mediante RIA y polimorfismo GHRd3 a través de PCR múltiple.

Resultados: La frecuencia alélica para el alelo d3 fue de $32,8 \%$ en diabéticos y de $25,1 \%$ en controles. No se observaron diferencias importantes entre el genotipo d3 y las variables peso y talla al nacimiento. El genotipo d3/d3 se asoció con altos títulos del anticuerpo anti-insulina. Además, los diabéticos portadortes del alelo d3 presentaron niveles significativamente mayores de IL-1ß comparados a los diabéticos portadores del genotipo f1/f1 (Tabla 1).

Conclusión: Nuestro estudio determinó una alta frecuencia de la isoforma d3 en población chilena. En la población diabética, los portadores de la isoforma d3 mostraron altos niveles de IAA e IL-1ß comparados con los portadores del genotipo f1/f1. La importancia reguladora de esta isoforma del receptor de hormona de crecimiento sobre el componente inflamatorio requiere ser analizada con modelos in vitro. 
Tabla 1. G enotipos G H Rd3 y citoquinas plasmáticas en niños diabéticos tipo 1.

\begin{tabular}{|cccccc|}
\hline GHRd3 & $\begin{array}{c}\text { IL-1ß } \\
(\mathrm{pg} / \mathrm{ml})\end{array}$ & $\begin{array}{c}\text { IL-2 } \\
(\mathrm{pg} / \mathrm{ml})\end{array}$ & $\begin{array}{c}\text { IL-4 } \\
(\mathrm{ng} / \mathrm{ml})\end{array}$ & $\begin{array}{c}\text { TGFß1 } \\
(\mathrm{pg} / \mathrm{ml})\end{array}$ & INFY \\
\hline $\mathrm{f1/f1}$ & 8,9 & 20,8 & 9,8 & 1,2 & 22,4 \\
$(\mathrm{n}=68)$ & $(2,7-192,2)$ & $(3,2-90,3)$ & $(7,2-32,6)$ & $(0,3-4,2)$ & $(7,6-50,8)$ \\
$\begin{array}{c}\text { Portadores d3 } \\
(\mathrm{n}=43)\end{array}$ & $15,5^{*}$ & 17,5 & 8,9 & 1,4 & 21,3 \\
& $(5,0-87,0)$ & $(3,0-59,8)$ & $(7,0-18,5)$ & $(0,5-2,8)$ & $(8,7-33,4)$ \\
\hline
\end{tabular}

\section{POLIMORFISMO DEL RECEPTOR DE VITAMINA D (VDR) Y SUSCEPTIBILIDAD PARA EL DESARROLLO DE DIABETES TIPO 1 EN CHILE: ESTUDIO DE TRÍOS}

Angel B, García D, Santos Jl, Albala C, Carrasco E, Pérez F. Laboratorio de Epidemiología Genética, INTA y Unidad de Diabetes. Hospital san Juan de Dios. Facultad de Medicina. Universidad de Chile.

Introducción: Los polimorfismos del gen VDR han sido considerados como marcadores candidatos en estudios de asociación con enfermedades de origen autoinmune. La vitamina D actúa a través de su receptor sobre el sistema inmune a nivel de la regulación de citoquinas, principalmente a nivel de modulación Th1/Th2.

Objetivo: El propósito de este diseño de estudio ha sido analizar la transmisión preferencial de haplotipos VDR en casos incidentes de diabetes tipo 1 de Santiago, Chile.

Pacientes y Métodos: Se estudiaron 104 trios familiares (caso-padre-madre, total $n=312$ individuos) y se determinaron alelos y haplotipos para 3 polimorfismos genéticos de VDR (BsmI, ApaI y TaqI) mediante PCR-RFLPs. Se realizó análisis de transmisión de alelos por test de desequilibrio de transmisión (TDT) y la distribución de haplotipos se evaluó utilizando el programa TRANSMIT.

Resultados: No se observó un aumento en la transmisión de alelos preferenciales para ninguno de los polimorfismos analizados; alelo B (probabilidad de transmisión 48,9\%, p- value $=0,90$ ), alelo A (probabilidad de transmisión $=45,4 \%$, pvalue $=0,39$ ) y alelo $\mathrm{T}$ (probabilidad de transmisión $=49,3 \%$, $\mathrm{p}$ value $=1,00)$. El análisis de haplotipos tampoco mostró combinaciones preferenciales (global $p$ value $=0,26$ ) (Tabla 1).

Conclusión: El presente estudio de transmisión sugiere que la contribución del polimorfismo VDR es sólo marginal en la etiología de los casos debutantes de diabetes tipo 1 en Santiago, Chile.

(Fondecyt 1030680)

\section{DIABETES TIPO 2 EN EL ADULTO MAYOR: CARACTE- RÍSTICAS CLÍNICAS Y DE LABORATORIO}

Araya $I^{1}$, Berríos $A^{1}$, Contreras $C^{1}$, Franulic $L^{1}$ y Lahsen $R^{2}$.

${ }^{1}$ Programa de Ayudante Alumno. ${ }^{2}$ Sección de Endocrinología Hospital Clínico U. de Chile

La Diabetes tipo 2 en el adulto mayor presenta caracteństicas especiales. El mayor tiempo de evolución de la enfermedad, asociado a largos periodos asintomáticos explica la mayor prevalencia de complicaciones crónicas, lo cual presenta implicancias terapéuticas. Se revisaron 113 fichas del Policlínico de Diabetes del HCUCh con el objetivo de comparar el grado de control metabólico, complicaciones crónicas y presencia de otros factores de riesgo cardiovascular en pacientes clasificados por edad en $>65$ años (adulto mayor) $(n=50)$ y $<65$ años $(n=63)$. Entre los resultados podemos destacar diferencias significativas en cuanto a HbA1c menor a 7,5\% (35 vs 52,9\%; $p=0,004$ ), no así

Tabla 1

\begin{tabular}{|c|c|c|c|c|c|c|}
\hline & \multicolumn{2}{|c|}{$\begin{array}{c}\text { Bsm1 } \\
\text { (alelo b) }\end{array}$} & \multicolumn{2}{|c|}{$\begin{array}{c}\text { Apa1 } \\
\text { (alelo a) }\end{array}$} & \multicolumn{2}{|c|}{$\begin{array}{c}\text { Taq1 } \\
\text { (alelo t) }\end{array}$} \\
\hline $\begin{array}{l}\text { Transmitido/ } \\
\text { no transmitido }\end{array}$ & \multicolumn{2}{|c|}{$47 / 96$} & \multicolumn{2}{|c|}{$50 / 110$} & \multicolumn{2}{|c|}{$40 / 81$} \\
\hline $\mathrm{p}$-value & \multicolumn{2}{|c|}{0,90} & \multicolumn{2}{|c|}{0,39} & \multicolumn{2}{|c|}{1,00} \\
\hline Haplotipos & bat & bAt & BAt & bAT & BAT & baT \\
\hline$p$ value & 0,14 & 0,78 & 0,90 & 0,33 & 0,66 & 0,22 \\
\hline $\mathrm{p}$ value (global) & \multicolumn{6}{|c|}{0,26} \\
\hline
\end{tabular}


en cuanto a glicemia capilar en ayunas menor a $140 \mathrm{mg} / \mathrm{dl}(58,7$ vs $40,7 \%)$. No encontramos diferencias significativas en cuanto a prevalencia de retinopatía (32 vs 20,8\%), nefropatía (45,8\% vs $32,7 \%)$, neuropatía ( $54,5 \%$ vs $36 \%)$, infarto al miocardio (39,4 vs $22,9 \%)$ ni enfermedad vascular periférica (47,2 vs $35,7 \%)$. Sin embargo, se observó mayor prevalencia de accidente cerebrovascular ( 27 vs $6 \% ; p=0,020)$, como también de pie diabético en el adulto mayor (83,3 vs 43,2\%; $\mathrm{p}=0,004)$. La prevalencia de HTA fue también mayor en este grupo ( 94,1 vs $70,8 \%$; $p=0,007$ ), no observándose diferencias significativas en cuanto a niveles lipídicos. Conclusión: Se observó en los pacientes adultos mayores un peor control metabólico a largo plazo, mayor prevalencia de HTA, pie diabético y antecedente de accidente cerebrovascular. Creemos que debe plantearse un enfoque terapéutico más agresivo en etapas tempranas de la enfermedad para minimizar las complicaciones crónicas y mejorar la calidad de vida de los adultos mayores.

\section{EXPRESIÓN DE ISOFORMAS DEL FACTOR DE CRECI- MIENTO DE ENDOTELIO VASCULAR (VEGF) EN FEO- CROMOCITOMAS}

Araya V, Espinoza J, Villanueva ME, Amat J, Rossi R, Rodriguez F, Gac P, Lara H, Romero C.

Sección de Endocrinología, Lab. de Endocrinología y Biología de la Reproducción, Depto. de Cirugía y Depto. de Anatomía Patológica Hospital Clínico y Facultad de Ciencias Químicas de la Universidad de Chile.

Los feocromocitomas (FC) son tumores ricamente vascularizados. Se ha sugerido que el VEGF puede estar involucrado en su formación y potencial maligno. Dos de sus 5 isoformas han sido demostradas en FC humanos (VEGF165 y VEGF121).

Objetivos: evaluar la expresión del mRNA de VEGF en tejido obtenido de FC humanos.

Metodología: se realizó un RT-PCR semi-cuantitativo con RNA extraído de muestras de 5 FC obtenidos de pacientes intervenidos en el Hospital Clínico de la U. de Chile en los últimos 4 años y que fueron preservadas a $-80^{\circ}$. Dos de estos correspondieron a FC malignos. Test no paramétricos se utilizaron para el cálculo estadístico.

Resultados: a diferencia de lo descrito previamente en la literatura, observamos la expresión de 3 de las isoformas de VEGF: 189, 165 y 121, siendo significativamente mayor la expresión de la isoforma $165(\mathrm{p}<0,05)$. Aunque existe una tendencia a una mayor expresión de las isoformas 165 y 121 en los FC malignos, ésta no alcanzó significancia estadística.

Conclusiones: la expresión de VEGF en feocromocitomas humanos sustenta la posible participación de este factor en la génesis de estas neoplasias. Estudios que evalúen la implicancia de la expresión de las distintas isoformas y que además demuestren la expresión de su proteína son necesarios para establecer su utilidad como un marcador de malignidad.

Financiado en parte por proyecto Fondecyt 1030661 (CR).

\section{EXPRESIÓN DEL FACTOR DE CRECIMIENTO NER- VIOSO Y DE SU RECEPTOR TRKA EN FEOCROMOCI- TOMAS}

Araya V, Espinoza J, Villanueva ME, Amat J, Rossi R, Ortuondo E, Pineda P, Gac P, Lara H, Romero C.

Sección de Endocrinología, Lab. de Endocrinología y Biología de la Reproducción, Depto. de Cirugía y Depto. de Anatomía Patológica Hospital Clínico y Facultad de Ciencias Químicas de la Universidad de Chile.

El factor de crecimiento nervioso (NGF) y su receptor de alta afinidad trkA han sido involucrados en la proliferación de algunas neoplasias epiteliales y en la diferenciación de tumores como el neuroblastoma. Ambos se expresan en células PC12 derivadas de un tumor de médula suprarrenal murino. No hay estudios en feocromocitomas (FC) humanos.

Objetivos: evaluar la expresión de NGF y trkA en FC benignos y malignos obtenidos de pacientes intervenidos en el Hospital Clínico de la U. de Chile.

Metodología: se obtuvo 12 tumores preservados en parafina. Cuatro de ellos correspondieron a FC malignos. Se evaluó por inmunohistoquímica (IHQ) la expresión de la proteína de NGF y trkA. También se contó con muestras de tejido preservadas a $-80^{\circ}$, correspondientes a $2 \mathrm{FC}$ malignos y 3 benignos, para el estudio de la expresión del mRNA por un RT-PCR semicuantitativo. El mismo estudio se realizó en suprarrenal normal.

Resultados: se observó expresión del mRNA de NGF en todos los FC, siendo menor en la suprarrenal normal. La expresión del mRNA de trkA fue notoriamente mayor en uno de los FC benignos y otro maligno. En ambos casos, en la IHQ se observó una tinción débil y focal en todas las muestras evaluadas.

Conclusiones: en este estudio preliminar demostramos que los feocromocitomas humanos expresan NGF y trkA en diferente proporción. Estudios con un mayor número de muestras se requieren para evaluar su utilidad como potenciales marcadores del comportamiento biológico de estas neoplasias endocrinas.

Financiado en parte por proyecto Fondecyt 1030661 (CR)

\section{HIPERTIROIDISMO NEONATAL TRANSITORIO}

Arriaza M, Escobar M, Diettes A, González A.

Servicio de Neonatología. Hospital Dr. Gustavo Fricke de Viña del Mar y Universidad de Valparaíso.

El hipertiroidismo neonatal transitorio (HNT) es infrecuente (incidencia 1/1000 gestaciones 0 afectando a 1 de cada 70 gestantes con Enf. de Graves), ocurre en hijos de madres con patología tiroídea autoinmune por paso transplacentario de anticuerpos estimulantes del tiroides. Puede manifestarse en el $3^{0}$ trimestre del embarazo con taquicardia fetal, RCIU, 
hidrops fetal no inmune y en el recién nacido con prematuridad, bajo peso, irritabilidad, temblor, taquicardia, poca ganancia ponderal, vómitos, diarrea, trombocitopenia y hepatoesplenomegalia, entre otros. Describimos 4 pacientes con HNT manejados en nuestro servicio. Paciente 1. RNpT 32 sem PEG de 1260 gr., femenino. La madre es hipertiroídea en tratamiento con PTU, sin complicación del embarazo. Presentó taquicardia al $7^{\circ}$ día de vida. La TSH fue de 0,0012 $\mu \mathrm{UI} / \mathrm{ml}$ y T4 de $17,9 \mu \mathrm{g} / \mathrm{dl}$. Paciente 2 . RNpT $33 \mathrm{sem}$ PEG de $1140 \mathrm{gr}$, masculino hijo de una hipertiroídea tomando PTU, con síntomas de parto prematuro. El RN tenía dismorfias craneofaciales, exoftalmos, irritabilidad, taquicardia, temblor desde sus primeras horas de vida. Su TSH fue de 0,005 $\mu \mathrm{UI} /$ ml y T4 de 17,5 $\mu \mathrm{g} / \mathrm{dL}$. Evoluciona con RDPM y talla baja. Paciente 3. RNpT 34 sem PEG de 1610 gr sexo femenino. Hermano de paciente 1. La madre aún hipertiroídea no se controló ni recibió PTU. Presentó irritabilidad y taquicardia desde primeros días de vida. Su TSH fue de $0,005 \mu \mathrm{UI} / \mathrm{ml}$ y T4 de 23,62 $\mu \mathrm{g} / \mathrm{dL}$. Paciente 4. Es hija de una hipotiroídea tratada con radioyodo por enf. de Graves. Presentó taquicardia fetal. Nace a las 37 sem de EG. Su peso fue de $2820 \mathrm{gr}$. tenía taquicardia, irritabilidad, diarrea, exoftalmos, bocio y baja de peso. Su TSH fue de $0,012 \mu \mathrm{UI} / \mathrm{ml}$ y T4 $>22,8 \mu \mathrm{g} / \mathrm{dL}$. En ningún paciente se midió niveles de TRab (no disponible). Todos recibieron propiltiuracilo y propanolol. El tratamiento varió de 3 semanas a 3 meses según evolución normalizando las pruebas tiroideas en todos; sin desarrollar hipotiroidismo ni hipertiroidismo permanente. Un paciente desarrolló secuelas. En la madre hipotiroídea, es probable que sus TRabs estén muy elevados dado que requirió radioyodo y que su hija desarrolló HNT. Estos casos nos recuerdan que frente a toda embarazada 0 madre con hipertiroidismo autoinmune actual o pasado, requiere de un mayor control para detectar y tratar el hipertiroidismo fetal 0 neonatal y evitar complicaciones derivadas de un diagnóstico tardío.

\section{CÁNCER DE TIROIDES EN PEDIATRÍA}

Arriaza M, lobos A, Chiang M, Novik V, Díaz M, Reyes P, Oyaneder R, Semler C, Zumelzu E.

Servicios de Pediatría, Medicina Interna y Cirugía Hospital Dr. Gustavo Fricke de Viña del Mar. Facultad de Medicina Universidad de Valparaíso.

El carcinoma de tiroides en pediatría es infrecuente, tiene una incidencia estimada de 0,2 a 5 casos por millón de habitantes. Constituye el 1,5\% de todos los cánceres en menores de 15 años y afecta preferentemente al sexo femenino. El tipo histológico más frecuente es el papilar (85\%) Presentamos 3 casos de carcinoma tiroideo quae afectaron a escolares desde 1999 al 2004. Describimos su presentación manejo y evolución (Tabla 1).

Destacamos que todos los pacientes son varones a pesar de ser más frecuente en mujeres y haber sido diagnosticados durante los 5 últimos años. El paciente con PAAF (-) desarrolló nódulo predominante. Sólo la cirugía confirmó la existencia de cáncer. El único carcinoma observado fue el papilar. Un paciente ha requerido altas dosis de radioyodo por sus metástasis. Se recalca la importancia de evaluar y seguir estrechamente a niños con bocio multinodular 0 adenopatias cervicales y de la necesidad de un manejo multidisciplinario, para su pesquisa y tratamiento oportuno.

Tabla 1.

\begin{tabular}{|lccc|}
\hline & Paciente 1 & Paciente 2 & Paciente 3 \\
\hline Edad actual & 19 años & 13 años 8 meses & 11 años 9 meses \\
Edad al diagnóstico & 13 años & 8,0 años & 8,0 años \\
Presentación & Nódulo tiroídeo & Adenopatía cervical & Bocio MN \\
T. de evolución & 3 semanas & 3-4 semanas & 3 meses \\
Otros síntomas & Disfagia y disfonía & No & Disfonía \\
TSH $(\mu \mathrm{U} / \mathrm{ml})$ & No registrado & 4,39 & 150 \\
Cintigrama & BMN & Normal & No se realiza \\
PAAF o biopsia & $(+)$ papilar & Bx (+) papilar & $(-)$ \\
Metástasis inicial & Linfoadenopatía & Linfoadenopatía & No \\
Tratamiento & Tiroidectomía total & Tiroidectomía total & Tiroidectomía \\
& y disección & y disección & total \\
Radioyodo (total) & 100 mCi & 320 mCi & $100 \mathrm{mCi}$ \\
Histología & Ca. papilar & Ca. papilar & Ca. papilar \\
Complicaciones & $(-)$ & Metastásis pulmonar & $(-)$ \\
\hline
\end{tabular}




\section{HIPOGLICEMIAS SEVERAS. UN RIESGO LATENTE. ANÁLISIS RETROSPECTIVO 1999-2003}

Atrinson M, Bello F, Silva $C^{1}$, Sepúlveda $G^{1}$, Samsó $C^{1}$. Servicio de Medicina, Sección Endocrinología, Hospital Las Higueras, Universidad de Concepción. Talcahuano.

${ }^{1}$ Internos de medicina.

La hipoglicemia severa, definida como aquella que requiere asistencia de terceros, es una condición poco frecuente, pero no exclusiva de la población diabética, donde la tardanza en su diagnóstico y tratamiento puede llevar a secuelas graves e incluso la muerte. Se presenta estudio retrospectivo, con revisión de fichas clínicas de todos los ingresos por hipoglicemia severa desde el 1 de enero de 1999 al 31 de diciembre de 2003, en el Hospital Las Higueras de Talcahuano. Se analizaron características epidemiológicas, patologías y tratamientos farmacológicos asociados, evolución intrahospitalaria del total de pacientes y luego separado en subgrupos diabéticos y no diabéticos.

Resultados: 74 pacientes (33 M; 41H), con edad promedio de $62,5 \pm 16,5$ años, concentrándose un $77 \%$ de los casos en la población mayor de 55 años. El promedio de glicemias fue de $33,9 \pm 14,85 \mathrm{mg} \%$. Un 23\% del grupo total recibió su primera atención por el SAMU, de ellos se recuperó antes de llegar al Hospital el 82\% (14). Un 71\% de las hipoglicemias ocumó en paciente diabéticos, principalmente diabetes mellitus tipo $2(96 \%)$. En relación a patología asociada predisponente se encontró Insuficiencia Renal, Insuficiencia Hepática e Insuficiencia Cardiaca en 15\%, 6,7\% y 5\% respectivamente. El antecedente de ingesta de alcohol se encontró en 13 pacientes (17,5\% del total), 4 de ellos diabéticos. El síntoma neurológico más frecuente fue la presencia de distintos grados de compromiso de conciencia (consignado en 38 de los 74 pacientes). La evolución intrahospitalaria fue satisfactoria en 67 pacientes (90,5\%), 4 de ellos presentaron cuadros infecciosos, 1 AVE extenso talámico y en otro se pesquisó un adenocarcinoma de páncreas. Sólo falleció 1 paciente alcohólico que presentaba neumonía y no era diabético. Subgrupo de Diabéticos, 53 pacientes, (21 M; $32 \mathrm{H})$, 52 tenían Diabetes Mellitus tipo 2. El promedio de edad fue $65 \pm 12,9$ años. Un 24,5\% (13) recibió su primera atención por el SAMU, recuperándose precozmente 12 de ellos (92\%). El promedio de glicemias en esta población fue de 34,35+13,96 mg\%. Sólo en 4 pacientes estaba consignada la HbAlc y en todos los valores eran < $7,0 \%$. Cuarenta y dos diabéticos (79,2\% de este subgrupo) usaba hipoglicemiantes orales, siendo el más frecuente la glibenclamida (39/53), 26 en monoterapia, 12 asociado a metformina y 3 asociado a insulina. Siete pacientes usaba monoterapia con insulina. Se encontró Insuficiencia Renal en 9 de los pacientes diabéticos (17\% de este grupo). El antecedente de ingesta de alcohol se obtuvo en 4 pacientes. Subgrupo de no diabéticos, 21 pacientes, (12 M; 9 H). El promedio de edad fue de $55 \pm 20$ años. La asociación más frecuente en este grupo fue el antecedente de ingesta excesiva de alcohol (7). La segunda asociación más frecuente fue el intento suicida (3).

Conclusión: La causa más frecuente de hipoglicemia severa es la Diabetes Mellitus tipo 2, asociada al uso de hipoglicemiantes orales, principalmente glibenclamida, espe- cialmente en población mayor de 55 años. En los casos no asociados a Diabetes, la condición más frecuente fue la ingesta excesiva de alcohol. La consulta precoz con una atención oportuna, como la brindada por el SAMU, evitó el desarrollo de complicaciones neurológicas severas o muerte.

\section{PRUEBAS DE TOLERANCIA A LA GLUCOSA DESPUÉS DE MUERTE CEREBRAL EN DONANTES DE PÁN- CREAS PARA ISLOTES}

Atwater $\mathbf{I}^{1}$,2, Belmar $\mathrm{P}^{3}$, Parrau $\mathrm{D}^{1}$, Galleguillos $\mathrm{I}^{3}$, Palacios $\mathrm{JM}^{4}$, Olguín $\mathrm{F}^{2}$, Billings $\mathrm{B}^{1}$, Navia $\mathrm{A}^{1}$, Romero $\mathrm{C}^{2}$, Espinosa $\mathrm{J}^{2}$, CaAmaño $E^{2}$, Rojas $E^{1}$.

${ }^{1}$ ICBM, Fac. de Medicina U. de Chile, ${ }^{2}$ Hosp. Clínico J.J.Aguirre U. de Chile, ${ }^{3}$ Hosp. Barros Luco Trudeau, Depto de Cirugía, ${ }^{4}$ Hosp. San Juan de Dios, Unidad de Transplantes.

Hoy en día la única cura para la diabetes tipo 1 es el transplante de islotes de Langerhans. Sin embargo, ha tenido menos éxito de lo esperado. Según algunos autores esto podría deberse a que la muerte cerebral estaría alterando la respuesta de las células beta a los niveles de glucosa así como de los islotes aislados y transplantados posteriormente, lo que se ha demostrado en ratas (Diabetes 52:2935, 2003). Nuestro objetivo fue evaluar el efecto de la muerte cerebral en el funcionamiento de células beta de donates humanos y buscar parámetros predictivos de su funcionamiento posterior al transplante. Efectuamos pruebas de tolerancia a la glucosa intravenosas (IVGTT) en 18 donantes de páncreas con muerte cerebral. Se inyectó $0,3 \mathrm{gr} / \mathrm{Kg}$ de glucosa vía endovenosa (tiempo 0) y obtuvimos tubos con sangre heparinizada a los tiempos -15, -10, -5, 0, 1, 2, 3, 4, 5, 7, $10,15,20,25$ y 30 minutos. Se midió de la glicemia en sangre entera mediante One Touch Ultra ${ }^{\circledR}$. Posteriormente los tubos se centrifugaron $5 \mathrm{~min}$ a $1500 \mathrm{rpm}$ y el suero fue guardado a $-20^{\circ} \mathrm{C}$ para la determinación posterior de insulina (IMMULTEE ${ }^{\circledR}$ y glucosa (glucosa oxidasa). Las (IVGTT) de 12 (63,2\%) de los donantes, fueron comparables a individuos normales vivos. En los otros 6 donantes, las glicemias basales fueron mayores a 200 $\mathrm{mg} / \mathrm{dl}$. Uno presentaba una glicemia constante mayor de 600 $\mathrm{mg} / \mathrm{dl}$. Sólo el 40\% de los donantes tenía respuesta insulínica al estímulo con glucosa. Casi todos los donantes fueron tratados con dopamina y algunos con epinefrina o norepinefrina lo que inhibe la secreción de insulina. El promedio de HOMA en los normales» fue $36,44+5,91 \quad(n=5)$. Este es el primer reporte de IVGTT en donantes cadavéricos. En conclusión, cerca de la mitad de los donantes muestra alguna anormalidad del metabolismo de la glucosa. Esto podría deberse tanto al daño cerebral como a los fármacos administrados. A futuro la IVGTT podría ser un parámetro para predecir cuales islotes son apropiados para ser trasplantados. Además, el tratamiento con insulina en donantes con glicemias mayores a $200 \mathrm{mg} / \mathrm{dl}$, podría aumentar la viabilidad de los órganos donados en su posterior transplante. Se agradece a la corporación del transplante.

Apoyado por FONCECYT 1030596. 


\section{TRIPTORELINA DE DEPÓSITO 3 MESES DE DURA- CIÓN, NO INCREMENTA EL ÍNDICE DE MASA COR- PORAL EN PACIENTES CON PUBERTAD PRECOZ CENTRAL. REPORTE DE LOS PRIMEROS 12 MESES}

Avila A, Martínez A, Iñiguez G, Sovino H, Beas F, Cassorla F. Instituto de Investigaciones Materno Infantil, Facultad de Medicina, Universidad de Chile, Santiago, Chile.

Se ha sugerido que los niños con Pubertad Precoz Central (PPC) son susceptibles de desarrollar obesidad durante el tratamiento con análogos GnRH, pero esta condición no ha sido sistemáticamente demostrada. Objetivo: evaluar si el uso Triptorelina 11,25 mg administrado cada 3 meses se asocia 0 no a un incremento del Índice de Masa Corporal (IMC) en pacientes PPC eutróficas y con sobrepeso u obesas. Tipo de Diseño: Longitudinal. Pacientes y métodos: Se incluyeron pacientes con PPC que recibieron Decapeptyl ${ }^{\circledR} 11,25$ mg administrado cada 3 meses, con adecuada supresión del eje hipofisiario gonadal. Para evaluar individuos de diferente edades y sexo se calculó el z-score de IMC utilizando EpiNut. Se consideró como eutrófico un z-score de IMC $<1$ DS; sobrepeso $\geq 1$ y $<2$ DS y obeso $\geq 2$ DS. Con la evaluación del IMC basal se crearon 2 grupos: Grupo 1= Eutróficos ( $n=10)$ y Grupo 2= Sobrepeso y obesos $(n=10)$. Resultados: Se estudiaron 19 niñas y 1 niño con PPC; todos han completado 12 meses de tratamiento con eje hipofisiariogonadal adecuadamente suprimido (Tabla 1).

Conclusiones: Un 25\% de las niñas eran obesas antes de iniciar el tratamiento con análogo $\mathrm{GnRH}$. En los primeros 12 meses de tratamiento con Decapeptyl ${ }^{\circledR} 11,25 \mathrm{mg}$ cada 90 días, no se observó variaciones estadísticamente significativas en el z-score de IMC tanto en los pacientes eutróficos como aquellos con sobrepeso u obesos. Estos pacientes serán tratados con Decapepyl ${ }^{\circledR} 11,25 \mathrm{mg}$ cada 90 días durante un período más prolongado, esto permitirá establecer posibles efectos más tardíos de análogo GnRH en el IMC.

\section{HIPOGLICEMIA FACTICIA. SÍNDROME DE MUN- CHAUSEN}

Bello F, Frías X, Atkinson M, Jara P1

Servicios Medicina Interna y Siquiatría Hospital Las Higueras, Universidad de Concepción. Talcahuano.

${ }^{1}$ Interno de medicina.

Caso Clínico. Mujer de 26 años, funcionaria de la Salud, con historia de Diabetes Mellitus de 5 años de evolución. El año 2003 se hospitaliza para estudio de una diarrea crónica, oportunidad en la que se reevaluó diagnóstico de DM tipo 1 que tenía a la fecha tratándose con múltiples dosis de insulina y autocontrol 5 veces al día. Rescatando antecedentes, tenía algunas glicemias fugaces límites, pero sus hemoglobinas glicadas eran siempre inferiores a 5,0\%. Se suspendió insulinoterapia sin problemas. TTG e insulinemias fueron normales. Sólo se encontró anticuerpos anti GAD positivos. Se planteó remisión espontánea de DM. Por su diarrea fue sometida a exhaustivo estudio: endoscopía alta y baja, biopsias de mucosa duodenal y colónica, tránsito de Intestino delgado, enema baritado, TAC abdominal, anticuerpos antiendomisio y antigliadina, todos ellos negativos. A pesar de lo anterior y múltiples tratamientos sintomáticos, incluída dieta sin gluten auto impuesta por la paciente no tiene resultados continuando por un año con su diarrea, pero sin bajar de peso. A raíz de un cuadro gripal habría presentado hiperglicemia (180 mg/dl), se le indicó $2,5 \mathrm{mg}$ de glibenclamida prealmuerzo presentando hiopoglicemia por lo que se le suspendió. Una semana después acude de urgencia por repetidos episodios de hipoglicemia que se tratan con suero glucosado en el consultorio en que trabaja, con respuesta «paradojal» según la paciente. Se indica hospitalización urgente llegando la paciente 6 horas después al hospital (distante $10 \mathrm{~km}$ ), para estudio de su hipoglicemia. Al ingreso glicemia $28 \mathrm{mg} / \mathrm{dl}$, insulinemia 55,69 uUI/ml. Se logra compensar con Suero Glucosado y alimentación fraccionada, presentando nuevas hipoglicemias bruscas después de ir al

Tabla 1.

\begin{tabular}{|lccccc|}
\hline & Características Generales & \multicolumn{3}{c|}{ Evolución del z-score de IMC } \\
\hline Variables & Grupo 1 & Grupo 2 & Tiempo & Grupo 1 & Grupo 2 \\
Edad (años) & $7,5 \pm 0,25$ & $7,5 \pm 0,34^{*}$ & Basal & $0,26 \pm 0,14$ & $1,87 \pm 0,18$ \\
Edad ósea (años) & $10,1 \pm 0,41$ & $10,8 \pm 0,61^{* *}$ & & & \\
Talla ( z-score) & $0,93 \pm 0,25$ & $1,13 \pm 0,21^{*}$ & 6 meses & $0,45 \pm 0,22$ & $1,83 \pm 0,16$ \\
LH basal (mUI/ml) & $1,5 \pm 0,32$ & $2,6 \pm 0,59^{*}$ & p value & 0,320 & 0,813 \\
LH peak (mUI/ml) & $21,1 \pm 18,9$ & $43,6 \pm 11,8^{* *}$ & 12 meses & $0,58 \pm 0,18$ & $1,56 \pm 0,15$ \\
Estradiol (pg/ml) & $12,5 \pm 3,1$ & $17,7 \pm 6,2^{* *}$ & p value $^{2}$ & 0,085 & 0,135 \\
& & & & & \\
\hline
\end{tabular}

(*) Prueba T, p=NS; (**) U Mann-Whitney, $\mathrm{p}=\mathrm{NS}$

Prueba T para muestras relacionada, (1) basal-6 meses; (2) basal-12 meses. 
baño, lo que llamó la atención. Es trasladada a servicio de Intermedio para mayor vigilancia, lugar en el que presentó un nuevo episodio de hipoglicemia después del horario de visita en que estuvo más 30 minutos aislada con su madre. Insulinemias 55,6 y $64,0 \mathrm{uUI} / \mathrm{ml}$ y Péptido C simultáneos indetectables $(<0,05)$, lo que confirma hiperinsulinemia exógena. Al entrevistar privadamente a la paciente, en conjunto con la siquiatra, ésta niega el hecho, a pesar de los hallazgos bioquímicos y al hecho de haber encontrado un frasco de insulina rápida entre sus útiles de aseo personal. Al segundo día reconoce el hecho y se deja en tratamiento siquiátrico.

\section{LOS RECEPTORES PARA ESTRÓGENOS PODRÍAN ME- DIAR LOS EFECTOS INHIBITORIOS DEL COBRE SO- BRE LA PROLIFERACIÓN Y LA EXPRESIÓN GÉNICA DE CÉLULAS DE CARCINOMA MAMARIO HORMO- NO-DEPENDIENTE}

\author{
Benitez DA ${ }^{1,2}$, Bruzzone ME², Castellón EA ${ }^{1}$. \\ ${ }^{1}$ Unidad de Reproducción, ${ }^{2}$ Laboratorio de Andrología Celular \\ y Molecular, Facultad de Medicina, Universidad de Chile.
}

La expresión de los receptores para estrógenos alfa (ERd) y beta (ERß) varía de acuerdo al grado y tipo de cáncer mamario. Por otra parte, algunos metales divalentes interfieren con la acción estrogénica tanto in vivo como in vitro. Objetivo. Investigar los efectos del cobre sobre la actividad proliferativa y expresión génica de los ERs y lactoferrina (LF; gen regulado por estrógenos), en células derivadas de adenocarcinoma mamario. Metodología. Se utilizaron las líneas celulares MCF-7 (sensible a estrógenos) y MDA-MB-231 (no sensible a estrógenos), las cuales fueron tratadas por 48 horas con diferentes concentraciones de $\mathrm{Cu}(1,2,5,5,10,50,100$ y $200 \mu \mathrm{M})$ en presencia 0 ausencia de $1 \mathrm{nM}$ de estradiol $\left(\mathrm{E}_{2}\right)$. La actividad proliferativa se ensayó por el método espectrofotométrico basado en el reactivo dimetiltetrazolio (MTT) y la expresión génica de $E R \alpha, E R ß$ y LF por transcripción reversa asociada a la reacción en cadena de la polimerasa (RTPCR). Resultados. El cobre inhibió la proliferación celular de las células MCF-7 a partir de $10 \mu \mathrm{M}$ en ausencia de $\mathrm{E}_{2}$, mientras que la proliferación inducida por $\mathrm{E}_{2}$ disminuyó a partir de $1 \mu \mathrm{M}$. En las células MDA-MB-231, la disminución de la proliferación se evidenció sólo a partir de $50 \mu \mathrm{M}$ de $\mathrm{Cu}$ y fue independiente de $\mathrm{E}_{2}$. En células MCF-7, la expresión génica de los ERs y LF fue estimulada por $E_{2} y$ disminuida por cobre, en presencia 0 ausencia de la hormona. La expresión del ERß resultó ser más sensible a la estimulación por $\mathrm{E}_{2}$ y a la inhibición por $\mathrm{Cu}$ que la del ERo. Conclusiones. Los efectos del $\mathrm{Cu}$ sobre la proliferación y expresión génica de los ERs y LF podrían estar mediados por la interferencia de este catión con la interacción del $\mathrm{E}_{2}$ con sus receptores, siendo más sensible a este efecto el ERß. Sin embargo, el efecto del $\mathrm{Cu}$ que se evidencia a mayores concentraciones podría estar mediado por un mecanismo independiente de los ERs.

Financiamiento: Proyecto SOCHEM 2003-08

\section{ACTINOMICOSIS CERVICAL SIMULANDO PATOLO- GÍA TIROIDEA}

Brusco $F^{1}$, Oyaneder R $R^{1}$, Ruiz $J^{1}$, Bravo $)^{2}$, Espinosa $R^{3}$, Barthel $E^{4}$. Sección de Endocrinología ${ }^{1}$, Servicio de Radiología ${ }^{2}$, Anatomía Patológica y Sección de Infectología ${ }^{3}$. Hospital Naval Almirante Nef, Viña del Mar.

La masa cervical anterior febril y dolorosa tiene entre sus diagnósticos diferenciales el flegmón cervical, la tiroiditis aguda y subaguda y el cáncer indiferenciado del tiroides. Algunos datos clínicos y de laboratorio, las pruebas tiroideas y las imágenes cervicales permiten hacer la distinción. Presentamos el caso de una masa cervical febril y dolorosa que clínicamente y bioquímicamente simuló las patologías descritas y que resultó ser una actinomicosis.

Mujer de 57 años, sana. Sin procedimientos cérvicofaciales previos. Consultó por cuadro de 20 días de evolución caracterizado por fiebre, sudoración y aumento de volumen cervical anterior bajo, lateralizado a derecha, intensamente doloroso que impedía la deglución. Al examen físico destacaba: temperatura $37,4^{\circ} \mathrm{C}$, pulso $90 \mathrm{x}^{\prime}$ y en zona de proyección del lóbulo tiroideo derecho, masa de $3 \times 7 \mathrm{~cm}$, dura, de bordes imprecisos, intensamente dolorosa. Laboratorio: Leucocitos: $6300 \mathrm{x} \mathrm{mm}^{3}$, VHS: $87 \mathrm{~mm} / \mathrm{h}$, TSH $2,29 \mathrm{uUI} / \mathrm{ml}, \mathrm{T} 4$ libre 0,93 ng/dl, T3 71,1 ng/dl. Ecografía: lesión expansiva sólido-quística, de límites mal definidos, lateral a la glándula tiroidea derecha, sin plano de clivaje claro con ella ni con la musculatura pretiroidea. Compatible con lesión infiltrativa de origen timoideo; menos probable lesión inflamatoria. Gram: abundantes PMN sin bacterias, cultivo (-). PAAF: Inflamación crónica en granulación con colonias bacterianas del género actinomices. Responde favorablemente a las 24 horas de tratamiento antibiótico y la masa desaparece al mes. La ruta de entrada sería una erosión laríngea por espina de pescado 10 meses antes.

La actinomicosis cérvico-facial habitualmente se presenta como un proceso supurativo subagudo o crónico de la región submandibular por contiguidad de un foco dentario, todo lo cual permite su sospecha clínica. Sin embargo, una presentación inhabitual, como en este caso, puede confundir: el dolor, su ubicación y rápida progresión simularon una tiroiditis, y, su consistencia y aspecto ecográfico, una neoplasia tiroidea. Este caso sugiere, que a pesar de su rareza, la actinomicosis debe ser sospechada por el endocrinólogo en la evaluación de la masa cervical inflamatoria o tumoral de supuesto origen tiroideo. 


\section{VALOR DE LOS ANTICUERPOS ANTI-TIROGLOBU- LINA (AC-TG) EN EL SEGUIMIENTO DE PACIENTES CON CÁNCER PAPILAR DE TIROIDES (CPT) DES- PUÉS DE TIROIDECTOMÍA TOTAL (TT)}

Campino C, Rodríguez ja, Arteaga E, lópez JM, Fardella C, Campusano C, González G, Mosso L, Valdivia L' ${ }^{1}$, Viviani P². Dptos: Endocrinología y ${ }^{2}$ Salud Pública, ${ }^{1}$ Servicio de Laboratorios Clínicos, Facultad de Medicina, Pontificia Universidad Católica de Chile.

Un problema frecuente en el seguimiento de pacientes con CPT es la presencia en el suero de Ac-Tg que pueden invalidar la medición de tiroglobulina. Sin embargo, después de la TT y de una dosis ablativa de ${ }^{131} \mathrm{I}$, los pacientes libres de cáncer no deberían tener el estímulo antigénico para la producción de Tg-Ac. La persistencia de Ac-Tg circulantes podría deberse a recidiva tumoral. Investigamos si en pacientes con CPT, tratados con TT y dosis ablativa de ${ }^{131} \mathrm{I}$, la concentración de Ac-Tg y su curso temporal se correlaciona con la presencia de recidiva tumoral. Pacientes y métodos: Estudiamos retrospectivamente 44 pacientes tratados por CPT $\left(\mathrm{TT}+{ }^{131} \mathrm{I}\right)$. Todos tenían Ac- $\mathrm{Tg}(+)$ medidos según Campino et al. (Rev Méd Chile 127:667-74,1999) y fueron seguidos desde 1 hasta 8 años post TT con ecografía cervical y Ac-Tg. Los pacientes se dividieron en 2 grupos: con y sin recidiva tumoral según clínica e imágenes (ecografía cervical o rastreo sistémico). El curso de los Ac-Tg se analizó mediante un modelo lineal generalizado no paramétrico.

Resultados (Tabla 1).

Conclusiones: En esta serie de pacientes, el curso de los Ac-Tg desciende significativamente en los pacientes sin recidiva tumoral, sugiriendo que la mantención de las concentraciones de Ac-Tg podría ser un marcador útil de persistencia 0 recidiva de enfermedad tumoral.
DIABETES NEONATAL Y ATRESIA DE VÍAS BILIARES: UN NUEVO SÍNDROME

Campos L, Giglio C, Torche S, Gandara F, Dedes C.

Servicio de Pediatría, Hospital Las Higueras, Talcahuano. Universidad de Concepción.

Diabetes Neonatal es un desorden extremadamente raro, con una incidencia de 1:500.000 RN vivos. Definido como Hiperglicemia requirente de insulina diagnosticada dentro de los primeros 3 meses de vida.

Se ha descrito en forma transitoria ( $60 \%$ de los casos) y permanente, existiendo algunos síndromes clínicos que pueden asociarse a la forma permanente. Su asociación con síndrome colestásico ha sido reportada en Hipotiroidismo Primario, Hiperquilomicronemia y Atresia de Vías Biliares.

Se presenta el caso de un RN, producto de cuarto embarazo de madre con Diabetes Gestacional Insulino-requirente, con RCIU severo. Cesárea a las 38 sem, peso: $1430 \mathrm{gr}$, talla: $40 \mathrm{~cm}$. Requiere insulina desde las primeras horas de vida. $\mathrm{Al} 2^{\circ}$ día de vida Protrombina de 15\%, GOT y GPT normales, GGT: 1097 U/ L, Bt: 4,93 mg/dl, Bc: 0,92 mg/dl. Eco abdominal: vía biliar de calibre normal, vesícula y páncreas no visualizados. Acolia desde el $6^{\circ}$ día de vida. Bt: $10 \mathrm{mg} / \mathrm{dl}$ y Bc 4,21 mg/dl. Cintigrafía de vías biliares: compatible con el diagnóstico de Atresia de Vías Biliares. Evoluciona con ganancia de peso progresiva, mantiene requerimientos de insulina, colestasia y acolia.

Fallece a los 34 días de vida por sepsis a bacilo Gram. (-). No se realiza Anatomía Patológica.

Comentario: Se presenta RN PEG extremo con DN y colestasia por atresia de vías biliares, aunque en este caso no se dispone de Anatomía Patológica, y estudio molecular, parece comesponder a un nuevo Síndrome descrito en la literatura en 4 pacientes, caracterizado por anomalías en el desarrollo de los islotes pancreáticos, intestino y vía biliar, en los cuales se descartó anomalías en el gen ZAC (6q24), glucokinasa, y gen IPF-1.

Tabla 1. Curso de las concentraciones de Ac-T g (UI/ml)

\begin{tabular}{|c|c|c|c|c|c|c|c|c|}
\hline \multirow{2}{*}{$\begin{array}{l}\text { Pacientes } \\
\text { Años post TT }\end{array}$} & \multicolumn{4}{|c|}{ Con recidiva tumoral } & \multicolumn{4}{|c|}{ Sin recidiva tumoral } \\
\hline & $\mathrm{n}$ & mediana & mínimo & máximo & $\mathrm{n}$ & mediana & mínimo & máximo \\
\hline 1 & 15 & 91 & 7,0 & 652,0 & 29 & 43,0 & 2,0 & 151,0 \\
\hline 2 & 14 & 56 & 5,0 & 4340,0 & 26 & 17,0 & 2,0 & 118,0 \\
\hline 3 & 13 & 115 & 2,0 & 8600,0 & 24 & 15,0 & 2,0 & 220,0 \\
\hline 4 & 15 & 74 & 2,0 & 824,0 & 17 & 11,0 & 2,0 & 100,0 \\
\hline 5 & 11 & 46 & 2,0 & 940,0 & 9 & 7,0 & 2,0 & 44,0 \\
\hline 6 & 6 & 13,5 & 2,0 & 264,0 & 4 & 17,5 & 2,0 & 28,0 \\
\hline 7 & 1 & 37 & 37,0 & 37,0 & 2 & 12,0 & 6,0 & 18,0 \\
\hline 8 & & & & & 1 & 26,0 & 26,0 & 26,0 \\
\hline
\end{tabular}

Con recidiva tumoral vs sin recidiva tumoral $\mathrm{p}<0,05$ 


\section{UTILIDAD DE 4 SCORES PARA LA IDENTIFICA- CIÓN DE MUJERES, POSTMENOPÁUSICAS CON BAJA DENSIDAD MINERAL ÓSEA}

Campusano $C^{1}$, Rodríguez $\mathrm{C}^{1}$, Cabezas $\mathrm{M}^{1}$, Viviani $\mathrm{P}^{2}$, Contreras $\mathrm{O}^{3}$, Pruzzo R ${ }^{4}$, Amaral $\mathrm{H}^{4}$, González $\mathrm{G}^{1}$, López JM ${ }^{1}$, RodríGuez JA $A^{1}$, Arteaga $E^{1}$.

Deptos. de Endocrinología ${ }^{1}$ Radiología ${ }^{3}$ y Salud Pública², Pontificia Universidad Católica de Chile, Servicio de Medicina Nuclear, Clínica Alemana, Stgo 4 .

La identificación de las mujeres postmenopáusicas con baja densidad mineral ósea (DMO) es una estrategia probada para reducir el riesgo de fracturas osteoporóticas. Existen diversas reglas de decisión para seleccionar la población de mayor riesgo, pero son aún materia de controversia. Objetivo: Comparar la precisión de 4 scores internacionales y el impacto de su modificación, considerando índice de masa corporal (IMC) en vez de peso para identificar mujeres postmenopáusicas con baja DMO. Sujetos y Método: Aplicación prospectiva de encuesta autoaplicada a una cohorte de mujeres postmenopáusicas que acudieron a distintos centros de densitometría ósea (DXA, LUNAR), entre agosto 2003 y enero 2004. Se excluyeron todas aquellas que estuvieran recibiendo drogas que modifiquen el metabolismo ósea a excepción de calcio, dosis fisiológicas de vitamina D y estrógenos. Se midió DMO en columna y cadera y se calcularon las siguientes guías de decisión: NOF (edad, peso, fractura personal y familiar, tabaquismo), ORAI (edad, peso, THR), SCORE (edad, peso, THR, raza, artritis reumatoidea) y ABONE (edad, peso, THR). Considerando la menor talla de la población chilena en comparación con la norteamericana en la que estos scores fueron diseñados, los recalculamos considerando IMC en vez de peso. Resultados: Se incluyeron 737 mujeres $(60,4 \pm 9,2$ años). Un 45,5\% tuvo DMO en rango de osteopenia (columna y/o cadera) y $17,2 \%$ en rango de osteoporosis; $32,2 \%$ estuvo bajo el umbral de tratamiento (T score <-2). Un 38,9\% recibía preparados en base a calcio. La precisión diagnóstica en la pesquisa de osteoporosis de los tests evaluados fue en $\%$ (m =score modificado) (Tabla 1).
Conclusiones: En esta serie, ORAI tuvo la mejor capacidad de discriminación. Los resultados de esta serie son similares a los de la literatura, sin embargo destaca su baja especificidad. Nuestras sensibilidades en los scores originales son menores que lo comunicado, pudiendo esto deberse al distinto origen racial de la muestra, y a la utilización de peso en vez de IMC. El uso del IMC mejora la especificidad permitiendo detectar a las paciente que NO requieren ser evaluadas con densitometría ósea.

\section{REGISTRO DE 133 TUMORES FUNCIONANTES OPE- RADOS EN EL INCA ENTRE 1984 Y 2004}

Carrasco C*, Vélz J, Ramos C, Rojas D*, Wohllk N.

Fac. Med. U. de Chile*, Depto Endocrino Hosp. Del Salvador e Instituto de Neurocirugía.

Objetivo: Describir características epidemiológicas, clínicas, radiológicas y quirúrgicas de tumores funcionantes operados en el INCA entre 1984 y 2004.

Método: Análisis retrospectivo de fichas. Se incluyen pacientes con evidencias bioquímicas y/o imagenológicas de tumores funcionantes operados; el estudio hormonal fue centralizado. En caso necesario se contactaron pacientes para realizar exámenes. Resultados: Total 133 tumores, 57 acromegálicos (Acro), 37 Cushing (Cush) y 37 prolactinomas (Pro). Mediana de duración de síntomas: 60 meses en Acro, 24 meses en Cush, 12 meses en Pro. En Acro el diagnóstico fue sospechado por médico general en $24,6 \%$ y endocrinólogo en 15,8\%. En Cush ambos sospecharon el 27\% de los casos respectivamente. En Pro, ginecólogos sospecharon 35,1\% y oftalmólogos el 24,3\%. Síntomas prevalentes: crecimiento acral y maxilofacial en Acro (98,2\%), aumento de peso (95\%), debilidad muscular proximal $(78,4 \%)$ en Cush e hipogonadismo (70,2\%) y cefalea (59\%) en Pro. El 31,2\% tenía compromiso neuroftalmológico y $61 \%$ algún grado de hipopituitarismo. 21,6\% de Pro se presentó con apoplejía. Encontramos 1 Pro asociado a NEM tipo 1 y 2 acromegalias familiares. Complicaciones cirugía (cx): DI (26,3\%), infecciones (2\%). Mortalidad 1,4\%. Curación por cx: $16 \%$ Acro, 48,6\% Cush y $22 \%$ Pro.

Tabla 1.

\begin{tabular}{|lcccc|}
\hline & NOF/(m) & ORAI/(m) & SCORE/(m) & ABONE/ (m) \\
\hline Sensibilidad & $80,2 / 84,3$ & $80,9 / 66,9$ & $76,9 / 62,2$ & $40,5 / 58,5$ \\
Especificidad & $35,9 / 27,5$ & $50,5 / 70,5$ & $31 / 73,2$ & $69,3 / 73,6$ \\
Valor Predict, Positivo & $19,7 / 18,6$ & $24,3 / 30,8$ & $17,9 / 30,7$ & $20,6 / 29,6$ \\
Valor Predict, Negativo & $90,2 / 89,5$ & $93,1 / 91,6$ & $83,4 / 91$ & $85,6 / 90,3$ \\
Falsos Positivos & $80,3 / 81,4$ & $75,7 / 69,2$ & $82,1 / 69,3$ & $79,4 / 70,4$ \\
Falsos Negativos & $16,4 / 10,1$ & $6,9 / 8,4$ & $12,6 / 15,9$ & $14,4 / 9,7$ \\
\hline
\end{tabular}


Conclusiones: al igual que en registros extranjeros, estos tumores afectan población joven y demoran en ser diagnosticados. Destaca el 2,2\% de formas familiares. Los resultados cx son malos, especialmente en acromegálicos, donde el acceso al tratamiento médico es prácticamente imposible y la RT tiene latencia.

\section{INCIDENCIA DE DIABETES TIPO 1 EN SANTIAGO DE CHILE: PERÍODO 2000-2003: ANÁLISIS POR COMU- NAS DE LA REGIÓN METROPOLITANA}

Carrasco E ${ }^{1}$, Pérez $F^{2}$, Angel B ${ }^{2}$, Causey $T^{3}$, Santos Jl ${ }^{2}$.

${ }^{1}$ Unidad de Diabetes. Hospital San Juan de Dios. Departamento de Medicina Facultad de Medicina Occidente. ${ }^{2}$ INTA. Universidad de Chile. Santiago, Chile. ${ }^{3}$ Fogarty Program. University of Michigan, USA (Proyecto Fondecyt 1030680).

Introducción: La implementación de Registros Estandarizados de población ha demostrado que la incidencia de diabetes tipo 1 varía ampliamente entre los diferentes países y grupos étnicos. El propósito de la recolección de esta información completa con un método estandarizado, permite comparar las tasas de incidencia de los diferentes países.

Objetivo: Determinar la incidencia de Diabetes tipo 1 en menores de 15 años durante un período de 4 años, entre el $1^{0}$ de Enero de 2000 y 31 de Diciembre de 2003 en Santiago, (Región Metropolitana, comunas urbanas y rurales) y observar diferencias por comunas.

Material y Método: El protocolo es el normalizado según el proyecto para la Diabetes Infantil (WHO DIAMOND). La identificación de los casos utilizó como fuente primaria: fichas clínicas hospitalarias, servicios de urgencia y registros de médicos privados. Como fuente secundaria, se utilizó el registro de la Fundación de Diabetes Juvenil de Chile. El criterio de inclusión fue: edad menor de 15 años al momento del diagnóstico, uso de insulina desde el comienzo y residencia permanente en la Región Metropolitana. La tasa de incidencia global se expresó como casos por 100.000 habitantes.

Resultados: El análisis por comunas del Gran Santiago mostró que las mayores incidencias se registraron para las comunas de Vitacura, Providencia, Las Condes y La Reina (> 15/100.000 hab.año) y las cifra más bajas se registraron en las comunas de Pedro Aguirre Cerda, Pudahuel, La Pintana y Recoleta (<2,5/100.000 hab.año). La tabla siguiente resume la información de incidencia global por sexo en los cuatro años analizados $\left(*_{p}^{p}<0,01\right)$ (Tabla 1$)$.

Conclusión: Se observó un claro aumento de la incidencia de diabetes tipo 1 en este período comparado con años anteriores. Si bien el grupo de edad más afectado sigue siendo el de 10-14 años, se ha registrado un incremento notable para el rango de edad de 0-2 años. La diferencia estacional sólo se observó durante el año 2001, donde la mayor incidencia se produjo en los meses fríos.
Tabla 1.

\begin{tabular}{|ccccc|}
\hline Años & niños & IC 95\% & niñas & IC 95\% \\
\hline \multirow{2}{*}{2000} & \multirow{2}{*}{5,08} & $3,23-$ & 5,80 & $3,25-$ \\
& & 6,11 & & 6,19 \\
2001 & 6,90 & $3,77-$ & 5,13 & $3,17-$ \\
& & 7,46 & & 5,98 \\
2002 & 6,38 & $3,13-$ & 4,72 & $3,30-$ \\
& & 7,34 & & 6,19 \\
2003 & \multirow{2}{*}{$8,47^{*}$} & $4,03-$ & 6,61 & $3,15-$ \\
& & 9,12 & & 7,66 \\
\hline
\end{tabular}

\section{DIABETES NEONATAL CAUSADA POR NUEVA MU- TACIÓN DEL RECEPTOR KIR6.2}

Codner $E^{1}$, García $\mathrm{H}^{2}$, Gaete $X^{3}$, Ugarte $\mathrm{F}^{4}$, Silva $\mathrm{R}^{2,3}$, Flanagan $S^{5}$, HatTersley $A^{5}$.

${ }^{1}$ IDIMI. Facultad de Medicina, U. de Chile. ${ }^{2}$ Clínica Santa María, ${ }^{3}$ Hospital Roberto del Río, ${ }^{4}$ Hospital Exequiel González Cortés, ${ }^{5}$ Peninsula Medical School, Exeter, Reino Unido.

Introducción. El receptor de sulfonilurea, en asociación al canal Kir6.2, tiene un rol fundamental en la regulación de la secreción de insulina por la célula $ß$ pancreática. En el año 2004 Gloyn et al* describieron casos de Diabetes Neonatal 0 de inicio en los primeros meses de vida causada por mutaciones del canal Kir6.2.

Objetivo. Determinar la presencia de mutaciones de Kir6.2 en pacientes con DM que debutan antes de los 6 meses de edad.

Método. Se reclutaron cinco pacientes y se determinó evolución clínica, presencia de autoanticuerpos (ELISA) y se estudió el gen completo del canal Kir6.2 (KCNJ11) con amplificación por PCR y secuenciación directa*

Resultados. Los detalles clínicos y de laboratorio se detallan en la Tabla. La paciente número 2 presentó una mutación Arg201Leu (CGT>CTT) en el canal Kir6.2. Ella debutó a los 4 meses con una cetoacidosis diabética grave con $\mathrm{pH}$ 6,9 y glicemia $790 \mathrm{mg} / \mathrm{dl}$. Su diabetes no ha remitido, y ha sido tratada con insulina NPH, posteriormente con ultralenta y finalmente con glargina y lispro diluída. Su peso de nacimiento fue de $2.120 \mathrm{gr}$. y su talla de $44 \mathrm{cms}$ a las 37 semanas de edad gestacional. El cuadro clínico de los pacientes 4 y 5 es sugerente de una mutación de HNF1 ß (MODY5)**, cuyo estudio molecular está en ejecución. El paciente 3 comesponde a una DM1 (AutoAc positivos) (Tabla 1).

Conclusión. En esta muestra de pacientes con DM de inicio antes de los 6 meses se detectó una nueva mutación heterocigota del canal Kir6.2 que causa diabetes permanente de inicio precoz, demostrando la presencia de esta alteración molecular en la población chilena. Esto permite suponer que la paciente podría responder al tratamiento oral con sulfonilurea.

*Gloyn AL, et al. N Engl J Med 2004; 350:1838-1849. *Yorifuji T, et al. JCEM 2004; 89: 2905-2908 
Tabla 1.

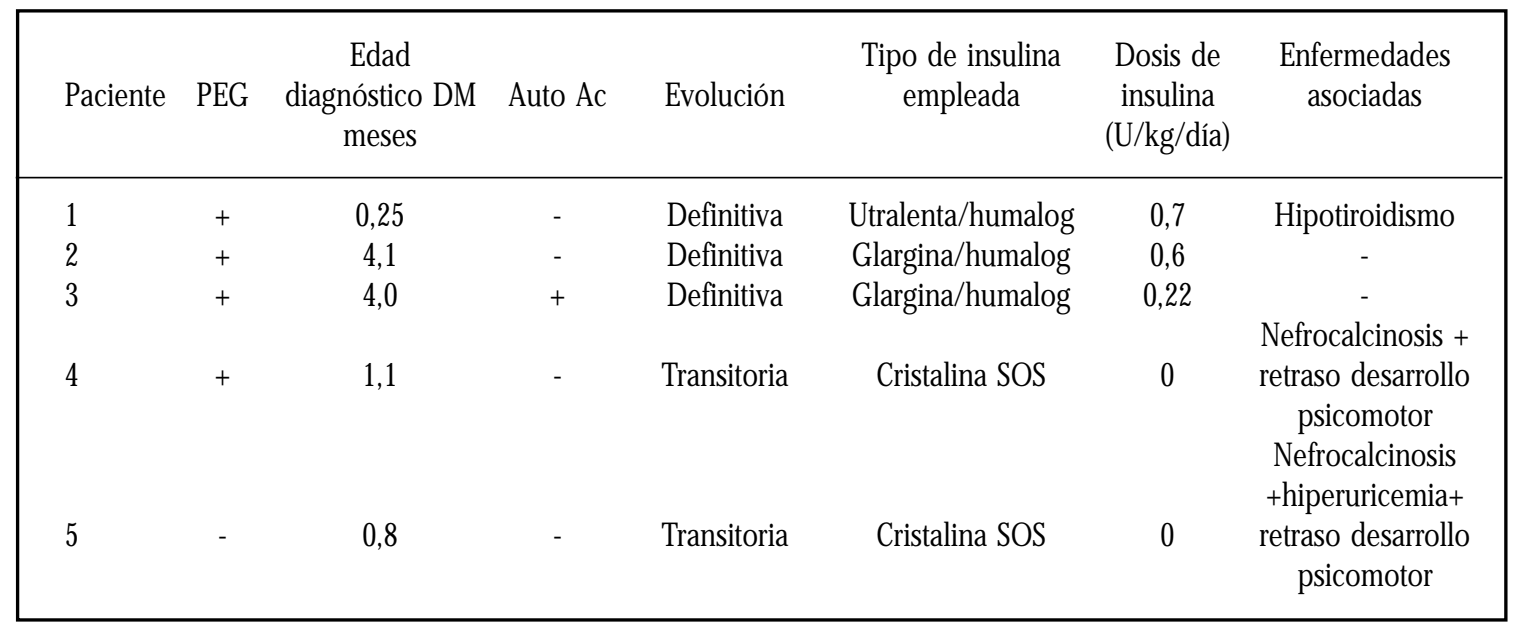

NUEVAS MUTACIONES DE GLUCOKINASA CAUSAN DIABETES MELLITUS (DM) TIPO MODY-2 EN LA INFANCIA

Codner $\mathrm{E}^{1}$, Pérez $\mathrm{F}^{2}$, Deng $\mathrm{L}^{3}$, Chung $\mathrm{W}^{3}$.

${ }^{1}$ I.D.I.M.I, Facultad de Medicina, U. de Chile. ${ }^{2}$ INTA: Facultad de Medicina, U. de Chile. ${ }^{3}$ Division of Molecular Genetics, School of Medicine, Columbia Univ.

Introducción: La DM tipo MODY es rara vez considerada como etiología de hiperglicemia en niños pequeños. MODY2 se caracteriza por hiperglicemia de ayuno leve, y por ausencia de complicaciones crónicas microvasculares.

Familias estudiadas: Familia 1: Niña de 19 meses con hiperglicemia de ayuno leve, asintomática (rango: 130-150 $\mathrm{mg} / \mathrm{dl}$ ). La madre, que tiene peso normal, está en tratamiento con sulfonilureas desde los 17 años con diagnóstico de DM2. Cuatro generaciones consecutivas en la familia matema han sido diagnosticadas con DM, pero no han desarrollado complicaciones crónicas. La niña se trata con régimen y mantiene estabilidad de los niveles de glicemia. Familia 2: Paciente de 6 años con hiperglicemia detectada en estudio de laboratorio, realizándose diagnóstico de DM1, e iniciando tratamiento con insulina. El hermano también presentó hiperglicemia leve a los 11,4 años, y fue tratado con insulina $(0,5 \mathrm{U} /$ día). Ambos hermanos, a pesar de que fueron tratados con dosis pequeñas de insulina, tenían un control glicémico óptimo. Se suspendió la insulina y no existió deterioro de los niveles glicéricos ni aparición de cetosis. La madre, una mujer delgada, presentó una diabetes gestacional.

Estudio Hormonal y Molecular: Se realizó prueba tolerancia oral a la glucosa (PTGO) con 1,75 g/kg de glucosa anhidrida (máximo $75 \mathrm{~g}$ ). Los niveles de glicemia, insulina y HbA1c y autoanticuerpos fueron medidos por glucosa oxidasa, RIA, intercambio iónico (Bayer DCA 2000), y ELISA, respectivamente. Se extrajo DNA de linfocitos y se amplifica- ron todos los exones de la glucokinasa por PCR, y se realizó secuenciación directa de los productos de la PCR.

Resultados: Familia 1: El probando de esta familia presentó insulinemia: 4,4 mUI/ml, glicemia a las 2 hrs en la PTGO de $155 \mathrm{mg} / \mathrm{dl}$. El padre y el hermano presentaron PTGO y estudio molecular normal. El paciente y su madre presentaron una mutación Arg302Trp en el exon 8 del gen de la glucokinasa. Familia 2: El probando, su hermano, y su madre presentaron glicemia a las 2 horas en la PTGO de 154, 226, $180 \mathrm{mg} / \mathrm{dl}$, respectivamente. El estudio molecular demostró una mutación Gly257Asp en el exon 7 del gen de la glucokinasa. El padre, la hermana, y el tío paterno presentaron PTGO y estudio molecular normal. Los autoanticuerpos anti GAD65 y anti IA2 de ambas familias fueron negativos.

Conclusiones: Se describen dos mutaciones nuevas en el gen de la glucokinasa en niños y sus madres. Concluimos que MODY2 debe ser considerado en el diagnóstico diferencial de hiperglicemia leve no cetótica en niños menores.

\section{NUEVOS ESQUEMAS DE TRATAMIENTO CON INSU- LINA EN NIÑOS Y ADOLESCENTES CON DIABETES MELLITUS TIPO 1 (DM1)}

Codner E, Mericq V, Román R, Hrlic I, Martínez A, Unanue N, Cáceres J, Avila A, Cassorla F.

I.D.I.M.I., Fac. de Medicina, Univ. Chile y Hosp. San Borja Arriarán, Santiago, Chile.

Introducción: La aparición de nuevas insulinas ha permitido ampliar las altemativas terapéuticas para los pacientes con DM1.

Objetivo Informar de los nuevos esquemas de tratamiento que se pueden utilizar en pacientes pediátricos con DM1 y sus efectos sobre el control metabólico.

Método: Se analizaron los esquemas de insulina empleados, el manejo nutricional, y el control metabólico en los 
niños tratados durante el año 2003. El manejo intensificado consistió en: tratamiento con multidosis de insulina, control frecuente de glicemia, apoyo nutricional, enfermera 24 horas del día, soporte psicológico y educacional.

Resultados. El grupo bajo tratamiento fueron 69 pacientes (36 mujeres, 59,7\% púberes) con edad de 12,0 $\pm 0,5$ años. Todos los pacientes utilizaban una insulina basal (69,2\% de la dosis diaria) y otra prandial (cristalina o lispro). Un $87 \%$ de los pacientes requieren $\geq$ tres dosis diarias de insulina con un tratamiento intensificado con tres o cuatro dosis diarias de insulina prandial, y los siguientes esquemas de insulina basal: dos dosis diarias de NPH (28\%), glangina (10\%), y tres dosis diarias de NPH (49\%). El esquema más utilizado correspondió a tres dosis diarias de NPH mezclada con insulina prandial (n:34), las dosis de NPH fueron aplicadas al desayuno (D), almuerzo (A) y comida (C) (n:29) o D, A y antes acostarse (B) (n:5). El tratamiento con NPH en dos dosis diarias y tres dosis diarias de insulina prandial fue utilizado en 19 pacientes; la NPH se coloca en el siguiente horario: D y C (n:11), D y B (n:6), D y A (n:3). Un 88,4\% y 46,4\% de los pacientes modificó la dosis de insulina rápida según la glicemia o ingesta de HC. El 27,5\% conoce la relación de insulina-hidratos de carbono que utiliza, y el $79,7 \%$ se coloca refuerzos adicionales de insulina cuando come fuera de horario. La HbA1C del grupo fue de $8,64 \pm 0,17 \%$ y un tercio de los pacientes logró el objetivo de HbA1C establecido en el programa, sin diferencias respecto al esquema de insulinoterapia basal utilizado. Por análisis de covarianza sólo la dosis total y basal de insulina se correlacionó significativamente con la HbA1C.

Conclusiones. Hemos demostrado que es posible instaurar un esquema de tratamiento intensificado modificado en población infanto-juvenil de un hospital público chileno, y hemos logrado un control metabólico muy satisfactorio con una amplia variedad de esquemas terapéuticos con insulina.

\section{EFICACIA Y SEGURIDAD DE LA TERAPIA MÉDICA DE GINECOMASTIA CON EL ANTIESTRÓGENO TA- MOXIFENO. INFLUENCIA DEL VOLUMEN Y DURA- CIÓN DE LA GINECOMASTIA EN EL RESULTADO TERAPÉUTICO}

Devoto E*, Madariaga $M^{* *}$, LIOI $X^{*}$.

*Departamento Endocrinología, Hospital Clínico San Borja Arriaran.**Instituto de Investigaciones Materno Infantil, Fac. Medicina, Universidad de Chile.

Las ginecomastias (Gi) fisiológicas o patológicas deben tratarse por: dolor, crecimiento rápido, no regresión en 2 años y repercusión psicosocial. Como alternativa a la terapia quirúrgica se utiliza terapia médica con el antiestrógeno Tamoxifeno. Se discute su eficacia en Gi de gran volumen y duración $>2$ años.
Objetivos: 1) Evaluar eficacia y seguridad de terapia con Tamoxifeno. 2) Influencia de mantención del fármaco causante de Gi, tamaño y duración de la Gi sobre resultado terapéutico.

Paciente y Método: 43 portadores de Gi (12 a 62 años), 27 fisiológicas de la pubertad, 16 patológicas (6 por antiandrógenos en terapia de acné) 20/43 mastalgia; 33/43 tamaño $>4$ cms. y 10/43< 4 cms. Informan 39/43 de tiempo de duración: $30<2$ años y $9>2$ años. El volumen se objetivó por la medición de diámetro máximo. Análisis estadístico: Chi-cuadrado y Fisher Exact Test.

Tratamiento: Tamoxifeno: $20 \mathrm{mg}$. diarios por 6 meses. Controles a los 3 y 6 meses.

Resultado: Tercer mes: 100\% desaparición de mastalgia y $16 \%$ de la Gi. Sexto mes: 59\% desaparición de Gi $(p<0,001)$. Terminada la terapia, recidivas $27 \%$.

En Gi por antiandrógenos al combinarlo con Tamoxifeno: 100\% desaparición de Gi. En Gi > 4 cms. desaparición en 52\% y $90 \%$ cuando es $<4 \mathrm{cms}$. $(\mathrm{p}<0,05)$. En Gi menor de 2 años de duración desaparición en $70 \%$ y en $>2$ años 56\% (NS). Efectos colaterales 2/43 (diarrea y bochornos).

Conclusiones: El Tamoxifeno se demostró eficaz y seguro; la combinación del fármaco causante de Gi más Tamoxifeno permite desaparecer $\mathrm{Gi}$.

$\mathrm{Ni}$ el mayor volumen ni mayor duración de la Gi contraindican la terapia, la que debe realizarse a lo menos por 6 meses.

\section{ETIOLOGÍA DE LA GINECOMASTIA. IMPORTANCIA DE NO SUBDIAGNOSTICAR LA GINECOMASTIA PA- TOLÓGICA EN PUBERTAD Y ADOLESCENCIA Y ANTE LA NO EXISTENCIA DE SÍNTOMAS Y SIGNOS PRE DETERMINADOS}

Devoto $E^{*}$, Madariaga $M^{* *}$, Lio $X^{*}$.

*Departamento Endocrinología, Hospital Clínico San Borja Arriaran. **Instituto de Investigaciones Materno Infantil, Fac. Medicina, Universidad de Chile.

La Ginecomastia (Gi) puede ser fisiológica o patológica. Se recomienda estudio mínimo en Gi de pubertad y senescencia consideradas generalmente fisiológicas; otros autores investigan ante dolor, crecimiento rápido, inicio reciente, diámetro mayor de $4 \mathrm{cms}$. y masa testicular.

Objetivos: investigar causas de Gi y determinar porcentaje de subdiagnóstico de Gi patológicas de cumplirse recomendaciones anteriores.

Pacientes y método: 118 pacientes (10-83 años) se estudiaron por: anamnesis, examen físico, medición de testosterona y estradiol. Otros estudios de acuerdo a semiología y laboratorio.

Resultados El 70\% de Gi entre 10 y 20 años. Una prepuberal y $5 \%$ mayor 50 años. Examen testicular: microrquia $\mathrm{n}=9$, tumor testicular $\mathrm{n}=2$. Laboratorio: Testosterona disminuida en $17 \%$ y Estradiol aumentado en $21 \%$. 

$(n=50)$.

Etiología: fisiológicas $58 \% \quad(n=68)$ y patológicas $42 \%$

Gi patológicas: 17 por fármacos, 17 endocrinas (9 hipogonadismos, 7 primarios y 2 secundarios) 3 tumores testiculares secretores de estradiol, uno de ellos no palpable (diagnóstico ecográfico) Otras causas: pesticidas, alcohol, diabetes, realimentación. 1 resistencia periférica a andrógenos (testosterona y LH aumentadas) y 5 hiperestrogenismos no tumorales (1 prepuberal).

Gi $<20$ años ( $\mathrm{n}=87)$ : fisiológicas $78 \%(\mathrm{n}=68)$ y patológicas $22 \%(n=19)$.

En senescentes $(n=5) 4$ patológicas, 1 fisiológica.

El 38\% (19/50) de las Gi patológicas no presentaban los síntomas y signos que según autores ameritan estudio completo.

Conclusiones. La Gi debe estudiarse acuciosamente a toda edad, incluyendo los períodos en que predominan las fisiológicas.

El realizar estudio sólo en base a síntomas y signos preestablecidos, determina a toda edad, un importante subdiagnóstico de Gi patológicas.

\section{TIROIDES ECTÓPICO CERVICAL LATERAL ASOCIA- DO A TIROIDES NORMOTÓPICO}

Díaz M, Lobos A, Novik V, Oyaneder R, Reyes P, Pozo P.

Departamentos de Cirugía y Endocrinología, Hospital Dr. G. Fricke, Viña del Mar. Facultad de Medicina, Universidad de Valparaíso, Chile.

La presentación de un tiroides ectópico en la línea media cervical anterior se observa con cierta frecuencia, pero no se describe en la literatura la presencia de dos glándulas tiroideas en un mismo sujeto; una normotópica, y otra ectópica, pero fuera de la línea de migración del tejido tiroideo embrionario.

Se presenta el caso de una mujer de 59 años que consulta por aparición de una masa lateral cervical izquierda de 2 años de evolución, de crecimiento lento y sin otros síntomas acompañantes.

La paciente es hipertensa y diabética en tratamiento con glibenclamida y enalapril.

Al examen se observa una paciente ectomorfa, IMC $24 \mathrm{~kg} /$ $\mathrm{m}^{2}$, con voz conservada, con aumento de volumen visible en cuello de $5 \mathrm{~cm}$. de diámetro en triángulo vascular izquierdo, con movilidad lateral, no pulsátil y de consistencia gomosa, sin otros hallazgos de consideración. Se pensó en quiste branquial o compromiso ganglionar (linfoma).

Los exámenes muestran función tiroidea normal (TSH: 1,2 $\mathrm{uU} / \mathrm{ml}$ ), así como hemograma, VHS y perfil bioquímico normales. La ecotomografía cervical informa presencia de tumor sólido»en la ubicación antes descrita. Se realizó PAAF que dio salida a $2 \mathrm{~cm}^{3}$ de líquido citrino, siendo informada como negativa para células neoplásicas». Se realizó extirpación quirúrgica de la masa en mayo de 2004, encontrándose un tumor ovoideo de $6 \mathrm{~cm}$ de diámetro, encapsulado, de bordes regulares, independiente de estructuras vasculares. El resultado de la biopsia definitiva fue socio nodular de timides».

Se realizó cintigrama cervical postoperatorio, el cual mostró la presencia de tiroides de captación heterogénea, de tamaño normal, en ubicación habitual. Se realizó determinación de TSH que fue de 0,993 uU/ml, lo cual demostraba el eutiroidismo del tiroides normotópico.

Comentario: Se presenta el caso inusual de una paciente con tiroides ectópico fuera de la línea media, con tiroides normotópico funcionante. No encontramos casos similares reportados en la literatura.

\section{PROGRAMA DE EVALUACIÓN DE PIE EN PACIENTES DIABÉTICOS}

DUARTE E.

Centro Médico San Joaquín. Pontificia Universidad Católica de Chile

A pesar de los avances en el tratamiento de la Diabetes Mellitus, el pie diabético sigue siendo la principal causa de amputación no traumática en el mundo. La prevención es el eje fundamental en el manejo de estas lesiones. Actualmente el cuidado de los pies, no se enfoca adecuadamente en las consultas de rutina, perdiendo esta función preventiva. Objetivos: El objetivo de este programa es evitar $\mathrm{y} / 0$ disminuir las complicaciones de los pies de los pacientes diabéticos, a través de la prevención de factores de riesgo, utilizando como estrategia la educación diferenciada y personalizada del paciente y su familia. Principalmente determinar el riesgo neurovascular de los pacientes y fortalecer la capacidad de autocuidado de los pies de acuerdo al riesgo establecido. Metodología: Programa de atención del paciente diabético que se realiza desde el año 2002 en el Centro médico San Joaquín. Entre el año 2002 y 2004 ( $1^{\circ}$ semestre) se evaluaron 256 pacientes. Es realizado por una enfermera adiestrada en podiatría y requiere algunos implementos de bajo costo (diapasón, monofilamento, martillo de reflejos). Se realiza educación individualizada según el riesgo de úlceras de los pacientes, el que se clasifica en alto, intermedio y bajo, estableciéndose intervenciones específicas de enfermería. La educación diferenciada y personalizada permite lograr una mayor atención y percepción por parte de la persona que es educada, ya que la información que esta recibiendo está centrada en sus intereses, preocupaciones y en la realidad de la enfermedad que está viviendo. Resultados: De 256 pacientes que ingresaron al programa, sólo 10 presentaron úlceras $(3,9 \%)$. De estos 10 pacientes las intervenciones realizadas curaron las úlceras y evitaron la hospitalización en 8 de ellos. Sólo 2 personas, del grupo de alto riesgo $(0,7 \%$ del total), sufrieron amputación de ortejos. Conclusión: La calidad de vida de la persona con pie diabético está en directa relación con la capacidad del pie para adaptarse a los procesos de cambios que lo acompañaran durante la vida. 
Para prevenir la aparición de lesiones y amputación, es indispensable la conformación de programas que incluyan equipos multidisciplinarios de atención primaria con atención en podiatría, como el nuestro. Las caracteństicas de este programa, además, lo hacen reproducible a nivel primario de atención.

\section{DIABETES INSÍPIDA CENTRAL EN PACIENTE CON HISTIOCITOSIS PULMONAR}

Dussaubat A*, Munizaga F.

Depto. de Endocrinología, Facultad de Medicina, Universidad de Chile, Campus Centro, Hospital Clínico San Borja-Arriarán, Santiago. *Becada Medicina Interna.

Introducción: La Histiocitosis Pulmonar de Células de Langerhans es un trastomo intersticial pulmonar de baja frecuencia, originado por la proliferación anormal de células de Langerhans y otras células inmunes, de causa desconocida. Se ha descrito fundamentalmente en adultos, presenta una evolución difícil de predecir, pudiendo asociarse a distintas complicaciones pulmonares y, en contadas ocasiones, a complicaciones extrapulmonares, con distintos grados de morbimortalidad. Entre estas últimas se encuentra el compromiso hipofisiario de distinto tipo, incluyendo la diabetes insípida, descrito básicamente en niños. Caso clínico: Hombre de 45 años, tabaquismo 11 paquetes año, con diagnóstico de Histiocitosis Pulmonar de dos años de evolución, confirmado histológicamente, tras debutar con cuadro de disnea progresiva hasta llegar a mediano esfuerzo asociada a tos imitativa, sin síntomas constitucionales. Consulta actual por poliuria de 7 meses de evolución (hasta 10 litros día), polidipsia y mareos, sin molestias respiratorias y con escasas crepitaciones al examen físico. Del laboratorio destaca glicemia normal y natremia de 144. Se plantea diagnóstico de diabetes insípida central por lo que se realiza prueba terapéutica con Desmopresina $40 \mu \mathrm{g}$ al día por tres días, desapareciendo los síntomas y cayendo la diuresis a menos de 2000 cc día, manteniendo natremia normal. Conclusiones: 1 . El compromiso extrapulmonar debe ser sospechado y buscado en pacientes con Histiocitosis Pulmonar y la poliuria nos obliga a descartar la diabetes insípida central. 2. La prueba terapéutica con Desmopresina es un recurso diagnóstico eficaz y de bajo costo.
POLIMORFISMO C $\rightarrow$ T (-34bp) DEL GEN CYP17 EN HERMANOS DE MUJERES CON SÍNDROME DE OVARIO POLIQUÍSTICO DE ACUERDO A LA RESPUESTA DE 17 OH PROGESTERONA AL ACETATO DE LEUPROLIDE

Echiburú $B^{1}$, Pérez $F^{1}{ }^{1}$, , Maliqueo $M^{1}$, Cartes $A^{1}$, Gutierrez $C^{1}$, Toloza $\mathrm{H}^{1}$, Sir-Petermann $\mathrm{T}^{1}$.

${ }^{1}$ Lab. de Endocrinología y Metabolismo, Facultad de Medicina Occidente, Universidad de Chile. ${ }^{2}$ Lab. Epidemiología Genética. Instituto de Nutrición y Tecnología de los Alimentos (INTA), Universidad de Chile.

Introducción: La hiperactividad de la enzima P450c17 $\alpha$ es un rasgo característico del síndrome de ovario poliquístico (SOP) que se puede poner en evidencia mediante un test de análogo de GnRH (Luprón). En un estudio previo (SOCHEM 2002/08) hemos establecido que el $45 \%$ de los hermanos de mujeres con SOP presentan una respuesta supranormal de $17 \mathrm{OH}$ progestorona (170HP) al test de luprón lo que podría sugerir la participación de un carácter genético en este fenotipo bioquímico. Por otro lado, se ha propuesto que el alelo A2 de la región promotora (-34bp) del gen CYP17 confiere hiperactividad de la enzima P450c17 $\alpha$. Objetivo: Relacionar la respuesta la test de luprón con el polimorfismo (-34bp) de la región promotora del gen CYP17 en hermanos de mujeres normales (HN) y con SOP (HSOP). Pacientes y Método: En 22 HSOP y 14 HN se determinó el polimorfismo CYP17 (-34bp) mediante PCR y análisis de RFLPs. En todos los sujetos se realizo un test de Luprón (10 ug/kg de peso s.c). La hiperespuesta al Luprón se definió como un aumento de la 170HP mayor de 2 DS sobre el promedio de los controles. Resultados: La frecuencia del alelo A2 no fue diferente en ambos grupos de hermanos (HSOP: 34,0\% vs HN 45\%, NS). La Tabla 1 muestra la distribución genotípica de ambos grupos de hermanos

Conclusión: Este estudio sugiere que no habría una asociación entre la hiperrespuesta de 170HP al test de Luprón con el alelo A2 del gen CYP17 en hermanos de mujeres con SOP.

(FONDECYT 1030487; SOCHEM 2002/08)

Tabla 1.

\begin{tabular}{|lccc|}
\hline HN (\%) & $\begin{array}{c}\text { HSOP-17OHP } \\
\text { normal (\%) }\end{array}$ & $\begin{array}{c}\text { HSOP-Hiperrespuesta } \\
\text { de 17OHP (\%) }\end{array}$ \\
\hline A1/A1 & 27,0 & 36,0 & 50,0 \\
A1/A2 & 55,0 & 55,0 & 30,0 \\
A2/A2 & 18,0 & 9,0 & 20,0 \\
\hline
\end{tabular}




\section{EVALUACIÓN DE LA EXPRESIÓN DEL RECEPTOR TIPO II DEL FACTOR DE CRECIMIENTO TRANSFOR- MANTE $\beta$ Y DE E-CADERINA EN TUMORES DE LA CORTEZA SUPRARRENAL}

Espinoza $J^{2}, V_{\text {IllanueVa }} \mathrm{ME}^{3}$, Tapia $\mathrm{V}^{2}$, Bordeau I $\mathrm{l}^{6}$, Amat $\mathrm{J}^{4}$, Rossi $R^{4}$, Valdebenito $R^{5}$, Romero $C^{2}$, Stratakis $C^{6}$, Araya $V^{1}$.

${ }^{1}$ Sección Endocrinología, ${ }^{2}$ Lab. Endocrinología y Biología de la Reproducción, ${ }^{3}$ Dpto. Patología, ${ }^{4}$ Dpto. Cirugía, ${ }^{5}$ Sección Urología, Hospital Clínico Universidad de Chile y ${ }^{6}$ SEGEN/ DEB/NICHD, National Institutes of Health, USA.

El Factor de crecimiento transformante $ß$ (TGF-ß) y el complejo de adhesión celular E-caderina-catenina participan en el proceso de tumorogénesis de diversos tejidos. Existen evidencias que TGF- $\beta$ regulańa la expresión de E-caderina (E-cad) y además inducińa el desacoplamiento de este sistema de adhesión. Objetivo: estudiar la expresión del receptor tipo II de TGF-ß (TGFBRII) y E-caderina en distintos tipos de tumores de la corteza supramenal. Metodología: se utilizó la técnica de inmunohistoquímica (IHQ) para evaluar la presencia de la proteína en el tejido y un RT-PCR semicuantitativo para evaluar la expresión del mRNA. Por IHQ se analizaron 27 tumores supramenales, preservados en parafina, que comespondían a 5 carcinomas $(\mathrm{Ca}), 4$ adenomas no funcionantes (ANF), 14 adenomas funcionantes (AF) y 4 supramenales normales que se emplearon como control. Para el estudio de mRNA se utilizaron 12 muestras de tejido supramenal congeladas a $-80^{\circ} \mathrm{C}$, clasificadas como: 2 Ca, 3 ANF, 4 AF y 3 supramenales normales, obtenidas de nefrectomías radicales. Para el análisis estadístico se aplicó el test de $\chi^{2}$. Resultados: la IHQ mostró expresión de TGFBRI en todos los tumores. Las diferencias observadas en el patrón de tinción entre tumores benignos y malignos no fueron estadísticamente significativas. Para E-cad se observó un patrón de tinción débil en ANF y AF y más intenso en los Ca. Esta diferencia fue estadísticamente significativa $(p \varangle 0,0001)$. Los datos anteriores se comelacionan con los resultados obtenidos por RT-PCR, en que se observó expresión del mRNA de TBRII en tejido tumoral y normal, siendo mayor en los AF. La expresión de E-cad fue significativamente mayor en los $\mathrm{Ca}$ que en los adenomas o el tejido normal. Conclusiones: la expresión de TGFBRII observada, sugenina la participación del TGF-ß en el origen de tumores cortico supramenales. Las diferencias encontradas podnáan estar relacionadas con la actividad esteroidogénica y/o malignidad del tumor. La mayor expresión de E-cad en los carcinomas podńa ser un marcador de malignidad y se requiere de más estudios para establecer su relación con TGF-ß3.

Finaciado por DID, REIN07/2002.

\section{DIFERENCIAS EN LA PRESENTACIÓN CLÍNICA DE LA DIABETES TIPO 1 (DM1) EN NIÑOS MENORES DE 5 AÑOS}

Eyzaguirre $\mathrm{F}^{1}, 6$, Peláez JM ${ }^{5}$, Sepúlveda $C^{5}$, Gaete $X^{2}$, Codner E E $^{1,6}$, Unuane $N^{1,6}$, Ávila $A^{1}$, Ugarte $F^{3}$, Silva ${ }^{4}$ y García $H^{4,5}$.
Hospitales ${ }^{1}$ San Borja Arriarán (HCSBA), ${ }^{2}$ Roberto del Río (HRR), ${ }^{3}$ E.González Cortés (HEGC), ${ }^{4}$ Clínica Santa María, ${ }^{5}$ U.de Los Andes y ${ }^{6}$ U.Chile.

Introducción: La DM1 es cada vez más frecuente en lactantes y niños de corta edad, por lo que es necesario que el pediatra mantenga un adecuado nivel de sospecha de esta patología. Objetivo: Comparar los parámetros clínicos y de laboratorio al debut de niños DM1 menores con los de mayor edad. Material y métodos: Se analizaron los datos obtenidos retrospectivamente de las fichas clínicas de todos los niños que debutaron con DM1 entre 1998 y 2003 en tres hospitales públicos y una clínica privada de Santiago de Chile (n:168) Para el análisis se incluyeron sólo aquellos (n:137) que tenían consignados los siguientes datos: peso y talla al nacer, edad al debut, antropometría, duración de síntomas previo al diagnóstico así como glicemia, gases sanguíneos, HbAlc, compromiso de conciencia (CC) y presencia 0 ausencia de infecciones concomitantes. Los pacientes se reunieron según edad en 3 grupos: I: 0-4 años; II: 5-9 años y III: 10-14 años. Resultados: En nuestra serie, 27 (19,7\%) de las DM1 ocume en niños $<5$ años vs 60 (43,8\%) entre 5 y 9 años y 50 (36,5\%) entre 10 y 14 años. No hubo diferencias por sexo (49,6\% mujeres).

Los pacientes del grupo I presentaron un peńodo más corto de síntomas y un valor inferior de HbA1c. Sin embargo, su nivel de acidosis fue el más alto de los 3 grupos, y tuvieron el porcentaje más alto de infecciones concomitantes, en su mayońa respiratorias y vulvovaginitis (33\% vs 20 y $28 \%$ respectivamente; $\mathrm{p}=\mathrm{NS})$. Antecedentes de DM en familiares de $1^{\circ}$ grado de observó en 12 casos (1, 7 y 4 por grupo respectivamente) y $2^{\circ}$ grado 50 casos (7, 17 y 26 por grupo respectivamente). (45\% en total)

Conclusiones: 1) Un porcentaje importante de las DM1 se inicia en menores de 5 años. 2) Hubo diferencias tanto clínicas como de laboratorio al comelacionarlas con edad del debut presentando mayor acidosis, hiperglicemia y compromiso de conciencia, como menor HbAlc y tiempo de duración de los síntomas a menor edad. 3) Estos datos son sugieren un cuadro de presentación de inicio más brusco, con mayor gravedad. 4) Lo anterior unido a la mayor frecuencia de infecciones concomitantes en los menores puede confundir el diagnóstico, hecho importante a considerar por los médicos a cargo de su tratamiento.

\section{FACTORES PREDICTORES DE ÉXITO EN EL CAMBIO DE COMPOSICIÓN CORPORAL EN NIÑOS OBESOS QUE INGRESAN A UN PROGRAMA DE TRATAMIEN- TO INTEGRAL DE OBESIDAD (PTI)}

Eyzaguirre $\mathrm{F}^{1,2}$, Román $R^{2}$, Silva $R^{2}$, Cosentino $\mathrm{M}^{2}$, Palacio $\mathrm{A}^{2}$, VeGa V², GarCía $\mathrm{H}^{2,3}$.

${ }^{1}$ U. Chile-Sede Centro, ${ }^{2}$ Clínica Santa María (CSM), ${ }^{3}$ U. de Los Andes.

Introducción: La estimación de la composición corporal (CC) en niños obesos es útil para evaluar riesgo cardiovascular. La 
impedanciometría (I) es un método objetivo validado con plicometría, que permite una adecuada orientación. Objetivos: describir los cambios en la CC medida por (I) en niños obesos que ingresan a un PTI y evaluar factores predictores de éxito respecto a la pérdida de grasa corporal. Material y Métodos: estudio prospectivo de 82 niños (47,6\% mujeres) de 11,9 $\pm 2,3$ años (6,1-18años), 64,6\% púberes, que ingresaron por 12 semanas (11-14sem) entre los años 2000-2004 al PTI en CSM (controles médicos, con nutricionista, psicólogo y actividad física supervisada). Al inicio y al final del PTI se registró desarrollo puberal, e IMC $\left(\mathrm{kg} / \mathrm{m}^{2}\right)$ y su z score y se realizó una (I) (Bodystat ${ }^{\circledR} 1500$ tetrapolar) en ayunas para conocer el \% grasa $(\% \mathrm{G})$, y \% masa magra (\%MM). Al inicio se midieron glicemia e insulina simultáneas (0 y 120') en un TTGO y perfil lipídico. Para el análisis de los resultados se utilizó t de student, correlación de Pearson y un modelo de regresión lineal múltiple para buscar variables predictoras de éxito en el PTI. Resultados: al finalizar el PTI el descenso de peso (D-P), IMC (D-IMC), z score IMC (D-z score IMC), \%P/T (D-P/T), \%G (D-\%G) fueron significativos $(*)$, así como el aumento de \%MM $(p=0,029)$ en el grupo total. Según desarrollo puberal, la pérdida de peso fue significativa (*) en prepúberes y púberes, pero D-\%G y D-\%MM sólo en niños puberales. ( $\mathrm{p}<0,0001$ y $p=0,041$ respectivamente). Al analizar por sexo, los varones eran más obesos que las mujeres (z score IMC $3 \pm 0,6$ vs $2,7 \pm 0,5 ; \lambda)$, pero éstas tenían un mayor $\% \mathrm{G}(34,5 \pm 7,4$ vs $23,7 \pm 4$; *) y menor \%MM $(65,5 \pm 7,4$ vs $76,4 \pm 4,3$; *), sin diferencias en el TTGO y lípidos en sangre. La pérdida de \%G y ganancia de \%MM no difirió luego del PTI.

Las variables predictoras de una mayor pérdida de $\% G$ fueron la masa grasa inicial $(\mathrm{r}=0,674 ; *)$ y para la ganancia de $\mathrm{MM}$, tanto la masa grasa $(\mathrm{r}=0,64 ; \mathrm{f})$ como el peso inicial $(\mathrm{r}=0,709$; _ $)$. Conclusiones: 1) A pesar que todos los pacientes reducen de peso significativamente en el PTI, la composición corporal medida por (I) mejora significativamente sólo en los niños puberales. 2) Los niños de mayor peso y \%G pierden más grasa y ganan más MM durante el PTI.

\section{INFLUENCIA DE LA COMPOSICIÓN CORPORAL ESTI- MADA POR IMC E IMPEDANCIOMETRÍA (I) EN LOS NIVELES DE INSULINA EN UN TTGO Y COLESTEROL HDL (COL HDL) EN NIÑOS Y ADOLESCENTES OBESOS}

\author{
Eyzaguirre $\mathrm{F}^{1,2}$, Román $R^{2}$, Silva $R^{2}$, Cosentino $\mathrm{M}^{2}$, Palacio $\mathrm{A}^{2}$, \\ VeGa $V^{2}$, García $\mathrm{H}^{2,3}$. \\ ${ }^{1}$ U.Chile-Sede Centro, ${ }^{2}$ Clínica Santa María (CSM), ${ }^{3}$ Universi- \\ dad de los Andes.
}

Introducción: La obesidad se asocia a un aumento de grasa corporal, la cual puede inducir el síndrome metabólico (insulinorresistencia, disminución col.HDL e hipertensión). Para la estimación de la composición corporal (CC) en niños se utiliza el IMC, Densitometría (DEXA), Plicometría e (I). Aun con sus limitaciones, la (I) es un método objetivo, que ha sido validado con la Plicometría en niños. Objetivo: Determinar si existe correlación entre la composición corporal medida por IMC e (I) con insulinemia (TTGO), y col. en niños obesos. Material y Métodos: se estudiaron prospectivamente 192 niños

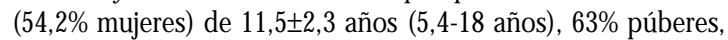
que consultaron por obesidad en CSM entre los años 19992003. Se consignó edad, sexo, desarrollo puberal, peso y talla, IMC $\left(\mathrm{kg} / \mathrm{m}^{2}\right)$ y su z score. En todos los casos se realizó un TTGO con medición simultánea de glicemia e insulina $(0$ y $\left.120^{\prime}\right)$, perfil lipídico y una (I) (Bodystat $\left.{ }^{\circledR}\right) 1500$ tetrapolar) matinal en ayunas para estimar el \%grasa (\%G) y \%masa magra (\%MM). Se analizaron los resultados con t de student y para la correlación entre exs. de laboratorio e (I), correlación de Pearson.

Resultados: Los varones presentaron mayor obesidad que las mujeres: $\mathrm{z}$ score IMC $+2,9 \pm 0,5$ vs $2,5 \pm 0,6$ (*), así como un mayor \%MM: $76,7 \pm 4,1$ vs $66,5 \pm 6,1$ (*). Las niñas presentaron un mayor \%G $33,5 \pm 6,1$ vs $23,3 \pm 4$ (*). La edad se correlacionó con los niveles de insulina $0^{\prime}$ (r:0,282*), 120'(r:0,2398), \%G $(\mathrm{r}: 0,16 \S)$ y negativamente con \%MM (r:-0,159§). El IMC se correlacionó con ins.0' (r:0,276*); 120'(r:0,223§); \%G (r:0,31*) y negativamente con \%MM (r:-0,314*). Hubo correlación negativa entre niveles de HDL y \%G (r:-0,182§) y positiva con \%MM (r:0,184§), y correlación NS de col. total y LDL con \%G. Conclusiones: 1 . Un mayor IMC y $\% \mathrm{G}$, y un menor $\% \mathrm{MM}$ se correlaciona con mayores insulinemias $0^{\prime}$ y $120^{\prime}$ y menor col.HDL. 2. La edad, sexo femenino y pubertad se correlacionaron con mayores niveles de insulina, mayor \%G y menor \%MM. 3. La (I) es un método no invasivo de utilidad para estimar CC en niños y adolescentes obesos.

\section{TIMO INTRATIROIDEO: DIAGNÓSTICO DIFEREN- CIAL DE CÁNCER TIROIDEO EN NIÑOS}

Eyzaguirre $\mathrm{F}^{1,3}$, Asenjo $\mathrm{S}^{2}$, Blanco $\mathrm{A}^{3}$, García $\mathrm{H}^{3,4}$.

${ }^{1}$ U. Chile-Sede Centro, ${ }^{2}$ Universidad de Concepción, ${ }^{3}$ Clínica Santa María, ${ }^{4}$ U. de Los Andes.

Los nódulos tiroideos (NT) en niños son más frecuentemente malignos (15-50\%), lo que motiva una conducta más agresiva cuando existe crecimiento de ellos. Se presentan 3 casos clínicos de niños que presentaron NT que aumentó de tamaño dentro de la evolución, lo que motivó su extippación y cuyo estudio histológico resultó ser tejido tímico ectópico. Caso No1: Prescolar de sexo femenino, consulta a los 2,6 años por sensibilidad cervical. Ecotomografía (E) revela NT de $5,6 \mathrm{~mm}$ en lóbulo izquierdo (LI), sin adenopatías. T4: 8,5 ug/dl y TSH: 3,2 $\mathrm{uU} / \mathrm{ml}$. Cintigrafía tiroidea Tc99 normocaptante, con área fotopénica en el 1/3 medio del L. E de control (3,1 años) mostró aumento discreto de la glándula y microcalcificaciones, por lo que se decide realizar lobectomía izq. e itsmectomía. Biopsia informó NT correspondiente a timo intratiroideo. 
Seguimiento a los 5,6 años, paciente sin tratamiento, T4 libre 1,1 ng/dl, TSH: 2,25 uU/ml y T3: 198 ng/ml. Caso No: Preescolar varón con cuadro febril (3,2 años) con adenopatías cervicales izq. Se solicita E de cuello que informó NT sólido de 2x4 mm en L y adenopatías submaxilares. TSH: 3,4 uU/ml, T4 libre: 1,4 ng/ dl. Cintigrafía Tc99 normal. Se decide mantener en observación. E de control (5,9años) reveló aumento de tamaño a 3x5 mm. TSH: 3,5 uU/ml, T4: 7,8 ug/dl. Nueva E (7,2 años) NT de 9x6x4,4 mm y adenopatías cervicales izq. Debido al crecimiento progresivo se realizó hemitioidectomía izq. Estudio histológico informó que NT correspondía a tejido tímico. Control a los 8,5 años: TSH: 3,9 uU/ml, T4: 8,4 ug/dl. Evoluciona con desarmollo puberal normal, eutrófico. Caso No3: Escolar varón, consulta a los 6,5 años por retraso de talla (talla/edad p8 NCHS). TSH: 3,2 $\mathrm{uU} / \mathrm{ml}, \mathrm{T4}: 7,05 \mathrm{ug} / \mathrm{dl}$, edad ósea 5,5 años. E tiroidea mostró NT de $7 \mathrm{~mm}$ en LI. Se indica levotiroxina $50 \mathrm{ug} /$ día que recibió por 1,2 años y $E$ de control sin cambios (7,8 años). Se mantiene en observación, con mala progresión de talla. Nueva E (8,8 años) describe NT de $5 \mathrm{~mm}$. TSH: 2,02 uU/ml, T4: 9,2 ug/dl, IGF-1: 174, IGFBP-3: 2474 y a los 10,9 años la E muestra NT de mayor tamaño con microcalcificaciones, sin adenopatías. Se realiza hemitiroidectomía izq. Estudio anatomopatológico informó timo ectópico de $5 \mathrm{~mm}$ con microcalcificaciones.

Comentarios: El timo se origina de la 3a bolsa faringea junto a las paratiroides inferiores (5a semana), migrando hacia caudal para alcanzar su ubicación definitiva. En su trayecto puede quedar incluido dentro de la tiroides, lo que puede confundirse con un NT sólido maligno, como lo ocurrido en estos pacientes. Conclusiones: 1. El timo ectópico intratiroideo debe considerarse en el diagnóstico diferencial del NT en niños, en especial si presenta crecimiento $\mathrm{y} / 0$ calcificaciones. Como se sabe, este tejido involuciona hacia la vida adulta. 2. No tenemos una interpretación distinta al azar para explicar la localización en el $\mathrm{L}$ en los 3 casos.

\section{RESISTENCIA PERIFÉRICA A HORMONAS TIROIDEAS MANIFESTADA POR UNA DEPRESIÓN CRÓNICA RE- FRACTARIA A PSICOFÁRMACOS}

Fardella $C^{1}$, Jiménez $M^{1}$, Krall $P^{1}$, Gloger $S^{2}$, Mosso L ${ }^{1}$, Carvajal $\mathrm{C}^{1}$, Quiroz D $\mathrm{D}^{2}$.

${ }^{1}$ Dpto. de Endocrinología, Facultad de Medicina, Pontificia Universidad Católica de Chile. ${ }^{2}$ PSICOMEDICA.

La resistencia a hormonas timideas (RHT) es una enfermedad de rara incidencia y presentación clínica variable; su diagnóstico se basa en exámenes clínicos y confirmación genético-molecular. En este trabajo presentamos una paciente con antecedentes de trastorno depresivo mayor refractario a terapia combinada (hasta 5 psicofármacos) que revirtió al uso de altas dosis de triiodotimnina $\left(\mathrm{T}_{3}\right)$, sin aparecer evidencias de hipertiroidismo. Objetivo: Evaluar la respuesta clínica y bioquímica al uso de altas dosis de $\mathrm{T}_{3}$ y realizar los estudios moleculares que puedan sustentar la existencia de una RHT. Paciente: Mujer de 38 años con antecedentes de cuadros depresivos desde los 8 años de edad, refractaria al uso de múltiples psicofármacos, psicoterapia y terapia electroconvulsiva. Además refenía en forma crónica intolerancia al frío, piel seca, fatiga muscular, constipación y una acentuada astenia psicomotora. Métodos: Para evaluar la existencia de una RHT se realizó el protocolo de Refetoff, administrando $\mathrm{T}_{3}$ en dosis crecientes por 10 días (0-225mg/día) controlando hormonas tiroideas, fosfatasas alcalinas e isoenzimas, CK total, SHBG, feritina, OH-prolina y parámetros hemodinámicos. Paralelamente se evaluó la respuesta del cuadro depresivo mediante los test HAM-D y MADRS, por evaluador independiente. Para certificar la resistencia se realizaron estudios de afinidad del receptor $ß$ para hormonas tiroideas de la paciente y dos casos controles, incubando linfocitos con $\mathrm{T}_{3}$ marcada ([1 $\left.{ }^{125}\right] \mathrm{T}_{3}$ 0.010.35nM). Resultados: Hubo mejonía clínica evidente del ánimo, y reducción en puntaje de escalas (HAM-D de 24 a 8, y MADRS de 40 a 11) asociado a la dosis máxima de $T_{3}$, con mejonía evidente de los síntomas físicos. El protocolo de Refetoff demostró al final de la fase de estudio $\left(\mathrm{T}_{4} 200 \mu \mathrm{g} /\right.$ día $+\mathrm{T}_{3} 225 \mu \mathrm{g} /$ día $)$ que no se modificaron la frecuencia cardiaca, presión arterial, fosfatasas alcalinas totales, fracción ósea y excreción de $\mathrm{OH}-$ prolina cuando los niveles séricos de $\mathrm{T}_{3}$ eran >800 ng/dL y de $\mathrm{T}_{3}$ libre 1409 pg/ $\mathrm{dL}$, la TSH se mantuvo suprimida durante todo el estudio. El estudio molecular de los linfocitos demostró la existencia de una constante de afinidad significativamente menor en la paciente en comparación con los casos controles (Ka 3.8x1010M-1 vs 9.0x1010 M-1). Conclusiones: Este estudio demuestra la existencia de una resistencia periférica a hormonas timoideas cuya principal manifestación fue un cuadro depresivo refractario que revirió con el uso de dosis altas de T3, sin alterar otros parámetros clínicos o bioquímicos. Este estudio pone una nota de alerta frente a pacientes similares y podría explicar la respuesta de depresivos eutiroideos a terapia de potenciación con hormonas troideas, ampliamente conocidas en el campo de la psiquiatría.

\section{REGULACIÓN DE LA METALOPROTEINASA 9 (MMP- 9) EN CÉLULAS DE LA GRANULOSA LUTEINIZADA PREVIO A LA RUPTURA FOLICULAR}

Ferrand P, Henríquez S, González F, Morales P, Castro O, Del Canto F, Devoto L.

Instituto de Investigaciones Materno Infantil. Universidad de Chile. Centro de Estudios Moleculares de la Célula (CEMC) Fondap Grant 15010006

La remodelación celular es un proceso necesario para que ocura la ruptura folicular. Este proceso de remodelación requiere que exista una degradación de los componentes de matriz extracelular en las células tecales y de la granulosa de la superficie ovánica adyacente a la región apical del folículo ovulatorio lo que involucra la participación de metaloproteinasas. Existen evidencias que relacionan a la MMP-9 en el proceso de ruptura folicular. MMP-9 es estimulada por muchas citoquinas entre las que se encuentran TNFalfa e IL1 Beta y es inhibida por TIMP-1. Objetivos: deteminar 
la expresión de MMP-9 en cultivos de células de la granulosa luteinizadas humanas, estimuladas con TNFalfa e IL 1 Beta, a nivel de mensajero y de proteína, utilizando la técnica de RT-PCR y WB y estudiar la actividad de MMP-9 en medios condicionados mediante Zimografía. Los resultados de este trabajo muestran que la expresión de MMP-9 al nivel de mensajero y de proteina no fue afectada por TNFalfa, sin embargo la actividad de MMP-9 disminuyó en presencia de TNFalfa lo que puede deberse a que la presencia de TNF alfa indujo una mayor producción de TIMP-1. Por otro lado, la presencia de IL-1beta disminuyó la expresión de MMP-9 al nivel de mensajero, proteína y también la actividad de la MMP-9 secretada. Conclusión: esto nos permite concluir que la regulación de MMP-9 está influenciada por la presencia de citoquinas inflamatorias, lo que se puede traducir en alteraciones del proceso ovulatorio.

\section{PREVENCION DE PÉRDIDA DE MASA ÓSEA EN NI- ÑOS LEUCÉMICOS. INFORME PRELIMINAR}

Fischer S, Neira L, Díaz P, Milinarsky A, Torres Mt, Giadrosich V. Universidad de Valparaíso. Hospital Gustavo Fricke. Clinder.

Los niños que sobreviven la leucemia suelen presentar dolor y fracturas óseas asociadas a pérdida de masa ósea.

El objetivo fue evaluar el efecto de $1,25(\mathrm{OH})_{2}$ vitamina D administrada por 12 meses sobre la masa ósea de niños con leucemia recién diagnosticada.

Diseño experimental: descriptivo longitudinal prospectivo de parejas.

Pacientes y método. Se incluyeron todos los niños que ingresaron a la Unidad Oncológica Pediátrica del Hospital Gustavo Fricke de Viña del Mar con el diagnóstico de leucemia linfática aguda, desde Julio 2001 a Marzo de 2003 y que aceptaron participar en el protocolo. Todos los niños recibieron tratamiento según protocolo nacional (PINDA) y suplemento de calcio $0,5 \mathrm{~g}$ oral diario. Se asignaron al azar en bloques para recibir (grupo 1) o no (grupo 2), 0,25-0,50 $\mu$ g/día de 1,25(OH) vitamina D. Al completar la inducción de la remisión (1 mes) y a los 12 meses, se midió composición corporal y DMO con equipo DEXA (Lunar Prodigy). Se aplicó test t de Student.

Resultados: 17 niños completaron el estudio lográndose parear a 8 niños según edad, talla y peso entre ambos grupos. No presentaron diferencias significativas de edad, talla y peso en ambos instantes $(p=0,3)$. No hubo diferencias entre ambos grupos en cuanto a las variables DMO de columna, cadera, cueppo completo, porcentaje de grasa y tejido magro. Se realizan gráficos box-plot que permiten sospechar que con un tamaño de muestra mayor se detectańan algunas diferencias entre el grupo control y el grupo con $1,25(\mathrm{OH})_{2}$ vitamina D para la DMO de columna.

Comentario: en esta muestra preliminar los niños leucémicos que recibieron $1,25(\mathrm{OH})_{2}$ vitamina D por 1 año mostraron una tendencia a mayor incremento de DMO en columna que sus pares que no la recibieron.

\section{ESTUDIO PROSPECTIVO DE CORRELACIÓN EN- TRE HBME-1 Y GALECTINA-3 EN PUNCIÓN POR AGUJA FINA (PAF) DE TIROIDES Y LA HISTOLO- GÍA DE LA PIEZA OPERATORIA}

Franco $C^{1}$, Rossi $F R^{2}$, Rossi $M R^{3}$, Horvath $E^{2}$, Majlis $S^{2}$, Domínguez $\mathrm{M}^{2,4}$, Castro L ${ }^{2}$, Volpato $\mathrm{R}^{4}$, Niedmann JP2 .

Clínicas Alemana ${ }^{2}$ y Santa María ${ }^{1}$, Hospitales Padre Hurtado ${ }^{3}$ y San Juan de Dios ${ }^{4}$.

La mayor limitación de la PAF de tiroides está en el diagnóstico de las lesiones foliculares. Los marcadores HBME-1 y Galectina-3 (Gal-3) podrían ser útiles para mejorar el rendimiento de la PAF en el diagnóstico de estas lesiones.

Materiales y Métodos. Muestras de PAF con diagnóstico de Neoplasia Folicular o de Neoplasia de células de Hurthle fueron sometidas a tinciones de IHQ con HBME-1 0 con HBME-1 y Gal-3. El diagnóstico histológico de la pieza operatoria fue considerado como el gold standard.

Resultados. En 124 PAF con el diagnóstico de Neoplasia Folicular o Neoplasia de Células de Hurthle se realizó IHQ sólo con HBME-1 (86) o HBME-1 + Gal3 (38). De éstos, 43 pacientes fueron sometidos a cirugía (12 con ambos marcadores y 31 sólo con HBME-1). En 31 pacientes operados con uno 0 ambos marcadores positivos, se encontraron 27 cánceres de origen folicular, y 4 patologías benignas. Once pacientes con marcadores negativos fueron operados; todos con histología definitiva benigna. La sensibilidad para HBME1 fue de 100\% y para Gal-3 fue de 87,5\%; la especificidad para HBME-1 fue de 71,4\%. Para HBME-1 el valor predictivo positivo fue de 0,88 y el valor predictivo negativo fue 1. Para Galectina-3, el VPP fue 0,78 .

Conclusiones. HBME-1 y Gal-3 son útiles en PAF con diagnóstico de neoplasia folicular. Ambos muestran muy buena sensibilidad y especificidad aceptable para HBME-1. Cuando el HBME-1 es negativo hay una altísima probabilidad de que la lesión es benigna. Mientras que cuando uno 0 ambos marcadores son positivos el diagnóstico de carcinoma es probable pero se debe tener en cuenta los falsos positivos.

\section{DIABETES TIPO 2 EN LA MUJER: CARACTERÍSTICAS CLINICAS Y DE LABORATORIO}

Franulic $L^{1}$, Contreras $C^{1}$, Lahsen $R^{2}$, Araya I ${ }^{1}$, Berríos $A^{1}$.

${ }^{1}$ Programa de Ayudante Alumno. ${ }^{2}$ Sección de Endocrinología Hospital Clínico U. de Chile

La Diabetes tipo 2 presenta prevalencia similar en ambos sexos, sin embargo se asocia a mayores complicaciones en la mujer tanto micro (NH) como macrovasculares (Framingham). Se revisaron 113 fichas del Policlínico de Diabetes del HCUCh para comparar el 
grado de control metabólico, complicaciones crónicas y presencia de otros factores de riesgo entre mujeres $(n=63)$ y hombres $(n=50)$. No se encontró diferencias significativas en cuanto a HbAlc menor a $7 \%$ (33,3 vs 34,5\%), glicemia capilar en ayunas menor a $100 \mathrm{mg} /$ dl $(8,8$ vs $15 \%)$, presencia de retinopatía (22 vs $27,8 \%$ ), nefropatía ( $30 \%$ vs $45,7 \%$ ), neuropatía ( $37,8 \%$ vs $44,1 \%$ ), accidente cerebrovascular $(15,6$ vs $18,2 \%)$, infarto al miocardio ( 29,4 vs $30,3 \%)$ ni enfermedad vascular periférica (39,5 vs 44,1\%). La prevalencia de HTA fue similar en ambos grupos (78,3 vs 76,6\%), al igual que el porcentaje de pacientes con LDL menor a $100 \mathrm{mg}$ ( 33 vs $35 \%$ ), y los niveles de Triglicénidos menor a $150 \mathrm{mg} / \mathrm{dl}$ (50 vs 47,6\%). Sin embargo, se observó un mayor porcentaje de mujeres con HDL mayor o igual a $40 \mathrm{mg} / \mathrm{dl}$ en relación con los hombres (87 vs 59\%; $\mathrm{p}=0,048$ ). Conclusión: A diferencia de otros estudios publicados, en nuestra casuística no encontramos mayor frecuencia de complicaciones micro ni macrovasculares en el sexo femenino. La única diferencia encontrada entre ambos sexos fue en los niveles de HDL, los cuales podńan explicar, al menos parcialmente, esta protección»de nuestras pacientes.

\section{HIPOCALCEMIA SECUNDARIA A TIROIDECTOMÍA TOTAL}

Gac P, Rossi F R, amat J, Huidobro F, Oviedo S, araya V, Cardemil F, Rodríguez F, Ortuondo E, Covarrubias P, Miranda $\mathrm{E}^{1}$, López $\mathrm{J}^{1}$, Melgarejo $\mathrm{N}^{1}$, Cárcamo $\mathrm{C}^{1}$.

Departamento de Cirugía y Endocrinología, Hospital Clínico de la Universidad de Chile.

${ }^{1}$ Alumnos.

Introducción: La Tiroidectomía Total (TT) o Casi Total ha reemplazado gradualmente a cirugías parciales o subtotales en el manejo de enfermedades benignas y malignas del tiroides, lo cual aumenta la posibilidad de hipocalcemia transitoria. Evaluando retrospectivamente los pacientes operados entre los años $1985 \mathrm{y}$ 2000, se encontró un 4\% de hipoparatiroidismo clínico transitorio.

Objetivo: Evaluar la frecuencia de hipocalcemia secundaria a TT a través de la medición de calcemias $\left(\mathrm{Ca}^{++}\right)$en el postoperatorio. Material y métodos: Estudio prospectivo entre Mayo y Agosto del 2004. Se determinaron $\mathrm{Ca}^{++}$; preoperatorias, 24 y 48 horas postoperatorias. A los pacientes que desamollaron hipocalcemia se les controló 1 semana después. Se documentó la impresión clínica del cirujano en relación a la viabilidad de las glándulas paratimides al término de la operación. El punto de corte para definir hipocalcemia fue de 8,0 mg/dl. Resultados: Se realizaron 45 TT. Las $\mathrm{Ca}^{++}$postoperatonias variaron entre 6,8 y 9,3, con un promedio de 8,1 mg/dl. Hubo 19 pacientes (42\%) con $\mathrm{Ca}^{++}$menor a 8, de los cuales 17 (84\%) se produjeron a las 24 horas y $2(16 \%)$ a las 48 horas. Se describió vitalidad de las 4 paratiroides en 42 pacientes, de los cuales 14 presentaron hipocalcemia (33\%). En 2 pacientes se describió la vitalidad como dudosa de una de las paratioides y en 1 paciente fue necesario reimplantar una, los 3 casos presentaron hipocalcemia. La $\mathrm{Ca}^{++}$ preoperatoria determinada en 18 pacientes descendió en el 100\%, con una baja en los niveles que varió entre 0,2 y 2,2 mg/dl y un promedio de $1,32 \mathrm{mg} / \mathrm{dl}$. Siete pacientes $(15 \%)$ presentaron sintomatología (parestesias principalmente) y/o Chvostek, que fue significativa en $2(4 \%)$ y leve en $5(11 \%)$. No hubo casos con tetanias. Todos los pacientes con calcemia menor a 8 recibieron tratamiento con calcio oral (1/2 a $1 \mathrm{gr} \mathrm{c} / 6-8 \mathrm{~h})$ asociado en ocasiones a calcitriol, de los cuales 6 (31\%) se normalizaron en 24 horas, 10 (52\%) en 1 semana y 3 (16\%) en más de 1 semana. No hubo hipoparatiroidismos definitivos y en ningún paciente fue necesario terapia con calcio endovenoso. Conclusión: 1. Un porcentaje alto de pacientes sometidos a TT desamolla hipocalcemia transitoria (42\%) mayoritariamente asintomáticas durante las primeras 48 horas. 2. Síntomas o signos se presentaron en 15\% de los casos y fueron significativos en 4\%. 3. Algunos factores no considerados, como la hidratación durante el intra y postoperatono, la estandanización de la toma de muestras y el método de determinación de la $\mathrm{Ca}^{+}{ }^{+}$, podnían estar influyendo en la presencia de hipocalcemias no secundarias a hipoparatiroidismo. 4. El signo de Chvostek es poco sensible. 5. La impresión subjetiva de la vitalidad de las paratiroides en el intraoperatorio, es un predictor limitado. 6. La mayoría de los pacientes pueden ser manejados con terapia oral en forma exitosa, que puede ser retirada durante el primer mes. Es posible que el costo-beneficio sea mayor al realizar $\mathrm{Ca}^{++}$en pacientes sintomáticos 0 con signología en las primeras 48 horas.

\section{COMPARACIÓN DEL CINTIGRAMA CON TC99M-SESTA- MIBI, SPECT VERSUS PLANAR, PARA LA LOCALIZACIÓN PREOPERATORIA EN HIPERPARATIROIDISMO $1^{\circ}$ (HPP)}

Gajardo P, Velásquez $C^{1}$, Orellana P1 ${ }^{1}$, Quintana JC ${ }^{1}$, González $\mathrm{G}^{2}$.

Laboratorio de Medicina Nuclear ${ }^{1}$ y Departamento de Endocrinología ${ }^{2}$, Facultad de Medicina, P. Universidad Católica de Chile.

El cintigrama con Tc99m-sestamibi (MBI) es una de las técnicas de elección para la localización preoperatoria en HPP y posee una sensibilidad alrededor del 80\% al utilizar adquisición bidimensional y tardía para las imágenes de captación del isótopo (MBI planar). Estudios extranjeros muestran un rendimiento superior para esta técnica, utilizando imágenes tridimensionales o MBISPECT (single-photon emission computed tomography). En Chile, no existe información al respecto. Objetivo: Comparar la utilidad del MIBI-SPECT versus MIBI planar para la localización preoperatoria en HPP. Sujetos y Método: Desde 09/2003 y en todo paciente con HPP referido para cintigrafía se administró $15-20 \mathrm{mCi}$ de Tc99m-MIBI endovenoso, realizando MBI-SPECT a los 10 minutos (64 imágenes de 30 segundos cada una reconstruídas en 3 planos ortogonales) y MBI planar, 2-3 horas post inyección del radiofármaco (imágenes magnificadas de 10 minutos, reconstruídas en proyección anterior). Se consideró estudio positivo la visualización de un foco de mayor captación del trazador. Se seleccionó para el análisis a todo paciente así estudiado y operado de su HPP. Se comparó el resultado del MBI con los hallazgos 
histopatológicos, definiendo como criterio de curación del HPP la normocalcemia a las 24 horas post cirugía, junto a la confirmación histológica de resección de la lesión paratiroidea. Resultados: 15 pacientes (10 mujeres y 5 hombres) han sido estudiados a la fecha. La edad promedio de éstos fue de $62,2 \pm 15,2$ años, con calcemia y PTH basales de $12,1 \pm 2,0 \mathrm{mg} / \mathrm{dl}$ y $305 \pm 252 \mathrm{pg} / \mathrm{ml}$, respectivamente. Se encontraron 16 lesiones paratiroideas (un paciente con enfermedad multiglandular). La mediana del peso de las lesiones fue de $400 \mathrm{mg}$ (intervalo: 171-4100). El MIBI-SPECT detectó correctamente 15/16 lesiones paratiroideas (sensibilidad 94\%), mientras el MBI planar detectó correctamente 12/16 (sensibilidad 81\%). En un caso de doble lesión infenior derecha, ambas técnicas mostraron sólo una lesión. No hubo falso positivo con ninguna de las 2 técnicas. Conclusión: Nuestra experiencia inicial sugiere una sensibilidad superior del MBI-SPECT respecto MBI planar para la localización preoperatoria en HPP.

\section{DURACIÓN DEL PERÍODO DE LUNA DE MIEL EN DIABETES MELLITUS TIPO 1 (DM1) SEGÚN EDAD Y GRAVEDAD AL DEBUT}

Gallardo V, Codner E, Román R, Kusmanic A, IÑIguez G, Avila A, MERICQ V.

IDIMI, H.S.B Arriarán, Clínica Las Condes, Clínica Alemana, Clínica Santa María.

Objetivo: Establecer la duración del peníodo de luna de miel definido como requerimiento insulínico $(\mathrm{RI})<0,5 \mathrm{U} / \mathrm{kg} /$ día, según edad y factores de gravedad al debut en niños y adolescentes con DM1. Método: Se analizaron retrospectivamente fichas clínicas, obteniéndose datos del debut (HbAlc, cetoacidosis diabética (CAD)) y seguimiento cada 3 meses con HbA1c y R hasta 18 meses, comparando según subgrupos de edad $(<5,5-10$ y >10 años), HbAlc inicial (<0 > a 12\%) y presencia de CAD al debut (CAD (+) vs CAD(-). El análisis estadístico se realizó con la test de Mann-Whitney, los resultados se expresan como promedios \pm emor estándar. Resultados: 78 pacientes fueron evaluados
(39 mujeres) con un promedio de edad de 7 $\pm 0,4$ años (rango 0,916,9 años). El promedio de HbA1c al debut fue de 11,9 $\pm 0,6 \%$. El $56,5 \%$ debutó con CAD. El promedio de dosis de insulina para todos los grupos fue $>0,5 \mathrm{U} / \mathrm{kg} / \mathrm{d}$ a los 12 meses de evolución, presentándose ya a los 6 meses en el grupo $<5$ años. El debut con CAD (+) determina un mayor R y peor control metabólico posterior (Tabla 1). No hubo relación entre el nivel de HbA1c inicial y el control metabólico posterior ni con la duración del peńodo de luna de miel.

Conclusiones: El período de luna de miel es más prolongado en los niños que debutan después de los 5 años de edad $\mathrm{y}$ sin CAD. Los pacientes < 5 años presentan mayor RI y HbA1c durante el primer año de enfermedad.

\section{UTILIDAD DE LA GLICEMIA DE AYUNO (GA) $\geq 100$ MG/DL EN LA PESQUISA DE INTOLERANCIA A LA GLUCOSA (IG) EN NIÑOS Y ADOLESCENTES CON SOBREPESO Y OBESIDAD}

Gallardo V, Ávila A, Codner E.

IDIMI. F.Medicina, U. de Chile y H.S. Borja Arriarán.

Introducción. Recientemente la ADA disminuyó el límite de normalidad de la glicemia de ayuno a $100 \mathrm{mg} / \mathrm{dl}$. Objetivo. Comparar la utilidad de la GA para detectar alteraciones de los hidratos de carbono en comparación a la prueba de tolerancia oral a la glucosa (PTGO) Método. Se evaluaron todas las PTGO efectuadas a pacientes con sobrepeso y obesos entre 5/2000 y 4/2004. Se determinó la presencia de intolerancia de ayuno (IA), IG y DM según los criterios diagnósticos ADA 03, ADA 97, y OMS 99. La principal diferencia entre estos criterios es que ADA 03 y 97 no exigen la PTGO para evaluar a un paciente, y además ADA 03 clasifica como IA una GA entre $100-125 \mathrm{mg} / \mathrm{dl}$, en cambio ADA 97 y OMS 99 lo hace con una GA entre 110-125 mg/dl. Se evaluó sensibilidad y especificidad de la glicemia de ayuno utilizando curva ROC. Resultados. Se reclutaron 232

Tabla 1.

\begin{tabular}{|lcccccc|}
\hline & \multicolumn{2}{c}{6 meses } & \multicolumn{2}{c}{12 meses } & \multicolumn{2}{c|}{18 meses } \\
& HbA1c & RI & HbA1c & RI & HbA1c & RI \\
\hline Todos & $7,0 \pm 0,2$ & $0,46 \pm 0,03$ & $8,0 \pm 0,2$ & $0,55 \pm 0,03$ & $8,1 \pm 0,2$ & $0,69 \pm 0,04$ \\
$<5 \mathrm{a}$ & $7,3 \pm 0,3$ & $0,51 \pm 0,05$ & $8,3 \pm 0,4$ & $0,61 \pm 0,05$ & $8,3 \pm 0,5$ & $0,76 \pm 0,06$ \\
$5-10 \mathrm{a}$ & $6,7 \pm 0,2$ & $0,46 \pm 0,06$ & $7,6 \pm 0,2$ & $0,53 \pm 0,05$ & $8,1 \pm 0,3$ & $0,65 \pm 0,05$ \\
$>10 \mathrm{a}$ & $7,2 \pm 0,6$ & $0,34 \pm 0,04$ & $9,0 \pm 0,7$ & $0,51 \pm 0,09$ & $7,7 \pm 0,5$ & $0,71 \pm 0,1$ \\
CAD $(-)$ & $6,9 \pm 0,3$ & $0,39 \pm 0,05$ & $7,7 \pm 0,4$ & $0,45 \pm 0,06$ & $7,9 \pm 0,3$ & $0,7 \pm 0,04$ \\
CAD $(+)$ & $6,9 \pm 0,3$ & $0,52 \pm 0,04$ & $8,1 \pm 0,3$ & $0,60 \pm 0,05$ & $8,2 \pm 0,3$ & $0,7 \pm 0,05$ \\
& $\mathrm{~ns}$ & $\mathrm{p}=0,03$ & $\mathrm{~ns}$ & $\mathrm{p}=0,06$ & $\mathrm{~ns}$ & $\mathrm{p}=0,7$ \\
\hline
\end{tabular}


Tabla 1.

\begin{tabular}{|lccc|}
\hline & ADA 97 (n) & ADA 03 (n) & OMS 99 (n) \\
\hline Normales & 226 & 224 & 226 \\
Intolerante de ayuno (IA) & 0 & 2 & 0 \\
Intolerante a la glucosa (IG) & 5 & 5 & 5 \\
DM2 & 1 & 1 & 1 \\
\hline
\end{tabular}

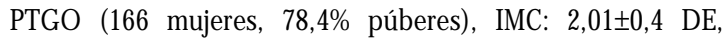
edad: $12,3 \pm 2,8$ años. Ocho pacientes $(3,5 \%)$ presentaron alteración de los carbohidratos. Todos los sujetos con IG fueron púberes y obesos. Usando la GA, ADA 97 detectó 1 paciente DM, ADA 03 diagnosticó 1 DM y 2 IA, y OMS pesquisó 1 DM y 5 IG. (Tabla 1). La GA habría diagnosticado según ADA 97 sólo 1 paciente (sensibilidad: 12,5\%) y según ADA 03, 3 sujetos (sensibilidad: 37,5\%). Los criterios OMS, que exigen GA y PTGO diagnosticaron a 6 sujetos, pero no pudo pesquisar a 2 sujetos con glicemia de ayuno entre 100 y $110 \mathrm{mg} / \mathrm{dl}$ y glicemia post carga normal. La curva ROC determinó que el punto de corte de la GA con mayor utilidad diagnóstica corresponde a una glicemia de $80 \mathrm{mg} / \mathrm{dl}$, teniendo una sensibilidad de un 75\% y una especificidad de 75,9\% en la pesquisa de una PTGO alterada.

Conclusión. Un 3,5\% de los niños y adolescentes obesos presentan alteración de los carbohidratos. El 3,02\% son IA o IG y el $0,43 \%$ DM2. La GA, aun con la disminución del límite a 100 $\mathrm{mg} / \mathrm{dl}$, no detecta el $62,5 \%$ de los adolescentes intolerantes. Aún disminuyendo el límite de la glicemia de ayuno normal a 80 $\mathrm{mg} / \mathrm{dl}$ no se logra detectar todos los casos de intolerantes.

\section{GENOTIPOS ASOCIADOS AL GEN DEL RECEPTOR DE VITAMINA D (VDR) Y SUSCEPTIBILIDAD A DIABETES TIPO 1 EN POBLACIÓN CHILENA}

García D, Angel B, Santos Jl, Albala C, Carrasco E, Pérez F. Laboratorio de Epidemiología Genética. Instituto de Nutrición y Tecnología de los Alimentos (INTA) y Unidad de Diabetes. Hospital San Juan de Dios. Facultad de Medicina. Universidad de Chile, Santiago, Chile (Proyecto Fondecyt 1030680).

Introducción: Diversos polimorfismos del gen VDR han sido asociados en la etiología de enfermedades de origen autoinmune, entre ellas la diabetes tipo 1. El papel inmunosupresor de la vitamina D ha generado importante discusión relacionada a producción de citoquinas y regulación de la secreción insulínica. Su principal forma de acción es a través de su receptor (VDR).
Objetivo: Analizar la frecuencia de tres polimorfismos del gen VDR en población chilena y estimar la concentración sérica de 25 hidroxivitamina $\mathrm{D}$ en niños diabéticos de reciente diagnóstico y niños controles.

Pacientes y Métodos: Se incluyó 128 niños diabéticos, menores de 15 años con diagnóstico reciente y 97 controles. Se determinó el polimorfismo Taq I, BsmI y Apa I para el gen VDR mediante PCR y RFLPs y se analizó la concentración sérica de 25 hidroxivitamina D mediante RIA. Análisis estadístico mediante prueba de Fisher.

Resultados: La construcción de genotipos prevalentes reveló 7 combinaciones frecuentes en población diabética (93,6\%) y 7 combinaciones en población control (89,7\%) (Tabla 1).

Los pacientes diabéticos mostraron valores significativamente más bajos en los niveles séricos de vitamina $\mathrm{D}$ que la población control $(26,7 \pm 10,6 \mathrm{ng} / \mathrm{ml}$ versus $42,8 \pm 7,7, \mathrm{p}<0,02)$. Conclusión: El análisis del polimorfismo VDR mostró dos genotipos muy frecuentes en niños diabéticos (AabbTT y aabbTT) y casi ausentes en los controles. Ambos genotipos podrían ser considerados como marcadores de riesgo para la enfermedad en la población analizada. Además, la población diabética mostró una importante disminución de los niveles séricos de 25 hidroxivitamina $\mathrm{D}$, evento que podría relacionarse a una baja respuesta inmunosupresora frente a la presentación de la enfermedad.

Tabla 1.

\begin{tabular}{|lccccc|}
\hline Genotipos & \multicolumn{2}{c}{ Diabéticos } & \multicolumn{2}{c|}{$\begin{array}{c}\text { Controles } \\
(\mathrm{n}=128)\end{array}$} & $\mathrm{p}$ \\
& $\mathrm{n}=97)$ & \\
& & Frec & $\mathrm{n}$ & Frec & \\
\hline AaBbTT & 10 & 21 & 0,217 & 0,012 & 0,078 \\
AabbTT & 23 & 3 & 0,031 & 0,001 & 0,179 \\
aaBbTT & 8 & 22 & 0,227 & 0,003 & 0,063 \\
AABBTt & 0 & 5 & 0,052 & $n s$ & 0,000 \\
AABbTt & 12 & 2 & 0,021 & 0,047 & 0,094 \\
AaBbTt & 32 & 32 & 0,330 & $n s$ & 0,250 \\
AABBtt & 12 & 2 & 0,021 & 0,047 & 0,094 \\
aabbTT & 23 & 0 & 0,000 & $<0,0001$ & 0,179 \\
\hline
\end{tabular}




\section{EVALUACIÓN DEL RESULTADO DEL TRATAMIEN- TO CON INSULINA GLARGINA EN EL CONTROL GLICÉMICO Y CALIDAD DE VIDA. ENCUESTA A 70 PACIENTES CON DM TIPO 1 (DM1)}

\author{
García G, Pérez J, Trajtman D, García $\mathrm{H}$. \\ Centro Endocrinológico Clínica Santa María. Univ. Católica; \\ Univ. Los Andes; Fund. Diabetes Juvenil Chile.
}

Introducción: La Insulina Glargina (IG) debido a su acción prolongada y ausencia de peak se ha constituido en una importante herramienta terapéutica para proveer los niveles basales de Insulina en el tratamiento de DM1. Objetivo: Conocer la percepción de pacientes DM1 que usan Glargina, respecto a las ventajas y desventajas de esta Insulina, en el control glicémico y en la calidad de vida. Material y métodos: Se confeccionó una encuesta estructurada de 23 ítems, con preguntas cerradas de tipo no probabilística, con un margen de emor de más/menos $4 \%$, administrada a 70 pacientes -0 apoderados- (33 mujeres y 37 hombres), todos DM1 que utilizan IG, escogidos al azar entre aquellos asistentes al Centro Endocrinológico de la Clínica Santa Mańa o Fundación de Diabetes Juvenil Chile. La distribución fue de 18 (25\%) niños de 0 a 11 años, 19 (28\%) adolescentes de 12 a 19 años y 31 (45\%) adultos jóvenes de 20 a 28 años. El 51,5\% presenta al menos 5 años de evolución de DM1 y el 62\% utiliza a IG hace más de 6 meses; todos residentes de la RM. Resultados: El 45\% de los usuarios son adultos jóvenes, el resto niños 0 adolescentes y sólo 4\% menores de 6 años Mientras el 85\% de los pacientes considera el cambio de tratamiento preferible al anterior, existe un $5,8 \%$ que no lo prefiere; sin embargo un $94 \%$ lo recomendańa a otros pacientes DM1. La mayonáa apreció mejonáa de la Hemoglobina $\mathrm{A} 1 \mathrm{C}$; desde un $41 \%$ a un $55 \%<8 \%$ y desde $16 \%$ a un $5 \%>10 \%$, antes y después de la introducción de IG respectivamente. Mientras el 76\% refiere que existen Hipoglicemias, el 50\% percibe que ocurren en menor cantidad y el $63 \%$ nota que sus glicemias han disminuido. Además, la mayonáa (51\%) refiere que utilizan IG en menor cantidad que NPH. Por otra parte, sólo el 10\% prefiere IG por notar mejońa en el control de DM1 y el 67,6\% la prefiere por una mejora en la calidad de vida, resaltando el 58,8\% disponer de mayor libertad respecto a los horarios e ingesta de hidratos de carbono. Finalmente el 82,4\% introduce IG por recomendación del médico tratante. Conclusiones: Los nuevos usuarios de IG perciben como principales ventajas, la libertad de horarios, la disminución de Hipoglicemias, de la HB A1C, de las glicemias y mejora de la calidad de vida. No perciben desventajas significativas.

\section{FRECUENCIA DE INSULINORESISTENCIA Y FACTORES DE RIESGO CARDIOVASCULAR EN UNA MUESTRA DE UNA POBLACIÓN CERRADA SIN PATOLOGÍA CONO- CIDA DE LA V REGIÓN}

Garrido B; Farías C; Urquieta MS; Palacios J.
Depto Diabetes, Servicio de Medicina Hospital Naval Almirante Nef Viña del Mar.

La Resistencia a la Insulina se asocia con mayor riesgo de enfermedad cardiovascular y metabólica. Para pesquisar y hacer el diagnóstico de esta condición existen métodos indirectos como el modelo matemático HOMA (homeostasis model asesesment) usado en este trabajo. Objetivo: determinar la frecuencia de resistencia a la insulina y factores de riesgo cardiovascular en un grupo de personas asintomáticas. Material y Método: se realizó un estudio descriptivo y prospectivo de cinco meses de duración, reclutándose un total de 300 voluntarios (223 varones y 77 mujeres) sin patología conocida, con edades entre 19 y 50 años, todos pertenecientes a reparticiones de la Armada. Se midió peso, talla, circunferencia cintura, presión arterial, glicemia, insulinemia y perfil lipídico en ayunas. Resultados: se pesquisó insulino-resistencia (por HOMA) en 6,6\% de la población estudiada. Obesidad: se detectó IMC $>30$ en 7,6\% de la muestra, encontrándose en ellos asociación estadísticamente significativa con $\mathrm{HOMA}>2,5$ $(p<0,001)$. Dislipidemia: presente en el $42 \%$ del total de participantes. En $22 \%$ del total de individuos se detectó TGS sobre $150 \mathrm{mg} / \mathrm{dl}$. Se observó que la relación TGS/HDL>3 tiene una asociación estadísticamente significativa en aquellos individuos con IMC $>25(\mathrm{p}<0,001)$. Se pesquisó presión arterial elevada en 18,3\% de la muestra. Además se hizo el diagnóstico de Síndrome Metabólico (según ATPIII) en 8 individuos $(2,6 \%)$, observándose correspondencia con HOMA $>2,5$ en 5 casos. Conclusiones: En la muestra estudiada encontramos un 6,6\% de insulino-resistencia por HOMA, porcentaje más bajo que lo descrito en la literatura y que puede explicarse por el hecho de que nuestro grupo mantiene una actividad física constante $(52 \%)$ y una dieta homogénea. Por otra parte se encontró una asociación estadísticamente significativa entre IMC $>30$ y HOMA $>2,5$. En relación con otros factores de riesgo detectamos un alto porcentaje de pacientes con dislipidemia (42\%) y una asociación estadísticamente significativa entre IMC $>25$ y TGS/HDL $>3$. Consideramos que estos datos nos llevan a fomentar el cambio en estilos de vida como una forma económica y efectiva de prevenir el S. Metabólico.

\section{ESTUDIO PROSPECTIVO DE FACTORES DE RIESGO CLÍNICOS DE ÚLCERA EN PIE DIABÉTICO}

Gayoso R, Zúñiga E, Merino S.

Unidad de Diabetes Universidad de La Frontera de Temuco.

Introducción: La amputación de extremidades inferiores es una frecuente complicación de la Diabetes, antecedida por una úlcera de la misma en el 85\% de los casos. Existe poca información en nuestro país respecto a la incidencia de ulceración y amputaciones. Objetivo: Evaluar la prevalencia, incidencia, y pronóstico de ulceraciones y amputaciones, en pacientes diabéticos. 
Pacientes y Método: Se reclutó una cohorte de 140 pacientes diabéticos entre 1997 y 1998, mayores de 18 años, consultantes en el policlínico de diabetes del Hospital de Temuco. Al ingreso se les realizó historia clínica, examen físico completo y exámenes de evaluación de repercusión visceral. Los individuos fueron seguidos para registrar, aparición de úlcera de extremidad inferior, amputación, o muerte. Seguimiento promedio: 5,5 años.

Análisis estadístico: Se usó t student, chi2, con programa estadístico Stata 7.0.

Resultados: Los pacientes fueron seguidos en promedio 66,2 meses (3 a 92 meses). El promedio de edad del grupo fue de 59 años (DS 12), con una distribución de 47,9\% de hombres y $52,1 \%$ de mujeres. El promedio de duración de la enfermedad fue de 14,05 años (DS 9,1). Un 88,6\% fue diabético tipo2.

La densidad de incidencia de ulceración en 5,5 años fue de 25\%, (35 ulceraciones en 27 pacientes), con una tasa de 4,5 úlceras/año/100 pac.

La densidad de incidencia acumulada de amputación en 5,5 años fue de 15\%, (21 amputaciones en 17 pacientes), tasa de 2,7 amputaciones/año/100 pac.

En el 93\% la amputación fue precedida de una úlcera.

El 77\% de las úlceras fue neuropática predominantemente.

En el 76\% la amputación fue por patología infecciosa con isquemia.

El 22,2\% de los pacientes que se ulceraron en el período estudiado presentaron una nueva úlcera. El 17,6\% de los pacientes que se amputaron presentaron una nueva amputación en el período estudiado.

Conclusiones. La incidencia de ulceraciones y amputaciones en los pies de pacientes diabéticos es muy alta en nuestro medio por lo que es urgente implementar un eficiente manejo del pie en riesgo y el pie ulcerado.

\section{REPRODUCIBILIDAD DEL MONOFILAMENTO DE SEMMES WEINSTEIN DE 5.07 (MF.SW)}

Gayoso R, Zúñiga E, Merino S.

Unidad de Diabetes Universidad de La Frontera de Temuco.

Introducción: El MF.SW, ha sido recomendado internacionalmente, para el diagnóstico de screening de pie diabético en riesgo por neuropatía hipoestésica. La aplicación de éste instrumento es operador-dependiente y no existen estudios de concordancia entre operadores. Objetivo: Evaluar la reproductibilidad (concordancia) Interobservador e intraobservador del MF.SW en 3 puntos plantares

Pacientes: Se examinó con MF.SW los pies de pacientes diabéticos consultantes en el policlínico de diabetes u hospitalizados en el Hospital de Temuco por patología distinta de pie diabético. Método: Se estandarizó la aplicación M:F.SW a 3 operadores, usando 3 puntos plantares: $1^{\circ}$ Ortejo, Epifisis del $1^{\circ}$ y $5^{\circ}$ metatarsiano de cada pie, con el paciente en decúbito dorsal. A cada paciente se le repitió el examen por un $2^{\circ}$ operador ciego y se citó en 15 días, o al momento del alta, para realizar la reevaluación por el $1^{\circ}$ operador.

Análisis estadístico: Se analizó la concordancia kappa con Stata 7.0.

Resultados: Se evaluaron 53 pacientes: Promedio de edad: 61,7 años (DS 8,3). Promedio de duración de la Diabetes fue de: 9,01 años (DS 7,0). Hubo: 35 pacientes mujeres (66\%) y 18 hombres (34\%). El 37,7\%, usa insulina, el 41,6\% drogas hipoglicemiantes y el 20,7\% con dieta.

Reproducibilidad de la sensibilidad al MF.SW (Tabla 1):

Conclusiones: 1. La mejor reproducibilidad (correlación) se alcanza con la sensibilidad e insensibilidad total. 2. Hay una buena reproducibilidad (correlación) en los puntajes intermedios, siendo la de 3 puntos insensibles la mejor Inter. e Intraobservador. 3. La reproducibilidad es mejor intraobservador para todas las mediciones.

\section{SEGUIMIENTO DE DENSIDAD MINERAL ÓSEA EN PACIENTES DIABÉTICOS TIPO 1}

Giadrosich V, Milinarsky A, Fischer S, TORRes MT.

Universidad de Valparaíso, Instituto Médico Infantil, Valparaíso, Chile.

Introducción: La diabetes mellitus 1 es una enfermedad autoinmune. La osteopenia es un acompañante frecuente de este tipo de enfermedades. Su etiología es multifactorial e incluye factores genéticos, nutricionales, reposo prolongado, citoquinas y tratamientos antiinflamatorio e inmunosupresor.

Tabla 1.

\begin{tabular}{|lcc|}
\hline Puntos plantares sensibles & Interobservador & Intraobservador \\
\hline $0-1$ (insensibilidad total) & $97 \%$ & $99 \%$ \\
2 & $76,6 \%$ & $65,6 \%$ \\
3 & $71,7 \%$ & $84,4 \%$ \\
4 & $651 \%$ & $881 \%$ \\
$5-6 \quad$ (sensibilidad total) & $98 \%$ & $99 \%$ \\
\hline
\end{tabular}


Objetivos: Describir el comportamiento de la ganancia de masa mineral ósea en un grupo de niños y adolescentes con DM 1 en un peńodo de 10 años. Relacionar la masa ósea actual con el IMC, con el control metabólico, actividad física e ingesta actual de calcio y complicaciones micro-vasculares. Pacientes y Método: En el año 1994 a 17 niños y adolescentes con DM 1 se les evaluó su masa ósea mediante absorciometría ósea de fuente radiológica DTX-100 radiocubital. Diez años después fueron reevaluados con este mismo método. Se realizó: fondo de ojo, microalbuminuria, hemoglobina glicosilada, hormonas tiroídeas, anticuerpos antitiroídeos y antiendomisio, PTHi, calcemia, calciuria y creatininuria. Se consignó actividad física e ingesta de calcio. Estadísticas se aplicó prueba de Shapiro-Wilks modificada, Test T de Student, correlación de Pearson y ANOVA. Resultados: 17 pacientes, 7 mujeres 10 hombres. Edades 14-24 años X 18,4 con 10-20 años de tratamiento. Patologías asociadas: 5 pacientes con tiroiditis autoinmune; 2 pacientes con retinopatía diabética inicial; ninguno con enfermedad celíaca; Calcemias y PTHi normales en todos los pacientes. La ingesta de calcio fue nomal en 8 pacientes e insuficiente en 9. El Z score del IMC previo y actual es significativamente superior al normal $p=0,0087$ y $p=0,0009$ respectivamente. El z score del BMD (densidad mineral ósea) previo fue significativamente inferior al normal $p=0,0166$, en tanto el z score del BMD actual no difiere significativamente del normal $p=0,4468$. El z score del BMD actual no se correlacionó de forma significativa con años de tratamiento $(p=0,47 ; R=0,28) \mathrm{ni}$ con el IMC actual ( $p=0,58 ; R=0,22)$. No se encontró evidencia significativa de que la actividad física, la hemoglobina glicosilada ni la microalbuminuria incidan sobre $Z$ score BMD ( $p=0,1838$; $\mathrm{p}=0,0894$ y $\mathrm{p}=0,4423$ respectivamente). Conclusión: los pacientes diabéticos tipo 1 estudiados hace 10 años tienen ahora su BMD normal, y no se encontró evidencias de que los años de tratamiento, el control metabólico, la actividad física, el IMC ni la dieta incidan sobre su BMD actual.

\section{CARACTERÍSTICAS ECOTOMOGRÁFICAS DE LOS NODULOS TIROIDEOS: BENIGNOS VS MALIGNOS}

Glasinovic A, Osorio M, Schachter D, Chamorro A, Medina FJ, Franco C, Ramírez I.

Unidades de Radiología, Endocrinología y Anatomía Patológica de Clínica Santa María.

El desarrollo de los transductores ultrasonográficos de alta resolución ha permitido una mejor caracterización de los nódulos tiroídeos (NT).

Objetivos: Caracterización ecográfica de los NT y su correlación con los resultados obtenidos en Anatomía Patológica después de punción con aguja fina o de su remoción quirúrgica.

Pacientesy Método: Estudio prospectivo de 172 pacientes (194

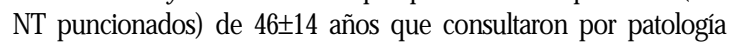
tiroídea en Clínica Santa Mańa entre los meses de Agosto 2003 y Julio 2004 (92\% mujeres). En todos se efectuó ecografía tiroídea con transductor lineal de 7.5-13 MHZ y se definieron las caracteństicas de los NT según la siguiente clasificación: Benigno (B), Aparentemente benigno (AB), Indeteminado (I) y Sospechoso de Malignidad (SM). Se realizó punción tiroídea con agujas entre 21 y 25 Gauge, obteniéndose citología y coágulo.

Resultados: Los 194 NT puncionados se distribuyeron de acuerdo a nuestra clasificación en: 7\% B, 31\% AB, 54\% I y 8\% SM. El resultado cito/histológico fue: benignos $62 \%$, neoplasia folicular 23\%, cáncer papilar $11 \%$ y muestras insuficientes $4 \%$.

Se sometieron a cirugía 45 pacientes y su distribución según la caracterización ecográfica fue:

\begin{tabular}{|lcccc|}
\hline & B & AB & I & SM \\
\hline Benignos & 0 & $3 / 5$ & $17 / 30$ & $1 / 10$ \\
Ca papilar & 0 & $2 / 5$ & $9 / 30$ & $7 / 10$ \\
Ca folicular & 0 & 0 & $3 / 30$ & $2 / 10$ \\
Ca medular & 0 & 0 & $1 / 30$ & 0 \\
Total & 0 & 5 & 30 & 10 \\
\hline
\end{tabular}

Sensibilidad $=37,5 \%$; Especificidad $=95,2 \%$

$\mathrm{VPP}=24,6 \%$; VPN= 97,3\%

Conclusiones:

1. La caracterización ecográfica de los NT puede sugerir malignidad.

2. De acuerdo a nuestros resultados parece posible clasificar a los NT en 3 Grupos: Benignos, Indeterminados (suma de AB + I) y Sospechosos de Malignidad.

3. La confirmación de la real utilidad de la caracterización propuesta requiere de una muestra que incluya un mayor número de casos intervenidos quirúrgicamente.

\section{ESTUDIO GENÉTICO DE LA SUBUNIDAD $\beta$ DEL CANAL EPITELIAL DE SODIO ( $\beta E N A C$ ) EN HIPERTEN- SOS ESENCIALES}

González A, Carvajal C, Krall P, Mosso L, Fardella C. Departamento de Endocrinología, Facultad de Medicina, Pontificia Universidad Católica de Chile.

El canal epitelial de sodio $(\mathrm{ENaC})$ es la etapa limitante en la reabsorción de sodio $(\mathrm{Na}+)$ en el túbulo distal del nefrón. Alteraciones en este canal son capaces de provocar una forma severa de hipertensión heredable conocida como síndrome de Liddle, generalmente secundaria a mutaciones localizadas en la subunidad ß de este canal. Recientemente identificamos la existencia de una región microsatélite (GT-repeat) que también podnía alterar la expresión del gen ENaC. Objetivo: Determinar la presencia de mutaciones y/o variaciones de la región microsatélite (GT-repeat) del gen de la subunidad $ß$ de ENaC (SCNN1B) en hipertensos esenciales (HE) y correlacionarlas con los niveles de actividad renina (ARP) y aldosterona plasmática (AP). Pacientes y 
Métodos: Estudiamos 145 HE y 47 normotensos (NT). Ninguno de los sujetos evaluados en este estudio presentaba patologías que pudiesen afectar los niveles de ARP o AP. Los pacientes HE y controles NT fueron genotipificados por PCR para un marcador microsatélite (GT-repeat) ubicado en el intron 8 del gen SCNN1B. La secuencia normal $(\mathrm{N})$ del gen posee 14 repeticiones GT. Mediante electroforesis se identificó un fragmento más pequeño (S) de 12 repeticiones GT y un fragmento más largo (L) de 16 repeticiones. Los diferentes genotipos fueron correlacionados con los niveles de ARP y AP. Adicionalmente, a 13 pacientes con bajos niveles de ARP $(\varangle 0,5 \mathrm{ng} / \mathrm{ml} * \mathrm{hr})$ y AP $(<5 \mathrm{ng} / \mathrm{dl})$, se les secuenció completamente el gen SCNN1B. Resultados: Los HE y NT mostraron una distribución genotípica ( $\mathrm{L} / \mathrm{NL} / \mathrm{NN} / \mathrm{SN} / \mathrm{SS}$ ) similar $\left(\chi^{2}=2,031\right.$ (3 g.l) $\left.\mathrm{p}=0,566\right)$ de la región microsatélite. No identificamos sujetos con genotipo SL Los pacientes portadores del alelo L mostraron niveles más bajos de ARP que los no portadores $(0,81 \pm 0,1$ vs $1,24 \pm 0,07 \mathrm{ng} / \mathrm{mL}$ *hr $\mathrm{p}<0,01)$ al igual que una tendencia a presentar niveles más bajos de $\mathrm{AP}(4,8 \pm 2,0$ vs 6,1 $\pm 3,3 \mathrm{ng} / \mathrm{dL}, \mathrm{p}=\mathrm{NS})$. En los $13 \mathrm{HE}$ que fueron a estudio de secuenciación no identificamos mutaciones o polimorfismos en el gen SCNN1B. Conclusión: En este estudio identificamos en hipertensos esenciales un marcador microsatélite del gen SCNN1B (región repetitiva GT), que se asoció a niveles bajos de ARP. Estos resultados sugieren que un subgrupo de hipertensos esenciales podńa presentar alteraciones a este nivel que expliquen la génesis del cuadro hipertensivo.

Financiado por proyecto FONDECYT 1040834.

\section{CÁNCER PAPILAR DE TIROIDES: MORBILIDAD DE LA DISECCIÓN GANGLIONAR PARATRAQUEAL}

González $H^{1}$, Goñ I I ${ }^{1}$, león $A^{1}$, Clauure ${ }^{1}$, Solar $A^{2}$, Arteaga $\mathrm{E}^{3}$, Lopez JM $\mathrm{M}^{3}$, Fardella $\mathrm{C}^{3}$, Mosso L ${ }^{3}$, Campusano $C^{3}$, González
$\mathrm{G}^{3}$, Rodriguez $\mathrm{J}^{3}$, Jiménez $\mathrm{M}^{3}$, Castillo $\mathrm{C}^{4}$, Lee $\mathrm{C}^{5}$, Iñiguez $\mathrm{M}^{5}$. División de Cirugía, Sección de Cirugía de Cabeza y Cuello ${ }^{1}$, Dptos. de Anatomía Patológica ${ }^{2}$ y Endocrinología ${ }^{3}$, Residente de Medicina Interna ${ }^{4}$, Interna de Medicina ${ }^{5}$, Facultad de Medicina, Pontificia Universidad Católica de Chile.

La exploración quirúrgica ganglionar del cuello en el cáncer papilar de tiroides (CPT) es controvertido. La disección paratraqueal es especialmente compleja, ya que puede asociarse a mayor morbilidad. En particular, el tratamiento de la recurrencia paratraqueal es de mayor dificultad técnica por la invasión circunvecina al momento de la exploración. Objetivos: i) Comparar la morbilidad quirúrgica de la disección paratraqueal en pacientes con CPT que debutan con metástasis ganglionares (MG) al diagnóstico con pacientes con MG recurrente (MG-R). ii) Correlacionar la morbilidad quirúrgica con la extensión extracapsular ganglionar (EEG) como índice de invasión local. Métodos: Es un estudio observacional prospectivo de pacientes sometidos a disección paratraqueal por CPT en el período Julio/03 - Agosto/2004 en el Hospital Clínico U.C. Se evaluaron las complicaciones post-operatorias precoces y a los 3 meses. Además, se estudió histológicamente la EEG en las piezas quirúrgicas. Para análisis estadístico se utilizó la prueba de $\chi^{2}$. Resultados: Esta serie incluye 35 pacientes con una relación mujer/varón: 4/1,14 con CPT que debutaron con MG (edad: 38,3 319 años) y 21 con MG-R (edad: 46,2 $2+15$ años) (Tabla 1).

Conclusiones: 1) La morbilidad quirúrgica de la disección paratraqueal es significativamente mayor en pacientes operados por recidiva ganglionar. 2) Es probable que esta mayor morbilidad se asocie a la alta frecuencia de EEG en este grupo de pacientes. 3) Por ésto, es preciso identificar los pacientes en riesgo de recurrencia para realizar la disección paratraqueal en forma primaria.

Tabla 1.

\begin{tabular}{|lrrrc|}
\hline & CPT+MG & $\%$ & MG-R & $\%$ \\
\hline Número de pacientes & 14 & 40 & 21 & 60 \\
Disección paratraqueal unilateral & 9 & 64,3 & 19 & 90,5 \\
Disección paratraqueal bilateral & 5 & 35,7 & 2 & 9,5 \\
Extensión extracapsular ganglionar (EEG) & 5 & 35,7 & 17 & $81,0^{*}$ \\
Compromiso tumoral de nervio laríngeo recurrente & 1 & 7,1 & 4 & 19,0 \\
Disfonía clínica presente a los 3 meses & 0 & 0,0 & 3 & 14,3 \\
Paresia transitoria de cuerda vocal & 3 & 21,4 & 9 & 42,9 \\
Parálisis de cuerda vocal presente a los 3 meses & 0 & 0,0 & 3 & 14,3 \\
Hipocalcemia precoz & 9 & 64,3 & 18 & 85,7 \\
Hipoparatiroidismo presente a los 3 meses & 0 & 0 & 2 & 9,5 \\
\hline
\end{tabular}

$* \mathrm{P}<0,01 \mathrm{CPT}+\mathrm{MG}$ v/s MG-R 


\section{DISECCIÓN SELECTIVA DE CUELLO EN CÁNCER PAPILAR DE TIROIDES: ¿CUÁL ES LA EXTENSIÓN ADECUADA DE DISECCIÓN?}

González $\mathrm{H}^{1}$, Goñ I $\mathrm{I}^{1}$, león $A^{1}$, Claure $\mathrm{R}^{1}$, Solar $\mathrm{A}^{2}$, Fardella $\mathrm{C}^{3}$, Arteaga $\mathrm{E}^{3}$, López JM ${ }^{3}$, Mosso $\mathrm{L}^{3}$, Jiménez $\mathrm{M}^{3}$, Lee $\mathrm{C}^{4}$, IñIGuez $\mathrm{M}^{4}$.

División de Cirugía - Sección Cirugía Cabeza y Cuello ${ }^{1}$, Dptos. de Anatomía Patológica ${ }^{2}$ y Endocrinología ${ }^{3}$, Interna de Medicina ${ }^{4}$, Fac. de Medicina, P. U. Católica de Chile.

La extensión de la disección de cuello adecuada en el tratamiento de la metástasis ganglionares (MG) del cáncer papilar de tiroides (CPT) es controvertida. Objetivos: Determinar el patrón de MG del CPT según la clasificación de los niveles ganglionares, en pacientes con CPT que debutan con MG al diagnóstico y en pacientes MG recurrente (MG-R). Evaluar la morbilidad de la disección de cuello. Métodos: Es un estudio observacional prospectivo de pacientes con CPT sometidos a disección de cuello de 2 o más niveles ganglionares en el período Julio/03 - Agosto/04 en el Hospital Clínico de la U. Católica. La disección ganglionar se realizó sólo en pacientes con evidencia clínica y/o ecográfica de adenopatías patológicas. Previo a la disección, se confirmaron histológicamente las metástasis ganglionares. Se evaluaron las complicaciones postoperatorias precoces y a los 3 meses de la operación. Para el análisis estadístico se utilizó prueba de $\chi^{2}$. Resultados: Esta serie incluye 41 pacientes, 15 con CPT que debutó con MG (44+17 años) y 26 con MG-R (39+19 años). En 22 pacientes se realizó disección unilateral y en 19 pacientes bilateral. No hubo diferencias en el área de distribución de MG entre los 2 grupos. Hubo compromiso ganglionar significativo (> al 20\%), en los niveles II (48\%), III (68\%) y IV (79\%) correspondientes a la cadena yugular profunda, del nivel $\mathrm{Vb}=$ supraclavicular $(60 \%)$ y del nivel VI= paratraqueal (95\%). No hubo MG en el nivel Va= triángulo posterior alto (0\%) (Tabla 1).

Conclusiones: La frecuencia y área de distribución de MG por CPT en pacientes que debutan con MG es similar a pacientes con recidiva ganglionar. Esto justifica incluir en forma sistemática los niveles II, III, IV, Vb y VI en disección cervical de pacientes con CPT metastásico. El hombro doloroso es la morbilidad más frecuente, el cual se recupera en la mayoría de los casos a los 3 meses.

\section{¿EXISTE EN CHILE VARIABILIDAD GEOGRÁFICA EN LA DETECCIÓN DE HIPOVITAMINOSIS D DURANTE EL INVIERNO?: ESTUDIO MULTICÉNTRICO NACIO- NAL EN MUJERES ADULTAS MAYORES SANAS}

González $\mathrm{G}^{1}$, Jiménez $\mathrm{M}^{1}$, Rosowski I ${ }^{2}$, Viviani $\mathrm{P}^{3}$, Montalvo $\mathrm{D}^{4}$, Besancon $F^{5}$, Grant $C^{6}$, Sapunar $J^{7}$, Aguayo CG $^{8}$.

Departamentos de Endocrinología ${ }^{1}$, Nutrición ${ }^{2}$ y Salud Públi$\mathrm{ca}^{3}$, Facultad de Medicina, Pontificia Universidad Católica de Chile y Hospitales Regionales de Arica ${ }^{4}$, Coquimbo ${ }^{5}$, Concepción ${ }^{6}$, Temuco $^{7}$ y Punta Arenas ${ }^{8}$.

Anteriormente hemos demostrado que la hipovitaminosis D $(250 \mathrm{HD}<15 \mathrm{ng} / \mathrm{ml})$ es endémica entre las adultas mayores sanas de Santiago (latitud $33^{\circ} \mathrm{S}$ ), afectando hasta el $82 \%$ de éstas en inviemo. Sin embargo, no existe información al respecto de otras zonas del país. Objetivo: Evaluar el estatus de vitamina D durante el inviemo en adultas mayores sanas, residentes en las distintas latitudes de Chile. Sujetos y Métodos: A fines del inviemo del 2003, se estudió en Arica, Coquimbo, Concepción, Temuco y Punta Arenas, mujeres > 60 años ambulatorias sin enfermedades o uso de fámacos que alteren el metabolismo de vitamina $\mathrm{D}$, según historia y exámenes nomales recientes. En todas se realizó estimación de la ingesta de vitamina D y calcio y medición de 250HD y PTH, que fueron procesadas centralmente. Resultados: La ingesta de vitamina D y calcio estuvo bajo lo adecuado en el $100 \%$ y $97 \%$ de las voluntarias, independientemente de su residencia; la Tabla 1 muestra los hallazgos principales en cada sitio estudiado.

Conclusiones: 1) En Chile, las adultas mayores sanas presentan una prevalencia elevada de hipovitaminosis D

Tabla 1.

\begin{tabular}{|lcccc|}
\hline Complicaciones & Precoz & $\%$ & 3 Meses & $\%$ \\
\hline Hematoma cervical & $0 / 41$ & 0 & $0 / 41$ & 0 \\
Infección herida operatoria & $0 / 41$ & 0 & $0 / 41$ & 0 \\
Hombro doloroso (nervio espinal accesorio) & $26 / 41$ & 63 & $4 / 41$ & $9,8^{*}$ \\
Fístula del conducto torácico & $1 / 41$ & 2,5 & $0 / 41$ & 0 \\
Necrosis colgalgo de piel & $0 / 41$ & 0 & $0 / 41$ & 0 \\
Sindrome Claude Bernard-Horner & $2 / 41$ & 4,8 & $0 / 41$ & 0 \\
Lesión del nervio frénico & $1 / 41$ & 2,5 & $1 / 41$ & 2,5 \\
\hline
\end{tabular}

* $\mathrm{P}<0,01 \mathrm{CPT}+\mathrm{MG}$ v/s MG-R 
Tabla 1.

\begin{tabular}{|lccccc|}
\hline Parámetro & Arica & Coquimbo & Concepción & Temuco & P. Arenas \\
\hline Latitud ( $\left.{ }^{\circ}\right)$ & $18^{\circ} \mathrm{S}$ & $29^{\circ} \mathrm{S}$ & $36^{\circ} \mathrm{S}$ & $38^{\circ} \mathrm{S}$ & $52^{\circ} \mathrm{S}$ \\
$\mathrm{n}$ & 25 & 24 & 28 & 28 & 23 \\
Edad (años) & $67,0(60-82)$ & $68,5(60-79)$ & $63,5(60-82)$ & $65,0(60-78)$ & $66,0(60-79)$ \\
250HD (ng/ml) & $25,5(6,7-35,7) \#$ & $11,4(5,6-25,6)$ & $11,6(6,6-25,6)$ & $12,5(6,7-29,5)^{*}$ & $7,5(5-15,4)$ \\
Hipovitaminosis D (\%) & 16 & 88 & 75 & 61 & 96 \\
PTH (vn: 7-53 pg/ml) & $20,6(6,7-41,4)$ & $33,5(10,1-94,5) \&$ & $56,3(22,3-101) \phi$ & $75,2(27,1-130)$ & $63,8(26,3-122)$ \\
\hline
\end{tabular}

Valores se expresan como mediana (mín-máx), \#: p<0,05 v/s resto; *: $p<0,05$ Temuco v/s Punta Arenas; \&: Arica y Coquimbo v/s resto; $\phi$ Concepción v/s Temuco (Kruskal Wallis test).

durante el invierno, independiente de su residencia geográfica; 2) Esta deficiencia ocurre en la mayoría de las adultas mayores que viven al sur del paralelo $29^{\circ} \mathrm{S}$, zona que representa el 94\% de esta población; 3) La hipovitaminosis D se asocia frecuentemente a Hiperparatirodismo $2^{\circ}$ y universalmente a baja ingesta de calcio y vitamina D y 4) Estas alteraciones ilustran la necesidad de políticas de fortificación de vitamina $\mathrm{D}$ en la dieta de las adultas mayores de nuestra población.

\section{HIPERPARATIROIDISMO PRIMARIO (HPP) PERSIS- TENTE POR ADENOMAS MÚLTIPLES: UTILIDAD DEL SESTAMIBI-SPECT Y LA PTH INTRAOPERATORIA (PTHI) EN REOPERACIÓN EXITOSA}

González $\mathrm{G}^{1}$, Jiménez $\mathrm{M}^{1}$, Claure $\mathrm{R}^{2}$, Orellana $\mathrm{P}^{3}$, López JM. Departamentos de Edocrinología ${ }^{1}$, Cirugía ${ }^{2}$ y Laboratorio de Medicina Nuclear ${ }^{3}$, Facultad de Medicina, Pontificia Universidad Católica de Chile.

En alrededor del 20\% de pacientes con HPP persistente postcirugía la causa es enfermedad multiglandular incompletamente resecada (15-18\% hiperplasia, 2-3\% adenomas múltiples). En estos casos la correcta localización pre-operatoria de la lesión causal y la certificación intra-operatoria de la resección asegura la curación definitiva. Caso clínico: Hombre de 67 años, sin antecedentes individuales 0 familiares de significación, es operado en Marzo/2000 por HPP, resecándose un adenoma paratimideo inferior izquierdo de 1,5 cm (121mg). Aunque en el post-operatorio se evidenció normocalcemia, destacó la persistencia de PTH elevada y calcemia en ascenso, con múltiples estudios de imagen negativos en los 3 años siguientes. La tabla muestra exámenes iniciales y su evolución (Tabla 1).

En 09/03 desarrolla hipercalcemia grave, requiriendo hidratación, furosemida y zoledronato e.v. La RNM y MIBISPECT, coincidieron en localizar un nódulo de $1,5 \mathrm{~cm}$ en mediastino superior derecho. El 23/09/03 se efectúa exploración cervical, con protocolo de PTHi. En la cirugía se identificó un adenoma paratiroideo inferior derecho de 1,0cm (258 mg), cuya extiparción determinó caída de sólo 14 y $24 \%$ de PTH a los +5 y +10 min. (caída negativa para resección curativa). En búsqueda de una localización intratiroidea se efectúo tiroidectomia, ubicándose otro adenoma de $958 \mathrm{mg}$, en posición posterior e inferior al lóbulo derecho. Su extirpación hizo caer PTH 80 y $85 \%$ a los +5 y +10 min. La paratiroides superior izquierda estaba atrófica. Al día siguiente la calcemia era $8,9 \mathrm{mg} / \mathrm{dl}$ y PTH $<1 \mathrm{pg} / \mathrm{ml}$. Sin recurrencia hasta la fecha. Comentario: Este sería el primer caso descrito en Chile de HPP por adenomas múltiples, el cual ilustra la necesidad en HPP persistente de ampliar el estudio con técnicas de imágenes, como MIBISPECT y el uso imprescindible de PTHi, para certificar la efectividad del tratamiento.

Tabla 1.

\begin{tabular}{|lccccccc|}
\hline Examen/Fecha & $03 / 00$ & $04 / 00$ & $06 / 00$ & $06 / 01$ & $08 / 02$ & $10 / 03$ & $09 / 03$ \\
\hline Calcemia mg/dl & 14,9 & 9,3 & 10 & 10 & 10,7 & 11 & 14,7 \\
PTH pg/ml & 493 & 383 & 178 & 202 & 108 & 151 & 944 \\
Ecografía & (+)Inf. Izq. & & $\begin{array}{c}(-) \\
\text { Cintigr.Sestamibi }\end{array}$ & & & $\begin{array}{c}\text { Planar (-) } \\
(-)\end{array}$ & Planar (-) \\
Cintigr. Ta-Tc & & & $(-)$ & & & & SPECT (+) \\
RNM & & & & & & $(+) 1,5 \mathrm{~cm}$ \\
\hline
\end{tabular}




\section{EVALUACIÓN DEL MANEJO DE PACIENTES CON DIABETES MELLITUS TIPO 2 (DM 2) EN ATENCIÓN TERCIARIA}

Grant C, García P, Mora D, inostroza M, Ávila C, Briano E, Rodríguez C, Meza M, Amthauer N, Quevedo I, Verdugo C. Departamento de Medicina Interna, Facultad de Medicina, Universidad de Concepción, Hospital Clínico Guillermo Grant Benavente de Concepción.

Los estudios DCCT y UKPDS han demostrado la efectividad de lograr un adecuado control metabólico en pacientes diabéticos en reducir las complicaciones micro y macrovasculares. Objetivo: Evaluar el control y manejo de los pacientes con DM2 en el policlínico de Endocrinología del Hospital Clínico de Concepción según las normas ATP III. Pacientes y Método: Diseño descriptivo transversal. Obtención de datos mediante revisión de fichas clínicas de pacientes DM2 controlados en policlínico de Endocrinología de este centro entre enero y agosto de 2002, registrando características demográficas, comorbilidades (CM), tratamientos, y cumplimiento de objetivos terapéuticos (COT). Se excluyeron quienes estuviesen menos de 1 año en control. Resultados: Se identificaron 141 pacientes ( $65 \%$ mujeres), de edad promedio $57,4+12,2$ años. El 68,2\% fue mayor de 50 años. El tiempo de

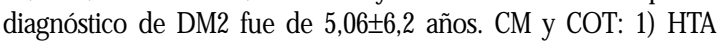
(63,1\%), de los cuales sólo el 31\% se mantenía normotenso, pese al uso de 2 o más hipotensores en el 50\% de los casos. 2) Obesidad (55,8\%), de los cuales el $26 \%$ fue derivado a nutricionista de la sección, estando sólo el 12\% normopeso. 3) Dislipidemias (80\%), siendo la forma mixta la más frecuente. El 22,7\% recibió tratamiento famacológico, Sólo el 20\% tuvo niveles LDL < $100 \mathrm{mg} \%$.4) Control glicémico: Sólo el 27,1\% tuvo Hb A1C $<7 \%$, habiéndose solicitado un promedio de 2,4+1,3 veces por año. Otros aspectos: a) Examen de pies consignado sólo en el $37,6 \%$ en el último control. b) Retinopatía: Fondo de ojo alterado en el $53 \%$ y vigente en el $57,4 \%$. c) Nefropatía: microalbuminuria vigente en el $63,1 \%$, siendo un $71,9 \%$ usuario IECA para este objetivo c) Fármacos hipoglicemiantes: El 66,6\% con insulinoterapia, con o sin HGO. Conclusiones: En esta serie, la minoría de los sujetos DM2 tienen un control metabólico óptimo, según la normativa de manejo vigente. Creemos relevante una mejor estandarización del control, así como en un manejo agresivo de este grupo de riesgo cardiovascular máximo.

\section{CARCINOMA PAPILAR FAMILIAR DE TIROIDES. RE- PORTE DE 4 CASOS EN 2 FAMILIAS}

Grünholz D, Palma C, Tabilo P, Pierret T.

Servicio de medicina Hospital Barros Luco Trudeau

Introducción: el carcinoma papilar de tiroides es el cáncer de tiroides más frecuente, pero hay pocos casos descrito en asociación familiar,que ocurre en un 3.8 a $6.2 \%$ de todos los casos de cánceres papilares tiroídeos. Existen formas de presentación: formando parte de un síndrome de tumores hereditarios y de presentación aislada. En Chile no se han publicado reportes de este tipo de neoplasia en asociación familiar y en la literatura extranjera se describen casos aislados. El presente trabajo tiene como objetivo analizar las características clínicas, el tratamiento y la evolución de los casos y al mismo tiempo compararlo con la literatura extranjera.

Pacientes y Método: estudio retrospectivo, en el que se estudiaron fichas clínicas del Servicio de Endocrinología del Hospital Barros Luco-Trudeau y se seleccionaron casos índices con al menos un familiar directo con cáncer papilar de tiroides cuyo diagnóstico y tratamiento se hubiere realizado en este centro.

Resultados: se analizaron datos de 4 pacientes, pertenecientes a 2 familias, y que correspondieron a 2 parejas de hermanas. El motivo de consulta más frecuente fue bocio. Las pruebas de función tiroídea fueron normales en todos los casos. El cintigrama mostró nódulos hipocaptantes. Recibieron tratamiento adicional a la cirugía 3 de 4 pacientes que correspondió a radioyodo. El tiempo de seguimiento promedio de estas pacientes fue de 61,5 meses, tras lo cual ningún caso ha mostrado evidencias de recurrencia de la enfermedad, demostrada por radiografía de tórax y niveles de tiroglobulina normales.

Conclusiones: El carcinoma papilar familiar de tiroides es una entidad poco frecuente en nuestro medio, en ningún caso se presentó asociado a otra neoplasia. En nuestra serie se reporta pronóstico favorable, sin evidencias de recurrencia de enfermedad al tiempo de seguimiento estudiado.

\section{ANÁLISIS COMPARATIVO DE LA COMPOSICIÓN CORPORAL(CC) EN NIÑOS CHILENOS. ANTROPO- METRÍA VERSUS DEXA}

Hernández MI, Urrejola P, Reyes ML, Velandia S, Urrutia P. Departamento de Pediatría. Pontificia Universidad Católica de Chile.

Introducción: En la actualidad existen diversos métodos clínicos para evaluar CC, pero ninguno de ellos ha demostrado ser el ideal, especialmente en la edad pediátrica. Dado que en Chile se ha observado un aumento en la prevalencia de obesidad y trastomos de conducta alimentaria en la última década es necesario validar métodos clínicos para evaluar CC y así ser utilizados en forma rutinaria.

Objetivo: Comparar el porcentaje de masa grasa (MG) estimado por fórmulas utilizando pliegues subcutáneos (PS) con la medición realizada por DEXA y analizar concordancia según sexo y estadio de tanner.

Material y Método: Se evaluaron 129 niños (71 mujeres-58 varones) 75 prepúberes, sanos, eutróficos, provenientes de Santiago. Edad x: 114,3 meses, IMC percentil 10-85 (x:17,74), 
Tabla 1. Promedio ( $\mathrm{x}$ ) porcentaje de M G según método empleado (\% $\mathrm{x} \pm \mathrm{DS}$ )

\begin{tabular}{|lccccc|}
\hline Método & Total & Prepuber & Puber & Varones & Mujeres \\
\hline DEXA & $19,9 \pm 7,5$ & $17,7 \pm 5,4$ & $24,3 \pm 9,1$ & $17,2 \pm 6,4$ & $22,2 \pm 7,7$ \\
Slaughter & $14,7 \pm 5,2$ & $12,8 \pm 4,5$ & $17,7 \pm 5,1$ & $13,1 \pm 4,5$ & $15,9 \pm 5,4$ \\
Westrate-Duremberg & $17,7 \pm 6,1$ & $16,1 \pm 5,1$ & $20,3 \pm 6,9$ & $14,8 \pm 5,1$ & $20 \pm 5,8$ \\
\hline
\end{tabular}

talla p25-75. Se estimó el porcentaje de MG utilizando mediciones de PS aplicadas sobre ecuaciones de Slaughter y Westrate y Duremberg. Se realizó densitometría ósea (DexaLunar, software pediátrico versión 4.7, precisión 1-2\%) para estudio de CC. Se analizó el nivel de concordancia mediante métodos de Bland y Altman.

Resultados (Tabla 1).

En el grupo total hubo buena concordancia entre MG por DEXA y estimado por PS, la ecuación de Westrate y Duremberg menor diferencia promedio $(2,21 \pm 2,66)$.

La estimación por la fórmula de Slaughter mostró buena concordancia en el grupo con tanner I, menos adecuada en los otros estadíos de tanner (diferencia $\mathrm{x}$ prepúberes vs

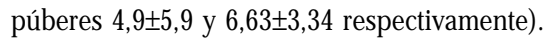

En el análisis según sexo la mejor concordancia en ambos se logró con la fórmula de Westrate y Duremberg

Conclusiones: Los resultados obtenidos en este estudio permiten concluir que en niños chilenos, sanos, eutróficos, la medición de PS y la estimación del porcentaje de MG a partir de estos es altamente concordante con la medición realizada por DEXA. De la fórmulas analizadas, la mejor concordancia en este grupo se logró con la de Westrate y Duremberg a todas las edades y con la de Salughter en edad prepuberal.

\section{FACTORES ASOCIADOS A LA DENSIDAD MINERAL ÓSEA EN NIÑOS CHILENOS}

Hernández Mi, Aglony M, Velásquez CG, Parada J, Reyes Ml. Depto. de Pediatría y Servicio de Laboratorios Clínicos, Facultad de Medicina, Pontificia Universidad Católica de Chile.

La masa ósea máxima es fundamental en la prevención de la osteoporosis post menopáusica, por esto, es importante conocer que factores podrías estar asociados para optimizar su ganancia. Objetivo: Establecer los factores que influyen en la densidad mineral ósea en niños chilenos.

Métodos: Estudio de sección de corte, en que se reclutaron niños y niñas entre los 2 y 18 años, 12 a 18 por cada grupo etario. Criterios de inclusión: sanos, peso nacimiento $>2500 \mathrm{~g}$, ingesta de calcio (ICa) normal para su edad y sexo, talla \pm 2DS, peso para la talla 10-90\% o IMC p25-75 (NCHS); 2 apellidos españoles, residentes en Santiago; criterios de exclusión: ingesta de medicamentos, antecedente de fracturas, antecedente familiar de osteoporosis precoz, osteopatías 0 litiasis urinaria, ejercicio(E) $>6 \mathrm{hr} / \mathrm{sem}$. Se evaluó marcadores de recambio óseo, radiografía de carpo y densitometría ósea (DMO) cuerpo total (CT), columna lumbar (L2-L4), cuello femoral (CF) y densitometría volumétrica (DVOL), contenido mineral óseo total (CMOT) (Dexa-Lunar, software pediátrico versión 4.7, precisión 1-2\%). Se obtuvo z de IMC y DMO. Los valores se expresaron como promedio \pm DS. Mediante test de regresión múltiple y ANOVA se analizó Z de DMO de CT, L2L4, CF, DVOL y CMOT con las siguientes variables: $\mathrm{Z}$ de IMC, edad ósea, E, 25 hidroxivitamina D (250HD), PTH y Calciura/ Creatininuria $(\mathrm{Ca} / \mathrm{CrU})$, Fos. Alcalinas, Fos. Acidas tartrato resistente y Deoxipiridinolina en orina.

Resultados: IMC: 0,14 $\pm 0,76$, ICa: $1234 \pm 375 \mathrm{mg} / \mathrm{d}, \mathrm{E}$ :

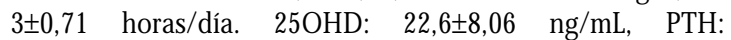

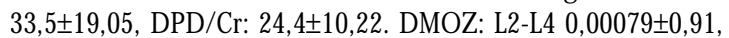

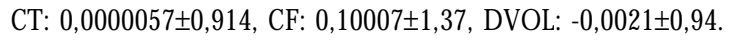
Resultados estadísticos (valores de p) (Tabla 1).

Discusión: Los valores de DMO a nivel de L2-L4 y CT muestran una correlación significativa con el Z IMC; pero no DVOL, DCF y CMOT. Estos resultados confirman la independencia de DVOL del tamaño corporal; lo que la haría más útil en niños con talla baja, obesos o desnutridos. Encontramos una tendencia no significativa hacia un mayor ZDVOL al aumentar la ingesta de calcio; probablemente debido al estrecho rango de la ICa. La asociación con la excreción de calcio sería independiente del recambio óseo. Se evaluará el rol de la ingesta de sodio y proteínas sobre la calciuria y su relación con DMO.

Tabla 1.

\begin{tabular}{|lccccc|}
\hline & ZL2-L4 & ZDVOL & ZCT & ZCF & ZCMOT \\
\hline Z IMC & 0,003 & 0,18 & 0,005 & 0,083 & 0,079 \\
Z Ca/Cr U & 0,009 & 0,035 & 0,195 & 0,006 & 0,017 \\
\hline
\end{tabular}




\section{FACTORES ASOCIADOS A LA OSTEOPOROSIS IN- DUCIDA POR CORTICOIDES(OIC) EN NIÑOS. ES- TUDIO MULTICÉNTRICO}

Hernández MI, Talesnik E, King A, Vinet aM, Vogel A, Lagomarsino E, MericQ V, Méndez C, Reyes ML.

Programa de Metabolismo Oseo, Depto. de Pediatría, Facultad de Medicina, P. Univ. Católica de Chile, Hospital. LC Mackenna, IDIMI Univ. de Chile.

La OIC es una complicación que empeora adicionalmente la calidad de vida de los pacientes. Poco se conoce de los factores que lleva a algunos pacientes y no otros a desarrollar OIC.

Objetivo: Establecer los factores que influyen en la disminución de la DMO en niños chilenos con enfermedades en corticoterapia crónica.

Métodos: Se evaluaron 54 niños con enfermedades en corticoterapia crónica: Artritis reumatoidea:13, Lupus: 9, Dermatomiositis: 6, Enfermedad mixta del tejido conectivo: 3, otras enfermedades reumatológicas:7, nefropatías: 5, otras: 6 . Edad: 10,3土3,53; 36 de sexo femenino. Se reclutó información sobre: Etnia, residencia, tipo de enfermedad, tiempo de evolución, tipo de corticoides, dosis inicial, tiempo de uso, uso y tiempo de metotrexate, ciclosporina y/o plaquinol, ingesta de calcio, actividad física, retraso de crecimiento (pérdida de percentiles respecto a curva antes inicio de corticoides) y antecedentes familiares de osteoporosis y litiasis, 250H-vitamina D, marcadores de recambio óseo y densitometría ósea (DMO) cuerpo total (CT), columna lumbar (L2-L4) y densitometría volumétrica (DVOL) (Dexa-Lunar, software pediátrico versión 4.7, precisión 1-2\%) Los valores se expresaron como promedio \pm DS. Mediante ANOVA se analizó DVOL con las variables arriba mencionadas.

Resultados: Tiempo evolución enfermedad: 3,21 $\pm 3,46$ años. Etnia: 4 apellidos españoles 38 (70\%), 1 mapuche 6 (11\%). Corticoides: Prednisona 48 (88\%), Dosis inicial: $1,88 \pm 3,46 \mathrm{mg} / \mathrm{kg} /$ día, tiempo uso: $2,5 \pm 2,8$ años. Uso Metotrexate 22 (40\%), tiempo uso 2,23 $\pm 2,16$ años. Ingesta de calcio bajo recomendación: 22 (40\%). Actividad física: No caminan: 7 (13\%), sólo camina: 27 (50\%), normal: 9 (16,6\%), deportistas: 5 (9\%), en rehabilitación: 4 (7,4\%). Retraso crecimiento 29 (53\%). Familiares: osteoporosis: 7 (13\%), litiasis 6 (11\%). $250 \mathrm{H}$ vitamina D: 17,5 $\pm 6,7$. (22,2\% < $15 \mathrm{ng} / \mathrm{ml})$. DMO: CT Z: -

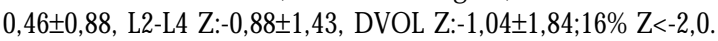
Fracturas vertebrales: 9 (16,6\%). Se encontró una asociación significativa entre menor DVOL y actividad física $(p=0,0012)$, retraso de crecimiento $(\mathrm{p}=0,0044)$, y tiempo uso de Metotrexate $(\mathrm{p}<0,0001)$.

Conclusiones: Encontramos una asociación independiente entre menor DVOL y presentación de retraso de crecimiento, menor actividad física y tiempo de uso de metotrexate. Pareciera interesante estudiar factores de crecimiento que expliquen la asociación con el retraso de crecimiento. Es importante el conocimiento de estos factores para mejorar el seguimiento y estrategias de prevención de la OIC en niños.

\section{COMPLICACIONES CARDIOVASCULARES EN PA- CIENTES HIPERTIROIDEOS}

Hidalgo S, Lioi X, Munizaga F.

Departamento de Endocrinología, Hospital C. San Borja Arriarán.

El hipertiroidismo es una patología que afecta principalmente a mujeres jóvenes y que puede presentar complicaciones importantes, fundamentalmente de tipo cardiovascular. Objetivos: Evaluar la frecuencia y tipo de complicaciones cardiovasculares en una población hipertimidea seguida en forma prospectiva. Pacientes y Métodos: Se siguieron en forma prospectiva 167 pacientes con diagnóstico de hipertiroidismo durante un tiempo promedio de 15 meses, hasta que estuvieron eutimideas. La pacientes era en su mayonía mujeres (80,8\%), con un promedio de edad de 39,4 años (16 a 77). La causa más frecuente de hipertimidismo fue la enfermedad de Basedow Graves, 89,4\%, seguida por BMN, 7,2\% y nódulo tóxico, 3,4\%. Se evaluó en las pacientes sintomáticas, la presencia de Hipertensión pulmonar mediante ecocardiograma, AC por FA, mediante ECG, AVE, mediante TAC de encéfalo, IAM, mediante ECG, alza enzimática y coronariografía. Se comparó este grupo de pacientes que hizo complicaciones con el grupo mayoritario de pacientes que no las hizo, buscando factores de riesgo. El estudio estadístico se realizó con test de T y test de Chi cuadrado. Resultados: De las 167 pacientes seguidos, 35 abandonaron el control, lo que comesponde a un $21 \%$. Del grupo restante, que corresponde a 132, 21 pacientes presentaron complicaciones cardiovasculares (15,9\%). Las complicaciones fueron las siguientes: Hipertensión Pulmonar en 7 pacientes (5,3\%), amitmia completa en $10(7,6 \%)$, accidente vascular encefálico en 2 (1,5\%) e IAM en 2 (1,5\%) Si comparamos el grupo de pacientes que no presentó complicaciones con el grupo que sí las hizo, no hay diferencias en cuanto a tiempo de hipertiroidismo, valor de T4 y T3 al comienzo de la enfermedad, sexo, causa del hipertimidismo. Sólo hubo diferencias significativas en la edad: 38,9 vs 48,6 ( $p<0,044$ ) siendo de mayor edad el grupo que tuvo complicaciones y el nivel de T3 a los 6 meses de tratamiento: 169,5 vs 239,3 ( $p<0,038$ ) teniendo un valor más alto el grupo que se complicó. Conclusión: Un 16\% de los pacientes hipertimideos presenta una complicación cardiovascular grave durante la enfermedad. Los pacientes de mayor edad y los que tienen un peor control de su enfermedad son los que tienen mayor riesgo de tener dichas complicaciones.

\section{EVOLUCIÓN DE LA FUNCIÓN HEPÁTICA EN PA- CIENTES HIPERTIROIDEOS EN TRATAMIENTO CON PROPILTIOURACILO}

Hidalgo S, Munizaga F, Lioı X.

Departamento de Endocrinología Hospital C. San Borja Arriarán.

El daño hepático por Propiltiouracilo (PTU) es una complicación grave del tratamiento del hipertiroidismo ya que tiene una alta mortalidad. Lo habitual es que se diagnostique una vez que hay 
Tabla 1.

\begin{tabular}{|lcccc|}
\hline Meses & Bilimubina $\mathrm{T}$ & SGPT & SGOT & GGT \\
\hline Basal & 0,7 & 21 & 28 & 86 \\
1 & 0,6 & 44,9 & 32,7 & 63 \\
2 & 0,5 & 42,6 & 34,5 & 42 \\
3 & 0,7 & $110,9(\mathrm{p}<, 004)$ & $68,5(\mathrm{p}<, 001)$ & 53 \\
6 & 0,5 & 50,5 & 53 & 15 \\
\hline
\end{tabular}

necrosis hepática severa. Objetivos: Evaluar la función hepática de pacientes hipertiroideos en tratamiento con PTU. Pacientes y Métodos: Se siguieron en forma prospectiva 47 pacientes hipertiroideos, sin otras patologías, tratados con PTU durante al menos 6 meses. El control de la función hepática fue mediante medición de: Bilimubina total, SGPT, SGOT, GGT y Fosfatasas alcalinas. Se midió estos parámetros en forma basal y a los: 1, 2, 3 y 6 meses de iniciada la terapia. Se evaluó cuántos pacientes hicieron daño hepático agudo con el medicamento y la evolución al suspenderlo. El estudio estadístico se realizó mediante test de T. Resultados: Abandonaron control 11 pacientes. De los 36 restantes, 9 presentaron daño hepático agudo por drogas (25\%), caractenizado por alza de enzimas hepáticas por sobre 2,5 (promedio 5,3) veces el valor basal. La mayońa presentó esta alza dentro de los primeros 3 meses de tratamiento y en todos ellos al suspender el medicamento la función hepática se recuperó. La Tabla 1 muestra la evolución de las enzimas en los pacientes que hicieron daño hepático, con un alza significativa de éstas al tercer mes, comparado con el basal.

Al comparar el grupo de pacientes que hizo daño hepático con el que no lo hizo, la diferencia en el valor de SGPT a los tres meses fue significativamente mayor en el primero 110.9 vs $28.6(\mathrm{p}<0.0009)$ como también la SGOT 68,5 vs $29(p<0,0055)$ Conclusión: La terapia con Propiltiouracilo puede inducir un daño hepático agudo en el $25 \%$ de los pacientes hipertiroideos, el cual se evidencia a partir del tercer mes y puede revertirse al suspender el medicamento.

\section{EVALUACIÓN DE LA FUNCIÓN GONADAL MEDIAN- TE TEST DE ANÁLOGO DE GNRH EN LACTANTES PEQUEÑOS PARA LA EDAD GESTACIONAL (PEG) DURANTE LA «MINI PUBERTAD POSTNATAL»}

Hitschfeld $\mathrm{C}^{1}$, Codner $\mathrm{E}^{2}$, Cassorla $\mathrm{F}^{2}$, Maliqueo $\mathrm{M}^{1}$, Avila $\mathrm{A}^{2}$, Vera $\mathrm{P}^{1}$, Echiburú $\mathrm{B}^{1}$, Sir Petermann $\mathrm{T}^{1}$.

${ }^{1}$ Laboratorio de Endocrinología y Metabolismo, ${ }^{2}$ IDIMI, Facultad de Medicina Occidente y Centro, Universidad de Chile.

Introducción: Se ha descrito que individuos con antecedentes de PEG presentan mayor riesgo de desarmollar: pubarquia prematura y síndrome de ovário poliquístico en la mujer y menor recuento espermático, testosterona baja e infertilidad de causa desconocida en el hombre. Es posible que estas alteraciones estén condicionadas tempranamente en el desamollo fetal, lo cual se puede evaluar durante la minipubertad postnatal mediante el test de análogo de $\mathrm{GnRH}$ (GnRH-a). Objetivo: Evaluar la respuesta al test de GnRH-a en niños PEG durante la minipubertad» postnatal. Sujetos y Métodos: En 9 varones y 11 niñas PEG ( $§ 5$, entre-1,43 a -2,52 DS) pareados con 18 controles (C) 10 varones y 8 niñas (p25-75 Juez, 1984) hijos de madres sanas, entre 18-35 años, con un embarazo de término y sin patologías. Se realizó entre los 2 y 3 meses de vida un test de GnRH-a (luprón $10 \mathrm{ug} / \mathrm{kg}$ de peso sc) Se tomó una muestra basal, a las 3 y 24 hs postestímulo. Se determinó gonadotrofinas, estradiol, testosterona, 17-0HP, A4 e inhibina B. Resultados: La concentación de gonatrofina y esteroides sexuales fueron comparables entre PEG y C. No obstante, en 4 niñas PEG la concentración de E2 postestímulo fue mayor a la observada en las C ( $\bar{x} \pm \mathrm{ES}: 105,33 \pm 17,2$ vs $22,57 \pm 6,42 \mathrm{pg} / \mathrm{ml} /$ $\mathrm{p}=0,0074)$. En estas niñas la concentración basal de inhibina $\mathrm{B}$ fue mayor a las $C(\bar{x} \pm E S: 45,28 \pm 5,52$ vs $33,58 \pm 3,41 \mathrm{pg} / \mathrm{ml} /$ $\mathrm{p}=0,24)$. En 4 varones $P E G$, los valores de testosterona basal fue menor a lo observado en los C $(0,39 \pm 0,1$ vs $0,82 \pm 0.05 \mathrm{ng} / \mathrm{ml}$ basal $\mathrm{p}=0,045)$. En ellos la concentración basal de inhibina $B$ fue menor a los C $(91,11 \pm 9,11$ vs $123,24 \pm 22,2 \mathrm{pg} / \mathrm{ml} / \mathrm{p}=0,012)$. Conclusiones: Estos datos preliminares sugieren que algunos niños PEG presentan niveles alterados de esteroides sexuales en la minipubertad» postnatal, lo que podnía reflejar una disfunción de células de la granulosa en las niñas y de leydig-sertoli en los niños.

FONDECYT 1030487 Y BECA PG/81/2003

\section{IGF-I INDUCE SEÑALES DE Ca++ INTRACELULAR EN CULTIVOS PRIMARIOS DE MÚSCULO ESQUELÉTICO HUMANO}

Iñiguez $G^{1}$, Gilbert $M^{1}$, Lopez $T^{3}$, Eterovic $P^{3}$, Espinosa $A^{2}$, Jaimovich $E^{2}$, CAsSORla $\mathrm{F}^{1}$.

Instituto de Investigaciones Materno Infantil (IDIMI) $)^{1}$, Instituto de Ciencias Biomédicas (ICBM)², Escuela de Medicina, Universidad de Chile, Hospital Clínico San Borja Arriarán 3 , Santiago-Chile (FONDECYT 1020965).

Introducción: El IGF-I, in vitro, es capaz de alterar la expresión de factores de transcripción músculo-específicos, así como promover la división y diferenciación de 
mioblastos a miotubos. La sobreexpresión celular de IGF-I se traduce en un aumento de la masa muscular debido a un incremento en la síntesis proteica y contenido de DNA. Las modificaciones en la concentración intracelular de $\mathrm{Ca}^{++}$controlan una serie de funciones celulares, tales como el acoplamiento excitación-contracción, secreción, división y la expresión de genes asociados a la diferenciación celular. Objetivo: Determinar el posible efecto de IGF-I sobre el $\mathrm{Ca}^{++}$intracelular de células músculo esqueléticos humanas. Método: Se realizaron cultivos primarios de músculo esquelético humano a partir de muestras provenientes de 10 niños prepuberales con talla baja y edad promedio $6,4 \pm 1,1$ años, peso promedio $22,7 \pm 7,1 \mathrm{~kg}$

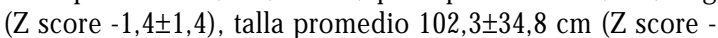
$1,93 \pm 1,5)$ e IMC promedio $17,1 \pm 2,7 \mathrm{~kg} / \mathrm{m} 2$. Los miotubos obtenidos $(n=27)$ fueron incubados en una solución Krebs libre de $\mathrm{Ca}^{++}$, cargados con Fluo3-AM, y posteriormente estimulados con IGF-I 10-8 M. Mediante un microscopio de fluorescencia, fueron capturadas y adquiridas imágenes cada un segundo (rango de adquisiciones: 80-150 segundos). La fluorescencia se evaluó utilizando el programa ImageJ.

Resultados: Al estimular con IGF-I, observamos un aumento en la fluorescencia en 17 de los 27 miotubos estudiados. Este aumento se inició dentro de los primeros 10 segundos de aplicado el estímulo y se observó tanto en el citoplasma como en el núcleo, siendo más evidente en este último compartimento celular. Se observaron diferentes patrones cinéticos y tiempos máximos de fluorescencia entre los pacientes estudiados (Figura A y B).Conclusión: Se presenta el primer reporte que muestra que IGF-I induce un aumento del $\mathrm{Ca}^{++}$intracelular, tanto en el citoplasma como en el núcleo de miotubos humanos. Sugerimos que la movilización precoz de $\mathrm{Ca}^{++}$intracelular provocada por IGF-I podría ser necesario para la vía de transducción de señales involucrada en la proliferación y crecimiento muscular.

\section{NIVELES SÉRICOS AUMENTADOS DE ADIPONEC- TINA DURANTE EL INICIO DE LA PUBERTAD EN NIÑAS CON DIABETES MELLITUS TIPO 1}

Iñiguez G, Bazáes R, Cassorla F, Codner E.

Instituto de Investigaciones Materno Infantil (IDIMI), Facultad de Medicina, Universidad de Chile, Hospital Clinico San Borja Arriarán, Santiago, Chile.

La adiponectina (A) y la leptina (L) son proteinas producidas por el tejido adiposo y participarían en la patogénesis de la insulino resistencia en humanos. Los niveles séricos de A se encuentran disminuidos en individuos con diabetes tipo 2 en cambio los de L se encuentran aumentados. Objetivo: Evaluar las concentraciones séricas de adiponectina y la relación $\mathrm{A} / \mathrm{L}$ en niñas adolescentes con Diabetes Mellitus tipo 1 (DM1) y compararlas con sujetos controles sanos. Métodos: Estudiamos 51 niñas adolescentes con DM1 (12,3 $\pm 0,2$ años) y 59 niñas controles (C) sanas $(11,7 \pm 0,2$ años) hasta dos años post menarquia, pareadas por edad y desarrollo puberal. Se determinaron las concentraciones en ayunas de adiponectina (RIA), leptina (IRMA) y triglicéridos en ambos grupos. Las concentraciones de insulina (RIA) fueron mediadas en los controles y HbA1c (Bayer DCA 2000) y péptido-C (RIA) en las pacientes con DM1. Los resultados se muestran como promedio \pm EEM.

Resultados: Las concentraciones de A fueron mas altas en DM1 respecto al grupo control $(10,7 \pm 0,5$ vs $9,1 \pm 0,4 \mu \mathrm{g} / \mathrm{ml}$ respectivamente, $p=0,011$ ), especialmente en Tanner 2 y 3 . Las concentraciones de L aumentaron durante la pubertad tanto en DM1 como en C, en correlación con el IMC; sin embargo solo en las niñas con DM1 las concentraciones de adiponectina disminuyeron, (Tanner 5 vs 2-3, $p<0,05$ Mann Whitney). Las concentraciones de A en las niñas con DM1 se correlacionaron positivamente con la HbA1c $(r=0,307, p=0,032)$ y negativamente con las concentraciones de leptina $(r=-0,283, p=0,044)$. No se encontraron correlaciones entre las concentraciones de

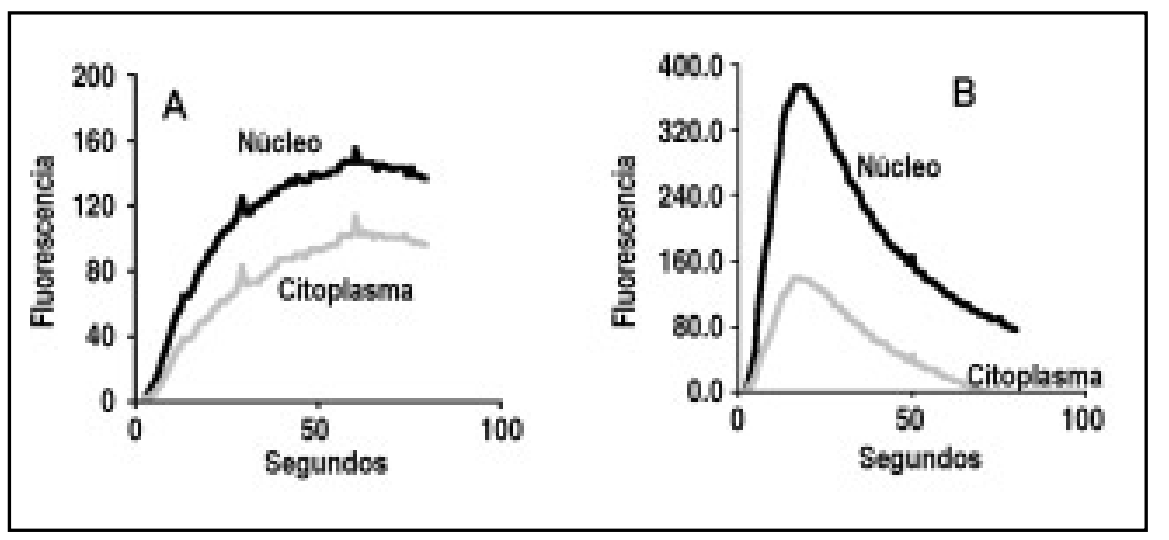

Figura A y B. 
Tabla 1.

\begin{tabular}{|lcccccccc|}
\hline & \multicolumn{2}{c}{ Tanner 2 } & \multicolumn{2}{c}{ Tanner 3 } & \multicolumn{2}{c|}{ Tanner 4 } & \multicolumn{2}{c|}{ Tanner 5 } \\
& DM1 (12) & C (15) & DM1 (14) & C (15) & DM1 (10) & C (16) & DM1 (15) & C (13) \\
\hline Edad (años) & $10,6 \pm 0,4$ & $10,4 \pm 0,3$ & $11,7 \pm 0,2$ & $11,3 \pm 0,3$ & $12,6 \pm 0,4$ & $12,2 \pm 0,3$ & $13,9 \pm 0,4$ & $13,1 \pm 0,2$ \\
IMC-SDS & $-0,2 \pm 0,4$ & $0,4 \pm 0,2$ & $0,1 \pm 0,2$ & $0,3 \pm 0,3$ & $0,4 \pm 0,2$ & $0,7 \pm 0,2$ & $0,8 \pm 0,2$ & $0,9 \pm 0,3$ \\
Adiponectina (ug/ml) & $12,5 \pm 0,9 *$ & $9,0 \pm 1,0$ & $11,6 \pm 0,8^{*}$ & $9,5 \pm 0,6$ & $9,7 \pm 1,1$ & $9,8 \pm 0,6$ & $9,1 \pm 0,8 \$$ & $8,0 \pm 0,8$ \\
Leptina (ng/ml) & $9,4 \pm 1,8$ & $11,3 \pm 1,0$ & $10,4 \pm 1,2$ & $19,9 \pm 5,9$ & $14,2 \pm 1,8$ & $18,8 \pm 4,1$ & $27,9 \pm 4,0 \$$ & $25,3 \pm 5,3 \$$ \\
Triglyceridos (mg/dl) & $87,2 \pm 5,8^{*}$ & $106,9 \pm 7,4$ & $98,6 \pm 7,9 *$ & $162,3 \pm 22,1$ & $90,7 \pm 5,5$ & $122,0 \pm 10,4$ & $108,3 \pm 14,6 *$ & $137,0 \pm 13,1$ \\
\hline
\end{tabular}

*p $<0,05$ DM1 vs C; $\$ p<0,05$ T5 vs T2

adiponectina e insulina en las niñas controles, o con la dosis de insulina en las niñas con DM1 (Tabla 1). Conclusiones: Las concentraciones de adiponectina son significativamente mas altas al comienzo de la pubertad en niñas con DM1 en comparación a niñas controles, pero disminuyen a través de la pubertad sólo en las niñas con DM1. Postulamos que la disminución observada de las concentraciones de adiponectina durante la pubertad en niñas con DM1 podría tener una participación en el desarrollo de las complicaciones diabéticas durante la vida adulta.

\section{CARACTERÍSTICAS DE PRESENTACIÓN ANÁTOMO- PATOLÓGICA DEL MICROCARCINOMA TIROIDEO}

Jiménez $M^{1}$, Fardella $C^{1}$, Mosso L L ${ }^{1}$, Solar $A^{2}$, Torres $J^{2}$, Arteaga E$^{1}$, Rodríguez $\mathrm{J}^{1}$, López JM ${ }^{1}$, Campusano $\mathrm{C}^{1}$, González $\mathrm{G}^{1}$, Goñ $1^{3}$, González H3 $\mathrm{H}^{3}$, Cruz F $\mathrm{F}^{4}$, León $\mathrm{A}^{3}$.

Departamentos de Endocrinología ${ }^{1}$, Anatomía Patológica², Sección de Cirugía Oncológica de Cabeza y Cuello ${ }^{3}$ y Radiología ${ }^{4}$, Pontificia Universidad Católica de Chile.

La Organización Mundial de la Salud en 1992, acuña el término de MCT, para definir a un subtipo de cáncer troideo menor de $10 \mathrm{~mm}$, el que tendría bajo riesgo de morbimortalidad. En los últimos años se ha evidenciado que un subgrupo de ellos podría tener un curso tan agresivo como el descrito para tumores de mayor tamaño, planteando así controversia respecto al diagnóstico y tratamiento. Objetivo: Conocer las características de presentación anatomo-patológicas de MCT, que pudieran indicar un cambio en el genio biológico de estos microcánceres. Pacientes y Métodos: Los casos de MCT y noMCT fueron obtenidos del archivo de Anatomía Patológica del Hospital Clínico de la Universidad Católica en el período Enero/1992 - Diciembre/2003. El total de casos estudiados fue de 357 de los cuales 116 comespondieron a MCT y 241 a no-MCT. En todas las biopsias revisadas se consignó el tipo histológico, el tamaño tumoral, la focalidad (uni o multifocal), la presencia de ganglios compro- metidos y la presencia o ausencia de tiroiditis inmunológica o hiperplasia tiroidea. Además se consignó la edad y sexo de los casos analizados. Para el análisis estadístico se usó la prueba de $\chi^{2}$. Resultados: Los MCT (tamaño promedio $=8,9 \mathrm{~mm})$ fueron en su totalidad carcinomas papilares (bien diferenciados= 109 (94\%), moderadamente diferenciados $=7(6 \%)$. Estos presentaron una alta frecuencia de multifocalidad que alcanzó al 30\% de la muestra (36/116 casos) y de ganglios linfáticos comprometidos al momento del diagnóstico que fue de 8,6\% (10/116). Los no-MCT presentaron una frecuencia de multifocalidad de $35,3 \%$ (85/241 casos) semejante al grupo MCT, pero un mayor porcentaje de ganglios comprometidos 18\% (44/241 casos). El grupo MCT presentó mayor prevalencia de de tiroiditis crónica e hiperplasia comparado con el grupo noMCT ( $15 \%$ vs $2,6 \%, p<0,001 ; 32,4 \%$ vs $3,4 \%, p<0,001)$. No se demostró diferencias por edad y sexo en los grupos estudiados. Conclusiones: Los MCT pueden presentarse como una enfermedad agresiva con metástasis ganglionares $\mathrm{y} / 0$ multifocalidad en alrededor de un tercio de los casos. La coexistencia de patología benigna asociada es un hecho frecuente de encontrar, la cual podría encubrir la presencia de un microcarcinoma. De allí que hacemos un llamado de alerta ante un posible cambio en el genio biológico del MCT tiroideo.

\section{MICROCARCINOMA TIROIDEO DE EVOLUCIÓN AGRESIVA CON AGREGACIÓN FAMILIAR}

Jiménez $M^{1}$, Mosso $L^{1}$, González $H^{3}$, Solar $A^{2}$, Torres $J^{2}$, FARDELLA $C^{1}$.

Departamentos de Endocrinología 1 , Anatomía Patológica ${ }^{2}$ y Sección Cirugía Cabeza y Cuello ${ }^{3}$. Hospital Clínico Universidad Católica. Pontificia .Universidad Católica de Chile.

El microcarcinoma diferenciado de tiroides (MCT) es una patología que clásicamente se ha considerado de pronóstico favorable con bajo riesgo de recurrencia y mortalidad, sin embargo, su tratamiento es actualmente un tema de amplia 
controversia. Algunos autores han planteado que estos tumores serían biológicamente inactivos y que incluso podrían ser observados clínicamente. Comunicamos el caso de una mujer con diagnóstico de MCT, con agregación familiar y evolución particularmente agresiva, para la historia natural clásicamente reportada. Caso clínico: Mujer de 21 años quien consultó por aumento de volumen cervical. Presentaba bocio, hormonas tiroideas normales y la ecografía mostraba tres nódulos tiroideos, el mayor de $7 \mathrm{~mm}$ con microcalcificaciones en su interior. Se realiza punción-biopsia bajo ecografía que demuestra cáncer papilar de tiroides. Se somete a tiroidectomía total resultando un foco de MCT (6x5x5 mm) y metástasis paratraqueales bilaterales. Recibe $200 \mathrm{mCi}$ de radioyodo ( $\left.\mathrm{I}^{131}\right)$ con rastreo sistémico post-dosis negativo. Tiroglobulina (TG) no fue de utilidad dada la presencia de anticuerpos antirimglobulina (AAT: $164 \mathrm{ng} / \mathrm{ml}$ ). Al 2o año de seguimiento la ecografía cervical detecta nódulo de 9,6 mm el cual no fue técnicamente posible de puncionar; se asociaba a un aumento de los títulos de AAT $(174 \mathrm{ng} / \mathrm{mL})$. Se administra $2^{\text {a }}$ dosis de $I^{131} 200 \mathrm{mCi}$ con rastreo, que muestra captación a nivel cervical. Ecografía de control al año post $2^{\underline{a}}$ dosis de $I^{131}$ detecta masa de $2 \mathrm{~cm}$ a nivel supraesternal central y 3 ganglios de $1 \mathrm{~cm}$ sospechosos en cadena cervical izquierda (contralateral a lesión primaria) asociada a un ascenso de los AAT (217 $\mathrm{ng} / \mathrm{ml}$ ). Se decide exploración quirúrgica, realizándose una disección selectiva de cuello bilateral de los niveles II, III, IV y $\mathrm{Vb}$ y una disección del nivel VI izquierdo y pretraqueal. La biopsia muestra compromiso ganglionar de los niveles IV y $\mathrm{Vb}$ derechos y de los niveles IIb, III, IV, Vb y VI izquierdo. Recibe $300 \mathrm{mCi}$ de $\mathrm{I}^{131}$ con rastreo post-dosis negativo y AAT se hacen negativos con una TG $<0,2 \mathrm{ng} / \mathrm{mL}$. Dado la evolución de la paciente, la familia solicita estudio tiroideo. La madre presenta a la ecografía tiroidea un nódulo de $7 \mathrm{~mm}$ que resulta MCT. Comentario: Este caso ilustra la necesidad de replantear el concepto acerca de la clásica benignidad atribuida a esta neoplasia, y junto a ello el enfrentamiento que el clínico debe tener en la patología micronodular del tiroides. Este llamado de alerta podría evitar retrasos en el diagnóstico y tratamiento del microcarcinoma tiroideo.

\section{UTILIDAD DE LA PTH INTRAOPERATORIA EN CIRU- GÍA DEL HIPERPARATIROIDISMO PRIMARIO (HPP): EXPERIENCIA HOSPITAL U. CATÓLICA}

Jiménez $M^{1}$, Rodríguez $C^{1}$, León $S^{2}$, Solar $A^{3}$, Arteaga $E^{1}$, Campusano $C^{1}$, López JM ${ }^{1}$, Mosso L ${ }^{1}$, Rodríguez JA ${ }^{1}$, Claure R ${ }^{4}$, González $\mathrm{H}^{4}$, GoÑ I ${ }^{4}$, León $A^{4}$, GonzÁlez $\mathrm{G}^{1}$.

Departamentos de Endocrinología1, Anatomía Patológica ${ }^{3}$, Cirugía 4 y Laboratorio Clínico ${ }^{2}$, Facultad de Medicina, Pontificia Universidad Católica de Chile.

En los últimos años se ha incorporado la medición de la PTH intraoperatoria (PTHi) para predecir el éxito de la cirugía en HPP. Sin embargo, su utilidad es controversial aún y la experiencia en nuestro medio es limitada. Objetivo: Validar el uso de PTHi en una serie de pacientes chilenos utilizando el protocolo original de Irvin (Ann Surg, 1994). Pacientes y Métodos: Se incluyeron todos los pacientes con HPP operados entre 09/03 a 08/04. El protocolo incluye dos muestras basales y muestras a los $+5 \mathrm{y}+10$ minutos, post resección de cada lesión sospechosa, para medir PTHi (ELECSYS, Roche). Se definió criterio de curación la caída de PTHi 50\% respecto al promedio de las muestras basales en adenoma único (AU) y de $75 \%$ en enfermedad multiglandular (MG). Se consideró regla de oro para la curación quirúrgica del HPP la nomocalcemia a las 24 horas, junto a la confirmación histológica contemporánea de resección de lesión paratiroidea. Resultados: 26 pacientes, edad 62,6ะ14,3 años, 21 de ellos mujeres y 62\% con HPP asintomático, han sido reclutados hasta la fecha. La calcemia preoperatoria fue de $12,2 \pm 1,7 \mathrm{mg} \%$. En 2 casos existía cirugía previa. Del total, 17 (65\%) fueron AU y 9 (35\%). enfermedad MG (1 caso por NEM1). El protocolo de PTHi anticipó la curación quirúrgica del HPP en el 100\% de los casos. En 3 pacientes cuya primera biopsia contemporánea fue negativa para tejido paratiroideo se mantuvo PTHi elevada hasta la resección de la lesión (dos de éstos en localización ectópica). A la fecha, 23 pacientes han sido seguidos con al menos un segundo control post operatorio (mediana 7 meses, intervalo 110 meses). De éstos, 21 están normocalcémicos y 2 casos (primer y tercer mes post cirugía) presentan hipercalcemia leve (10,6 y 10,8 mg\%) con PTH nomal, suginiendo HPP peristente.

Conclusiones: Nuestra serie demuestra la utilidad del protocolo utilizado de PTHi para certificar la curación quirúrgica del HPP. Una mayor experiencia permitirá definir la indicación de PTHi en la cirugía del HPP.

\section{PLASMOCITOMA SELAR REVELADOR DE UN MIELO- MA MÚLTIPLE}

Jurado M, Pierret T, Lois V, Osorio G.

Endocrinología, Servicio de Medicina, Hospital Barros Luco Trudeau

Introducción: El Mieloma Múltiple puede comprometer el Sistema Nervioso Central en forma de Plasmocitoma, comprimiendo diversas estructuras nerviosas. La ubicación de un Plasmocitoma en la silla turca, simulando un macroadenoma hipofisiario es extremadamente infrecuente.

Caso Clínico: Mujer, 54 años, ingresa el 8 de Diciembre de 1999, por síndrome tumoral de la región selar, caracterizado por cefalea, ptosis palpebral derecha y diplopia, de 2 meses de evolución. Resonancia Nuclear Magnética de silla turca revela proceso expansivo de $3,5 \mathrm{~cm}$, que compromete base de cráneo, piso selar, clivus y seno esfenoidal. Radiografía de cráneo; silla turca de contornos mal definidos y múltiples lesiones osteolíticas de calota. La paciente esta enflaquecida, Glasgow 15, afebril, signos vitales conservados. Los exámenes de laboratorio revelan: Cortisol 116 ug\% (N: 5-25) Prolactina 
$42 \mathrm{ng} / \mathrm{ml}$ (N:5-18) FSH 13,1 mU/ml (N: 42-126) LH 5,7 mU/ml (N: 11-50) T3 0,92 ng/ml (N: 0,8-1,8) T4 9,7 ng/ml (N: 8-12) TSH 1,22 uU/ml (N: 0,5-4,6) Glicemia 108 mg\% Nitrógeno 13 $\mathrm{mg} \%$ Calcemia 10,2 mg\% Hematocrito 46,8\% Hemoglobina 15,9 gr\% Leucocitos 4900 Plaquetas 300.000 VHS 3 mm/hora Orina: pH 6,5 D 1015 Proteínas trazas Glucosa (-) Antecedentes de osteoporosis grave, con múltiples fracturas y aplastamiento vertebral que le dificulta la marcha. Diagnóstico de ingreso: Macroadenoma Hipofisiario ¿Enfermedad de Cushing? ¿Mieloma Múltiple? Osteoporosis severa. Evoluciona con deterioro progresivo del estado general, anemización, aumento de VHS hasta $100 \mathrm{~mm} /$ hora, plaquetas bajan a 76.000, aparecen 9 plasmocitos y 3 eritroblastos en el frotis periférico. Cortisol AM 44,2 ug\% Cortisol PM 36,7 ug\% Cintigrama Oseo: aumento de actividad osteoblástica en calota, columna, parilla costal y pelvis. Mielograma: plasmocitosis medular. Electroforesis de proteínas plasmáticas: hipogammaglobulinemia severa, ausencia de pick monoclonal. Aparece compromiso respiratorio y neurológico, fallece el 5 de Enero del 2000. Anatomía patológica concluye: Mieloma Múltiple, Plasmocitoma de silla turca, Osteoporosis.

Conclusión: Consideramos este caso de particular importancia por su rareza y dificultad diagnóstica.

\section{ELEVACIÓN DEL CORTISOL URINARIO LIBRE EN PACIENTES HIPERTENSOS: POSIBLE MECANISMO ETIOPATOGÉNICO}

Krall P, Mosso L, Carvajal C, Fardella C.

Departamento de Endocrinología, Facultad de Medicina, Pontificia Universidad Católica de Chile.

Los glucocorticoides cumplen un papel clave en el control de la presión arterial (PA) y se asocian a hipertensión en pacientes con síndrome de Cushing. El cortisol (F) puede desencadenar un aumento de la presión arterial al unirse al receptor de mineralocorticoides, gatillando la reabsorción de sodio y agua en los túbulos renales distales. Objetivo: Evaluar la excreción de F urinario libre (FUL) como potencial marcador fenotípico de hipertensión esencial y comelacionar los niveles de FUL con la actividad de renina (ARP) y aldosterona (AP) plasmáticas. Pacientes y Métodos: Estudiamos 132 hipertensos esenciales (HT) y 16 normotensos (NT) de edades y sexo comparables. En todos ellos, se tomaron muestras de sangre y orina de 24 horas para análisis de FUL, ARP y AP. Las diferencias entre sexos fueron normalizadas con la excreción de creatinina (Cr). El valor límite superior de FUL se determinó en el grupo de NT considerando como valor máximo normal el promedio + 2SD. De acuerdo a este valor los HT fueron divididos en FUL alto y FUL normal-bajo; pacientes con FUL alto fueron citados para medición de ACTH y realización de TAC en caso de sospecha de adenomas o tumores adrenales. Resultados: Los valores de FUL/Cr en HT y NT resultaron $36,9 \pm 17,0$ y $30,9 \pm 8,8 \mu \mathrm{g} / \mathrm{gr}$, respectivamente. El valor máximo normal resultó $48,5 \mu \mathrm{g} / \mathrm{gr}$, de acuerdo a lo definido en métodos. Detectamos 20/132 pacientes HT (15\%) y 0/16 NT con FUL alto. Los pacientes HT con FUL alto presentaron menor nivel de ARP que aquellos con FUL normal-bajo $(0,8 \pm 0,5$ vs $1,1 \pm 0,7 \mathrm{ng} / \mathrm{ml} * \mathrm{~h}, \mathrm{p}=0,027)$ y menor nivel de AP $(4,5 \pm 1,7$ vs $6,3 \pm 3,4 \mathrm{ng} / \mathrm{dl}, \mathrm{p}=0,018)$. El grupo de hipertensos con FUL alto presentó un mayor porcentaje de pacientes hiporreninémicos ( $\mathrm{ARP}<1 \mathrm{ng} / \mathrm{ml}$ *hr) y de pacientes hipoaldosterónicos (AP $<5 \mathrm{ng} / \mathrm{dl}$ ) que el grupo con FUL normalbajo ( $50 \%$ vs $21 \%, p=0.016 ; 70 \%$ vs $39 \%, p=0,021$ ). Cuatro de los 17 pacientes que continuaron el estudio presentaron niveles suprimidos de ACTH $(<10 \mathrm{pg} / \mathrm{ml}) ;$ los 13 pacientes restantes presentaron valores normales. Las tomografías de los cuatro pacientes resultaron negativas para adenomas 0 tumores adrenales mayores a $3 \mathrm{~mm}$. Conclusiones: En nuestro estudio logramos identificar un subgrupo de hipertensos esenciales con aumento en la excreción urinaria de cortisol, que se asoció a niveles disminuidos de renina y aldosterona plasmática. Estos datos sugieren que el cortisol podría estar implicado en la génesis de la hipertensión arterial mediante una acción mineralocorticoidea. La etiología del hipercortisolismo en estos pacientes aún no ha sido determinada.

Financiado por Proyecto FONDECYT 104-0834.

\section{ROL DEL POLIMORFISMO IVS8+242 T>C EN GEN DEL RECEPTOR DE GLUCOCORTICOIDE EN HIPER- TENSIÓN ARTERIAL}

Krall P, Mosso L, Carvajal C, Fardella C.

Departamento de Endocrinología, Facultad de Medicina, Pontificia Universidad Católica de Chile.

El gen del receptor de glucocorticoide (NR3C1-OMIM: 138040) ha sido ampliamente estudiado con el objetivo de encontrar polimorfismos y/o mutaciones, que expliquen la aparición de patologías como la resistencia a glucocorticoides e hipertensión esencial. Recientemente reportamos la existencia de un subgrupo de pacientes hipertensos esenciales con niveles de cortisol (F) urinario elevado, asociado a supresión de renina y aldosterona, perfil compatible con el de la resistencia a glucocorticoides. En un estudio preliminar de secuenciación de dichos pacientes, detectamos un polimorfismo en el gen del receptor de glucocorticoides (IVS8+242 T>C) no reportado anteriormente, cuyo rol en la hipertensión pretendemos definir. Objetivo: Evaluar el rol del polimorfismo IVS8+242 $\mathrm{T}>\mathrm{C}$ del gen de receptor glucocorticoideo (RG) en hipertensos esenciales; analizar en estos pacientes, la asociación de los niveles de $\mathrm{F}$ urinario libre (FUL), actividad de renina y aldosterona plasmáticas con la presencia/ausencia de la variante C. Pacientes y Métodos: Se estudiaron 111 hipertensos esenciales (HE) y 37 normotensos (NT) de edades y sexos comparables. Para todos ellos se tomaron muestras de sangre y orina de $24 \mathrm{hrs}$ para determinar actividad de renina (ARP), aldosterona plasmática (AP) y FUL. Se aisló DNA genómico a partir de leucocitos para 
determinar la presencia/ausencia de la variante $\mathrm{C}$ en cada individuo mediante la técnica PCR-RFLP. Para ello se usó la enzima de restricción TspRI, que reconoce y corta la variante C. La distribución genotípica y alélica fue comparada en HE y NT por test de $\chi^{2}$. El grupo HE fue dividido en pacientes C+ y pacientes C- y se compararon los parámetros clínicos y bioquímicos por test de Mann-Whitney. Resultados: Los pacientes HE presentaron una menor prevalencia de la variante $C$ (individuos $C+36 / 111 \cong 32 \%$ ) que los NT (individuos $C+15 / 37 \cong 41 \%)$, pero sin significancia estadística $\left(\chi^{2}=0,489 ; 1\right.$ g.l.; $\left.p=0,485\right)$. No se encontraron diferencias significativas entre hipertensos esenciales $\mathrm{C}+\mathrm{y} \mathrm{C}$ - en los niveles de FUL, AP y ARP. Los grupos de HE y NT cumplen con el Equilibrio de Hardy-Weinberg. Conclusiones: Nuestros resultados reportan la existencia de un nuevo polimorfismo en el gen del RG de alta prevalencia ( $35 \%)$ en la población chilena estudiada. Si bien, inicialmente, detectamos el polimorfismo IVS8+242 $\mathrm{T}>\mathrm{C}$ en HE con un perfil sugerente de resistencia a glucocorticoides, demostramos que la presencia de éste no es exclusiva de dichos pacientes y por lo tanto no constituye un factor de riesgo para hipertensión, ni se relaciona con los niveles de $\mathrm{F}$ urinario libre.

Financiado por Proyecto FONDECYT 104-0834.

\section{ANÁLISIS DE MUTACIONES DE LA PROTEINA G $\alpha$ EN PACIENTES CON MUERTE SÚBITA}

López $\mathrm{P}^{1,2}$, Boric $M A^{1}$, Johnson MC ${ }^{1}$, Román $\mathrm{R}^{1,2}$, Gallo $\mathrm{M}^{4}$, Ponce $\mathrm{C}^{3}$, Vargas $\mathrm{S}^{3}$, Codner $\mathrm{E}^{1}$, Cassorla $\mathrm{F}^{1}$.

Instituto de Investigaciones Materno Infantil ${ }^{1}$, Hospital Clínico San Borja Arriarán², Instituto de Ciencias Biomédicas ${ }^{3}$, Universidad de Chile y Servicio Médico Legal ${ }^{4}$.

El síndrome de muerte súbita del lactante es un importante problema de salud pública, en el cual diversos factores infecciosos, metabólicos y/o neurológicos podnian estar involucrados.

Mutaciones del gen GNAS1 que codifica a la proteína G $\alpha$ s son causales del síndrome de McCune Albright y se han detectado en diversos órganos de pacientes que muestran hipersecreción hormonal, en especial pubertad precoz. Además, se han documentado estas mutaciones en pacientes pediátricos gravemente enfermos con alteraciones hepáticas y cardíacas que han fallecido por esta causa.

El propósito de nuestro trabajo fue estudiar la posible presencia de mutaciones del gen GNAS1 en diversos tejidos de niños con síndrome de muerte súbita.

Sujetos y Método: Muestras de tejidos de 27 niños fallecidos por muerte súbita idiopática, sin signos de pubertad precoz, displasia esquelética, o lesiones sugerentes de síndrome de McCune Albright fueron obtenidas del Servicio Médico Legal. Se analizaron las mutaciones R201H y R201C del gen GNAS1 por PCR seguida de digestión enzimática y PCR alelo específico, respectivamente. Se estudió la mutación en DNA obtenido retrospectivamente de tejido pulmonar $(n=20)$ y prospectivamente $(\mathrm{n}=7)$ de tejido pancreático, hepático, renal y cardíaco.

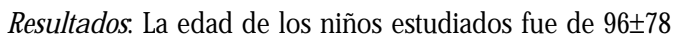
días y el 55\% correspondió a niñas. Los estudios moleculares no detectaron la presencia de mutaciones R201H y R201C del gen GNAS1en ninguno de los tejidos analizados.

Conclusión: Las mutaciones R201H y R201C del gen GNAS1 no están presentes en los tejidos estudiados obtenidos de niños con muerte súbita. Sin embargo, no se puede descartar la presencia de otras mutaciones descritas en el codón 201 de este gen. Estamos estudiando un número mayor de niños con muerte súbita para confirmar estos resultados.

\section{FUNCIÓN GONADAL DURANTE LA NIÑEZ TEMPRA- NA EN HIJOS/AS DE MUJERES CON SÍNDROME DE OVARIO POLIQUÍSTICO (SOP)}

Maliqueo $M^{1}$, Codner $E^{2}$, Hitschfeld $C^{1}$, Vera $P^{1}$, Avila $A^{2}$, Echiburú $\mathrm{B}^{1}$, Cassorla $\mathrm{F}^{2}$, Sir Petermann $\mathrm{T}^{1}$.

${ }^{1}$ Laboratorio de Endocrinología y Metabolismo, Facultad de Medicina Occidente, Universidad de Chile, ${ }^{2}$ Instituto de Investigaciones Materno Infantil (IDIMI), Facultad de Medicina Centro, Universidad de Chile.

Introducción: Se ha planteado, que la exposición prenatal a andrógenos tendría consecuencias deletéreas sobre la función reproductiva en la vida postnatal. Recientemente, hemos establecido que las embarazadas SOP presentan niveles elevados de andrógenos los cuales podrían modificar la función gonadal del feto. Objetivo: Evaluar la función del eje reproductivo mediante un test de análogo de $\mathrm{GnRH}$ entre el segundo y tercer mes de vida (minipubertad postnatal) en 6 hijos y 8 hijas de mujeres con SOP y en 9 hijos y 8 hijas de mujeres normales. Pacientes y Métodos: Se administró un bolo de acetato de leuprolide (10 ug/kg s.c.) y se tomaron muestras a las 0, 3 y 24 hrs para la determinación de gonadotrofinas, estradiol, $17 \mathrm{OH}$ progesterona, testosterona, androstenediona y SHBG. Los datos se expresan en promedio \pm EEM. Resultados: Los grupos estudiados no presentaron diferencias clínicas. Las concentraciones basales de gonadotrofinas y esteroides sexuales fueron comparables entre los hijos/as SOP y los hijos/as controles. No obstante, la testosterona post estímulo fue más baja en los hijos SOP respecto a los controles $(0,89 \pm 0,10 \mathrm{ng} / \mathrm{ml}$ vs $1,18 \pm 0,08 \mathrm{ng} / \mathrm{ml}$; $\mathrm{p}=0,045)$ y la concentración de estradiol post estímulo fue más alta en las hijas SOP en comparación a las hijas controles $(73,49 \pm 32,89 \mathrm{pg} / \mathrm{ml}$ vs $25,08 \pm 6,83 \mathrm{pg} / \mathrm{ml} ; \mathrm{p}<0,01)$. Conclusiones: Estos datos sugieren que tanto los hijos como las hijas de madres SOP presentan alteraciones de la esteroidogénesis gonadal, se evidencian en el hombre por un menor nivel de testosterona, mientras que en las niñas por una excesiva producción de estrógenos.

FONDECYT 1030487 


\section{UN SÍNDROME DE RETARDO MENTAL SEVERO LIGADO AL CROMOSOMA X DEBIDO A UNA MUTACIÓN EN UN TRANSPORTADOR DE HOR- MONAS TIROIDEAS: UN MECANISMO NUEVO DE RESISTENCIA A HORMONAS TIROIDEAS}

Mancilla EE 1 , Friesema ECH ${ }^{2}$, Cattani $A^{3}$, Visser T) ${ }^{2}$.

${ }^{1}$ Programa de Fisiología, ICBM, Facultad de Medicina, Univ de Chile, Santiago, Chile; ${ }^{2}$ Dept of Internal Medicine, Erasmus MC, Rotterdam, Netherlands; ${ }^{3}$ Depto de Pediatría, P.Universidad Católica de Chile.

El MCT8 es un transportador específico de hormonas timideas cuyo gen se encuentra en el cromosoma X. El desamollo pre y postnatal del SNC requiere de la acción intracelular de las hormonas tiroideas, especialmente de T3. El transporte de T3 hacia el interior de las neuronas es necesario para la unión de la hormona a su receptor y su deiodinización por D3. Se describe un niño con un síndrome de retardo mental severo y niveles elevados de T3 causado por una mutación de MCT8. Pacientey Métodos: El paciente fue el primer hijo de padres no consanguíneos. Durante los primeros meses de vida se pesquisó un retraso del desarrollo psicomotor e hipotonía, lo cual fue más evidente a mayor edad. Su curva de crecimiento se mantuvo entre el 10-25\% para talla y cercana al 5\% para peso. Agregado a su patología neurológica se diagnosticó acidosis tubular renal tipo IV y se trató esta patología. Los exámenes de función tiroidea iniciales fueron: TSH neo: 8,3 $\mu \mathrm{U} / \mathrm{ml}$. A la edad de 5 1/2 meses: T4 3,9 $\mu \mathrm{g} / \mathrm{dl}$ (Normal (N): 4,7-11,5), T3 $213 \mathrm{ng} / \mathrm{dl}(\mathrm{N}: 80-220)$, TSH 5,13 $\mu \mathrm{U} / \mathrm{ml}$ (N:0,38-6,15). Se trató con l-tiroxina con lo cual mantuvo niveles normales de TSH, niveles elevados de T3 y niveles bajos de T4. Sin tratamiento a la edad de 1 año 9 meses sus exámenes fueron: T3 425 ng/dl (N:103,9-266,2), TSH 7,12 $\mu$ Uml (N:0,7-5,7), T4 libre $0,8 \mathrm{ng} / \mathrm{dl}(\mathrm{N}: 0,8-2,1), \mathrm{T} 3$ reversa $0,08 \mathrm{nmol} / \mathrm{l}(\mathrm{N}: 0,18-0,51)$, T3 libre 6,5 pg/ml (N:2,3-4,2), TBG $23 \mu \mathrm{g} / \mathrm{ml}$ (N:12-26). Un estudio metabólico extenso por el retardo del desarrollo psicomotor fue negativo y, como parte del estudio de la función tiroidea, se investigó la posibilidad de una mutación del gen de MCT8. La secuencia codificante del gen MCT8 se analizó por PCR de los 6 exones usando partidores intrónicos y secuenciación directa de los productos, con un subsiguiente análisis del locus de MCT8 por PCR. Resultados: El análisis del gen MCT8 mostró una deleción de 2,4 kb, comprometiendo parte del exón 3, todo el intrón 3 y el exón 4, y parte del intrón 4 . La madre resultó ser portadora de la misma mutación. Conclusiones: Se describe el caso clínico y el estudio molecular de un niño con un síndrome recientemente descrito de retardo severo del desarrollo psicomotor ligado al cromosoma $\mathrm{X}$ debido a un defecto del transporte de hormonas tiroideas al interior de las neuronas a través de MCT8. Esta reducción en la entrada de T3 hacia las neuronas altera el desarmollo del SNC y se asocia al perfil de hormonas tiroideas que presenta este niño.

\section{COMPOSICIÓN CORPORAL, SENSIBILIDAD Y SECRE- CIÓN DE INSULINA AL INICIO DEL DESARROLLO PUBERAL EN NIÑAS PEG Y AEG: RESULTADOS PRELI- MINARES}

Martínez $A^{1}$, Capurro $T^{1}$, Peña $V^{1}$, Iñiguez G1, Avila $A^{1}$, Salazar $\mathrm{T}^{1}$, Asenjo $\mathrm{S}^{2}$, MericQ $\mathrm{V}^{1}$.

${ }^{1}$ Instituto de Investigaciones Materno Infantil, Facultad de Medicina, Universidad de Chile; ${ }^{2}$ Endocrinología Infantil, Universidad de Concepción.

Existe evidencia que asocia el bajo peso de nacimiento con una disminución en la sensibilidad a insulina en la vida postnatal. Una de las hipótesis es que esta condición podría ser gatillada por una adquisición de composición corporal metabólicamente adversa.

Objetivo: Determinar si al inicio del desarrollo puberal existen diferencias en la composición corporal y la sensibilidad insulínica entre niñas pequeñas PEG y adecuadas para la edad gestacional (AEG).

Paciente y método: Se diseñó un estudio longitudinal en una muestra piloto con 58 niñas de la comunidad, sanas, de las comunas de Santiago Centro y Concepción, con estadio Tanner II de mamas e Índice de Masa Corporal (IMC) entre los percentiles 10 y 95. Se realizó antropometría, plicometría y bioimpedianciometría para grasa corporal (GC). Después de un ayuno noctumo de 12 horas se realizó Test de Tolerancia Oral a la Glucosa, determinando los niveles séricos de Insulina (In) y glucosa (Gl) a los 0', 30' y 120'. Se calculó HOMA-IR e Índice Insulinogénico (IIn). Resultados: Fuemon PEG 18 niñas (PRN 2356 \pm 585 g) y 40 niñas fueron AEG (PRN $3338 \pm 341 \mathrm{~g}$, p value $<0,001$ ) (Tabla 1).

En las niñas PEG no se observó correlación (Spearman) entre HOMA, In-basal, I-In e IMC, GC, suma de pliegues, perímetro abdominal ni relación cintura-cadera. En cambió en

Tabla 1.

\begin{tabular}{|lcccccccc|}
\hline & Edad & $\begin{array}{c}\text { Edad } \\
\text { ósea }\end{array}$ & $\begin{array}{c}\text { Talla } \\
\text { z-score }\end{array}$ & $\begin{array}{c}\text { IMC } \\
\text { z-score }\end{array}$ & $\begin{array}{c}\% \text { Grasa } \\
\text { Corporal }\end{array}$ & $\begin{array}{c}\text { In-basal } \\
\text { mUI/ml }\end{array}$ & HOMA & I-In \\
\hline AEG & $9,6 \pm 1,0$ & $9,7 \pm 1,0$ & $-0,40 \pm 1$ & $0,43 \pm 0,8$ & $27,3 \pm 5,0$ & $11,7 \pm 1,2$ & $2,45 \pm 0,29$ & $2,2 \pm 0,7$ \\
PEG & $9,9 \pm 0,8$ & $9,9 \pm 0,5$ & $-0,44 \pm 1$ & $0,46 \pm 0,8$ & $27,1 \pm 5,2$ & $13,3 \pm 1,0$ & $2,59 \pm 0,23$ & $2,6 \pm 0,6$ \\
p & NS* & NS* & NS* & NS* & NS(\&) & $0,042^{*}$ & NS* & $0,014^{*}$ \\
\hline
\end{tabular}

Prueba de Student (\&); U de Mann-Whitney (*). 
las niñas AEG se observó correlación entre HOMA e IMC ( $p$ value $=0,007) ; \%$ GC ( $p$ value $=0,019$ ) y suma de pliegues ( $p$ value $=0,019$ ).

Conclusiones: Durante el inicio puberal en un grupo de niñas sanas de la comunidad, se observó una mayor insulinemia basal e índice insulinogénico en las niñas PEG, a pesar de tener similar composición corporal (IMC y $\%$ de GC) que las niñas AEG. Estos resultados sugieren que la sensibilidad y secreción de insulina parecen estar determinadas por el efecto combinado del PRN y distribución de la grasa corporal que podría explicar la diferencia en el comportamiento de estas variables ente los PEG y AEG.

FONDECYT 1030610

\section{EVOLUCIÓN DE LOS TRABAJOS CIENTÍFICOS EN- DOCRINOLÓGICOS EN CHILE. ANÁLISIS DE LA ÚLTIMA DÉCADA}

Martínez A, Eyzaguirre F, Morales O, Pérez F, Wohllk N, Gajardo H, García H.

Comité Editorial Página Web. Sochem, Univ.de Chile.

Objetivo: Conocer algunas características de los trabajos de investigación presentados durante los últimos años en las jomadas y congresos de la SOCHEM. Diseño: Estudio retrospectivo, descriptivo. Unidad de observación: Libro de resúmenes de los diferentes Congresos y Jomadas de la SOCHEM. Material y Método: A partir de los libros de Jomadas y Congresos realizados entre 1993 y 2003 se obtuvieron los siguientes datos: Universidad, Hospital o Centro de Investigación, naturaleza del trabajo (básico, básico-clínico o clínico), el diseño del estudio; si fue colaborativo, tipo de financiamiento y el tipo de población estudiada (adulto o pediátrico). Resultados: Se evaluaron 778 trabajos presentados (poster $y / 0$ oral). Las tres Universidades que más trabajos han publicado fueron la Universidad de Chile 51,3\%, Universidad Católica 25,8\% y Universidad de Concepción 8,9\%; otros centros 14\%, destacando Clínicas Privadas 3,0\% y Universidad de la Frontera 2,6\%; Chi-cuadrado $\left(\chi^{2}\right), p<0,001$. La naturaleza de los trabajos fueron: Investigación básica 10,2\% (1,2-19,7\%); clínico-básica 12,6\% (4,7-20\%) y Clínica 77,2\% $(66,7-86,9 \%) ; \chi^{2}, \mathrm{p}<0,001$. Los tipos de diseños fueron descriptivos 28,5\% (10,9-44\%); corte transversal 19\% (13-31,2\%); analítico-prospectivo 18,5\% (12,5-25,7\%); casos clínicos 16,1\%

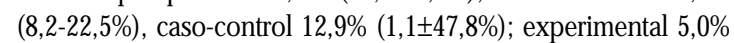
$(1,6-18,4 \%) ; \chi^{2}, p<0,001$. Fueron estudios colaborativos nacionales $18,3 \%(6,6-28,1 \%)$ e internacionales $4,9 \%(1,2-12,3 \%) ; \chi^{2}$, $\mathrm{p}<0,001$. El tipo de financiamiento reportado fue: FONDECYT $23,7 \%(13,4-36,1 \%)$, proyectos universitarios $4,1 \%(1,1-8,6 \%)$, SOCHEM 1,3\% (1,1-4,7\%), industria farmacéutica 1,5\% (1,1$4,7 \%)$, fundaciones nacionales $0,5 \%(0,5-2,2 \%)$ y extranjeras $1,3 \%(1,1-7,5 \%)$. No reportó financiamiento el 67,6\% (53,8-82\%); $\chi^{2}, \mathrm{p}<0,001$. El tipo de población estudiada fueron adultos $75,7 \%$ (59,3-85,4\%), pediátricos 24,3\% (14,6-40,7\%); $\chi^{2}, p$
$<0,001$. Sin embargo, durante el periodo estudiado han aumentado los trabajos pediátricos con una comelación de Spearman= t0,791, $p=0,004$; disminuyendo los trabajos en adultos Spearman $=-0,791, p=0,004$. En la población pediátrica el tópico relacionado con Diabetes Mellitus fue el más frecuente 22,9\%, $p$ $<0,001$; y en la población de adultos fue en relación a patología tiroidea 25\%, p <0,001. Comentarios: Durante los últimos 10 años, la mayońa de los trabajos que han sido presentados pertenecen a la Universidad de Chile, de tipo clínicos y descriptivos. En forma progresiva se observa un incremento en la proporción de trabajos realizados en la población pediátrica. Es necesario mejorar el formato de los resúmenes, señalando las características de los trabajos y la nota de evaluación realizada por el Comité Científico. Posteriormente sería útil su almacenamiento en una base de datos que permita en el futuro una evaluación más expedita de nuestros congresos y de esa forma mejorar la calidad de los trabajos presentados.

\section{MAYOR FRECUENCIA DE PUBARQUIA AL INICIO DEL DESAROLLO PUBERAL EN NIÑAS PEQUEÑAS PARA LA EDAD GESTACIONAL}

Martínez $A^{1}$, Peña $V^{1}$, Iñiguez $G^{1}$, Avila $A^{1}$, Salazar $T^{1}$, Capurro $\mathrm{T}^{1}$, ASENJO $\mathrm{S}^{2}$, MERICQ $\mathrm{V}^{1}$.

${ }^{1}$ Instituto de Investigaciones Materno Infantil, Facultad de Medicina, Universidad de Chile; ${ }^{2}$ Endocrinología Pediátrica, Universidad de Concepción.

Se ha sugerido que la programación de la secreción de andrógenos postnatales ocurriría durante la vida fetal, y que en los casos de restricción de crecimiento intrauterino existiría mayor riesgo de hiperandrogenismo suprarrenal y ovárico.

Objetivo: Comparar las características clínicas, edad ósea y niveles séricos de DHEA-S y Androstenediona (A2) entre niñas pequeñas (PEG) y adecuadas para la edad gestacional (AEG) al comienzo del desarrollo puberal.

Paciente y método: Se diseñó un estudio longitudinal en una muestra piloto con 58 niñas de la comunidad, sanas, de las comunas de Santiago Centro y Concepción, con estadio Tanner II de mamas e Índice de Masa Corporal (IMC) entre los percentiles 10-95. Se realizó antropometría y bioimpedianciometría para grasa corporal y se consignó la presencia de vello axilar, olor apocrino y estadio de Tanner para vello púbico. Después de un ayuno nocturno de 12 horas se realizó Test de Tolerancia Oral a la Glucosa determinando los niveles séricos de Insulina (In) y glucosa (Gl) a los 0', 30' y 120'. Se calculó HOMA-IR, Índice Insulínico (I-In). Se midieron los niveles séricos de Androstenediona (RIA) y de DHEA-S (RIA) y se realizó radiografía de carpo para edad ósea.

Resultados: Fueron PEG 18 niñas (PRN 2356 \pm 585 g) con

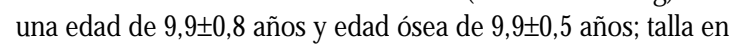
z-score $-0,44 \pm 1,3$. Fueron AEG 40 niñas (PRN 3338 $\pm 341 \mathrm{~g}, \mathrm{p}$ 
Tabla 1.

\begin{tabular}{|c|c|c|c|c|c|c|c|}
\hline & \multirow{2}{*}{$\begin{array}{l}\text { Olor } \\
\text { Axilar }\end{array}$} & \multirow{2}{*}{$\begin{array}{l}\text { Vello } \\
\text { Axilar }\end{array}$} & \multicolumn{3}{|c|}{ Tanner vello púbico (\%) } & \multirow{2}{*}{$\begin{array}{c}\mathrm{A} 2 \\
\mathrm{ng} / \mathrm{ml}\end{array}$} & \multirow{2}{*}{$\begin{array}{c}\text { DHEA-S } \\
\mathrm{ng} / \mathrm{dl}\end{array}$} \\
\hline & & & I & II & III & & \\
\hline AEG & $60,0 \%$ & $10,0 \%$ & $65,0 \%$ & $32,5 \%$ & $2,5 \%$ & $0,91 \pm 0,29$ & $515 \pm 342$ \\
\hline PEG & $61,1 \%$ & $22,2 \%$ & $38,9 \%$ & $38,9 \%$ & $22,2 \%$ & $0,97 \pm 0,39$ & $585 \pm 362$ \\
\hline$P$ value & 0,586* & 0,198* & $0,027^{* *}$ & $0,98 \bullet$ & $0,63 \bullet$ & & \\
\hline
\end{tabular}

Test de Fisher (*); $\chi^{2}$ de pearson (**);U de Mann-Whitney $(\bullet)$

value $<0,001)$. No hubo diferencias en edad $(9,6 \pm 1$ años), edad ósea $(9,7 \pm 1$ años) ni talla (z-score $-0,40 \pm 1)$ entre las AEG y PEG (Tabla 1).

Observamos pubarquia en una mayor proporción de niñas PEG al inicio del desarrollo puberal comparado con las AEG, sin embargo este hallazgo no se correlacionó con los niveles séricos de andrógenos estudiados. En las niñas PEG, con y sin pubarquia, no hubo diferencias en los niveles de A2 ni DHEA-S como tampoco con HOMA e I-In. Este hallazgo sugiere que genes que modulan la expresión clínica de la aparición del vello pubiano podrían ser expresado en forma diferencial en niñas expuestas a retraso de crecimiento fetal.

FONDECYT 1030610.

\section{TAMAÑO UTERINO, VOLUMEN OVÁRICO Y PA- TRÓN FOLICULAR EN NIÑAS PEQUEÑAS PARA LA EDAD GESTACIONAL (PEG), AL INICIO DEL DESA- RROLLO PUBERAL: RESULTADOS PRELIMINARES}

Martínez $A^{1}$, Peña V, Pommer $R^{1}$, Iñiguez $G^{1}$, Avila $A^{1}$, Salazar $T^{1}$, VIÑALS F, ASENJO S ${ }^{2}$, MERICQ V ${ }^{1}$.

${ }^{1}$ Instituto de Investigaciones Materno Infantil, Facultad de Medicina, Universidad de Chile; 'Endocrinología Infantil, Universidad de Concepción.

Introducción: Existe evidencia que asocia menor peso de nacimiento con menor número de folículos primordiales, tamaño uterino y volumen ovárico e hiperandrogenismo y anovulación durante la adolescencia. Sin embargo, estos estudios poseen sesgo: son transversales, incluyen sólo una etnia, provienen de un solo grupo científico (Ibáñez y cols) y no han sido replicados.

Objetivo: Estudiar las características de tamaño uterino, volumen ovárico y patrón folicular entre niñas PEG y adecuadas para la edad gestacional (AEG) al inicio del desarrollo puberal. Material y método: Se diseñó un estudio longitudinal en una muestra piloto con 56 niñas de la comunidad, sanas, de las comunas de Santiago Centro y Concepción, con estadio Tanner II de mamas e Índice de Masa Corporal (IMC) entre los percentiles $10 \mathrm{y}$ 95. Con vejiga llena, se realizó ecotomografía pélvica transabdominal utilizando un equipo Medison 6000 con un transductor de 3,5 Mhz y VOLUSON730 Expert. General Electric Transductor 5-8MHZ. Se obtuvo la longitud uterina (LU), área uterina (AU=Longitud * diámetro antero-posterior), volumen ovárico (VO), número de foliculos (NF), volumen folicular promedio (VFP).

Resultados: 17 niñas fueron PEG (PRN 2328 $\pm 606 \mathrm{~g}$ ) y 39 niñas fueron AEG (PRN 3339 $\pm 345 \mathrm{~g}, \mathrm{p}$ value $<0,001$ ). Se observó $>6$ folículos en el $37,5 \%$ de las PEG y en el $25,6 \%$ de las AEG (Test de Fisher, $p=0,286$ ) y $>10 \mathrm{~mm}$ en el $12,5 \%$ de las PEG y en el 7,7\% de las AEG (Test de Fisher; $p=0,45$ ) (Tabla 1).

Conclusiones: Nuestros resultados preliminares muestran que en niñas PEG de la comunidad, al inicio del desarmollo puberal, no se observan diferencias en las características de los genitales intemos comparadas con las niñas AEG. El seguimiento longitudinal de los genitales internos de estas pacientes durante la pubertad, acoplado a las pruebas de función ovárica secuencial nos permitirán conclusiones más definitivas sobre el efecto del PRN y la función gonadal durante la pubertad.

FONDECYT 1030610

Tabla 1.

\begin{tabular}{|c|c|c|c|c|c|c|c|}
\hline & \multicolumn{3}{|c|}{ Características Clínicas } & \multicolumn{4}{|c|}{ Características Del Estudio Ecográfico } \\
\hline & Talla (z-score) & $\mathrm{EC}$ & EO & $\mathrm{LU}, \mathrm{mm}$ & $\mathrm{AU}, \mathrm{mm}^{2}$ & $\mathrm{VO}, \mathrm{cc}$ & NF \\
\hline PEG & $-0,54 \pm 1,3$ & $10,1 \pm 0,8$ & $10,2 \pm 0,9$ & $34,4+11,4$ & $455 \pm 401$ & $2,8 \pm 1,7$ & $4(0-15)$ \\
\hline AEG & $-0,42 \pm 1,0$ & $9,6 \pm 1,0$ & $9,7 \pm 1,9$ & $30,9 \pm 7,0$ & $317 \pm 160$ & $2,4 \pm 1,4$ & $4(0-20)$ \\
\hline $\mathrm{p}$ & $0,719 *$ & 0,095* & $0,198 * *$ & $0,464^{* *}$ & $0,265^{* *}$ & $0,574^{* *}$ & $0,902^{* *}$ \\
\hline
\end{tabular}

Prueba de Student (*); Mann-Whitney(**); NF se expresó en mediana (rango). 


\section{TRASTORNOS DE CONDUCTA ALIMENTARIA $Y$ MANIPULACIÓN DEL TRATAMIENTO DE DIABE- TES MELLITUS TIPO 1 (DM1) UTILIZANDO UNA NUEVA HERRAMIENTA}

\begin{abstract}
Martínez A ${ }^{1}$, Gleisner A ${ }^{2}$, Fernández $\mathrm{D}^{3}$, Pérez $\mathrm{V}^{4}$, Codner $\mathrm{E}^{1}$. ${ }^{1}$ Instituto de Investigaciones Materno Infantil, Facultad de Medicina, Universidad de Chile. ${ }^{2}$ Endocrinología Pediátrica, Facultad de Medicina, Universidad de Concepción; ${ }^{3}$ Psicóloga, ${ }^{4}$ Endocrinología Pediátrica del Hospital Sótero del Río, Santiago; Chile.
\end{abstract}

EL \iabetes Eating Problem Survey, 2001» (DEPS) es una encuesta recientemente diseñado para individuos con DM1. El «Eating Attitudes Test-26» (EAT-26) constituye un cuestionario altamente eficiente en identificar Trastornos de la Conducta Alimentario (TCA) en la población general; pero no evalúa la omisión y manipulación de las dosis de insulina. Objetivos: Evaluar la presencia TCA en adolescentes con DM1 y compararlos con un gran grupo control. Determinar sí existe asociación entre control metabólico (HbA1c) y el Índice de Masa Corporal (IMC) y TCA. Material y métodos: El Universo estuvo constituido por adolescentes con DM1 $(\mathrm{N}=216)$ que fueron reclutados durante sus controles en Hospitales Públicos y en Campamentos de Verano, donde se aplicaron el EAT-26 y DEPS. El grupo control (C) fueron 648 individuos sin DM1 que contestaron el EAT-26. Se ha considerado como sugerente de TCA un puntaje $\geq 40 \mathrm{y}$ en el $D E P S ~ \geq 20$ puntos. Se informa los resultados de una muestra pareada por edad (DM1, $n=180$ y C, $n=270$ ). Resultados: De los pacientes con DM1 un $17,2 \%$ tuvo un DESP $\geq 40$ (Comparado con EAT-26 alterado en $\mathrm{C}, \mathrm{p}=0,7$ ). La concordancia entre DEPS y EAT-26 en DM1 fue de un 41,9\% (Cohen's Kappa Test, $\mathrm{p}$ value=0,37) (Tabla 1).

Con el objeto de disminuir de peso un 8,3\% de DM1 y 9,6\% de $\mathrm{C}$ se provocan vómitos $(\mathrm{p}=0,38)$. Del grupo con $\mathrm{DM} 1$ : Omiten insulina 54,4\%; permanecen en hiperglicemia 6,7\%. Los individuos con DEPS $>40$ y DEPS $<40$ tuvieron HbAlc de $9,2 \pm 1,4 \%$ y $8,3 \pm 1,6 \%$ ( $p<0,01)$.Hubo correlación entre el puntaje obtenido en DESP (pero no en EAT-26) con la HbA1c $(p=0,02)$ e IMC $(p=0,005)$. En DM1, las mujeres tuvieron un puntaje mayor en el DEPS que los varones $(\mathrm{p}=0,02)$. Los resultados del Universo fueron similares al grupo pareado por edad.

Conclusiones: El DEPS es útil para detectar omisión de insulina y manipulación del tratamiento que pueden incidir en un mal control metabólico. Al utilizar una encuesta específica para DM1 no se encontró mayor proporción de TCA que en la población control; probablemente EAT-26 sobreestima la presencia de TCA en DM1.

\section{TRATAMIENTO DE LA PUBERTAD PRECOZ CENTRAL CON ANÁLOGO LHRH DE DEPÓSITO 3 MESES DE DURACIÓN, REPORTE DE LOS PRIMEROS 12 MESES}

Martínez A, Iñiguez G, Avila A, Sovino H, Beas F, Cassorla F. Instituto de Investigaciones Materno Infantil, Facultad de Medicina, Universidad de Chile, Santiago, Chile.

Objetivo: Evaluar la eficacia del uso de Triptorelina 11,25 $\mathrm{mg}$ administrado cada 3 meses en la supresión del eje hipofisiario gonadal y signos de desarrollo puberal en pacientes con Pubertad Precoz Central (PPC) durante 2 años de tratamiento.

Pacientes y métodos: Se incluyeron pacientes con inicio de desarrollo puberal antes de los 8 años en niñas y 9 años en niños, con aceleración de la edad ósea (EO), y respuesta puberal de la $\mathrm{LH}$ al test de $\mathrm{GnRH}$ (peak $>5 \mathrm{mUI} / \mathrm{ml}$ ). Los pacientes recibieron Decapeptyl ${ }^{\circledR} 11,25 \mathrm{mg}$ administrado cada 3 meses. Los niveles séricos de LH y FSH fueron determinados por IRMA; estradiol y testosterona por RIA.

Resultados: Se estudiaron 19 niñas y 1 niño con PPC; todos han completado 12 meses de tratamiento. Al momento iniciar tratamiento, la edad cronológica (EC) fue de 7,5 50,9 años (rango 6-9 años). El desarrollo mamario se habría iniciado a los 5,4+1,3 años. En el momento del ingreso 10 niñas estabas en Tanner III de mama, 4 en Tanner IV y 5 en Tanner V; cinco niñas habían tenido menarquia antes de iniciar el uso de GnRHa (7,6 $\pm 0,5$ años). El volumen testicular en el varón fue de 10 cc. El z-score de talla estaba en promedio en 1,2 $\pm 0,8$ DS; el avance de la Edad Ósea (EO) en

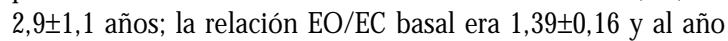
$1,28 \pm 0,16$ (Wilcoxon; $p=0,004$ ). La longitud uterina disminuyó de un basal de $46 \mathrm{~mm}$ a $37 \mathrm{~mm}$ a los 6 meses $(\mathrm{p}=0,007) \mathrm{y}$ $33 \mathrm{~mm}$ al año de tratamiento $(\mathrm{p}=0,001)$. El peak de LH post $\mathrm{GnRH} \leq 3 \mathrm{mUI} / \mathrm{ml}$ se logró en $18 / 20$ al tercer mes y en todos a los 6,9 y 12 meses. El desarrollo mamario regresó 16/19 pacientes y en $3 / 19$ pacientes se mantuvo estable a los 12 meses.

Tabla 1.

\begin{tabular}{|lccccccc|}
\hline & Sexo (\%;F) & Edad (años) & IMC, $\mathrm{K} / \mathrm{m}^{2}$ & DEPS, ptos & DEPS $\geq 40$ & EAT 26, ptos, & EAT-26 $\geq 20$ \\
\hline DM1 & $49,4 \%$ & $14,8 \pm 1,5$ & $21,3 \pm 3,2$ & $26,9 \pm 14$ & $17,2 \%$ & $17,8 \pm 9,9$ & $35,0 \%$ \\
C & $50,6 \%$ & $14,9 \pm 1,1$ & $21,4 \pm 3,0$ & & & $11,0 \pm 10,2 * *$ & $17,8 \% *$ \\
\hline
\end{tabular}

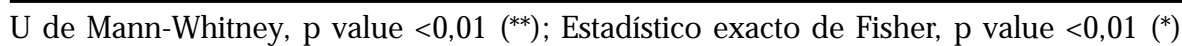


Tabla 1.

\begin{tabular}{|lcccccc|}
\hline & Basal & $3 \mathrm{~m} *$ & $6 \mathrm{~m}$ & $9 \mathrm{~m}$ & $12 \mathrm{~m}$ & $* \mathrm{p}$ value \\
\hline LH Basal (mUI/ml) & $2,1 \pm 1,6$ & $0,46 \pm 0,2$ & $0,40 \pm 0,2$ & $0,51 \pm 0,3$ & $0,51 \pm 0,3$ & $<0,001$ \\
Peak LH (mUI/ml) & $32,3 \pm 31,3$ & $1,3 \pm 0,9$ & $1,0 \pm 0,5$ & $1,1 \pm 0,6$ & $1,01 \pm 0,5$ & $<0,001$ \\
Estradiol (pg/ml) & $14,9 \pm 3,3$ & $5,4 \pm 0,2$ & $5,0 \pm 0,3$ & $5,4 \pm 0,3$ & $5,2 \pm 0,9$ & $<0,001$ \\
Testosterona $(\mathrm{ng} / \mathrm{dl})$ & 210 & 27 & 25 & 34 & 27 & \\
\hline
\end{tabular}

La evolución de los niveles basales y post estímulo con LHRH de gonadotropinas y estradiol en niñas y testosterona en el niño se presentan en la Tabla 1.

Conclusión: Estos resultados sugieren que el tratamiento con Decapeptyl® 11,25 mg logra una adecuada frenación del eje hipofisiario-gonadal durante el primer año de tratamiento, disminuyendo el costo y la frecuencia de inyecciones.

\section{CASO CLÍNICO HIPERPARATIROIDISMO PRIMARIO}

Martínez C, Ruiz C, Adriazola P, Aylwin C, Ilzauspe J. Servicio Medicina Interna, Hospital DIPRECA

Paciente F.E.S., mujer, 30 años. Antecedentes: enfermedad celiaca (EC) diagnosticada a los 9 años. Antecedentes Familiares: Padre y hermano fallecido por cáncer de colon (42 años y 20 años respectivamente).

En julio/02 presenta cuadro de disentería (3 meses de evolución) con baja de peso de $8 \mathrm{~kg}$. Se planteó diagnóstico de colitis ulcerosa (CU) con Biopsia compatible, e inicia tratamiento con azulfidine $2 \mathrm{grs} /$ día, con mala respuesta. Se deriva para estudio. Diagnósticos de ingreso: 1) Desnutrición calónica proteica, 2) Anemia, 3) Colitis Ulcerosa, 4) Enfermedad Celiaca.

Se confirmó diagnóstico de CU y EC mediante biopsias y Anticuerpos específicos. Se evidenció hipercalcemia sostenida (11,05 a 11,25 mg/dl, comegida según albúmina). Planteamos como diagnostico diferencial: Hipercalcemia $2^{\circ}$ Neoplasia?, HPT $1^{\circ}$ ?

La paciente estaba asintomática, pero destacaba: Calcio plasmático y urinario: persistentemente elevado. Cl: 123 P: 1,9 Índice $\mathrm{Cl} / \mathrm{P}=64,7, \mathrm{GSV}$ : Acidosis metabólica. Para definir etiología se solicito PTH intacta pg./mL: 75,6 (N: 7-53), Planteándose que la etiología mas probable seria: HPT1ª Se realizó Ecografía cervical: compatible con adenoma paratimideo. Cintigrafía paratiroidea: con Tc.99m-MIBI: Tej. Paratiroideo hiperfuncionante en relación con el polo inferior LDT.

Basados en los criterios de cirugía para HPT1 1 a del consenso nacional de institutos de salud de 1990, la paciente cumplía sólo un criterio relativo (edad <50 años) para ser sometida a cirugía. Planteamos que la cirugía seria beneficiosa por la edad de la paciente, para evitar complicaciones clínicas de la hipercalcemia, y por estudios publicados que demuestran disminución de la densidad ósea en pacientes sometidos a tratamiento médico. Se realizó Paratimoidectomia inferior derecha, diagnóstico histo- lógico: adenoma paratiroideo. En el postoperatorio y hasta la fecha evoluciona asintomática, con normocalcemias.

Las patologías coexistentes en esta paciente son de baja prevalencia, además destaca el antecedente familiar de cáncer de colon. Aunque no fue posible en nuestra revisión encontrar asociación etiológica para este conjunto de patologías existen 2 casos de iguales características clínicas en 2 mujeres italianas publicados en la literatura.

\section{TRASPLANTE DE CÉLULAS BETA EN LCR: EL SUPLE- MENTO DE NUTRIENTES MEJORA LA VIABILIDAD CELULAR IN VITRO A LARGO PLAZO}

Mears D, Berhe T, Zimliki C, Ommaya A, Sobel D, Atwater I, ROJAS E.

Prog. en Genética Humana, ICBM, Facultad de Medicina, Universidad de Chile.

Introducción: Aunque el trasplante de islotes promete ser el tratamiento para la reversión de la diabetes, persisten dificultades como el rechazo y la escasez de donantes. Para solucionar estos problemas, Ommaya et al. (Transplant. Proc. 29:2111,1997) propusieron trasplantar islotes en líquido céfalo raquídeo (LCR), un lugar inmunológicamente privilegiado, mediante un «hunt» ventriculo-peritoneal. Esta estrategia se apoya en la premisa que el LCR podría mantener a la viabilidad y funcionalidad de los islotes a pesar de contener cantidades menores de proteínas, aminoácidos y vitaminas que el suero normal. El objetivo de este trabajo era probar este hipótesis con estudios in vitro, para determinar: (1) la capacidad de las células de insulinoma de hámster (HIT) para sobrevivir en LCR artificial (LCRa), un medio diseñado para imitar la composición del LCR humano; (2) los efectos del suplemento de nutrientes a la viabilidad de células HIT en LCRa; (3) el método más adecuado de entrega de nutrientes (intermitente vs continuo).

Resultados: Encontramos que el LCRa no favorece la viabilidad de los islotes. Al ser cultivados en LCRa, el número de células viables disminuyó un $65 \%$ en la primera semana y mantuvo su descenso durante un peńodo de incubación de cuatro semanas. Nosotros probamos muchas combinaciones de nutrientes y descubrimos que la mayor contribución a la viabilidad de las células HIT en LCRa fue el suplemento de aminoácidos y proteínas en las concentraciones utilizadas en los medios de cultivo. El número de 
células viables después de cuatro semanas de cultivo en LCRa suplementado con aminoácidos y vitaminas (LCRa,s) fue similar a las cantidades encontradas inicialmente, y fue significativamente mayor que las células HIT mantenidas en LCRa $(p<0,01)$. Las células HIT mantenidas en LCRa,s mantuvieron su respuesta a la glucosa, aumentando tres veces los niveles de secreción de insulina, medido durante un peńodo de incubación de dos horas $(p<0,05)$. La exposición diaria a corto plazo de ciertos nutrientes retardó, pero no previno la disminución de la viabilidad de células HIT en LCR. Conclusión: La viabilidad de las células HIT en LCRa se ve aumentada significativamente mediante la suplementación continua de nutrientes. Por esto la sobrevivencia de islotes transplantados en «hunts» de LCR u otros medios deprivados nutricionalmente podńa ser mejorada a través de la suplementación continua con aminoácidos y vitaminas.

\section{CARACTERISTICAS ULTRASONOGRÁFICAS (US) DE NÓDULOS TIROIDEOS: PREDICCIÓN DE MALIGNI- DAD}

Munizaga F, Hidalgo S, Lio X, Humphreys J, Solís I, Silva P. Dpto. de Endocrinología, Universidad de Chile, Hospital San Borja Arriarán.

En el estudio de la patología nodular se considera de elección la punción biopsia con aguja fina (PAAF). En los últimos años la US se establece como elemento importante en el diagnóstico de cáncer. Objetivos: evaluar la US como método de predicción de cáncer diferenciado de tiroides. Material y métodos. Se estudiaron en forma prospectiva 492 pacientes con US (de alta resolución y doppler) y PAAF. Se indica cirugía a PAAF positiva o sospechosa y a nódulos con PAAF negativa, $>3 \mathrm{~cm} 0$ que crecen. Son intervenidos 51 pacientes, en que se compara la biopsia quinúrgica con la US del nódulo. Se evalúan ocho caracteństicas nodulares por US: ecoestructura, ecogenicidad, homogeneidad, límites, bordes, calcificaciones, circulación al doppler y adenopatías. En estudio estadístico se calcula S,E, VPP,VPN y se utiliza test de Fischer. Se considera significativo $\mathrm{p} \varangle 0,05$. Resultados (Tabla 1).
Conclusiones: la US como método diagnóstico de cáncer diferenciado de tiroides es sensible y específico, y altamente predictivo en un nódulo sólido, marcadamente hipoecogénico, heterogéneo y de bordes irregulares.

\section{PERFIL DE ANTICUERPOS $\beta$ PANCREÁTICOS EN NI- ÑOS CON DIABETES TIPO 1 Y TIPO 2}

Muzzo S, Ramírez I, Jara A, Asenjo S, Giadrosic V, Golsak E, PÉrez F.

INTA, Universidad de Chile y Hospitales Roberto del Río (Santiago); Van Buren (Valparaíso), y Regional de Concepción y Valdivia.

Introducción: Se ha descrito que un alto porcentaje de niños con diabetes tipo 1 (DT1) presentaba susceptibilidad genética y un factor disparador que dió inicio a una respuesta inmune con participación de anticuerpos ß pancreáticos que destruyen lenta y progresivamente las células beta de los islotes de Langerhans. La diabetes tipo 2 (DT2) en el adolescente habitualmente se manifiesta en obesos con resistencia a la insulina, acantosis nigricans, sin gran pérdida de peso al debut y sin mediar un proceso autoinmune.

Objetivo: Nos interesó analizar la presencia de estos anticuerpos en ambos tipos de diabéticos y relacionarlos con el estado nutricional, presencia de acantosis y pérdida de peso al debut.

Sujetos y método: Se estudiaron 18 niños con DT2 y 31 con DT1, menores de 16 años y 3 meses. Se determinó el peso y talla con una balanza de precisión con cartabón y se para calculó la adecuación del índice de masa corporal adecuada según CDCNCHS. Los anticuerpos $\beta$ pancreáticos $\left(\mathrm{GAD}_{65}\right.$ e IA-2) se midieron por RIA (Cis Corp. Francia) y se expresaron como positivos (+) 0 negativos (-) según curva de calibración. Se utilizó una cohorte de 150 niños chilenos sanos para determinar el \% de positividad de anticuerpos $ß$ pancreáticos en este grupo etáreo.

Resultados: De los niños con DT2 un 52,9\% presentó acantosis, $58,8 \%$ sobrepeso u obesidad y $41,2 \%$ sin pérdida de

Tabla 1.

\begin{tabular}{|lccccccc|}
\hline US & Cáncer & Benigna & $\mathrm{p}$ & $\mathrm{S}$ & $\mathrm{E}$ & $\mathrm{VPP}$ & VPN \\
\hline $\mathrm{N}$ & 31 & 20 & & $\%$ & $\%$ & $\%$ & $\%$ \\
Tipo (sólido) & 31 & 14 & 0,002 & 100 & 70 & 69 & \\
Ecogenidad (marcadamente hipoeco.) & 24 & 2 & $<0,001$ & 71 & 90 & 91,7 & 66,7 \\
Homogeneidad (heterogéne0) & 27 & 7 & $<0,001$ & 87 & 65 & 79,4 & 76,5 \\
Límites (mal delimitad0) & 20 & 2 & $<0,001$ & 64,5 & 90 & 90,9 & 62,1 \\
Bordes (irregulares) & 26 & 6 & $<0,001$ & 83,9 & 70 & 81,25 & 73,7 \\
Calcificaciones (microcalcificaciones) & 7 & 1 & 0,09 & 27,6 & 95 & 87,5 & 44,2 \\
Flujo al Doppler (central) & 12 & 3 & 0,002 & 92,3 & 72,7 & 80 & 88,9 \\
Adenopatias (+) & 4 & 0 & 0,13 & 13 & & 100 & 42,5 \\
SOLDO+MARC.HIPOECO+HETERO+BORD. IRREG & 16 & 1 & $<0,001$ & 61,3 & 95 & 95 & 61,3 \\
\hline
\end{tabular}


peso al debut, mientras que en los DT1 un 12,5\% tuvo acantosis, un $42,1 \%$ sobrepeso y un $30,4 \%$ no presentó pérdida de peso al debut. La cifra de positividad de los anticuerpos ß pancreáticos en la población control fue de $1,2 \%$ para $\mathrm{GAD}_{65}$ y de $1,6 \%$ para IA-2. Un 38,9\% de los DT2 tuvieron al menos un anticuerpo antipáncreas (+), cifra que se observó en el 75\% de los DT1. De los DT2 con acantosis el 22,2\% tuvo anticuerpos (-), 40\% de los con obesidad y $86 \%$ de los sin pérdida de peso al debut, mientras que en DT1 fueron $12,5 \%$, $12,5 \%$ y $12,5 \%$ respectivamente.

Conclusiones: Los niños con DT2 mostramon con mayor frecuencia más acantosis nigricans, exceso de peso y menor pérdida de peso al debut que los con DT1. Además, los DT2 tuvieron un valor significativamente menor de anticuerpos $(+)$ que los DT1, diferencia que se hizo más notoria en aquellos que tenían el antecedente de poca pérdida de peso al debut.

\section{PREVALENCIA DE FACTORES DE RIESGO CARDIO- VASCULAR EN PACIENTES INGRESADOS POR EVEN- TOS VASCULARES AGUDOS, EN EL HOSPITAL DR. GUSTAVO FRICKE}

NoviK V, Borja H, González C.

Servicio de Medicina, Hospital Dr. Gustavo Fricke. Cátedra de Medicina, Facultad de Medicina, U. de Valparaíso. Chile.

Las enfermedades cardiovasculares (ECV) son causa importante de morbi-mortalidad en el mundo, y en Chile son la principal causa de muerte. El objetivo de este estudio es analizar la prevalencia de factores de riesgo cardiovascular (FRCV) en pacientes que son hospitalizados por un evento agudo (enfermedad coronaria, crisis 0 emergencia hipertensiva $\mathrm{y} / 0$ accidente vascular cerebral). Materiales y método: estudio observacional, mediante encuesta a pacientes, familiar responsable y análisis de la ficha clínica de 83 pacientes seleccionados al azar que ingresaron entre el $1^{0}$ de junio y el 31 de octubre del 2003. Resultados: De los 83 pacientes, 37 eran mujeres y 46 hombres. El promedio de edad fue de 69,6 años, sin diferencia en ambos sexos. Prevalencia de los FRCV: $97,8 \%$ de los hombres era mayor de 45 años, y el 86,5\% de las mujeres era postmenopáusica sin tratamiento de reemplazo hormonal. El $62,2 \%$ de los hombres y el $35,4 \%$ de las mujeres fumaba. Hipertensión arterial (HTA) previamente conocida se encontró en el $72 \%$ de los pacientes (78\% de las mujeres, y $67 \%$ de los hombres), sólo el 41,6\% de ellos seguía las indicaciones de su médico. El 28\% restante de los pacientes dijo no ser hipertenso, pero el $65,2 \%$ de éstos presentó HTA al ingreso. El 30,1\% de los pacientes era diabético, cumpliendo con la terapia el $72,7 \%$ de las mujeres y el $35 \%$ de los hombres, observándose especialmente una falta de realización de la dieta. El 34,9\% de los pacientes presentaba dislipidemia, ninguno estaba recibiendo medicamentos hipolipemiantes. El 74,4\% de los pacientes se reconoció sedentario, y el $24,1 \%$ era obeso $\left(\mathrm{IMC}>30 \mathrm{~kg} / \mathrm{m}^{2}\right)$. Todos los pacientes del estudio presentaron al menos un FR mayor. El riesgo de Framingham calculado fue de 12,5\% para las mujeres del estudio y de 19,6\% para los hombres.
Discusión: La prevalencia de los FRCV encontrados es superior a otros estudios nacionales ( $75 \%$ de los pacientes tenían un FR mayor en el Programa CARMEN). Destacamos la poca adherencia al tratamiento médico de los pacientes estudiados. Creemos que podemos hacer mucho en la prevención primaria de estos FRCV y enfatizar a los pacientes la importancia del control médico y del tratamiento de sus enfermedades de base.

\section{DIABETES GESTACIONAL E INSULINOTERAPIA IN- TENSIFICADA}

Olmos P, Salinas P, Trincado A, Belmar C, Poblete A, Campano M. Departamentos de Nutrición \& Diabetes y Obstetricia, Facultad de Medicina. P.U.C.

Objetivos: Analizar embarazos con diabetes mellitus gestacional (DMG) para (a) Comparar los embarazos manejados con dieta [DMG-D] o con insulina [DMG-I] y (b) Optimizar el cálculo de dosis en la insulinoterapia intensificada. Diseño: Longitudinal-Retrospectivo desde el inicio del Programa de Diabetes y Embarazo (1997). Métodos: 66 embarazos con DMG. Tabla (SPSS versión 11.5) con 240 variables por trimestre. Estadística: Mann-Whitney, regresión polinomial de 3 o orden, Percentiles y $\chi^{2} \quad[\mathrm{p} \geq 0,05 \rightarrow(\mathrm{NS}) ; \mathrm{p}<0,05 \rightarrow(*)$; $\mathrm{p}<0,01 \rightarrow\left(^{*}\right)$ ]. Resultados: DMG-D ( $\left.\mathrm{n}=52\right)$ vs DMG-I $(\mathrm{n}=14)$.

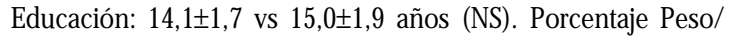
Talla inicial $157,4 \pm 32,7$ vs $151,0 \pm 18,2$ (NS). Porcentaje Peso/ Talla 38 semanas $136,0 \pm 13,2$ vs $158,6 \pm 15,3$ (NS). Creatinina: $0,65 \pm 0,13$ vs $0,62 \pm 0,09 \mathrm{mg} / \mathrm{dL}$ (NS). HbA1c semana $29=$ $4,8 \pm 0,35$ vs $6,8 \pm 1,62$ (NS). HbA1c semana $38=5,6 \pm 0,32$ vs $7,1 \pm 0,4(*)$. Entre estas semanas, y tanto en DMG-D como DMG-I, las HbAlc medias no difieren estadísticamente de $5,2 \pm 0,8 \%$ en austríacas (NS). Recién Nacidos: APGAR al 1으 minuto $=8,8 \pm 0,44$ vs $9,0 \pm 0,4$ (NS). En neonatología $=22 / 52$ vs $7 / 14$ (NS). Semanas $=37,0 \pm 1,5$ vs $35,6 \pm 4,1$ (NS). Malformaciones $=0 / 52$ vs $0 / 14$. Hipoglicemia $=0 / 52$ vs $0 / 14$. Fetos GEG: $3 /$ 52 vs 2/14 (NS). Evolución: Las 14 DMG-I, recibieron Insulinoterapia Intensificada (NPH matinal y nocturna, Cristalina antes de cada comida según 3 glicemias diarias). El requerimiento insulínico total diario fue 38,8 u/día $\pm 6,2$ en semana 29 , y de 40,3 u/día $+11,3$ en semana 38, cifras que son inferiores a las de las diabéticas pregestacionales austríacas (*). La dosis total diaria de insulina por $\mathrm{kg}$ de peso bajó linealmente de

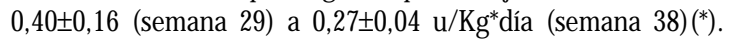
Conclusiones: $78 \%$ de las diabéticas gestacionales fue tratada con dieta, y 22\% con Insulinoterapia Intensificada. La calidad del control glicémico en diabéticas gestacionales tratadas con dieta es mejor que en las tratadas con insulina, pero en ambas no difiere significativamente con la de diabéticas pregestacionales austríacas. En diabéticas gestacionales que requieren insulina, el requerimiento insulínico expresado por $\mathrm{kg}$ de peso tiene un descenso suficientemente lineal a lo largo de la gestación como para facilitar enormemente el cálculo de las dosis de insulinoterapia intensificada en el futuro. 


\section{DIABETES PREGESTACIONAL E INSULINOTERAPIA INTENSIFICADA}

Olmos P, Salinas P, Trincado A, Belmar C, Poblete A, Campano M. Departamentos de Nutrición \& Diabetes y Obstetricia, Facultad de Medicina. P.U.C.

Objetivos: Analizar embarazos con diabetes mellitus pregestacional (DMPG) para (a) comparar la evolución de DMPG-1 con la creciente proporción de DMPG-2; (b) Comparar DMPG1+2 con los de Insulinoterapia Funcional en Austria (Howorka et al, 1997) y (c) Optimizar el cálculo de dosis en la insulinoterapia intensificada. Diseño: Longitudinal-Retrospectivo desde 1997. Métodos: DMPG-1= 16 embarazos/15 mujeres; DMPG-2= 20 embarazos/19 mujeres. Tabla (SPSS versión 11.5) con 240 variables por trimestre. Estadística: Mann-Whitney, regresión polinomial de 30 orden, Pencentiles y $\chi^{2}$. Resultados: (a) DMPG-1 vs DMPG-2: Clase de White $=7 \mathrm{~B} / 5 \mathrm{C} / 3 \mathrm{D} / 1 \mathrm{~F}$ y $16 \mathrm{~B} / 1 \mathrm{C} / 1 \mathrm{D} / 1 \mathrm{~F}$ (NS). Edad= 30,1 $(4,1)$ y $30,0(7,9)$ años, $p=0,459$. Duración $=12,7(8,5)$ y $2,5(4,6)$ años, $\mathrm{p}=0,0001$. Mi-croalbuminuria $=88,1(197,3)$ y $101,5(96,8) \mathrm{mg} /$ 24horas, $\mathrm{p}=0,158$. Retinopatía (Nomal/NoProliferativa/Proliferativa) $=13 / 2 / 1$ y $20 / 0 / 0, p=1,0 . \mathrm{IMC}=24,4(3,8)$ y $30,5(7,7) \mathrm{kg} / \mathrm{m}^{2}, \mathrm{p}=$ 0,019 . HbA1c pregestacional $=7,4(2,8)$ y $6,0(1,6), p=0,282$. (b) $E l$ requerimiento insulínico total diario en DMPG1+2 varió desde $40 \pm 12$ U/día a las 10 semanas, hasta $55 \pm 14$ U/día a las 38 semanas, 0 sea 11,0 $\pm 4,1 \mathrm{u}$ /día inferiores a las de Howorka et al $(p=0,02)$. La glicemia media semanal fue similar en DMPG-1 y 2 y varió de $111 \pm 11 \mathrm{mg} / \mathrm{dL}$ a las 11 semanas, hasta $105 \pm 4 \mathrm{mg} / \mathrm{dL}$ a las 38 semanas, cifras similares a las de Howorka et al (NS). La HbA1c en

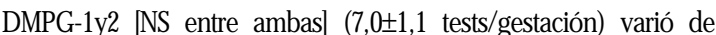
$7,7 \% \pm 1,0$ a las 10 semanas, hasta 5,4\% $\pm 0,5$ a las 38 semanas, similar a las de Howorka et al $(\mathrm{p}>0,1)$. (c) El requerimiento insulínico diario por kg de peso en DMPG 1+2 (NS entre ambas) varió poco, desde $0,50 \mathrm{u} / \mathrm{kg}^{*}$ día a las 10 semanas $\left(\mathrm{P}_{75}=0,62\right.$ y $\left.\mathrm{P}_{25}=0,40\right)$ hasta de $0,62 \mathrm{u} / \mathrm{kg}^{*}$ día $\left(\mathrm{P}_{75}=0,85\right.$ y $\left.\mathrm{P}_{25}=0,45\right)$ a las 38 semanas. Conclusiones: Un 55\% de los embarazos con DMPG fueron con diabéticas tipo 2, las que tienen tiempo de evolución mas corto y menor prevalencia de complicaciones que las DMPG-1. El requenimiento insulínico total dianio de nuestras DMPG-1 y 2 es similar al de las mujeres austríacas, lo mismo que la glicemia media semanal y la HbA1c. Al expresar el requenimiento insulínico por kg de peso en DMPG 1 y 2 éste permanece lo suficientemente estable a lo largo de la gestación como para facilitar enomemente el cálculo de las dosis de insulinoterapia intensificada en el futuro.

\section{NEFROCALCINOSIS MEDULAR ASOCIADA A USO MASIVO DE FUROSEMIDA. CASO CLÍNICO}

Ortiz E1 ${ }^{1}$, Aravena $C^{2}$, Valdivieso A ${ }^{2}$, Tagle R ${ }^{2}$, González $M^{3}$, Velasco $A^{4}$, Vásquez $\mathrm{F}^{4}$, González $\mathrm{G}^{1}$.

Departamentos de Endocrinología ${ }^{1}$, Nefrología ${ }^{2}$, Psiquiatría ${ }^{3}$ y Urología ${ }^{4}$. Facultad de Medicina, Pontificia Universidad Católica de Chile.

La nefrocalcinosis medular asociada al uso de furosemida es una enfermedad rara y descrita habitualmente en neonatos. En adultos, se han comunicado casos aislados de esta entidad en pacientes con uso prolongado y con dosis excesivas de este diurético. Caso Clínico: Mujer de 38 años con antecedente de automedicación de diuréticos desde 1989 por edema premenstrual. Posteriormente presentó episodios recurrentes de hipokalemia hasta de $2,0 \mathrm{mEq} / \mathrm{L}$ y podagra. Debutó con cólico renal el año 2000. Evaluada en el 2002, destacó:hipocitraturia e hipercalciuria por lo que se indicó citrato de potasio (K3Cit) y suspender diurético. En junio del 2004 es hospitalizada por cólico renal. Ecografía y radiografía renal simple muestran imagen compatible con nefrocalcinosis medular. PieloTAC con hidroureteronefrosis derecha y litiasis ureteral.Se efectuó ureterolitectomía con extracción de cálculo de oxalato de calcio. Reinterrogada, reconoció por primera vez ingesta regular hasta de 120 tabletas diarias de furosemida desde el año 1989. Su evaluación psiquiátrica reveló trastorno depresivo mixto y rasgos de personalidad histriónica (Tabla 1).

Comentario: Este caso ilustra una complicación no comunicada anteriormente en nuestro medio del uso de furosemida y que alerta sobre la importancia de sospechar el uso subrepticio de éste, especialmente en pacientes con nefrocalcionosis medular y con antecedente de alteraciones psiquiátricas tales como anorexia nervosa o bulimia.

Tabla 1.

\begin{tabular}{|lccc|}
\hline Exámenes & $\begin{array}{c}11 / 2002 \\
\text { (Basal) }\end{array}$ & $\begin{array}{c}\text { 05/2003 (isin furosemide?) } \\
\text { (Tto con K3Cit; } \mathrm{K}^{+} \text {91mEq/d) }\end{array}$ & $\begin{array}{c}\text { 06/2004 } \\
\text { (sin fármacos) }\end{array}$ \\
\hline Creatinina $(\mathrm{mg} / \mathrm{dl})$ & 0,8 & 0,8 & 1,0 \\
$\mathrm{Na}^{+} / \mathrm{K}^{+} / \mathrm{Cl}^{-} \mid(\mathrm{mEq} / \mathrm{l})$ & $136 / 3,6 / 103$ & $138 / 4,0 / 98$ & $135 / 4,7 / 106$ \\
$\mathrm{Fe} \mathrm{Na} / \mathrm{K}^{+} / \mathrm{Cl}-(\%)$ & $2,1 / 73 / 4$ & $0,3 / 22 / 0,3$ & $\mathrm{ND}$ \\
Calciuria $(\mathrm{mg} / \mathrm{d})(\mathrm{mg} / \mathrm{kg} / \mathrm{día})$ & $562(9,6)$ & $152(2,5)$ & 31 \\
Citraturia mg/día (VN:> 300) & 42 & 458 & 158 \\
PTHi (pg/ml) (VN:7-53) & & & 9,0 \\
Calcemia (mg/dl) & & & 932 \\
\hline
\end{tabular}

Fe: fracción excretada (orina de 24 horas); ND: No disponible. 


\section{OSIFICACIÓN HETEROTÓPICA COMO CAUSA DE SÍNDROME FEBRIL PROLONGADO EN PACIENTE CON INJURIA NEUROLÓGICA GRAVE}

Ortiz E ${ }^{1}$, Contreras $\mathrm{O}^{2}$, Morel L ${ }^{3}$, González $\mathrm{G}^{1}$. Departamentos de Endocrinología 1 , Radiología y Medicina Interna ${ }^{3}$. Facultad de Medicina, Pontificia Universidad Católica de Chile.

La osificación heterotópica es una entidad poco conocida y que se origina por múltiples causas, alguna de ellas endocrinológicas. Hasta un 20\% de los pacientes con injunia neurológica grave pueden desarmollar osificación heterotópica, la cual en su etapa inicial puede presentarse como fiebre prolongada de onigen no conocido. Caso clínico: Hombre de 18 años, previamente sano, quien presenta paro cardiomespiratorio post apendicectomía. Ingresa a nuestro hospital 2 semanas después con encefalopatía hipóxica isquémica. Evoluciona con fiebre prolongada de ongen no conocido (hemocultivos, urocultivos y panel viral respiratorio negativos, radiografía de tórax normal). En búsqueda de colección intrabdominal, se efectuó TAC de abdomen y pelvis que mostró proceso expansivo en músculos vasto intermedio e ileopsoas, con densidad heterogénea y distribución fibrillar, compatible con osificación heterotópica. Se observó entonces aumento de volumen de tercio proximal de muslo y cadera izquierda, doloroso a la movilización. Radiografía simple y cintigrama con $\mathrm{Tc}^{99}-\mathrm{MDP}$, mostraron en región peniarticular de cadera izquierda imágenes de densidad ósea lineales concéntricas y aumento de captación extra óseo del isótopo en tercio proximal de muslo, respectivamente. Además, hubo aumento de las fosfatasas alcalinas totales (FA) desde $166 \mathrm{UI} / \mathrm{L}$ al ingreso, hasta $251 \mathrm{UI} / \mathrm{L}$ (vn: 52-171) al momento del diagnóstico, con peak posterior de 418 UI/L Calcemia, fosfemia, creatininemia y PTH fueron nomales. Fue tratado con Indometacina $75 \mathrm{mg} /$ día con desaparición de fiebre al 5a día y disminución del aumento de volumen del muslo y cadera, así como de FA, las que se nomalizaron (153 UI/L) a las 5 semanas de tratamiento. Al suspender Indometacina reapareció fiebre y elevación de FA a 181UI/L, remitiendo ambas alteraciones nuevamente al reiniciar Indometacina. Comentario: Este caso, al igual que otro que presentáramos en el Congreso 2002 ilustran respecto de dos formas diversas de presentación de la osificación heterotópica en pacientes con injuria neurológica grave, que esta vez fue diagnosticada en el estudio de un síndrome febril prolongado. Ello alerta de la importancia de la búsqueda activa de esta entidad, dado que el reconocimiento precoz de ésta evita exámenes o tratamientos innecesarios.

\section{TUMOR DESMOIDE Y SUS IMPLICANCIAS ENDOCRI- NOLÓGICAS. CASO CLÍNICO}

Ortiz $\mathrm{E}^{1}$, Campusano $\mathrm{C}^{1}$, Lopez $\mathrm{F}^{2}$.

Departamento de Endocrinología y División de Cirugía (Digestiva) ${ }^{2}$ Facultad de Medicina, Pontificia Universidad Católica de Chile.
Introducción: El tumor desmoide, es poco frecuente y puede formar parte de una poliposis adenomatosa familiar de colon (PAF), lo cual constituye el Síndrome de Gardner. Es un tumor benigno fibromatoso, que en ocasiones presenta gran crecimiento con compresión de estructuras vitales en su localización intrabdominal. La dependencia a estrógenos de estos ha sido sugerida por su mayor prevalencia en mujeres jóvenes y la regresión de algunos en la menopausia. Caso Clínico: Paciente de 28 años con antecedente de poliposis colónica familiar, sometida a colectomía total en julio de 2002 y de un bocio difuso hipotiroideo diagnosticado a los 21 años. En abril de 2003 se diagnosticó una lesión tumoral en el espesor de músculo recto anterior izquierdo del abdomen, compatible con un tumor desmoide de $2 \mathrm{~cm}$, por lo que inició tratamiento con Sulindac $150 \mathrm{mg}$ día. Tiene antecedente de una tía, un hermano y hermana con PA, colectomizados y portadores de tumor desmoide. Sus hermanos tienen tumores mesentéricos, uno de los cuales es un tumor gigante y fistulizado a pared abdominal. En agosto de 2003 se efectúa TAC de abdomen y pelvis, que muestra tumor de 4,2 cm x 2,5 cm x 5,2 cm, se mantiene terapia con Sunlidac. En mayo de 2004, se evidencia crecimiento de la lesión $(6,8 \mathrm{~cm} \times 4,2 \mathrm{~cm} \mathrm{x} \mathrm{7,4} \mathrm{cm).} \mathrm{Se} \mathrm{decide} \mathrm{iniciar} \mathrm{tratamiento}$ con tamoxifeno en forma gradual hasta llegar a $120 \mathrm{mg}$ al día. Entre los efectos colaterales refiere bochornos, despertar precoz y amenorrea. TAC de control, un mes post tratamiento, muestra estabilidad del tumor y describe lesión quística anexial derecha de $7 \mathrm{~cm}$. Ecotomografía ginecológica confirma quiste anexial simple. Por este último hallazgo se decide agregar análogos de $\mathrm{GnRH}$. Comentario: La poca respuesta a Sulindac y el rápido crecimiento del tumor, así como la alta posibilidad de recurrencia post quirúrgica de éste, plantean la necesidad uso de terapia antiestrogénica. El tamoxifeno en altas dosis ha demostrado una respuesta favorable en un 50\% de los casos (estabilización 0 regresión del tamaño tumoral), se han usado también agonistas de GnRH o progesterona con resultados variables. En nuestra paciente observamos estabilización del tamaño tumoral pero con aparición de complicación por uso de tamoxifeno.

\section{LINFOMA TIROIDEO. UTILIDAD DE LA CITOMETRÍA DE FLUJO}

Oyaneder R, Brusco F, Peña A, Ruiz J. Servicio Medicina Hospital Naval Altm. Nef.

El linfoma tiroideo puede presentarse como un bocio de crecimiento rápido y compresivo; en estos casos urge un diagnóstico diferencial rápido para instaurar la modalidad terapéutica específica. Presentamos el caso de un linfoma tiroideo que se presentó como masa cervical gigante compresiva en la que el estudio por citometría de flujo permitió su diagnóstico en 24 horas.

Mujer de 75 años, con hipotimoidismo $1^{\circ}$ por Tiroiditis autoinmune en tratamiento con Levotiroxina hace 4 años. Consulta en Junio 2003 por notar crecimiento cervical anterior, indoloro, no compresivo hace 3 meses; se objetiva un bocio 
de 80 gramos, fijo a planos profundos, con nódulo palpable en lóbulo izquierdo. PAAF bilateral: Histología compatible con tiroiditis de Hashimoto. Inmunohistoquímica para linfocitos $\mathrm{T}$ (CD45 Ro) y linfocitos B (CD20) sin evidencia de clonalidad. Dada la sospecha diagnóstica se sugiere biopsia quirúrgica, que es rechazada por la paciente. Consulta en septiembre 2003 de urgencia por crecimiento acelerado de la masa en pocos días, con disfonía, disfagia y finalmente disnea de reposo. Por sospecha de linfoma tiroideo se realiza biopsia a cielo abierto y se administran corticoides; se envía a citometría de flujo y biopsia convencional. A las 24 horas el resultado de la citometría muestra claramente un patrón de síndrome linfoproliferativo de estirpe B. Se continúa con corticoides con estabilización de la masa. La biopsia diferida confirma Linfoma no Hogkin de células B. Estudio de diseminación fue negativo. Se realiza quimioterapia y radioterapia de consolidación. La paciente un año después, se encuentra libre de enfermedad.

La citometría de flujo es en la actualidad uno de los principales métodos de estudio de síndromes linfoproliferativos. La técnica analiza cualitativa y cuantitativamente diversas características de las células que permiten determinar su clonalidad, aún cuando estas provengan de líquidos corporales 0 de pequeñas cantidades de tejido. En la literatura, la citometría de flujo aplicada a muestras de PAAF tiene una correlación entre un 87 a 100\% con la biopsia de tejido. Además la información obtenida con esta metodología tiene mayor sensibilidad que la obtenida por inmunohistoquímica en muestras pequeñas; tal como queda reflejado en este caso. En nuestro caso la citometría se utilizó con biopsia a cielo abierto, sin embaryo, por la naturaleza de este examen, nosotros recomendamos que al existir una alta sospecha de esta patología tiroidea, el clínico indique PAAF convencional asociado a citometría de flujo para un rápido y precoz diagnóstico.

\section{POLIMORFISMO C $\rightarrow$ T (-34bp) DE LA REGIÓN PRO- MOTORA DEL GEN CYP17 EN MUJERES CON SÍN- DROME DE OVARIO POLIQUÍSTICO}

Pérez $\mathrm{F}^{1}{ }^{1} 2$, Maliqueo $\mathrm{M}^{1}$, Echiburú $\mathrm{B}^{1}$, Galgani $\mathrm{J}^{2}$, Villarroel AC $^{1}$, Sánchez $\mathrm{F}^{1}$, Sir-Petermann $\mathrm{T}^{1}$.

${ }^{1}$ Lab. de Endocrinología y Metabolismo, Facultad de Medicina Occidente, Universidad de Chile. ${ }^{2}$ Lab. Epidemiología Genética. Instituto de Nutrición y Tecnología de los Alimentos (INTA), Universidad de Chile.
Introducción: El síndrome de ovario poliquístico (SOP), es un desorden endocrino-metabólico frecuente con base genética. Se ha planteado que la hiperactividad de la enzima P450c17 $\alpha$, codificada por el gen CYP17, estaría implicada en la hiperandrogenemia del SOP. Diversos estudios han sugerido el posible papel del alelo A2 de la región promotora del gen CYP17 como candidato en la etipatogenia de este fenómeno. Objetivo: Evaluar la frecuencia y la asociación del polimorfismo (-34bp) de la región promotora del gen CYP17 con parámetros clínicos y bioquímicos en mujeres normales $(\mathrm{MN})$ y mujeres con SOP (SOP). Pacientes y Método: En 72 mujeres SOP y $80 \mathrm{MN}$ se determinó el polimorfismo CYP17 (-34bp) mediante PCR y análisis de RFLPs. Se realizó PTGO con medición de glucosa e insulina (Ins). En la muestra basal se midió: Testosterona (T), androstenediona, SHBG, 170H Progesterona (170HP), DHEA-S y se calculó el índice de andrógenos libres (IAL). La insulino resistencia fue establecida mediante $\mathrm{HOMA}_{\mathrm{IR}}$ e ISI composite. Resultados: La frecuencia del alelo A2 fue similar en ambos grupos de mujeres (SOP 40,3\% vs MN 37,5\%, NS). En la Tabla 1 se muestran las variables bioquímicas entre portadores $(\mathrm{P})$ y no portadores (NP) del alelo A2 en mujeres con SOP.

No se observaron diferencias en edad, IMC, concentración de andrógenos entre las portadoras y no portadoras del alelo A2. Conclusión: Los resultados sugieren que el alelo A2 del gen CYP17 no está asociado a la hiperandrogenemia del SOP. Sin embargo, las mujeres SOP portadoras del alelo A2 presentaron mayor insulino resistencia.

(FONDECYT 1030487)

\section{POLIMORFISMO DE LA PROTEÍNA LIGANTE DE ÁCI- DOS GRASOS (FABP-2) Y SU ASOCIACIÓN CON TNF $\alpha$ Y SUS RECEPTORES SOLUBLES: EFECTO DE LA OBESIDAD Y LA INSULINO-RESISTENCIA}

Pérez F, Angel B, Lera L, Santos Jl, Gómez R, Liberman C, Albala C.

Laboratorio de Epidemiología Genética. Instituto de Nutrición y Tecnología de los Alimentos (INTA) y Dpto. de Endocrinología. Hospital Clínico de la Universidad de Chile. Facultad de Medicina. Universidad de Chile.

Introducción: FABP2 juega un papel clave en la absorción y transporte intracelular de los ácidos grasos de cadena larga

Tabla 1.

\begin{tabular}{|lccccccc|}
\hline & $\begin{array}{c}\mathrm{T} \\
(\mathrm{ng} / \mathrm{ml})\end{array}$ & $\begin{array}{c}\text { SHBG } \\
(\mathrm{nmol} / \mathrm{L})\end{array}$ & IAL & $\begin{array}{c}\text { Ins. Basal } \\
(\mathrm{uUI} / \mathrm{ml})\end{array}$ & $\begin{array}{c}\mathrm{AUC}_{\text {insulina }} \\
(\mathrm{uUI} / \mathrm{ml} / 2 \mathrm{~h})\end{array}$ & HOMA $_{\text {IR }}$ & ISI $_{\text {composite }}$ \\
\hline NP-A2 & $0,8 \pm 0,4$ & $38,1 \pm 16,5$ & $7,9 \pm 5,2$ & $18,0 \pm 11,8$ & $9438 \pm 7047$ & $4,2 \pm 3,9$ & $4,7 \pm 3,5$ \\
P-A2 & $0,9 \pm 0,4$ & $26,4 \pm 19,1$ & $18,5 \pm 13,9$ & $26,8 \pm 18,2^{*}$ & $14231 \pm 9109^{*}$ & $6,2 \pm 4,9$ & $2,7 \pm 1,8$ \\
\hline
\end{tabular}

$*_{\mathrm{P}}<0,05$ 
Tabla 1.

\begin{tabular}{|ccccccc|}
\hline FABP-2 & $\begin{array}{c}\text { Obesidad } \\
(\%)\end{array}$ & $\begin{array}{c}\mathrm{TNF} \alpha \\
(\mathrm{pg} / \mathrm{ml})\end{array}$ & $\begin{array}{c}\text { TNFR1 } \\
(\mu \mathrm{g} / \mathrm{ml})\end{array}$ & $\begin{array}{c}\text { TNFR2 } \\
(\mu \mathrm{g} / \mathrm{ml})\end{array}$ & $\begin{array}{c}\text { Leptina } \\
(\mathrm{ng} / \mathrm{ml})\end{array}$ & HOMA \\
\hline Ala/Ala & 32,1 & $14,0(1,6)$ & $2,41(0,8)$ & $5,93(1,8)$ & $17,2(10)$ & $2,29(1,1)$ \\
Ala/Thr & 37,5 & $12,5(1,3)$ & $2,23(0,7)$ & $5,48(1,4)$ & $20,6(14)$ & $2,54(1,8)$ \\
Thr/Thr & 44,0 & $13,7(1,9)$ & $2,16(0,6)$ & $5,62(2,0)$ & $26,0(22)$ & $2,54(1,9)$ \\
\hline
\end{tabular}

provenientes de la dieta. Los portadores de la variante alélica Thr54 de FABP-2 presentan una afinidad hasta dos veces mayor por estos ácidos grasos, fenómeno que podría involucrar a este polimorfismo en la etiología de la obesidad y la insulino-resistencia (IR).

Objetivo: Evaluar la frecuencia del polimorfismo Ala54Thr de FABP-2 en población chilena y determinar la posible asociación de esta variante con obesidad e IR.

Pacientes y Metodología: 83 sujetos (rango de edad 60-69 años) fuemon ingresados al estudio. 51 mujeres (20 obesas) y 32 hombres (16 obesos). En muestra en ayunas se deteminó: glucosa, insulina, leptina, TNF $\alpha$, receptores solubles (STNF R1, STNF R2) y perfil lipídico. La estimación de IR se realizó por HOMA-IR. El polimorfismo Ala54Thr se determinó mediante PCR y RFLP.

Resultados: La frecuencia genotípica de FABP-2 fue: Ala/ Ala:0,35; Ala/Thr: 0,32, Thr/Thr: 0,33. El IMC promedio del grupo fue de 29 $\pm 4,19$ ( $\min 21,5-\max 43,6$ ). Asociaciones positivas se detectaron entre STNF R2 e IMC (IMC $r=0,20$ $\mathrm{p}<0,08)$ y STNFR2 con leptina $(r=0,26, p<0,02)$. No se observó asociación entre para IMC, leptina 0 insulina con STNF R1. La insulina se asoció con TNF $\alpha(r=0,26, p<0,06)$ sólo en mujeres. La Tabla 1 muestra los valores de algunas variables según genotipo FABP-2 (media y DS).

Conclusión: Nuestros datos sugieren que la variante Thr54 de FABP2 es más frecuente entre los obesos, pero este polimorfismo tendría un papel menor en relación a la posible asociación con obesidad o IR en esta población.

(Proyecto Fondecyt 1020703)

\section{EXPRESIÓN DE CITOQUERATINA 19 POR RT-PCR EN TIEMPO REAL (REALTIME PCR) EN EL DIAGNÓSTICO DE CÁNCER PAPILAR DE TIROIDES}

Pineda P, Flanagan J, De las Morenas A, Lee S, Braverman L. Sección Endocrinología Hospital Clínico Universidad de Chile y Endocrine Section Boston Medical Center, Boston University, EEUU.

El cáncer papilar de tiroides (PC) es la neoplasia maligna tiroidea más frecuente. Diferentes marcadores moleculares de malignidad han sido descritos para el estudio de esta neoplasia. Citoqueratina 19 (CK 19) ha sido detectada por técnicas de inmohistoquímica en cáncer papilar, sin embargo existe controversia en su utilidad en el diagnóstico diferencial debido a su detección en otras lesiones tiroideas. Objetivo. Examina niveles de expresión de CK 19 por inmunohistoquímica en combinación con una técnica más sensible, la transcripción reversa con reacción de polimerasa en cadena cuantitativa en tiempo real (realtime PCR) en diferentes lesiones tiroideas. Método. Un total de 44 muestras de tejido tirideo obtenido por cinugía fuemon recolectadas y se realizó extracción de RNA y síntesis de cDNA en muestras frescas congeladas. Los cortes de tejido fueron teñidos con anticuemos monoclonales específicos para CK 19. El real time PCR fue realizado a partir del cDNA con primers específicos para CK 19 humano junto a ribonucleoproteína RNA S18 para nomalización. Resultados. Se observó tinción intensa y difusa para CK 19 en todos los PC estando casi ausente en bocio multinodular (BMN), con tinción focal ocasional. Las lesiones de tiroiditis crónica (TC), adenoma folicular (AF) y de Hürthle (AH) fuemon negativas para CK 19, excepto débilmente en áreas focales. La expresión de CK 19 por realtime PCR reveló un valor promedio 32 veces más elevado en $\mathrm{PC}(\mathrm{n}=17)$ comparado con $\mathrm{BMN}(\mathrm{n}=12)(\mathrm{p}(0,01)$. Dicha expresión en $\mathrm{AH}(\mathrm{n}=5), \mathrm{AF}(\mathrm{n}=3)$ y TC $(n=7)$ no fue significativamente diferente comparada con BMN. Conclusión: La expresión de CK 19 por real-time PCR puede ser adoptada en combinación con otras técnicas y marcadores para definir los diferentes subtipos de lesiones tiroideas y así colaborar en el diagnóstico diferencial postoperatorio y eventualmente preoperatorio de las neoplasias tiroideas.

\section{CARACTERÍSTICAS DEMOGRÁFICAS Y ETAREAS DE LOS NUEVOS CASOS DE DIABETES TIPO 1 (DM1) EN CHILE. 1990-2003}

Preisler J, Peláez JM, Pérez J, Velasco C, García H.

Fundación de Diabetes Juvenil (FDJ). Clínica Santa María. Universidad de los Andes.

Introducción: La FDJ es una Institución creada en 1988 para ayudar a los pacientes con DM1. Posee sucursales en todo el país y sus socios son los DM1 que debutan en las distintas regiones de Chile. Por las caracteństicas de nuestro sistema de salud, los registros oficiales aunque son muy confiables, sólo incluyen una parte de los casos. La FDJ debido a su prestigio y alta convocatoria, inscribe a los pacientes que debutan con DM1 en todo el país independiente de su sistema de salud, por lo que constituye un registro relativamente confiable de los casos nuevos de DM1 en Chile. Objetivo: Analizar las caractenísticas demográficas y etareas 
de los DM1 que debutaron en Chile entre 1990-2003, según los registros de la FDJ. Material y Métodos: Se analizaron los registros de los DM1 que debutaron entre enero de 1990 y diciembre del 2003, consignando sexo, fecha nacimiento, fecha del debut y región de residencia de los pacientes. Resultados: Entre 1990 y 2003 se registró en FDJ el debut de 3313 DM1. Su número se incrementa desde 127 el año 1990 a 260 el año 1998. Posteriomente se observa un plateu hasta el año 2003. Se analizó por separado estos últimos 6 años (1998-2003), fecha en que debutan 1547 DM 1 de 12,97士8,14 años (0-34,8 años), 52,8\% de los cuales comesponde a la Región Metropolitana (Santiago), un 12,1\% a la V Región (Valparaíso) y un 8,1\% a la VIII Región (Concepción). Analizados según número de habitantes (Censo 2002), la mayor incidencia se observa en Santiago, seguido de Valparaíso y Antofagasta (2,24, 2,02 y 1,99 casos nuevos x 100.000 habitantes/año respectivamente). La menor incidencia se observa en Temuco y Coyhaique: 0,71 y 0,72 x 100.000 habitantes/año respectivamente. Del total de casos nuevos, 1079 (69,7\%) comesponden a menores de 15 años y entre ellos $213(19,7 \%)$ comesponde a lactantes y preescolares menores de 4 años y 55 (5\%) a menores de 2 años. Conclusiones:1) La FDJ constituye un registro confiable del número y distribución geográfica de diabéticos tipo 1, aunque no podemos descartar el subregistro de casos no inscritos, especialmente en provincias. 2) La mayor incidencia de casos se observa en Santiago, Valparaíso y Antofagasta, siendo las menores Temuco y Coyhaique, regiones con mayor proporción mapuche en su población, etnia con protección demostrada para DM1. 3) Llama la atención la elevada proporción de niños menores de 4 años afectados.

\section{DIFICULTADES EN EL DIAGNÓSTICO DE INSULINO- RRESISTENCIA EN PACIENTES OBESOS SOMETIDOS A UN PROGRAMA DE TRATAMIENTO INTEGRAL (PTI)}

Preisler J, Sepúlveda A, lópez C, García H, Díaz J.

Clínica Santa María. Universidad de los Andes. U de Chile.

La obesidad se asocia frecuentemente a insulinorresistencia (IR) y a sindrome metabólico (SM). Conocer las alteraciones metabólicas asociadas, permite un mejor enfoque terapéutico en estos pacientes. Objetivos: evaluar distintos parámetros diagnósticos de IR en una población de obesos sin SM, Diabetes (DM2) ni intolerancia a la glucosa (ITG) y buscar variables predictoras de respuesta al tratamiento. Material y
Métodos: Se estudiaron 287 pacientes obesos (236 mujeres) sin SM, DM2 ni ITG; se determinó IMC, perímetro de cintura (PC), test de tolerancia a la glucosa con insulinemia $0^{\prime}(\mathrm{I})$ y 120 '(IP), HOMA, QUICKI, perfil lipídico, relación TG/HDL al inicio y final de un PTI de 3 meses. Para el análisis estadístico se utilizó t de student, correlación de Pearson, curvas ROC y se usó un modelo para cálculo de variables predictoras de respuesta al tratamiento médico. Se definió como respuesta deficiente una disminución < de $10 \%$ del peso inicial. Resultados: en la muestra total, el parámetro que pesquisó la mayor cantidad de pacientes con IR fue perímetro de cintura (PC) > 88 en mujeres y $102 \mathrm{~cm}$ en hombres, seguido de HOMA $\geq 2,5$ (ver Tabla 1 ).

No hubo correlación de HOMA e IP (r:0,39) ni HOMA vs TG/HDL (r:0,27). Usando curva ROC y estableciendo un HOMA $\geq 2,5$ como diagnóstico de IR, los puntos de corte óptimos son $64.4 \mathrm{uU} / \mathrm{ml}$ para IP y 2 para TG/HDL; con una sensibilidad de 71 y $75,7 \%$, y una especificidad de 75 y $50,7 \%$, respectivamente. La disminución de peso > a 10\% se observó en un $39 \%$ del grupo, siendo la glicemia inicial la única variable predictora de respuesta deficiente al tratamiento $(p=0,011)$. Conclusiones: 1) Los criterios que obtienen mayor prevalencia de IR son el PC seguido de HOMA e IP; QUICKI y TG/HDL obtienen semejante prevalencia de IR. 2) El diagnóstico de IR no es fácil, ya que hubo una baja correlación entre los distintos parámetros estudiados, lo que aconseja utilizar mas de un criterio diagnóstico. 3) Glicemia ayunas fue la variable predictora de mala respuesta al PTI.

\section{ASOCIACIÓN DE LA FRACTURA OSTEOPORÓTICA DE CADERA EN LA MUJER ADULTA MAYOR CHILE- NA CON EL POLIMORFISMO PML-I DEL GEN DE PPARY: IMPORTANCIA DE LA DIFERENCIACIÓN ADI- POGENICA}

Quevedo I ${ }^{1-2}$, CAstillo $\mathrm{M}^{2}$.

Sección Endocrinología, Depto. Medicina Interna ${ }^{1}$, Laboratorio de Medicina Molecular ${ }^{2}$, Facultad de Medicina. Universidad de Concepción.

La Osteoporosis es una enfermedad que afecta un número creciente de mujeres tanto en Chile como en el mundo. La disminución de la masa ósea que caracteriza a la osteoporosis

Tabla 1.

\begin{tabular}{|lccccc|}
\hline Prevalencia de IR & PC (H>102cm y M> 88 cm) & IP>60 uU/ml & HOMA $\geq 2,5$ & QUICKI < 0,32 & TG/HDL > 3 \\
\hline Hombre & $88,1 \%$ & $77,7 \%$ & $79,6 \%$ & $64,3 \%$ & $65,8 \%$ \\
Mujer & $75,2 \%$ & $51,5 \%$ & $55,4 \%$ & $36,4 \%$ & $36,6 \%$ \\
Total & & $57,8 \%$ & $61 \%$ & $43 \%$ & $44 \%$ \\
\hline
\end{tabular}


aumenta la susceptibilidad a las fracturas, especial relevancia dentro de éstas tiene la fractura de cadera dado su alto impacto de la morbi y mortalidad asociadas. El tejido óseo se encuentra en un constante recambio. La resorción ósea es producida por los osteoclastos, células que derivan de precursores hematopoyéticos. La formación ósea es producida por los osteoblastos, los que derivan de células progenitoras mesenquimáticas (MSC). La MSC son células pluripotenciales que pueden diferenciarse a distintos fenotipos celulares, tales como osteoblastos, adipocitos u otros tejidos conectivos. La diferenciación de las MSC a osteoblastos o adipocitos necesita la expresión de genes asociados a cada uno de los fenotipos celulares. Para la diferenciación hacia adipocitos se requiere del PPAR\%. Se ha descrito en la población Japonesa que el alelo CC del polimorfismo Pml-I del gen PPAR $\gamma$ se asocia a una menor masa ósea. El objetivo del trabajo fue estudiar si existe en la población adulta mayor chilena algún alelo del gen del PPAR $\gamma$ que se asocia con fractura osteoporótica de cadera. En 120 pacientes adultas mayores (90 con fractura osteoporótica de cadera y 30 pacientes controles), que no tenían criterios de exclusión como insuficiencia renal 0 hepática, usuaria de glucocorticoides o vitamina D, se les extrajo de leucocitos de sangre periférica ADN genómico. Por técnica de la polimerasa en cadena (PCR) se amplificó un fragmento de 208 pares de bases (pb). Posteriormente el producto PCR fue digerido por la enzima de restricción Pml-I. Se observó que existe en la población chilena los tres genotipos descritos en la población japonesa: TT (208 pb), CT (158pb), y CC (50 pb). En el grupo con fractura osteoporótica de cadera 72 (80\%) fueron CC, 11 $(12,2 \%)$ CT y $(7,8 \%)$ TT. En la población control 10 (33,3\%) fueron CT y $7(23,3 \%)$ fueron TT. $(p<0,05)$.

Nuestro resultado sugiere que el genotipo CC del polimorfismo Pml-I del gen de PPARy se asocia a un mayor riesgo de fractura osteoporótica en la población adulta mayor chilena.

\section{EFECTO DE LA INHIBICIÓN FARMACOLÓGICA DEL RECEPTOR NUCLEAR FXR SOBRE EL COLESTEROL HDL Y LA EXPRESIÓN HEPÁTICA DEL RECEPTOR LIPOPROTEICO SCAVENGER RECEPTOR CLASE B TIPO I Y DEL TRANSPORTADOR ABCA1, AMBOS GENES INVOLUCRADOS EN EL METABOLISMO DE HDL}

Quezada N, Riaño C, Mardones P, Rigotti A.

Departamento de Gastroenterología, Facultad de Medicina, Pontificia Universidad Católica de Chile. Santiago, Chile.

Actualmente existen distintas alternativas terapéuticas para el manejo de las dislipidemias, destacando el uso de las estatinas (que reducen principalmente el colesterol LDL) y los fibratos (que disminuyen los triglicéridos). Sin embargo, aún no existen mecanismos eficientes que permitan elevar considerablemente el colesterol HDL plasmático. El gugulípido (GL) es un esteroide natural utilizado en la reducción del colesterol LDL y los triglicéridos en humanos que actualmente está disponible dentro de las altemativas farmacológicas no tradicionales para el tratamiento de las dislipidemias. Estudios recientes han demostrado que el GL es un antagonista del receptor nuclear FXR, el cual es un factor transcripcional hepático que establece un nexo entre el metabolismo del colesterol y de las sales biliares. Hasta la fecha, se desconoce el efecto del GL sobre el metabolismo de HDL Objetivo: evaluar si el GL modifica los niveles de colesterol HDL en el plasma del ratón y si este efecto se correlaciona con cambios en la expresión hepática del transportador ATP-Binding Cassette A1 (ABCA1) y/o del receptor de HDL Scavenger Receptor-Class B Type I (SR-BI), los cuales regulan la formación y el catabolismo de HDL, respectivamente. Métodos: En comparación con el grupo control, los grupos experimentales recibieron dosis crecientes de GL en la dieta $(2,5,7,5$, 12,5 y 25 mg día/ratón). El colesterol plasmático total, el perfil lipoproteico y los triglicéridos plasmáticos fueron medidos por ensayos enzimáticos. La expresión de las proteínas SR-BI y ABCA1 en el hígado se evaluó mediante westem blot. Resultados: La administración de GL produjo un aumento en el colesterol HDL plasmático (hasta 40\% de los niveles basales) y una reducción en la expresión de SR-BI (de hasta 45\%) en forma dosis dependiente. Los triglicéridos plasmáticos y los niveles hepáticos de ABCA1 no presentaron modificaciones estadísticamente significativas. Conclusión: Este estudio demuestra que el GL es un compuesto efectivo para elevar el colesterol HDL en el ratón, lo cual se asocia a una reducción en la expresión de SR-BI como posible mecanismo causal.

(FONDECYT No.1030416)

\section{EFECTO DE HORMONAS SEXUALES FEMENINAS $Y$ FITOESTEROLES SOBRE MECANISMOS INVOLUCRA- DOS EN EL EFLUJO DE COLESTEROL DESDE MACRÓ- FAGOS HUMANOS}

\section{RadojKOvic C. \\ Facultad de Farmacia, Campus Universitario, Universidad de Concepción.}

El metabolismo lipídico comprende procesos biológicos finamente regulados, cuyas alteraciones pueden conducir a una sobrecarga celular de colesterol y aterosclerosis. Para revertir este proceso existe un mecanismo encargado de la remoción de lípidos desde los tejidos, denominado eflujo de colesterol, el cual ocurre desde las células hacia aceptores plasmáticos, y es mediado por la proteína ATP-binding cassette transporter A1 (ABCA-1). Mutaciones del gen de ABCA1 pueden generar una proteína no funcional como ocurre en la Enfermedad de Tangier, cuyos pacientes sufren de enfermedad ateromatosa prematura. Éstas y otras evidencias han permitido establecer la relevancia de ABCA-1 en el eflujo de colesterol y los niveles intracelulares de colesterol. Por otro lado, se han identificado factores protectores del desarrollo de aterosclerosis, como, las hormonas sexuales femeninas endógenas y la ingesta de 
esteroles vegetales o fitoesteroles. Basado en estas evidencias se plantea como Objetivo de Trabajo evaluar el efecto de 17-ß estradiol, progesterona y de ß-sitosterol sobre la expresión del gen de ABCA-1 y la actividad de esta proteína. Metodos. Se utilizó como modelo experimental una línea celular de macrófagos derivados de monocitos humanos (THP-1), expuestos a LDL-acetilada. En este modelo se probó el efecto de 17-ß-estradiol, progesterona y ß-sitosterol (fitoesterol de la dieta) sobre la expresión del mRNA de la ABCA1 y sobre la magnitud del eflujo de colesterol. El mRNA se determinó amplificando un segmento de la ABCA1 mediante RT-PCR. El eflujo de colesterol se midió marcando las células con ${ }^{3} \mathrm{H}$ colesterol y usando como aceptor extracelular apolipoproteina A-I, incluida en liposomas. Resultados. La expresión del gen de ABCA1 no fue modificada por 17-ß-estradiol (15 nM) durante $18 \mathrm{hr}$ de tratamiento. Progesterona incrementó significativamente la expresión de este gen luego de $18 \mathrm{hr}$. ßSitosterol $(25 \mathrm{uM})$ produjo un aumento significativo en la expresión de este gen a partir de las $12 \mathrm{hr}$. Estas modificaciones se asociaron a variaciones en la magnitud del eflujo de colesterol. Conclusiones. Las hormonas sexuales femeninas y el componente de la dieta ß-sitosterol modulan la expresión y la actividad del transportador de colesterol ATP-binding cassette A1 (ABCA1), involucrado en la homeostasis celular del colesterol, sugiriendo la participación de estas moléculas en mecanismos anti-aterogénicos.

Financiado por Proyectos DIU: 202.072.027 y 203.072.029.

\section{UN ANÁLISIS CRÍTICO DE LOS PROLACTINOMAS OPERADOS}

Ramos C, Herrera M, Carrasco C, Vélz J, Rojas D*, Wohllk N. Universidad de Chile, Hospital del Salvador Sección Endocrinología, Instituto de Neurocirugía Asenjo (INCA)*, Instituto de Estudios Médicos Avanzados.

Introducción: Los prolactinomas (P) constituyen el 30\% de todos los tumores pituitarios y el $60 \%$ de los funcionantes. Existe relativo consenso en que la terapia de elección es médica $\mathrm{y}$, ocasionalmente quirúrgica y/o con radioterapia. Objetivos: evaluar la presentación clínica, complicaciones quirúrgicas y resultado postoperatorio, con y sin terapia médica, de los $\mathrm{P}$ operados.

Material y método: estudio retrospectivo de pacientes operados en INCA entre 1984 y 2004 con prolactinemia (PRL) $>150 \mathrm{ng} / \mathrm{ml}$ e histología de adenoma cromófobo. Resultados: total 36 tumores: $54 \%$ mujeres con edad promedio de 31 años (17-45) y 46\% hombres con edad promedio de 35 años (15-69). $8 \%$ (3) eran microadenomas. Hallazgos prevalentes en mujeres: hipogonadismo $95 \%$, galactorrea $70 \%$, cefalea $50 \%$ con latencia diagnóstica 72 meses (1-240). Hallazgos prevalentes en hombres: trastornos visuales $75 \%$, cefalea $69 \%$, hipogonadismo $31 \%$ y latencia diagnóstica 11 meses (0-36). Del grupo total, el 22\% debutó con apoplejía y el 56\% con compromiso visual. La PRL preoperatoria (preop.) promedio fue de $745 \mathrm{ng} / \mathrm{ml}(1-4240)$, destacando 2 casos con PRL preop. normal y postop >180 ng/ $\mathrm{ml}$ (diluída). Sólo el 44\% tuvo evaluación endocrina preop. Complicaciones más frecuentes: $25 \%$ diabetes insípida transitonia y $5,5 \%$ III par y $3 \%$ amenorrea. Mortalidad: 0 . Mejoría visual completa $50 \%$ y parcial $30 \%$. Se logró curación bioquímica con cirugía en el 22\% (1 microprolactinoma). El resto usó Bromocriptina o Cabergolina (tratamiento irregular y con dosis bajas), logrando cura bioquímica en $70 \%$ y $75 \%$ respectivamente. Conclusiones: a diferencia de lo publicado: a) la frecuencia fue similar en ambos sexos; b) la demora diagnóstica fue menor en hombres; c) el éxito quirúrgico fue inferior (50-75\% publicado vs $22 \%$ INCA) lo que podría explicarse por el mayor tamaño e invasión tumoral y niveles elevados de PRL preop. Las complicaciones quirúrgicas fueron similares a las publicadas por otros grupos. La respuesta al tratamiento médico fue concondante con la literatura, a pesar de la falta de adherencia. En suma, nuestros resultados apoyan la elección del tratamiento médico sobre el quirúrgico.

\section{UTILIDAD DE LA DE DENSITOMETRÍA DE CUELLO FEMORAL (DCF) VERSUS VOLUMÉTRICA DE COLUM- NA (DV) EN NIÑOS CON GRADOS VARIABLES DE EJERCICIO CON CARGA}

Reyes ML, Cattani A, Hernández Mi, Talesnik E, Hernández M, ESCOBAR R.

Programa de Metabolismo Oseo, Unidad de Neurología Infantil. Depto. de Pediatría, Facultad de Medicina, P. Universidad Católica de Chile.

Valores normales DCF en niños son poco asequibles, y por esto, la DCF (a diferencia de columna lumbar) no es evaluada regularmente. La falta de ejercicios con carga se sabe afecta el hueso cortical de cadera en adultos.

Objetivos: Evaluar el grado de compromiso de DCF versus DV en niños con patologías con disminución variable del ejercicio con carga.

Métodos: Se analizaron mediante ANOVA el puntaje Z de DCF y DV (ZCF y ZDV) (Lunar-DPX-L) de 34 niños; 21 mujeres; 10,8 (3,4-18,9) años. La actividad física se estratificó en: $1=$ no camina; $2=$ camina, no corre; $3=$ corre normalmente. Los diagnósticos fueron en el grupo $1=$ Parálisis cerebral: 3 ; Miopatías:5; Malformación SNC:3; Atrofia músculo espinal tipo I=1; Daño 2a motoneurona:1; grupo 2= Artritis reumatoidea :4; Leucemia linfática aguda: 3; Artrogriposis:1; Hemiplejia:1; Osteosarcoma:1; grupo 3= Anorexia nerviosa:3; Osteoporosis inducida por corticoides:2; Hipovitaminosis D:1; Déficit de hormona de crecimiento:1. Se descartaron aquellos con terapia antiresotiva, elementos metálicos óseos, o deformaciones de la cadera.

Resultados: EL ZCF disminuye progresiva y significativamente a medida que disminuye la carga. ZDV disminuye 
Tabla 1.

\begin{tabular}{|lcccc|}
\hline & \multicolumn{3}{c}{ Promedio \pm Error estándar } & p \\
& Grupo 1 & Grupo 2 & Grupo 3 & \\
\hline ZCF & $-4,88 \pm 0,52^{*}$ & $-2,12 \pm 0,57 *$ & $-0,479 \pm 0,60^{*}$ & $* 0,00001$ \\
ZDV & $-1,62 \pm 0,51$ & $-2,31 \pm 0,55$ & $-0,22 \pm 0,58^{*}$ & $* 0,004$ \\
ZCF-ZDV & $-3,26 \pm 0,70^{*}$ & $0,18 \pm 0,77$ & $-0,25 \pm 0,80$ & $* 0,004$ \\
\hline
\end{tabular}

significativamente sólo en el grupo 3 respecto a 1 y 2 . ZCF se afecta más que ZDV sólo en el grupo 1. 25\% de los niños con $\mathrm{ZCF} \leq-1,5$ tienen un ZDV >1,5 (Tabla 1).

Discusión: La DCF se compromete significativamente en los niños con menos ejercicio con carga, pero no muestra un compromiso mayor que el de DVOL en niños capaces de caminar. Una densitometría normal en columna lumbar no descarta osteoporosis en cadera. En niños con disminución de la carga se debe evaluar DCF. En lo posible, se debe preservar 0 rehabilitar la marcha.

\section{CORRELACIÓN ENTRE TESTOSTERONA TOTAL Y BIODISPONIBLE EN HIPOGONADISMO CON DIS- FUNCIÓN SEXUAL}

Ríos R, BASSAS L.

Endocrinología Hospital San Borja Arriaran, Universidad de Chile. Fundación Puigvert, Hospital Sant Pau, Barcelona, España.

Objetivos: determinar en pacientes con el diagnóstico de hipogonadismo el grado de disfunción eréctil (DE) y la correlación con los niveles de testosterona total, biodisponible (calculada) y la edad. Metodología: se incluyeron retrospectivamente 33 pacientes con el diagnostico de hipogonadismo que consultaron por DE en la Fundación Puigvert periodo 2002-2003 de los cuales se consideró el tipo de hipogonadismo, testosterona total (TE) medida por electroquimioluminiscencia y testosterona biodisponible (Tbd). Según la formula de Vermueler (J Clin Endocrinol Metab 84:3666, 1999) mas (DE) según el IIEF-5 (Tabla 1).

Conclusiones la mayoría de los pacientes resultaron ser hipogonadotropos y en este grupo se concentró la DE moderada, no hubo significación entre los niveles de testosterona total y los grados de $\mathrm{DE}$, la correlación de la Tb con la edad fue mejor y significativa con respecto a la $\mathrm{Tt}$. con la edad.

\section{TUMOR PLURIHORMONAL PRODUCTOR DE TSH Y $\mathrm{FSH}$}

Ríos R, Garzon V, Lıo X, Sáez L.

Dpto. de Endocrinología y Neurocirugía Hospital San Borja Arriaran, Campus Centro, Anatomía Patológica, Hospital J.J. Aguirre, Campus Norte, Facultad de Medicina Universidad de Chile

Paciente de 28 años con antecedentes de depresión mayor comenzó con cefalea en nov. del 2002, por lo que se

Tabla 1.

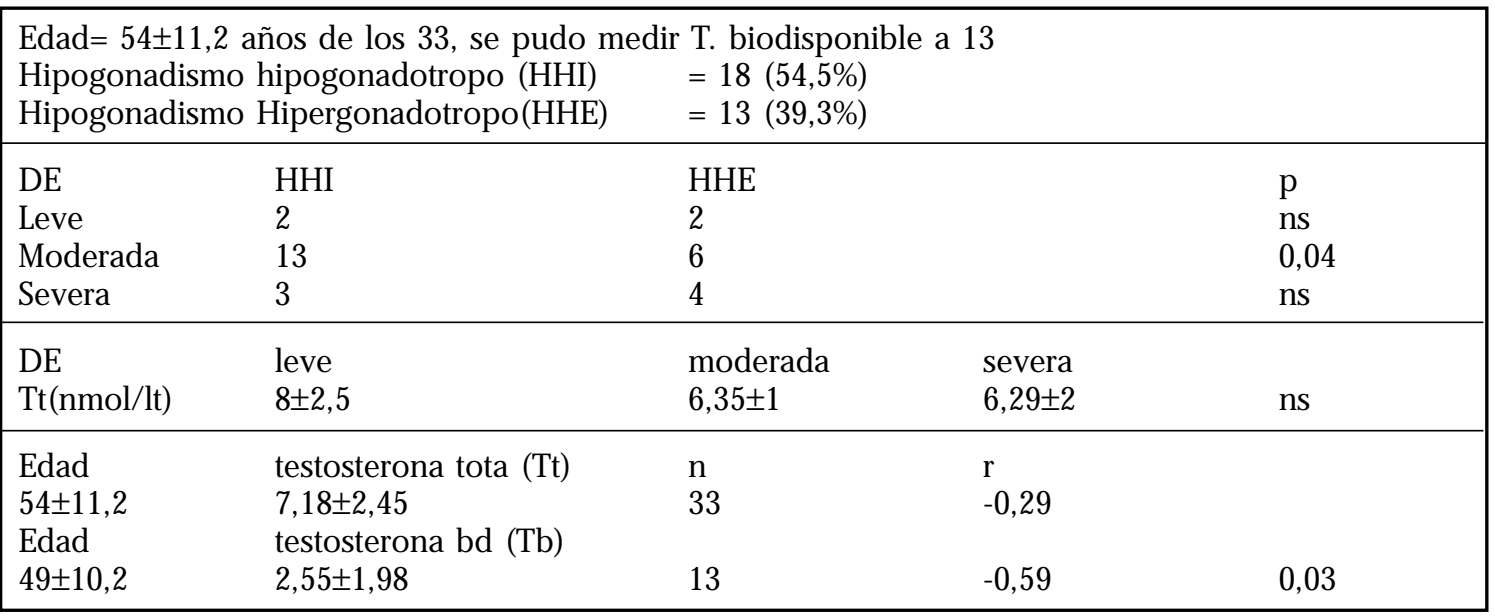


solicita el 6/6/03 TAC cerebral= Proceso expansivo supraselar sugerente de macro adenoma hipofisiario. Por este motivo se deriva a endocrinología, en donde se solicitan exámenes (julio 2003) = TSH: 11,01 (0,3-5 mUi/ml) T3: 218 $\mathrm{ng} / \mathrm{ml}$ (86-186), FSH: 2,1 (1,1-13,5 mU/ml), LH: 2,0 (0,4-5,7 $\mathrm{mU} / \mathrm{ml})$, PRL: $26,7 \mathrm{ng} / \mathrm{dl}$, IGF 1: $75(70-554 \mathrm{ng} / \mathrm{ml})$, Cortisol: $6,5 \mathrm{ng}(6,5-26 \mathrm{Mg} / \mathrm{ml})$, ACTH: $15,5(0-50 \mathrm{pg} / \mathrm{ml})$, Testosterona: $240(300-1100 \mathrm{ng} / \mathrm{dl})$. Se plantea posible Hipertiroidismo mas Hipogonadismo impresiona eutiroideo pero refiere disminución de libido y erección matinal, al examen no se palpa bocio y los testes son normales. Se le solicita eco. tiroidea que muestra Bocio leve, mas campimetria ocular normal y Test de TRH:TSH basal 8,7 TSH 13,1 (30 min), Anticuerpos (+) y TSH: 10,8 mUi/ml, T4: $13,5(4,2-12 \mathrm{ng} / \mathrm{ml})$.

Con estos antecedentes se pide captación de tiroides que muestra $41 \%$ a las $24 \mathrm{~h}$, y se plantea posible tumor productor de TSH, se opera por vía transesfenoidal el 6-10-03, resultando cirugía sin complicaciones, la Inmunohistoquímica muestra Adenoma Hipofisiario Plurihormonal productor de TSH y FSH. El control postoperatorio muestra (23-11-03) Testosterona: 226 ng/dl, LH: <1,5mU, FSH: 3 mU, TSH: 3,9 mU, T3: $168 \mathrm{ng} / \mathrm{dl}$, T4: 10,2 ng/dl .Inicia terapia con cortisol $20 \mathrm{mg} /$ día, testosterona $250 \mathrm{mg} / 21$ días y se le realiza un test de weber: TSH y T3 basal: 3,9-168, post t3: 1,7-344, más una Shbg: $123 \mathrm{ng} / \mathrm{ml}$, se decide control cd. dos meses.

En enero 2004 con T4, T3 y Tsh, Normales reinicia cefalea y disminución de campo visual, se realiza una resonancia de control (10-3-04) demuestra recidiva tumoral con macroadenoma de $20 \mathrm{~mm}$ y compresión del quiasma óptico, por lo que se reopera por vía transesfenoidal (19-5-04), y la biopsia demuestra un Adenoma Plurihormonal productor de TSH Y FSH,mas una Ki67 positivo. En julio 2004, con su mismo reemplazo hormonal, sin cefalea se inicia ciclos de radioterapia la que recibe hasta la fecha.

\section{NUEVOS FACTORES DE RIESGO PARA COMPLICA- CIONES CRÓNICAS EN PACIENTES DIABÉTICOS TIPO 2}

Rivera S, Liberman C, Conte G, Schiattino I, Cuneo M, Caamaño E, Lechuga M, Vargas C.

Sección Endocrinología; Hospital Clínico Universidad de Chile.

Homocisteína, PAI y Ferritina han surgido como nuevos factores de riesgo ateroesclerótico; en ellos se han demostrado efectos agudos y crónicos a nivel endotelial. El objetivo de este trabajo fue evaluar el grado de asociación entre estos factores y las complicaciones crónicas en pacientes diabéticos tipo 2. Materiales y Métodos: Se incluyeron 60 pacientes: 40 diabéticos tipo 2 y 20 sujetos controles. Se excluyeron aquellos con: creatinina sérica $>1,5 \mathrm{mg} / \mathrm{dl}$, hipertensión arterial, embarazo, insuficiencia cardíaca congestiva. Los diabéticos se dividieron en 2 grupos: con y sin cardiopatía coronaria demostrada mediante coronariografía. Resultados: En la Tabla 1 se muestran las características.

Método estadístico: se aplicó la prueba de Kruskal-Wallis para comparar los niveles de las mediciones consideradas (homocisteína, PAI, Ferritina). Además se aplicó prueba no parámetrica de comparaciones múltiples y prueba Wilcoxon. Conclusiones: 1. Los niveles de homocisteína son mayores en pacientes diabéticos con cardiopatía coronaria. En no coronarios son similares a los encontrados en el grupo control. 2. Los niveles de ferritina fueron similares en diabéticos con y sin complicación coronaria. 3. Los niveles de PAI son mayores en pacientes diabéticos comparados con el grupo control, pero no fueron diferentes entre sí. Estos resultados apoyan un rol aterogénico para homocisteína, y PAI, pero no para ferritina. Estudios prospectivos son necesarios para confirmar estos hallazgos.

Tabla 1.

\begin{tabular}{|lccc|}
\hline Características & Sin EC & Con EC & Control \\
\hline $\mathrm{n}$ & 20 & 20 & 20 \\
Hombre/Mujer & $11 / 9$ & $12 / 8$ & $10 / 10$ \\
Edad & $58,8(6,26)^{*}$ & $65,4(8,2)^{*}$ & $58,2(7,96)^{*}$ \\
Tiempo Diagnóstico DM & $3,48(3,7)$ & $8,1(9,8)$ & - \\
$\mathrm{IMC}\left(\mathrm{kg} / \mathrm{m}^{2}\right)$ & $28,4(4,28)$ & $27,7(3,88)$ & $26,9(2,3)$ \\
HbA1C (\%) & $6,27(0,7)^{*}$ & $6,53(0,8)^{*}$ & - \\
Creatinina Sérica (mg/dl) & $0,93(0,16)$ & $1,03(0,2)$ & - \\
Colesterol Total Sérico $(\mathrm{mg} / \mathrm{dl})$ & $181(34,7)$ & $174(41,8)$ & - \\
Colesterol LDL $(\mathrm{mg} / \mathrm{dl})$ & $107(31,8)$ & $95,9(39,9)$ & $8,24(1,93)^{*}$ \\
Homocisteina $(\mathrm{mol} / \mathrm{L})$ & $9,19(1,99)^{*}$ & $10,9(3,76)^{*}$ & $110,9(55,1)$ \\
Ferritina $(\mathrm{ng} / \mathrm{mL})$ & $145(98,6)$ & $123(99,5)$ & $5,65(2,6)^{*}$ \\
PAI (AU/ml) & $11,4(6,6)^{*}$ & $12,4(7,7)^{*}$ & \\
\hline
\end{tabular}

n, media o D.S.*Significativo P Value $<=0,05$. 


\section{ENFERMEDAD DE VAN BUCHEN (EVB): UNA FOR- MA GRAVE DE HIPEROSTOSIS GENERALIZADA}

RoA N, López JM, González G.

Departamento de Endocrinología, Facultad de Medicina. pontificia Universidad Católica de Chile.

La EVB es un forma muy rara de engrosamiento óseo cortical del endostio o hiperostosis. El aumento de la masa ósea se manifiesta como crecimiento post-puberal asimétrico de la mandíbula, oclusión de la salida de los nervios craneanos (con anosmia, sordera, ceguera, parálisis facial) y del foramen oval, y además anemia por restricción de la médula ósea. La EVB compromete huesos largos, cráneo, vértebras, pelvis y costillas; no se asocia a aumento de riesgo de fractura. El hueso en exceso es de calidad normal. El laboratorio señala aumento universal de la densidad mineral ósea y de los marcadores de remodelación ósea, con predominio de los de formación ósea. Una deleción de 52-kb en el gen SOST está relacionada a esta enfermedad (Balemans W et al. 2002 J Med Genet 39: 91-97). No se conoce terapia específica y la descompresión del foramen oval es la alternativa ante la gravedad de su cierre. Nuestro objetivo es comunicar un caso de EVB, patología no descrita en Chile, para favorecer el reconocimiento en nuestro medio de futuros casos de esta rara enfermedad. Caso clínico: Hombre de 25 años a quién a los 3 años se le detectó aumento de la densidad radiológica de costillas y vértebras, siendo rotulado como osteopetrosis. Progresivamente, notó mentón cuadrado y prominente, hipertelorismo, puente nasal ancho, hipoacusia bilateral, disminución de la visión a distancia y anosmia. Refería además hundirse al nadar; sin cefalea. CI normal (108). Sus padres de origen italiano y español. Examen: peso $99 \mathrm{~kg}$, talla 1,91 mt, IMC 27,1 k/ $\mathrm{mt}^{2}$, facies característica de EVB, sin desviaciones faciales; anosmia e hipoacusia leves, conjuntivas rosadas. PA: 132/78 mmHg. Resto del examen sin hallazgos de significación. El paciente ha sido controlado durante 7 años. Usó calcitriol los tres años iniciales, lo que produjo hipercalciuria (> $700 \mathrm{mg} / 24 \mathrm{~h}$; V.N. $<300 \mathrm{mg} / 24 \mathrm{~h}$ ). Actualmente sin terapia específica. La evolución de la DMO $\left(\mathrm{g} / \mathrm{cm}^{2}\right)$ y el T score, según fecha y localización es: $\mathrm{L}_{2}-\mathrm{L}_{4}$ (05/95): 2.097; (07/02): 2.958; T +14,6; (11/03): 2.935; T +14,1; Cuello fémur izquierdo (05/95): 3.357; T +19,8; (07/ 02): 3.357; $\mathrm{T}+19,8(11 / 03)$ : 3.235; T +16,7. F. alcalinas 710$683 \mathrm{UI} / \mathrm{L}$ (VN: 45-115 UI/L), osteocalcina $167 \mathrm{ng} / \mathrm{ml}$ (VN:25 $\pm 8,1)$, (OH) Prolina/creat: $77 \mathrm{mg} / \mathrm{g}(\mathrm{VN}:<45)$; DPD: $38,4 \mathrm{nM} / \mathrm{mMcreat}$ (VN: 2,3-5,4 nM/mM). Ca: $9,7 \mathrm{mg} / \mathrm{dl}$ y $\mathrm{P}$ : 4,0 mg/dl; PTH: 55-67 pg/ml (VN:7-53 pg/ml); 25(OH)D: 16,5 ng/mL(VN: 15-40 ng/mL). El estudio del gen SOST (Dra. Balemans, Bélgica) no encontró la deleción de 52-kb descrita en pacientes holandeses, pero si demostró otra mutación presente en el paciente y en su madre, aunque en ella no existe expresión fenotípica de la enfermedad. El gen LRP5, implicado también en aumento de densidad ósea, no mostró alteraciones.
FRACTURAS VERTEBRALES, DENSIDAD OSEA Y VITAMINA D: HALLAZGOS EN 555 MUJERES POSTMENOPÁUSICAS

Rodríguez JA, Trincado P, Nápoli C.

Depto. Endocrinología y Centro de Investigaciones Médicas, Fac. Medicina P. Universidad Católica de Chile.

Las fracturas vertebrales confieren alto riesgo para nuevas fracturas, por lo que es importante identificar a quienes las portan. Objetivo: Determinar la frecuencia de fracturas vertebrales en 555 mujeres postmenopáusicas de la Región Metropolitana. Secundariamente, averiguar si la presencia de fracturas se correlaciona con una menor densidad ósea mineral 0 con niveles más bajos de vitamina D. Diseño: Estudio observacional transversal. Sujetos y métodos: 555 mujeres entre 55 y 84 años, postmenopaúsicas desde al menos 2 años, seleccionadas por su interés en participar en un estudio de osteoporosis, sin uso de fármacos con actividad sobre hueso desde al menos 6 meses, sin patologías relevantes.

Se tomó radiografía digitalizada lateral de columna (T4 a L4) con técnica estandarizada. Un radiólogo evaluó las placas usando morfometría cuantitativa y semicuantitativa para identificar fracturas. En caso de discordancia entre ambas técnicas, otro radiólogo revisó las placas usando el método semicuantitativo. Para el diagnóstico de fractura se requirió la conformidad de al menos 2 de estas 3 determinaciones. A todas las pacientes se les midió la densidad ósea mineral (DOM) en columna y cadera en un densitómetro Lunar DPXL, y se les tomó muestra de sangre en ayunas para medir calcidiol. Para comparar grupos se usó el test de t de Student y el de Mann-Whitney. Resultados: Se encontró al menos una fractura vertebral en 142 pacientes (25,6\%). El porcentaje de mujeres con fractura aumentó progresivamente con la edad. Se encontró osteoporosis ( $\mathrm{T}<-2.5 \mathrm{DE}$ ) en columna en 31,9\% y en cadera en $14,1 \%$ de las pacientes. La proporción de pacientes con osteoporosis en columna se duplicó entre los 55 y los 70 años manteniéndose constante después. En cambio en cadera la proporción fue en ascenso hasta llegar a 53,3\% a los 80-84 años. Los niveles de calcidiol fueron $16,78 \pm 6,79 \mathrm{ng} / \mathrm{mL}$ (promedio $\pm \mathrm{DE}$ ). Usando un punto de corte de $17 \mathrm{ng} / \mathrm{mL}$, un $47,5 \%$ de las pacientes tenían hipovitaminosis D. No hubo correlación significativa entre niveles de calcidiol y presencia de fracturas vertebrales, ni con DOM en columna o cuello femoral. Las pacientes con fractura vertebral difirieron de las sin fractura en que tuvieron DOM significativamente menor en columna y cuello femoral $(p<0,001)$ y una edad significativamente mayor $(\mathrm{p}<0,001)$ pero no difirieron en peso, IMC, ni en niveles de calcidiol. Conclusiones:1) Hay una alta frecuencia de fracturas vertebrales, de osteoporosis y de hipovitaminosis D en mujeres postmenopáusicas 2) A pesar de la alta frecuencia de hipovitaminosis D, ello no se correlacionó con DOM ni con fracturas. 


\section{MASTOCITOSIS SISTÉMICA Y OSTEOPOROSIS: EFECTO DE ALENDRONATO}

RodríGUEZ JA, NACHARI I.

Depto. Endocrinología, P.Universidad Católica de Chile.

La mastocitosis sistémica es una enfermedad poco frecuente que puede causar osteoporosis y cuyo tratamiento con alendronato no ha sido comunicado. Se presenta el caso de un hombre de 36 años que consultó por fractura de L1 al levantar un mueble. Entre sus antecedentes destacaban 3 fracturas traumáticas periféricas, episodios de disnea catalogados de asma, dolores óseos generalizados, episodios de prurito y rashes cutáneos no pruriginosos. Calcemia 9,3 mg/ $\mathrm{dL}$, fosfemia 3,7 mg/dL, PTH 24,14 pg/mL, 25 hidroxivitamina D $26 \mathrm{ng} / \mathrm{mL}$, TSH 2,1 mUI/mL, LH 1mUI/mL, testosterona total $412 \mathrm{ng} / \mathrm{dL}$, calciuria $338 \mathrm{mg} / 24 \mathrm{~h}, \mathrm{pH}$ orina fresca 5,5, puentes de desoxipiridinolina urinaria $2,5 \mathrm{nM} / \mathrm{mM}$ creat $(\mathrm{N}=2,3-5,4)$. La densitometría ósea mostró un score $\mathrm{T}$ de 4,8 en L2-L4 y -3,7 en cuello femoral izquierdo. El estudio histomorfométrico de una biopsia ósea de cresta ilíaca mostró osteoporosis severa con ausencia de conectividad trabecular. Inició tratamiento con alendronato (Fosamax) 10 $\mathrm{mg} / \mathrm{d}$ y luego $70 \mathrm{mg} / \mathrm{semana}$, calcio elemental $1000 \mathrm{mg} / \mathrm{d}$, hidroclorotiazida $25 \mathrm{mg} / \mathrm{d}$. Al cabo de 4 años, la DOM subió $16 \%$ en L2-L4 y 8,9\% en cuello femoral. Una segunda biopsia ósea en cresta ilíaca para histomorfometría mostró proliferación difusa de mastocitos por lo que se hizo el diagnóstico de mastocitosis sistémica con rarefacción del hueso trabecular con aumento de la resorción y baja formación ósea.

En conclusión, se presenta un caso de osteoporosis masculina severa asociado a proliferación de mastocitos en médula ósea y cuadro clínico compatible con mastocitosis sistémica. El tratamiento con alendronato mejoró la densidad ósea mineral pero disminuyó la formación ósea histomorfométrica.
EL CRECIMIENTO COMPENSADOR DE NIÑOS PEQUEÑOS PARA LA EDAD GESTACIONAL (PEG) ESTÁ RELACIONADO CON LA SENSIBILIDAD A IGF-I

Román R, IÑiguez G, Salazar T, Avila A, Barrera A, Merice V, GUNN R, CASSORLA F.

Instituto de Investigaciones Materno Infantil, Universidad de Chile, Santiago, Chile; Insmed Inc, Glen Allen, VA.

Considerando que los niños PEG pueden desarmollar insulinoresistencia, y que IGF-I, Insulina y sus receptores tienen una alta homología estructural, postulamos que una disminución de la sensibilidad a IGF-I podría afectar el crecimiento compensador (CC) de algunos niños PEG. Objetivo: estudiar la sensibilidad a IGF-I en niños PEG con $(\mathrm{CC}(+))$ y sin $(\mathrm{CC}(-))$ crecimiento compensador. Métodos: estudiamos 20 niños PEG prepúberes. Se clasificaron $\mathrm{CC}(+)$ con estatura actual >-1Ds bajo la talla diana, y CC(-) con estatura actual <-1Ds bajo la talla diana. Para medir la sensibilidad a IGF-I se realizó un test funcional, midiendo el perfil noctumo espontáneo de $\mathrm{GH}$ (muestras cada 20 minutos desde las 23 a las $07 \mathrm{hrs}$ ) (perfil A) y después de un bolo sc de IGFI+IGFBP-3 (B) (Somatokine ${ }^{\circledR}$, donado por Insmed). En cada paciente se comparó el promedio de la concentración de $\mathrm{GH}$ (GH), del área bajo la curva de GH (ABCGH) y de la amplitud de los pulsos de $\mathrm{GH}(\mathrm{AmpGH})$ en condiciones basales (A) y post Somatokine (B) (Test de Wilcoxon). Resultados: Las características clínicas se muestran en Tabla 1 y los perfiles A y $\mathrm{B}$ en Tabla 2. No hubo diferencias basales de $\mathrm{GH}$ entre $\mathrm{CC}(+) \mathrm{y}$ CC(-); sin embargo, post Somatokine, los CC(+) disminuyeron significativamente la $\mathrm{GH}$, lo que no se observó en los CC(-).

Conclusión: IGF-I/IGFBP-3 inhibe la secreción de GH en niños $\mathrm{CC}(+)$ pero no en niños CC(-), indicando una sensibilidad pituitaria disminuida a IGF-I. Nuestros resultados sugieren que una disminución de la sensibilidad a IGF-I puede afectar el crecimiento compensador en algunos niños PEG. Tablas 1 y 2: (promedio y EEM) test $t$ de Student 0 de Mann-Whitney $\left({ }^{*} p<0,05\right)$

Financiado por Fondecyt 1020965.

Tabla 1. Comparación de H istomorfometría 1999 Y 2003

\begin{tabular}{|lccc|}
\hline & 1999 & 2003 & V. Normales \\
\hline Vol. H. trabecular \% & 9,8 & 16,7 & $19,3 \pm 3,1$ \\
Ext.sups. erosionadas & 2,2 & 5,4 & $3,6 \pm 1,1$ \\
Vol. Osteoide \% & 2,5 & 1,2 & $2,7 \pm 1,3$ \\
Sups. Osteoides \% & 17,0 & 6,6 & $14,4 \pm 5,9$ \\
Indice capa osteoide & 14,7 & 18,2 & $18,7 \pm 4,5$ \\
Tasa calcif. Cortical $\mu \mathrm{m} / \mathrm{d}$ & 0,68 & 0,71 & $0,72 \pm 0,12$ \\
Tasa calcif. Trabec. $\mu \mathrm{m} / \mathrm{d}$ & 0,71 & 0,76 & $0,72 \pm 0,12$ \\
\hline
\end{tabular}


Tabla 1.

\begin{tabular}{|cccccc|}
\hline & Niños/niñas & $\begin{array}{c}\text { Peso al nacer } \\
(\mathrm{g})\end{array}$ & $\begin{array}{c}\text { Edad actual } \\
\text { (años) }\end{array}$ & $\begin{array}{c}\text { Estatura actual } \\
(\mathrm{Z} \text { score })\end{array}$ & $\begin{array}{c}\text { BMI actual } \\
\text { (Z score })\end{array}$ \\
\hline $\mathrm{CC}(+)$ & $9 / 3$ & $2670 \pm 24$ & $6,7 \pm 0,7$ & $-1,52 \pm 0,30$ & $0,17 \pm 0,32$ \\
$\mathrm{CC}(-)$ & $4 / 4$ & $2524 \pm 128$ & $8,2 \pm 0,5$ & $-2,83 \pm 0,16^{*}$ & $-0,15 \pm 0,37$ \\
\hline
\end{tabular}

Tabla 2.

\begin{tabular}{|lcccccc|}
\hline & $\begin{array}{c}\text { GH A } \\
(\mathrm{ng} / \mathrm{ml})\end{array}$ & $\begin{array}{c}\text { GH B } \\
(\mathrm{ng} / \mathrm{ml})\end{array}$ & $\begin{array}{c}\text { ABC-GH A } \\
(\mathrm{ng} / \mathrm{ml} \text { x min })\end{array}$ & $\begin{array}{c}\text { ABC-GH B } \\
(\mathrm{ng} / \mathrm{ml} \text { x min })\end{array}$ & $\begin{array}{c}\text { AmpGH A } \\
(\mathrm{ng} / \mathrm{ml})\end{array}$ & $\begin{array}{c}\text { AmpGH B } \\
(\mathrm{ng} / \mathrm{ml})\end{array}$ \\
\hline $\mathrm{CC}(+)$ & $7,2 \pm 0,7$ & $4,0 \pm 0,3^{*}$ & $3444 \pm 243$ & $2011 \pm 162^{*}$ & $11,4 \pm 1,3$ & $8,2 \pm 1,1^{*}$ \\
$\mathrm{CC}(-)$ & $5,2 \pm 0,8$ & $4,0 \pm 0,6$ & $2628 \pm 375$ & $2029 \pm 296$ & $8,0 \pm 1,6$ & $7,6 \pm 1,6$ \\
\hline
\end{tabular}

${ }^{*} \mathrm{p}<0,05 \mathrm{~A}$ vs B en $\mathrm{CC}(+)$

\section{TUMORES NEUROENDOCRINOS DE PÁNCREAS- AVANCES DIAGNÓSTICOS Y TERAPÉUTICOS}

Rosi F R, Franco C, Moyano L, Fernández G, Rossi M R, Rojas H, Amaral H, Paganelli G.

Departamentos de Cirugía y Anatomía Patológica, Hospital Clínico de la Universidad de Chile, Clínica Alemana de Santiago, Clínica Santa María, Instituto Oncológico Europeo de Milán.

Introducción: Ha aumentado por uso masivo de imagenología abdominal el diagnóstico precoz y se han introducido nuevas modalidades terapéuticas en tumores neuroendocrinos de páncreas (TNEP). La mayoría de los incidentalomas»pancreáticos sólidos son TNEP. Objetivos: Evaluar el impacto del diagnóstico precoz y de nuevos métodos diagnósticos y terapéuticos en la biología de los TNEP. Pacientes y Método: Se evalúa una serie consecutiva de pacientes tratados desde 1996 a 2004 con el diagnóstico patológico de TNEP. Resultados: Se trató 9 hombres y 7 mujeres entre 19 y 71 años. Seis se presentaron asintomáticos con diagnóstico incidental y 10 eran sintomáticos (5 con hiperfunción hormonal, 5 con ictericia obstructiva y/o dolor). Tres tenían TNEP múltiples. Se realizaron 6 resecciones pancreáticas (R:P.) cefálicas diversas, 5 R.P. distales (3 abiertas, 2 laparoscópicas), 2 RP segmentarias centrales, 1 pancretectomía subtotal, 1 enucleación y 1 biopsia percutánea. No hubo mortalidad. La histología reveló: 6 TNEP benignos, 3 TNEP de conducta incierta, 7 TNEP malignos (TNEM). El seguimiento medio fue de 4 años (9 a 108 meses). La cintigrafía con octreótido detectó el tumor primario y recurrencias en los TNEP no funcionantes y en el gastrinoma. El tamaño medio de los TNEP incidentales fue de 1,5 cm (1-2), 2/6 tenían micrometástasis ganglionares y/0 microinvasión. Ambos desarrollaron metástasis hepáticas. El resto (4/6) está libre de enfermedad. El tamaño tumoral medio en los 7 pacientes sintomáticos con TMEM fue 4,5 $\mathrm{cm}(2,5$ a $7 \mathrm{~cm}), 6$ tuvieron ganglios positivos y 4 han desarrollado metástasis y/0 recurrencias. Tres pacientes han recibido Dotatoc Y 90 con mejoría sintomática y regresión tumoral entre 40\% y $90 \%$, sin haber tenido respuesta previa a quimioterapia. Conclusiones: 1) El incidentaloma sólido debe resecarse, ya que TNEP pequeños pueden metastatizar. 2) El cintigrama con ocreótrido parece útil en etapificación y seguimiento en el subgrupo con receptores para somatostatina (hoy identificable por inmunohistoquímica) 3) La selección del procedimiento quirúrgico permite conservar tejido pancreático y minimizar morbimortalidad. 4) Hubo respuesta a Dotatoc Y 90 y no a quimioterapia.

\section{ANGIOPLASTIA CON STENT-RAPAMICINA EN DIA- BÉTICOS TIPO 2}

Ruiz C, Martínez C, Aylwin CG, Deck C*, Alcaíno M*. Unidad de Diabetes, Serv. Medicina y Centro Cardiovascular* Hospital DIPRECA.

La cardiopatía coronaria es una de las principales causas de morbimortalidad en diabéticos (DM). A pesar de los avances en el tratamiento médico, intervencional y quinúrgico de la enfermedad coronaria, sus resultados en el DM son inferiores a los no DM. La angioplastía simple o con stent constituye una importante opción terapéutica de la patología comnaria. Sin embargo, en $\mathrm{DM}$, presenta un riesgo de reestenosis de 50-70\%, según la severidad de la lesión y tipo de angioplastía. Ésta se produce preferentemente durante el primer año, la mitad con manifestaciones clínicas, por lo que la diabetes es considerada un factor de alto riesgo de reestenosis. Los stent con drogas inhibidoras de la proliferación intimal han demostrado reducción del riesgo de reestenosis a $0-18 \%$ en DM, por lo que ésta patología es considerada un criterio de selección para su uso, independiente 
de la severidad de la lesión angiográfica. Las indicaciones en no DM incluyen lesiones severas (diámetro $<2,7 \mathrm{~mm}, \mathrm{y} / \mathrm{o}$ longitud $>$ $20 \mathrm{~mm}$ ) y lesión proximal de arteria descendente anterior (ADA). Objetivos: Evaluar evolución clínica en DM tipo 2 tratados con stent con rapamicina (SR) y compararla según gravedad de la lesión angiográfica. Pacientes y método. Entre junio 2002 y enero 2004 se implantaron 27 SR en 20 DM 2. Hombres: 12, mujeres: 8, edad $63 \pm 8,6$ años, antigüedad DM 9,5 55,5 años. Síndrome coronario agudo 16, angina estable 1 , isquemia silente 3 . Enfermedad de 3 vasos: 4, enf 2 vasos 9, enf. 1 vaso 5, enf. Tronco 1. Reestenosis de by-pass safeno 1.14 DM con otro factor de alto resgo de reestenosis: 9 con lesión coronaria severa y 5 con lesión proximal de ADA. Se efectuó seguimiento clínico por un mínimo de 6 meses evaluando capacidad funcional, disnea, angor y eventos coronarios. Resultados: Seguimiento $14+7,0$ meses. Todo los implantes se realizaron en forma exitosa y sin complicaciones. Durante el peńodo de observación 18 pacientes permanecieron asintomáticos. 2 pacientes (1 lesión severa y 1 simple) presentaron angina con capacidad funcional II a los $6 \mathrm{y}$ 12 meses de seguimiento, sin reestenosis angiográfica. No hubo diferencias en la evolución clínica según severidad de la lesión angiográfica. Conclusión: Este grupo de DM 2 presentó evolución clínica favorable y no asociada a la severidad de la lesion angiografica post SR. Esta observación clínica concuerda con el bajo riesgo de reestenosis angiográfica con SR comunicado en la literatura.

\section{EL ÁCIDO ASCÓRBICO AUMENTA DIFERENCIAL- MENTE LA SECRECIÓN DE INSULINA DE ISLOTES DE LANGERHANS AISLADOS DE PORCIONES PANCREÁ- TICAS ESPLÉNICAS Y DUODENALES}

Salas $A^{1}$, Atwater $I^{1}, 2$, Arraigada $C^{1}$, Parrau $D^{1}$, Jeffs $S^{1}$, Olguín $\mathrm{F}^{1}$, Maass $\mathrm{R}^{1}$, Atlaglich $\mathrm{M}^{1}$, Caamaño $\mathrm{E}^{2}$, Espinosa $\mathrm{J}^{2}$, Romero $C^{2}, \operatorname{ROJAS} \mathrm{E}^{1}$.

${ }^{1}$ ICBM, Fac. de Medicina U. de Chile, ${ }^{2}$ Hosp. Clínico J.J.Aguirre U. de Chile.

El trasplante de islotes de Langerhans para revertir la diabetes no ha tenido el éxito esperado, debido parcialmente a la poca viabilidad de los islotes aislados. Se piensa que estos podrían dañarse por la formación de radicales libres durante el aislamiento y cultivo. El ácido ascórbico, un fuerte antioxidante, es transportado y concentrado en las células beta (J.Biol.Chem. 269:1041-1045,1994). Sin embargo, su degradación es muy rápida y las células beta requieren su suministro constante. Por otro lado, los islotes duodenales y esplénicos tienen funcionalidades diferentes, siendo los esplénicos los que responden mejor a los estímulos de glucosa. Objetivo: mejorar la secreción de insulina de islotes destinados a transplante, utilizando un modelo canino. Métodos: Se realizo una prueba de tolerancia a la glucosa (IVGTT) en perros bajo anestesia. Luego, el páncreas fue perfundido con solución de preservación Eurocollins a $4^{\circ} \mathrm{C}$, y extraído. Los islotes fueron aislados con Liberasa, lavados y puestos en cultivo por seis días en medio RPMI 1640 (glucosa $10 \mathrm{mM}$ ) a $37^{\circ} \mathrm{C}$, con $5 \%$ de $\mathrm{CO}_{2}$. Cada 24 horas, el medio fue recolectado y cambiado por uno con ácido ascórbico recién disuelto a concentraciones finales de 50, 100 ó $200 \mu \mathrm{M}$; el medio recolectado fue congelado para la posterior medición de insulina (IMMULI$\mathrm{TE}^{\circledR}$ ). El día 6, la proteína total fue medida por método de Bradford. Resultados: La secreción de insulina (UI/mg proteína total) disminuyó a un 30\% del día 1 al día 4 y posteriormente aumento, recuperando el día 6 el $60 \%$ de la función inicial. Los islotes aislados de la porción pancreática esplénica secretaron 4 veces más insulina que los islotes aislados de la porción duodenal. El ácido ascórbico aumentó la secreción de insulina de los islotes esplénicos en un 15\%, mientras que en los islotes duodenales la secreción se triplicó (300\%). Conclusiones: Los perros son un buen modelo ya que muestran una IVGTT casi idéntica al humano, y sus islotes son parecidos en función, tamaño y composición. Además, los islotes aislados de la porción pancreática esplénica secretan mas insulina. Los islotes de la porción duodenal mejoramon notablemente su respuesta al suplementarlos con ácido ascórbico. Se concluye que los islotes duodenales son los mas susceptibles al daño oxidativo. Financiado por FONDECYT 1030596 y 1030611.

ASOCIACIÓN ENTRE POLIMORFISMOS DE LA RE-
GIÓN PROMOTORA DEL GEN DEL FACTOR DE NE-
CROSIS TUMORAL ALFA (TNF $\alpha$ ) CON OBESIDAD Y
RESISTENCIA A LA INSULINA EN MUJERES CHILENAS

Santos Jl ${ }^{1,2}$, Albala $C^{1}$, Villarroel aC ${ }^{1}$, Patiño-García $A^{2}$, Pérez $\mathrm{F}^{1}$, Angel $\mathrm{B}^{1}$, Martínez JA2 ${ }^{2}$.

${ }^{1}$ Instituto de Nutrición y Tecnología de los Alimentos (INTA). Universidad de Chile. Santiago, Chile. ${ }^{2}$ Departamento de Fisiología y Nutrición. Universidad de Navarra. Pamplona, España.

Introducción: El tejido adiposo en obesos muestra una expresión aumentada de la citoquina proinflamatoria TNF2. Numerosos polimorfismos se han descrito en la región promotora de este gen y se ha propuesto que la variante G308A podría ejercer influencia relevante sobre su actividad transcripcional.

Objetivo: Estimar la frecuencia alélica y desequilibrio de ligamiento en cuatro polimorfismos simples de la región promotora del gen TNF $\alpha$ (G-308A, G-238A, G-376A y G-163A), así como evaluar su asociación con variables relacionadas con la obesidad y resistencia a la insulina.

Sujetos y método: Se seleccionaron 100 mujeres (edad: 60-69 años) provenientes de un estudio transversal de base poblacional que realizaron una prueba oral de tolerancia a la glucosa con medición de leptina, TNF $\alpha$, y lípidos plasmáticos en la muestra basal. Los genotipos de TNFo fuenon determinados mediante PCR y RFLPs con apropiadas enzimas de restricción.

Resultados: La frecuencia de alelos poco frecuentes de los polimorfismos estudiados no supera el valor de $6 \%$. Se detectó 
un fuerte desequilibrio de ligamiento entre las variantes G238A y G-376A. No se encontraron diferencias significativas en frecuencias genotípicas entre sujetos diabéticos, sujetos intolerantes a la glucosa o sujetos normales. Después de excluir a los pacientes con diabetes, no se encontraron diferencias relevantes al comparar portadores de alelo A en los polimorfismos G-308A, G-238A en relación con los promedios de variables relacionadas con la obesidad, excepto en la comparación del índice de cintura-cadera según genotipos en G308A. En cualquier caso, la significación se perdió al aplicar la corrección por comparaciones múltiples.

Conclusión: Es improbable que los polimorfismos de la región promotora del gen TNF $\alpha$ tengan un impacto importante sobre la obesidad y resistencia a la insulina en mujeres chilenas, aunque el polimorfismo G-308A podría ejercer un efecto sensible sobre la distribución de grasa corporal.

(Fondecyt 1020703).

\section{IMPACTO DEL DESCENSO DE PESO EN FACTORES DE RIESGO CARDIOVASCULAR EN ADULTOS OBESOS}

Sepúlveda A, lópez C, Preisler J, García H, Osorio M, Schachter D, Bobadilla E, Díaz J.

Centro médico Endocrinológico Clínica Santa María. Univ. De los Andes. U de Chile

Introducción: La obesidad es una enfermedad crónica muy frecuente en nuestro país. Se asocia a alteraciones metabólicas y riesgo cardiovascular. La reducción de este riesgo es el principal objetivo de los programas médicos integrales (PTI) de modificación de estilo de vida en sujetos obesos. Objetivo: Evaluar los resultados de un PTI en obesos adultos, considerando la baja de peso y la mejoría de alteraciones metabólicas asociadas. Material y Métodos: Se estudiaron 452 adultos obesos (352 mujeres) que realizaron un PTI de 3 meses de duración en Clínica Santa María entre 1999-2003. En ellos se realizaron mediciones antropométricas completas, presión arterial (PA), perfil lipídico y prueba de tolerancia oral a la glucosa con medición de insulinemia. Para el estudio estadístico se utilizó t de student. Resultados: Según severidad de obesidad, 24,3\% presentaba sobrepeso, $42,7 \%$ obesidad grado I, $23,9 \%$ obesidad II y un $9 \%$ tenía obesidad mórbida. No hubo diferencias por sexo. Un 31,9\% presentaba síndrome metabólico (27,4\% mujeres y $45,1 \%$ hombres), $11 \%$ diabetes y $12,8 \%$ intolerancia a la glucosa. Tanto el peso como todas las variables metabólicas analizadas disminuyeron significativamente después del PTI. Estas lo hicieron independiente de la magnitud de la baja de peso obtenida. No hubo diferencias significativas en la baja de peso obtenida entre portadores de síndrome metabólico o trastornos del metabolismo de la glucosa y obesos simples. El mejor predictor de baja de peso fue la glicemia de ayuno inicial (Tabla 1).

Conclusiones: 1) La disminución de peso obtenida en un PTI, independiente de su magnitud, disminuye significativamente en el corto plazo las complicaciones metabólicas asociadas a la obesidad en adultos. 2) Esto puede deberse a cambios en la composición corporal asociados al PTI. 3) No hubo diferencias en la reducción ponderal ni en la respuesta metabólica entre obesos simples, con síndrome metabólico y trastornos del metabolismo de la glucosa, es decir todos se benefician por igual.

\section{INFLUENCIA DEL ESTADO CLIMATÉRICO Y LA PRE- SENCIA DEL SÍNDROME METABÓLICO EN LOS RE- SULTADOS DE UN PROGRAMA DE TRATAMIENTO INTEGRAL DE LA OBESIDAD (PTI)}

Sepúlveda A, lópez C, Preisler J, Schachter D, Osorio M, Bobadilla E, Díaz J.

Centro Médico Endocrinológico Clínica Santa María.

Introducción: La menopausia y el síndrome metabólico (Sd M) son altamente prevalentes en mujeres maduras y constituyen factores de riesgo cardiovascular independientes a la obesidad. Objetivos: Evaluar la influencia del estado climatérico (premenopausia $\leq 50$ años) y la presencia de síndrome metabólico en la respuesta a un PTI. Material y métodos: Se estudiaron 361 mujeres obesas (74\% premenopáusicas; $26 \%$ postmenopáusicas) que ingresaron a un PTI de 3 meses de duración en la Clínica Santa María (1999-2003). En todas ellas se comparó IMC,

Tabla 1.

\begin{tabular}{|lcccc|}
\hline & \multicolumn{2}{c}{ Mujeres } & \multicolumn{2}{c|}{ Hombres } \\
& Delta \% & $\mathrm{t}$ de student & Delta $\%$ & $\mathrm{t}$ de student \\
\hline IMC & $2,8 \pm 1,6$ & 0,000 & $3 \pm 1,5$ & 0,000 \\
Perímetro cintura & $9,2 \pm 13,4$ & 0,000 & $8,8 \pm 4,2$ & 0,000 \\
Glicemia & $8,0 \pm 18,8$ & 0,001 & $17,8 \pm 32,3$ & 0,003 \\
Insulinemia & $3,2 \pm 7,8$ & 0,003 & $2,9 \pm 22,5$ & 0,5 \\
TG & $82,3 \pm 9$ & 0,000 & $79,3 \pm 93,7$ & 0,000 \\
Colesterol total & $28 \pm 48,7$ & 0,000 & $45,4 \pm 57,1$ & 0,000 \\
\hline
\end{tabular}


Tabla 1.

\begin{tabular}{|lcccccc|}
\hline N & $\Delta \mathrm{IMC}$ & $\begin{array}{c}\Delta \mathrm{PC}(\mathrm{cm}) \\
\left(\mathrm{kg} / \mathrm{m}^{2}\right)\end{array}$ & $\Delta$ Colest T & $\begin{array}{c}\Delta \mathrm{TG} \\
(\mathrm{mg} / \mathrm{dl})\end{array}$ & $\begin{array}{c}\Delta \mathrm{LDL} \\
(\mathrm{mg} / \mathrm{dl})\end{array}$ & $(\mathrm{mg} / \mathrm{dl})$ \\
\hline Premenopáusica & 267 & $2,9 \pm 1,6$ & $8,9 \pm 4,6$ & $26,0 \pm 48,5$ & $45,5 \pm 94,3$ & $10,0 \pm 38,4$ \\
Postmenopáusica & 84 & $2,6 \pm 1,5$ & $8,1 \pm 3,7$ & $30,7 \pm 49,8$ & $61,0 \pm 62,4$ & $18,6 \pm 43,8$ \\
Premenop c/ Sd M & 58 & $3,1 \pm 2$ & $8,1 \pm 4,8$ & $31,3 \pm 43,8$ & $40 \pm 79,6$ & $18,2 \pm 37,3$ \\
Postmenop c/ Sd M & 40 & $2,3 \pm 1,8$ & $9,3 \pm 18,3$ & $44,1 \pm 47,8$ & $67,6 \pm 70$ & $31,3 \pm 42,1$ \\
Premenop s/ Sd M & 209 & $2,9 \pm 1,5$ & $9,1 \pm 12,7$ & $23,1 \pm 51,4$ & $48,3 \pm 102$ & $6,1 \pm 39$ \\
Postmenop s/ Sd M & 44 & $2,8 \pm 1,2$ & $11,2 \pm 18,5$ & $18,2 \pm 49,6$ & $54,8 \pm 55,6$ & $6,0 \pm 43,2$ \\
p & & $\mathrm{ns}$ & $\mathrm{ns}$ & $\mathrm{ns}$ & $\mathrm{ns}$ & $\mathrm{ns}$ \\
\hline
\end{tabular}

perímetro de cintura (PC) y perfil lipídico al inicio y al final del programa. El síndrome metabólico se definió según el criterio de ATP III con la presencia de 30 más de las siguientes condiciones: PC $>102 \mathrm{~cm}$ en hombres y $>88 \mathrm{~cm}$ en mujeres, glicemia basal $>100 \mathrm{mg} / \mathrm{dl}$, presión arterial $>130 / 85 \mathrm{mmHg}$, triglicéridos (TG) $>150 \mathrm{mg} / \mathrm{dl}$, o HDL < 40mg/dl en hombres y $<50 \mathrm{mg} / \mathrm{dl}$ en mujeres. Resultados: Ver Tabla 1.

La reducción ponderal fue estadísticamente significativa en todo el grupo, sin diferencia según estado climatérico. El síndrome metabólico estaba presente en 22\% del grupo premenopáusico y en $48 \%$ del postmenopáusico. Aunque la baja de peso fue mayor en el grupo premenopáusico, no alcanzó significancia estadística ( $\triangle \mathrm{IMC}$ pre: 3,06 , post: 2,34 , t: 0,68 ). Conclusiones: 1) La reducción ponderal y la mejońa de las alteraciones metabólicas asociadas a la obesidad fue significativa en todo el grupo. 2) No se observaron diferencias según el estado climatérico ni la presencia de síndrome metabólico.

\section{;JUEGA EL PERÍMETRO ABDOMINAL UN ROL CLAVE EN EL DESARROLLO DE LA RESISTENCIA A LA INSU- LINA?}

Serrano V*, Arteaga A*, Bustos P**, Amigo H**.

Departamento de Nutrición, Facultad de Medicina, Pontificia Universidad Católica de Chile*, Departamento de Nutrición, Facultad de Medicina, Universidad de Chile**.

Hay fuertes evidencias de que un incremento de la grasa corporal y fundamentalmente su acumulación a nivel abdominal seria clave en el desarrollo de la resistencia a la insulina (RI). Para la evaluación de grasa abdominal a nivel clínico recientemente se ha propuesto la medición del perímetro abdominal. Objetivos: Determinar el grado de asociación entre perímetro abdominal y desarrollo de RI, en personas obesas y no obesas. Metodología: Se trabajó con 1000 adultos jóvenes de ambos sexos de la ciudad de Limache, $\mathrm{V}$ región. Se midió peso y talla para calculo de IMC y se definio obesidad según criterio de la OMS. El perímetro abdominal se determinó en condiciones estandarizadas para definir obesidad abdominal según criterios enunciados en NCEP ATP III. Se determinó el grado de RI por medio de HOMA, utilizando 2,53 como valor de corte. Resultados: Se observó una estrecha correlacion entre IMC y perímetro abdominal $(R=0,87)(p<0,001)$. Un elevado porcentaje de las personas obesas definido por IMC, presentan obesidad abdominal (75\%), en cambio, en los no obesos sólo un pequeño porcentaje (8\%) la presenta.

En los obesos no se encontraron diferencias estadísticamente significativas en las prevalencias de RI en las personas con perímetro abdominal normal $(63,2 \%)$ y ancho $(75,2 \%)(p=$ $0,110)$. En los no obesos se observó que los que tienen obesidad abdominal presentan una mayor prevalencia de RI $(41,2 \%)$ comparado con las de perímetro normal $(26,3 \%)$ $(p=0,008)$. Se mantuvo esta significancia en las mujeres pero no en hombres. En el modelo predictivo de RI, destaca que en los no obesos el perimetro abdominal es significativamente predictivo (OR: 1,9 IC: 1,18-3,26) $(\mathrm{p}=0,009)$, hallazgo que no fue significativo en los obesos (OR: 1,7 IC: 0,81-3,86) ( $p=0,15)$. Conclusión: Estos hallazgos, que reducen la significancia del perimetro abdominal como indicador de RI en personas obesas, pudierm deberse a los puntos de corte utilizados 0 a que la cuantia del incremento de grasa corporal tienda a invalidar al perimetro como expresión de grasa visceral.

\section{PREVALENCIA Y FACTORES CONDICIONANTES DE RESISTENCIA INSULÍNICA EN 1000 ADULTOS JOVE- NES DE AMBOS SEXOS}

Serrano $V^{*}$, Arteaga A*, Bustos P**, Amigo H**.

Departamento de Nutrición, Facultad de Medicina, Pontificia Universidad Católica de Chile*, Departamento de Nutrición, Facultad de Medicina, Universidad de Chile**.

La Resistencia a la Insulina (R) corresponde a una respuesta biológica subnormal a la acción de la insulina. Es una condición prevalente con un rol esencial en diversas patologías asociadas al Síndrome Metabólico (SM). Se han descrito diversos factores condicionantes tanto genéticos como medioambientales, dentro de los que destacan la presencia de obesidad, sedentarismo, el tabaquismo, la ingesta de alcohol y 
el bajo peso de nacimiento, Objetivos: Determinar la prevalencia de RI, de SM y los factores condicionantes de RI. Metodología: Se trabajó con 1000 adultos jóvenes de ambos sexos de la ciudad de Limache, V región. Se midió peso, talla, perímetro abdominal y presión arterial en condiciones estandarizadas. Se evaluó por método de encuesta la presencia de tabaquismo, ingesta de alcohol y nivel de actividad física. El peso de nacimiento se obtuvo de los registros del libro de parto del Hospital de Limache. Se obtuvo muestras de sangre para glicemia, insulinemia, colesterol HDL y triglicéridos.

Se determinó el grado de RI por medio de HOMA y la presencia de SM según criterios NCEP, ATP III Resultados: La prevalencia de RI fue 34,4\% y la de SM 10,1\%, sin diferencias significativas entre sexos. En modelos de regresión logística se estimó el riesgo de RI, participando del modelo el perímetro abdominal y el antecedente familiar de alteraciones metabólicas en padres, con un R2 de 0,23. En el modelo del sexo masculino apareció como factor protector realizar actividad física. En el análisis de tendencia vemos que el riesgo de presentar RI está significativamente aumentado en las personas que están en el cuartil mayor de IMC $(\mathrm{OR}=25)$. No se encontró asociación con otros posibles factores condicionantes de RI, como tabaco, ingesta de alcohol y bajo peso al nacer. Sólo el Ejercicio físico mostró una tendencia protectora que no alcanzó a ser significativa. Conclusión: La RI es una condición prevalente en esta población. Sólo una proporción se expresa como SM. Con respecto a los factores condicionantes de RI destaca fundamentalmente la obesidad. El ejercicio físico aparece débilmente como factor protector. Los antecedentes familiares de alteraciones metabólicas propias de SM, aparecen formando parte del modelo predictor de RI, suginiendo el rol de factores genéticos en la expresión de esta condición.

\section{BOCIO NODULAR DE CRECIMIENTO PROGRESIVO: PRIMERA MANIFESTACIÓN DE SARCOMA GENERALI- ZADO}

Soto L, Morales B, Duval R, Oportos J, Canessa J, Humphreys J, Oddershede N, Munizaga F.

Comité de Tiroides. Hospital DIPRECA

Introducción: La presencia de metástasis de troides es de baja frecuencia, habitualmente se da en el contexto de un primario conocido. Damos a conocer un caso de manifestación inicial como nódulo de crecimiento progresivo, y la ayuda de la biopsia quirúrgica para el diagnóstico diferencial.

Caso Clínico: Hombre de 43 años, sin antecedentes mórbidos personales ni familiares de importancia, deportista, que nota último mes aumento de volumen progresivo en región anterior de cuello no doloroso. Al examen físico se palpa nódulo en lóbulo derecho de $3,5 \mathrm{~cm}$., de consistencia dura, resto del examen segmentario dentro de límites nomales. Ecografía tiroidea: nódulo sólido prominente en lóbulo derecho de $38 \mathrm{~mm}$, hipoecoico, con vasculanización central y otros pequeños nódulos $<5 \mathrm{~mm}$ en ambos lóbulos, TSH, T4, T3 nomales. Radiografía tórax: con lesiones nodulares. Punción biópsica: positivo para neoplasia indiferenciada.

Se somete a cirugía: tiroidectomía total y vaciamiento ganglionar modificado.

Biopsia quirúrgica: con estudio inmunohistoquímico con anticuerpos monoclonales que informa: metástasis tiroideas multinodulares de tumor fusocelular maligno con características morfológicas e inmunohistoquímicas de sarcoma miogénico.

Completa estudio, encontrando diseminación pulmonar, hepáticas y tumor primario retroperitoneal.

Inicia quimioterapia con respuesta parcial. Está con Ltiroxina en dosis de sustitución

Conclusiones: 1) El crecimiento progresivo de nódulo sólido tiroideo, además de neoplasia primaria debe hacer pensar en metástasis. 2) La biopsia quirúrgica se debe realizar con estudio inmunohistoquímico, para buscar otras etiologías.

\section{ESTATUS DE VITAMINA D EN HOMBRES MAYORES SANOS RESIDENTES EN SANTIAGO}

Tala $H^{1}$, Jiménez $M^{1}$, Rojas $A^{1}$, Polic $G^{2}$, Rosowzki J ${ }^{2}$, Vivianni $\mathrm{P}^{3}$, Velásquez $^{4}{ }^{4}$, González $\mathrm{G}^{1}$.

Departamentos de Endocrinología', Nutrición², Salud Públi$\mathrm{ca}^{3}$ y Laboratorios Clínicos ${ }^{4}$, Facultad de Medicina, Pontificia Universidad Católica de Chile.

La importancia de la hipovitaminosis D como factor de riesgo para osteoporosis es ampliamente aceptada. Estudios previos de nuestro grupo han demostrado una prevalencia elevada de hipovitaminosis D en mujeres postmenopáusicas sanas y residentes en Santiago $\left(33^{\circ} \mathrm{S}\right)$, latitud a la cual la radiación solar estimula la producción de vitamina D a lo largo de todo el año. Existen pocos estudios que hayan evaluado el estatus de vitamina $\mathrm{D}$ en hombres mayores sanos y en Chile no existen datos al respecto. Objetivo: Caracterizar el estatus de vitamina D durante el inviemo en hombres mayores sanos y residentes en Santiago. Sujetos y Métodos: Se estudiaron 39 hombres sanos mayores de 60 años durante el invierno de 2003. Se excluyeron sujetos con enfermedades o uso de fármacos (los 6 meses previos) que alteren el metabolismo de vitamina D. En todos los voluntarios seleccionados se realizó evaluación médica, estimación de la ingesta alimentaria de vitamina D y calcio mediante una encuesta de consumo de la semana previa (software Food procesor II) y de la exposición solar. En ayunas y en sangre venosa se midió: 250HD, PTH y perfil bioquímico y se determinó calciuria 24 h (excluyéndose aquellos con hipercalciuria).El estudio fue aprobado por nuestro comité de ética y todos los voluntarios firmaron consentimiento informado. Los resultados son expresados como promedio $\pm \mathrm{DE}$. Resultados: La edad de los voluntarios fue de $67,1 \pm 4,9$ años y el IMC fue de $29,0 \pm 3,9 \mathrm{k} / \mathrm{m}^{2}$. La exposición solar fue adecuada en el $79 \%$ de éstos. Los valores en plasma de calcio, fósforo, creatinina, albúmina, pruebas de 
Tabla 1.

\begin{tabular}{|lccc|}
\hline Parámetro & Valor normal & Promedio $\pm \mathrm{DE}$ & $\%$ anormal \\
\hline 25OHD (ng/ml) & $>15^{* *}$ & $18,0 \pm 5,4$ & $33 \% \uparrow$ \\
PTH intacta (pg/mL) & $7-53$ & $53,7 \pm 20,8$ & $41 \% \uparrow$ \\
Fosf. alcalinas (UI/L) & $30-100$ & $93 \pm 25$ & $28 \% \uparrow$ \\
Ingesta cálcica (mg/d) & $\geq 1500$ & $375 \pm 296$ & $100 \% \uparrow$ \\
Ingesta de vit. D (UI/d) & $\geq 400-600$ & $95 \pm 108$ & $97 \% \uparrow$ \\
\hline
\end{tabular}

*: valor bajo el cual ocurre hiperparatiroidismo secundario en población chilena sana.

función hepática y en orina de 24 horas de calcio fueron normales en todos los sujetos. La ingesta de calcio y vitamina D estuvo bajo lo adecuado en casi todos ellos. En 1 de cada 3 adultos mayores sanos, se detectó hipovitaminosis D (250HD $<15 \mathrm{ng} / \mathrm{mL}$ ), acompañándose frecuentemente de hiperparatiroidismo $2^{\circ}$ (ver Tabla 1$)$.

Conclusiones: Este estudio demuestra que la hipovitaminosis D es común en hombres mayores sanos de Santiago durante el invierno a pesar de una adecuada exposición solar. Este hallazgo se asocia a una alta prevalencia de hiperparatiroidismo $2^{\circ}$ y a una ingesta de calcio y vitamina $\mathrm{D}$ bajo lo adecuado en casi todos ellos. Estas alteraciones ilustran la necesidad de aumentar también en los hombres mayores sanos la ingesta de vitamina D y calcio.

Financiado por proyecto de Becados de la PUC; PG-24/03.

\section{ESTUDIO MOLECULAR DE LA MUTACIÓN IVS9-1 G>T DEL GEN NEM1 EN UNA FAMILIA CON NEO- PLASIA ENDOCRINA MÚLTIPLE 1.}

Tala H, González A, Carvajal C, Solar A, Arteaga E, Fardella C. Dep. Endocrinología, Facultad de Medicina, P Universidad Católica de Chile.

Recientemente nuestro grupo reportó el caso de una paciente con neoplasia endocrina múltiple tipo 1 (NEM1), secundaria a la mutación heterocigota IVS9-1 G>T del gen NEM1 (Tala H. et al, XIV Congreso Chileno de Endocrinología). Objetivos: Evaluar la expresión de la mutación intrónica IVS9-1 G>T del gen NEM1 y la distribución subcelular de la proteína menina (68 kDa). Pacientes y Métodos: Se aisló RNA desde leucocitos periféricos para preparar cDNA mediante RT-PCR y se obtuvo tejido paratiroideo de la paciente. La zona de la mutación fue amplificada y se secuenciaron los productos PCR. Como control de amplificación se utilizó GAPDH. Las secuencias obtenidas por RT-PCR fueron comparadas con la publicada en GeneBank para el gen NEM1 (GI: 1945388). Se realizó la inmunodetección de menina por westen blot e inmununohistoquímica (IHC) con anticuerpos policlonales anti-menina (SC1080, hMEN-SQV, hMEN1) que reconocen el extremo $\mathrm{N}$-terminal, C-terminal y proteína completa, respectivamente. Resultados: El estudio mediante RT-PCR de sangre periférica en el caso índice evidenció la retención del intrón 9 en el mRNA mensajero del gen NEM1, detectándose dos productos PCR a 934 bp (mutante) y a 683 bp (normal). El análisis de secuencia indica presencia de la transversión $\mathrm{G}>\mathrm{T}$ en el sitio splice aceptor del RNA de NEM1. El western blot (hMEN1) identifica una proteína a $68 \mathrm{kDa}$ y dos bandas inespecíficas. El anticuerpo hMEN-SQV identifica también una proteína a 68 $\mathrm{kDa}$, pero aquí la densitometría revela la pérdida de aproximadamente el $40 \%$ de intensidad de la señal. No se detectó un péptido NEM1 de menor peso molecular ( $\sim 54 \mathrm{kDa})$ propuesto por los modelamientos de estructura secundaria. La IHC en tejido paratiroideo del caso índice revela sólo tinción de menina en el citoplasma. Conclusión: La mutación heterocigota IVS9-1 G>T del gen NEM1 generaría un mRNA aberrante, cuya expresión produciría una proteína trunca sin las señales de localización nuclear ubicadas en la región C-terminal. Esta proteína trunca se acumularía en el citoplasma, y sería degradada posteriormente. Este proceso en tejido neuroendocrino (hipótesis de inactivación bialélica) desencadenaría la nula expresión de esta proteína supresora de tumores.

(Financiado por proyecto FONDECYT 1011035-1040834 y Depto. Endocrinología de la P Universidad Católica).

\section{FUNCIÓN TIROIDEA EN EMBARAZO Y EXPOSICIÓN CRÓNICA A PERCLORATO}

Téllez R, Michaud P, Reyes C, Gibbs J.

S. Medicina Hosp. Sótero del Río, Facultad Medicina P. U. Católica de Chile, Kerr-McGee Corporation.

El embarazo es un período de mayores exigencias para la función tiroidea. Aumentan los requerimientos de yodo (I) y su déficit puede desencadenar alteraciones tiroideas en la madre y en el feto. El anión perclorato (ClO4) compite con I por el simportador $\mathrm{Na} / \mathrm{I}$ en la g. tiroides y por eso puede provocar carencia de I en el tirocito. En Taltal (T) el agua potable contiene 100 a $120 \mu \mathrm{g} / \mathrm{L}$ de ClO4 y en Chañaral (C) 5 a $7 \mu \mathrm{g} / \mathrm{L}$. Objetivos: Estudiar función tiroidea, frecuencia de bocio y excreción urinaria de I en embarazadas de T y C, comparándolas con embarazadas de Antofagasta (A) que no tiene $\mathrm{ClO} 4$ en el agua. Además, evaluar función tiroidea neonatal. Diseño Experimental: estudio de cohortes prospectivo. Sujetos: volunta- 
rias estudiadas en 1er. control prenatal (1C, antes de $24 \mathrm{sem}) \mathrm{y}$ después de 28 sem (2C), sin enfermedades tiroideas conocidas, y sus recién nacidos. Métodos: medición de TSH, T4L, tiroglobulina (Tg) y ClO4 sérico en embarazo y en sangre de cordón umbilical (CU), yoduria en las madres. Examen físico tiroideo según OMS. Análisis estadístico: test Kruskal-Wallis (K-W) para variables continuas independientes y $\chi^{2}$ para proporciones.

Resultados: Edades promedio: A: 23,1 años $(\mathrm{n}=64)$; T: 24,8 años ( $\mathrm{n}=65)$, y C: 28,4 años $(\mathrm{n}=52)$. Frecuencia de bocio: A: 8,7\%; T: 9,4\%; C: $24,4 \%\left(\chi^{2}, p=0,04\right)$. AcTPO (+) en 1C: A: 6,3\%; T: $10,8 \%$; $: 15,4 \%\left(\chi^{2}, p=0,28\right)$. Yoduria (mediana): A: 29; T:30,8; C: 24,5 $\mu \mathrm{g} / \mathrm{dL}$ (K-W, $\mathrm{p}=0,73)$. ClO4 suero materno: $\mathrm{A}:<0,4 ; \mathrm{T}: 10,9 ; \mathrm{C}:<0,4 \mu \mathrm{g} / \mathrm{L}$ (p<0,0001). ClO4 en suero CU: A y C: $<0,4 \mu \mathrm{g} / \mathrm{L} ; \mathrm{T}: 19,9 \mu \mathrm{g} / \mathrm{L}$ (Tabla 1).

Conclusiones: 1) A pesar de la exposición crónica a ClO4 las embarazadas de $\mathrm{T}$ no tienen mayor frecuencia de bocio y sus niveles de TSH y Tg no difieren de mujeres no expuestas. 2) T4L descendió más en mujeres de $\mathrm{T}$ en $3^{\mathrm{er}}$ trimestre, pero en ellas el examen se tomó a mayor edad gestacional. 3) La exposición a ClO4 no afectó la función tiroidea neonatal. 4) Las yodurias traducen una ingesta de I adecuada para embarazo e indican que el nivel actual de yodación de la sal en Chile es satisfactorio.

\section{PUNCIÓN CON AGUJA FINA DE NÓDULOS TIROI- DEOS CON VISIÓN DE ULTRASONIDO: CORRELA- CIÓN ECOGRÁFICA E HISTOLÓGICA}

Uchida $M^{1}$, Del Solar $M^{2}$, Paredes $A^{2}$, Cartes $A^{2}$, Candia $M^{2}$, DOMÍNGUEZ $\mathrm{M}^{2}$.

Servicio de Radiología ${ }^{1}$, Departamento de Endocrinología, Servicio de Medicina ${ }^{2}$, Hospital San Juan de Dios.

Objetivo: La biopsia por punción con aguja fina (PAF) del bocio nodular ha demostrado una alta sensibilidad y especificidad para estudiar la etiología de los nódulos tiroideos. Al asociarlo al ultrasonido (US), logramos caracterizar los nódulos más sospechosos de malignidad, guiar la punción obteniendo una muestra más representativa y evitar complicaciones. En este trabajo nos propusimos revisar nuestras PAF bajo US, correlacionando los hallazgos del US con el resultado de las biopsias por PAF y con la histología definitiva en los casos operados.

Material y Método: Se revisó las PAF bajo US de nódulos tiroideos, entre marzo del 2002 y junio del 2004, se seleccionó aquellas con resultado de neoplasia folicular y cáncer papilar, correlacionando este diagnóstico, con las características en el US y posterior hallazgo en biopsia postoperatoria de los casos que fueron operados. Se evaluó las características del nódulo al US, con el fin de establecer sospecha de malignidad. Las PAF se realizaron por endocrinólogos, guiados por un mismo radiólogo que utilizó ecógrafo ATL3500 y transductor lineal de 7 a 12 Mhz. Se obtuvo muestra para estudio citológico e histológico, las que fueron enviadas para su análisis al Servicio de Anatomía Patológica de nuestro hospital.

Resultados: De 315 PAF bajo US, un total de 71 (23\%) fueron neoplasias:31 cánceres papilares y 40 neoplasias foliculares Al US: 73\% eran sólidos, 70\% hetero-géneos, 21\% con calcificaciones, 50\% eran vascularizados, 10\% tenía adenopatías. El 13 (18\%) se catalogó probablemente benignos (PB); 44 (62\%) sospechosos de malignidad (SM); 14 (20\%) altamente sospechosos de malignidad (ASM) De esta serie se operaron 25 pacientes: la biopsia post-op demostró cáncer en 21 (20 papilares y un cáncer folicular); 18 (85\%) con PAF concordante. Las lesiones operadas catalogadas como ASM el 100\% fue cáncer, de las 16 como SM; 13 (52\%) fueron cánceres y de las PB; (4) sólo un 25\% demostraron malignidad.

Se calcula sensibilidad y especificidad del método y valor predictivo (+) y (-).

Conclusiones: La PAF bajo US es útil para el diagnóstico de lesiones tiroideas, permite caracterizar los nódulos y diagnosticar malignidad. Se observó que las lesiones ASM eran malignas y que las PB no pueden descartar esta posibilidad. Se seguirá recabando información sobre los pacientes que aún no se han operado y que tienen indicación de hacerlo, según la PAF bajo US.

Tabla 1.

\begin{tabular}{|c|c|c|c|c|c|c|c|c|}
\hline & & $\mathrm{n}$ & $\begin{array}{l}\text { Antofagasta } \\
\overline{\mathrm{x}} \pm \mathrm{ds}\end{array}$ & $\mathrm{n}$ & $\begin{array}{l}\text { Taltal } \\
\overline{\mathrm{x}} \pm \mathrm{ds}\end{array}$ & $\mathrm{n}$ & $\begin{array}{c}\text { Chañaral } \\
\overline{\mathrm{x}} \pm \mathrm{ds}\end{array}$ & $\begin{array}{c}\text { Kruskal-Wallis } \\
\mathrm{p}\end{array}$ \\
\hline T4L & $1 \mathrm{C}$ & 64 & $0,97 \pm 0,15$ & 65 & $0,99 \pm 0,13$ & 52 & $0,95 \pm 0,13$ & 0,19 \\
\hline \multirow[t]{2}{*}{$\mathrm{ng} / \mathrm{dL}$} & $2 C$ & 48 & $0,86 \pm 0,13$ & 38 & $0,83 \pm 0,12$ & 40 & $0,82 \pm 0,09$ & 0,015 \\
\hline & $\mathrm{CU}$ & 35 & $1,07 \pm 0,16$ & 28 & $1,03 \pm 0,14$ & 42 & $1,04 \pm 0,13$ & 0,73 \\
\hline TSH & $1 \mathrm{C}$ & 64 & $2,63 \pm 1,54$ & 65 & $2,61 \pm 1,45$ & 52 & $2,81 \pm 1,78$ & 0,91 \\
\hline \multirow[t]{2}{*}{$\mu \mathrm{UI} / \mathrm{mL}$} & $2 C$ & 48 & $3,69 \pm 8,69$ & 38 & $2,08 \pm 0,86$ & 40 & $2,55 \pm 2,12$ & 0,63 \\
\hline & CU & 33 & $6,20 \pm 2,96$ & 28 & $6,31 \pm 2,91$ & 40 & $6,69 \pm 4,13$ & 0,99 \\
\hline $\mathrm{Tg}$ & $1 \mathrm{C}$ & 58 & $4,32 \pm 3,63$ & 58 & $3,64 \pm 3,31$ & 45 & $3,67 \pm 3,49$ & 0,3 \\
\hline \multirow[t]{2}{*}{$\mathrm{ng} / \mathrm{mL}$} & $2 C$ & 47 & $2,97 \pm 2,05$ & 35 & $3,7 \pm 2,78$ & 38 & $2,99 \pm 2,39$ & 0,23 \\
\hline & $\mathrm{CU}$ & 30 & $16,8 \pm 9,9$ & 28 & $18,1 \pm 12,8$ & 36 & $14,0 \pm 11,0$ & 0,29 \\
\hline
\end{tabular}




\section{LA GLÁNDULA SUPRARRENAL DE LOS PRIMATES: ¿UN POSIBLE OSCILADOR CIRCADIANO?}

Valenzuela F, Torres-Farfán C, Monsó C, Campino $C^{1}$, Germain $A^{2}$, Torrealba F, Valenzuela $G^{3}$, Serón-Ferré $M$.

Dpto. Ciencias Fisiológicas, Facultad de Ciencias Biológicas; Dptos: ${ }^{1}$ Endocrinología y ${ }^{2}$ Obstetricia y Ginecología, Facultad de Medicina, Pontificia Universidad Católica de Chile. ${ }^{3}$ Department of Women's Health, Arrowead Regional Medical Center, Colton, CA, USA.

El ritmo circadiano de la concentración plasmática de cortisol en el adulto es la punta del iceberg de un complejo sistema de regulación fisiológica, el sistema circadiano, derivado de la necesidad de adaptarnos en forma predictiva a las alternancias día/noche. Evidencias recientes sugieren que el sistema circadiano está organizado como una jerarquía de relojes en tejidos periféricos (hígado, corazón, hipófisis y otros) comandados por un reloj central, el núcleo supraquiasmático del hipotálamo (NSQ). El motor molecular que determina las oscilaciones circadianas está constituido por un circuito de retroalimentación transcripcional/traduccional de los genes Bmal 1-2, Per 1-3, Cry1-2, Clock y CKI-epsilon, denominados genes reloj. Objetivos. Para saber si en primates (mono capuchino), la glándula suprarrenal (GSR), posee capacidad oscilatoria autónoma (reloj periférico), investigamos en adultos y en fetos ( $90 \%$ de la gestación): 1. La expresión de Bmal1, Per2 en NSQ y GSR a las 1400 y 2000 hrs. 2. La expresión oscilatoria de estos genes en cultivo de GSR. Materiales y Métodos: De 6 adultos se obtuvieron 6 NSQ ( 3 a las 1400 hrs y 3 a las 2000 hrs) y 5 GSR (2 a las 1400 hrs y 3 a las 2000 hrs). Cinco fetos se obtuvieron por histerotomía a las 1400 hrs y 3 a las 20 hrs. La expresión de mRNAs se midió por RT-PCR semicuantitativo respecto a 18S-rRNA. Se incubaron por $48 \mathrm{hrs}$ explantes de GSR de 6 adultos y de 4 fetos, recogiéndose muestras cada 6 y 4 horas respectivamente. Resultados: Se detecta la expresión de Bmal1, Per2 y Clock en NSQ y en GSR de adulto y feto. En el NSQ adulto se observan valores de Bmal1 más altos a las 2000 que a las 1400 horas. En el NSQ fetal se observa una tendencia al alza de Bmal1 a las 1400 hrs. En cultivo de GSR de adulto se observa un alza de Bmal1 entre las 1400 y las 2000 hrs y en la fetal se aprecia un alza para Per2 a las $24 \mathrm{hrs}$. Conclusiones: Estos resultados sugieren la expresión oscilatoria de genes reloj en NSQ de adultos y fetos. En cultivos de GSR, la variación en 24 hrs de Bmal1 en adultos y Per2 en fetos sugiere la presencia de un nuevo reloj periférico en la glándula suprarrenal.

Financiado por Fondecyt 1030425 y Grant San Bernardino Medical Foundation.

\section{DIAGNÓSTICO Y MANEJO DE ENFERMEDAD DE CUSHING: RESULTADOS EN 37 CASOS CONTROLA- DOS EN EL INSTITUTO DE NEUROCIRUGÍA}

Vélz J, Carrasco C, Ramos C, Rojas D, Wohllk N.

Depto Endocrino Hospital del Salvador, Instituto Neurocirugía Asenjo (INCA), Fac. Med. U. de Chile, Lab. IEMA.

La optimización de las técnicas diagnósticas (hormonales y radiológicas) permitiría un diagnóstico precoz y mejor manejo de estos tumores. Hasta ahora desconocemos la realidad local.

Objetivo: describir las características epidemiológicas, clínicas, radiológicas y quirúrgicas de Cushing controlados en el INCA entre 1988-2004.

Métodos: análisis restrospectivo de fichas. Se incluyeron pacientes con evidencias bioquímicas e imagenológicas de Enf. Cushing. El estudio hormonal fue centralizado.

Resultados: Total 37 tumores, 6 hombres y 31 mujeres. Edad promedio al diagnóstico 32,5 años (16-56); el diagnóstico fue sospechado por endocrinólogo en $40 \%$, internista en $28 \%$ y por ginecólogo en $16 \%$. Mediana de duración de síntomas 36,5 meses (12-240).

Síntomas más frecuentes: aumento de peso $92 \%$, relleno supraclavicular $80 \%$, debilidad muscular $78 \%$, estrías $74 \%$. El $82 \%$ tenía además HTA y/o DM. Un 35\% macroadenomas, 62\% microadenomas y $3 \%$ tumor no visible por imágenes (Tabla 1$)$.

Curación bioquímica post cirugía: 15 (48,6\%) (3 pacientes necesitaron más de 1 cirugía). Después de la cirugía, $81 \%$ de los curados eran microadenomas y el $66 \%$ de los activos eran macroadenomas. Complicaciones quirúrgicas: Diabetes Insípida $5,5 \%$, hemorragias $14 \%$, infecciones $7 \%$, fístula $11 \%$, trombosis venosa 7\%. Mortalidad: 1 paciente (3\%).

Conclusión: destacan en esta serie, la latencia al diagnóstico y prevalencia de estrías, relleno supraclavicular y debilidad muscular proximal como hallazgos de gran frecuencia. La cirugía logra curación sólo en el 48,6\% sin relación con el tamaño (p 0,11). La morbilidad asociada es frecuente tanto en la etapa previa al diagnóstico como postoperatoria.

Tabla 1.

\begin{tabular}{|lcccc|}
\hline Exs. preop & $\begin{array}{c}\text { Nugent } \\
\mu \mathrm{g} / \mathrm{dL}\end{array}$ & $\begin{array}{c}\mathrm{CLU} \\
\mu \mathrm{g} / 24 \mathrm{~h}\end{array}$ & $\begin{array}{c}\mathrm{ACTH} \text { basal } \\
\mathrm{pg} / \mathrm{mL}\end{array}$ & $\begin{array}{c}\text { Cortisol basal } \\
\mu \mathrm{g} / \mathrm{dL}\end{array}$ \\
\hline Promedio & 21,24 & 552,97 & 105 & 35,30 \\
DS & 8,65 & 401,78 & 129,91 & 14,28 \\
Dispersión & & $(144-1875)$ & $(16-625)$ & $(16-92)$ \\
\hline
\end{tabular}




\section{Indice de autores}

A

Adriazola P
Aglony M
Aguayo CG
Albala C
Alcaíno M
Allel NL
Amaral H
Amat J
Amigo H
Amthauer N
Angel B
Aravena C
Araya I
Araya V
Arraigada C
Arriza M
Arteaga A
Arteaga E
Asenjo S
Atkinson M
Atlaglich M
Atwater I
Avila A

Ávila C

Aylwin C

Aylwin CG

\section{B}

Barrera A

Bassas L

Bazáes R

Beas $\mathrm{F}$

Belmar C

Belmar P

Bello F

Benitez DA

Berhe $\mathrm{T}$

Berríos A

Besancon F

Billings $\mathrm{B}$

Blanco A

Bobadilla E

Bordeau I

Boric MA

Borja $\mathrm{H}$

Braverman L

Bravo J

B
Briano E

Brusco $\mathrm{F}$

1292

Bruzzone ME

1271, 1309

1271

1265, 1266, 1285, 1310, 1320

1319

1265

1273, 1319

1267, 1267, 1279, 1283

1322, 1322

1292

1265, 1266, 1274, 1285, 1310, 1320

1308

1266, 1282

1267, 1267, 1279, 1283

1320

1267, 1268

1322,1322

1272, 1273, 1289, 1290, 1297, 1298, 1324

1280, 1301, 1302, 1303, 1306

1269, 1270

1320

$1269,1305,1320$

$1270,1275,1279,1284,1284,1295,1300,1301$,

1302, 1303, 1304, 1318

1292

1305

1319

1318

1271

1315

1296

1270, 1304

1307, 1308

1269

1269, 1270

1271

1305

1266, 1282

1290

1269

1280

1321, 1321

1279

1300

1307

1311

1271
Bustos P

1322, 1322

\begin{tabular}{lr}
\multicolumn{1}{c}{ C } \\
\hline Caamaño E & $1269,1316,1320$ \\
Cabezas M & 1273 \\
Cáceres J & 1275 \\
Campano M & 1307,1308 \\
Campino C & 1272,1326 \\
Campos L & 1272 \\
Campusano C & $1272,1273,1289,1297,1298,1309$ \\
Candia M & 1325 \\
Canessa J & 1323 \\
Capurro T & 1301,1302 \\
Cárcamo C & 1283 \\
Cardemil F & 1283
\end{tabular}

Carrasco $\mathrm{C}$

Carrasco E

Cartes A

Carvajal C

Cassorla F

1273, 1314, 1326

1265, 1266, 1274, 1285

1278, 1325

1281, 1288, 1299, 1299, 1324

1304, 1318

Castellón EA

Castillo C

1271

Castillo M

1289

Castro L

1312

1282

Castro 0

1281

Cattani A

1301, 1314

Causey T

Claure R

Codner E

1274

$1289,1290,1291,1298$

$1274,1275,1275,1279,1284,1284,1295,1296$,

Conte G

1300, 1300, 1304

Contreras C

1316

Contreras 0

Cosentino M

1266, 1282

1273, 1309

Covarrubias P

1279, 1280

Cruz F

1283

1297

Cuneo M

1316

Chamorro A

Ch

Chiang $\mathrm{M}$

Chung W

1288

1268

1275

D

De las Morenas A

1311

Deck C
$1270,1275,1295,1295,1296,1300,1300$, 
Dedes C

Del Canto F

Del Solar MP

Deng L

Devoto E

Devoto L

Díaz J

Díaz $\mathrm{M}$

Díaz P

Diettes A

Domínguez $\mathrm{M}$

Duarte E

Dussaubat A

Duval R

1272
1281
1325
1275
1276,1276
1281
$1312,1321,1321$
1268,1277
1282
1267
1282,1325
1277
1278
1323


1300,1310
1267
1314
1295
1320
1271
1279
1295
1302

1279, 1279, 1280, 1280, 1302

\section{F}

Fardella C $1272,1281,1288,1289,1290,1297,1297,1299$,

Farías C

Fernández D

Fernández G

Ferrand $P$

Fischer S

Flanagan J

Flanagan S

Franco C

Franulic L

Frías X

Friesema ECH

1299, 1324

1286

1304

1319

1281

1282, 1287

1311

1274

1282, 1288, 1319

1266, 1282

1270

1301
González C

G

\begin{tabular}{lr}
\hline Gac P & 1267, 1267, 1283 \\
Gaete X & 1274,1279 \\
Gajardo H & 1302 \\
Gajardo P & 1283 \\
Galgani J & 1310 \\
Gallardo V & 1284,1284 \\
Galleguillos I & 1269 \\
Gallo M & 1300 \\
Gandara F & 1272 \\
García D & $1265,1266,1285$ \\
García G & 1286 \\
García H & $1274,1279,1279,1280,1280,1286,1302,1311$ \\
& 1312,1321 \\
García P & 1292 \\
Garrido B & 1286 \\
Garzon V & 1315
\end{tabular}

Gayoso R

Germain A

Giadrosic V

Gibbs J

Giglio C

Gilbert M

Glasinovic A

Gleisner A

Gloger S

Golsak E

Gómez R

González A

González F

González G

González H

González M

Goñi I

Grant C

Grünholz D

Gunn R

Gutiérrez C

1286, 1287

1326

1306, 1282, 1287

1324

1272

1295

1288

1304

1281

1306

1310

1267, 1288, 1324

1307

1281

$1272,1273,1283,1289,1290,1291,1297$,

1298, 1308, 1309, 1317, 1323

1289, 1290, 1297, 1297, 1298

1308

1289, 1290, 1297, 1298

1290, 1292

1292

1318

1278

H

\begin{tabular}{ll}
\hline Hattersley A & 1274 \\
Henríquez S & 1281 \\
Hernández M & 1314
\end{tabular}

Hernández MI 1292, 1293, 1294, 1314

Herrera M

Hidalgo S

Hitschfeld C

Horvath E

Hrlic I

Huidobro F

Humphreys J

1294, 1294, 1306

1295, 1300

1282

1275

1283

1306, 1323

\begin{tabular}{ll}
\multicolumn{1}{c}{$\mathbf{I}$} & 1305 \\
\hline Ilzauspe J & 1292
\end{tabular}

Iñíguez G 1270, 1284, 1295, 1296, 1301, 1302, 1303, 1304,

1318

Iñíguez M

1289, 1290

\begin{tabular}{lr}
\multicolumn{2}{c}{$\mathbf{J}$} \\
\hline Jaimovich E & 1295 \\
Jara A & 1306 \\
Jara P & 1270 \\
Jeffs S & 1320 \\
Jiménez M & 1281, 1289, 1290, 1290, 1291, 1297, 1297, 1298, \\
& 1323 \\
Johnson MC & 1300 \\
Jurado M & 1298
\end{tabular}

$\mathbf{K}$

King A 1294

Krall P 1281, 1288, 1299, 1299

Kusmanic A 1284 
L

\begin{tabular}{lr}
\hline \multicolumn{1}{c}{ L } \\
\hline Lagomarsino E & 1294 \\
Lahsen R & 1266,1282 \\
Lara H & 1267,1267 \\
Lechuga M & 1316 \\
Lee C & 1289,1290 \\
Lee S & 1311 \\
León A & 1298 \\
León S & 1310 \\
Lera L & 1310,1316 \\
Liberman C & $1289,1290,1297,1298$ \\
Lioi X & 1268,1277 \\
Lobos A & 1298 \\
Lois V & $1312,1321,1321$ \\
López C & 1309 \\
Lopez F & 1283 \\
López J & $1276,1276,1294,1294$ \\
López JM & 1306,1317 \\
López P & 1300 \\
Lopez T & 1295
\end{tabular}

M

\begin{tabular}{|c|c|c|}
\hline Maass $\mathrm{R}$ & & 1320 \\
\hline Madariaga M & 1276, & 1276 \\
\hline Majlis S & & 1282 \\
\hline Maliqueo M & $1278,1295,1300$, & 1310 \\
\hline Mancilla EE & & 1301 \\
\hline Mardones P & & 1313 \\
\hline Martínez A & $1270,1275,1301,1302,1302,1303,1304$ & 1304 \\
\hline Martínez C & 1305, & 1319 \\
\hline Martínez JA & & 1320 \\
\hline Mears D & & 1305 \\
\hline Medina FJ & & 1288 \\
\hline Melgarejo N & & 1283 \\
\hline Méndez C & & 1294 \\
\hline Mericq V & $1275,1284,1294,1301,1302,1303$, & 1318 \\
\hline Merino S & 1286 & 1287 \\
\hline Meza M & & 1292 \\
\hline Michaud P & & 1324 \\
\hline Milinarsky A & 1282 & 1287 \\
\hline Miranda E & & 1283 \\
\hline Monsó C & & 1326 \\
\hline Montalvo D & & 1290 \\
\hline Mora D & & 1292 \\
\hline Morales B & & 1323 \\
\hline Morales 0 & & 1302 \\
\hline Morales P & & 1281 \\
\hline Morel L & & 1309 \\
\hline Mosso L & $\begin{array}{r}1272,1281,1288,1289,1290,1297, \begin{array}{r}1297, \\
1299,\end{array}\end{array}$ & $\begin{array}{l}1298 \\
1299\end{array}$ \\
\hline Moyano L & & 1319 \\
\hline Munizaga F & 1278, 1294, 1294, 1306, & 1323 \\
\hline Muzzo S & & 1306 \\
\hline & $\mathbf{N}$ & \\
\hline Nachari I & & 1318 \\
\hline Nápoli C & & 1317 \\
\hline Navia A & & 1269 \\
\hline Neira L & & 1282 \\
\hline
\end{tabular}

Niedmann JP

1282

Novik V

1268, 1277, 1307

o

\begin{tabular}{lr}
\hline Oddershede N & 1323 \\
Olguín F & 1269,1320 \\
Olmos P & 1307,1308 \\
Ommaya A & 1305 \\
Oportos J & 1323 \\
Orellana P & 1283,1291
\end{tabular}

Ortiz $\mathrm{E}$

Ortuondo E

Osorio G

Osorio M

Oviedo $\mathrm{S}$

Oyaneder R

1308,1309

1267, 1283

1298

1288, 1321, 1321 1283

1268, 1271, 1277, 1309

\begin{tabular}{lr}
\hline & P \\
\hline Paganelli G & 1319
\end{tabular}

$\begin{array}{ll}\text { Palacio A } & 1279,1280\end{array}$

Palacios J

Palacios JM

1286

Palma C

Parada J

Paredes A

Parrau D

Patiño-García A

Peláez JM

1269

1292

1293

1325

1269, 1320 1320

1279, 1311

Peña A

Peña $\mathrm{V}$

Pérez F

1309

$1301,1302,1303$

$1265,1266,1274,1275,1278,1285,1302,1306$,

Pérez J

Pérez V

Pierret T

Pineda $\mathrm{P}$

Piñeiro L

Poblete A

Polic G

Pommer R

1310, 1310, 1320

Ponce $\mathrm{C}$

Pozo P

1286, 1311

Preisler J

Pruzzo R

1292,1298

1267, 1311

1265

1307, 1308

1323

1303

1300

1277

1311, 1312, 1321, 1321

1273

\begin{tabular}{lrr} 
& Q & \\
\hline Quevedo I & & 1292,1312 \\
Quezada N & & 1313 \\
Quintana JC & & 1283 \\
Quiroz D & & \\
& R & \\
\hline Radojkovic C & & 1313
\end{tabular}

Ramírez I

1288, 1306

Ramos C

Reyes C

Reyes ML

Reyes P
1273, 1314, 1326

1324

1292, 1293, 1294, 1314

1268, 1277 
Riaño C

Rigotti A

Ríos R

Rivera S

Roa N

Rodríguez C

Rodríguez CG

Rodriguez F

Rodriguez J

Rodríguez JA

Rojas A

Rojas D

Rojas E

Rojas H

Román $\mathrm{R}$

Romero C

Rosowski J

Rossi F R

Rossi M R

Rossi $\mathrm{R}$

Ruiz C

Ruiz J

\section{Sáez L}

Salas A

Salazar T

Salinas P

Samsó C

Sánchez F

Santos JL

Sapunar J

Schachter D

Schiattino I

Semler C

Sepúlveda A

Sepúlveda C

Sepúlveda G

Serón-Ferré M

Serrano V

Silva C

Silva $P$

Silva $R$

Sir Petermann T

Sobel D

Solar A

Solís I

Soto L

Sovino $\mathrm{H}$

Stratakis C

\begin{tabular}{lr}
\multicolumn{1}{c}{ T } \\
\hline Tabilo P & 1292 \\
Tagle R & 1308 \\
Tala H & 1323,1324 \\
Talesnik E & 1294,1314 \\
Tapia V & 1279 \\
Téllez R & 1324
\end{tabular}

1272, 1273, 1298, 1317, 1318

$1273,1314,1326$

$1269,1305,1320$

1319

$1275,1279,1280,1284,1300,1318$

1267, 1267, 1269, 1279, 1320

1290,1323

1282, 1283, 1319

1282,1319

1267, 1267, 1279

1305, 1319

1271, 1309

S

1315

1320

1301, 1302, 1303, 1318

1307, 1308

1269

1310

1265, 1266, 1274, 1285, 1310, 1320

1290

$1288,1321,1321$

1316

1268

$1312,1321,1321$

1279

1269

1326

1322, 1322

1269

1306

$1274,1279,1279,1280$

$1295,1300,1278,1310$

1305

$1289,1290,1297,1297,1298,1324$

1306

1323

1270, 1304

1279

308

1314

1279

324
Toloza H 1278

Torche S 1272

Torrealba F 1326

Torres J 1297, 1297

Torres MT 1282, 1287

Torres-Farfán C 1326

Trajtman D 1286

$\begin{array}{ll}\text { Trincado A 1307, } 1308 & \end{array}$

Trincado P 1317
$\mathbf{U}$

\begin{tabular}{lr}
\hline Uchida M & 1325 \\
Ugarte F & 1274,1279 \\
Unanue N & 1275,1279 \\
Urquieta MS & 1286 \\
Urrejola P & 1292 \\
Urrutia P & 1292
\end{tabular}

\begin{tabular}{lll} 
& V & \\
\hline Valdebenito R & 1279
\end{tabular}

Valdivia L 1272

Valdivieso A 1308

Valenzuela F 1326

Valenzuela G 1326

Vargas C 1316

Vargas S 1300

Vásquez F 1308

Vega V 1279, 1280

Velandia S 1292

Velasco A 1308

Velasco C 1311

Velásquez C 1283, 1323

Velásquez CG 1293

Véliz J 1273, 1314, 1326

Vera P 1295

Vera P 1300

Verdugo C 1292

Villanueva ME 1267, 1267, 1279

Villarroel AC 1310, 1320

Vinet AM $\quad 1294$

Viñals F 1303

Visser TJ 1301

Viviani P 1272

Viviani P 1273, 1290, 1323

Vogel A 1294

$\begin{array}{ll}\text { Volpato R } & 1282\end{array}$

\begin{tabular}{ll} 
W \\
\hline Wohllk N & $1273,1302,1314,1326$
\end{tabular}

\begin{tabular}{ll} 
Y & \\
\hline Yánez MA & 1265
\end{tabular}

\begin{tabular}{lr}
\multicolumn{2}{c}{ Z } \\
\hline Zimliki C & 1305 \\
Zumelzu E & 1268 \\
Zúñiga E & 1286,1287
\end{tabular}

